\author{
UNIVERSIDADE DE SÃO PAULO \\ ESCOLA DE ENGENHARIA DE SÃO CARLOS \\ DEPARTAMENTO DE ENGENHARIA DE PRODUÇÃO
}

\title{
CARACTERIZAÇÃO DO PROCESSO DE DESENVOLVIMENTO DE PRODUTOS EM UMA COMUNIDADE DE OPEN SOURCE DESIGN
}

\author{
Víctor Cussiol Macul
}

Dissertação apresentada à Escola de Engenharia de São Carlos, da Universidade de São Paulo, como parte dos requisitos para obtenção do título de Mestre em Engenharia de Produção Área de Concentração: Processos e Gestão de Operações

Orientador: Prof. Tit. Henrique Rozenfeld

São Carlos

Agosto de 2015 
AUTORIZO A REPRODUÇÃO TOTAL OU PARCIAL DESTE TRABALHO, POR QUALQUER MEIO CONVENCIONAL OU ELETRÔNICO, PARA FINS DE ESTUDO E PESQUISA, DESDE QUE CITADA A FONTE.

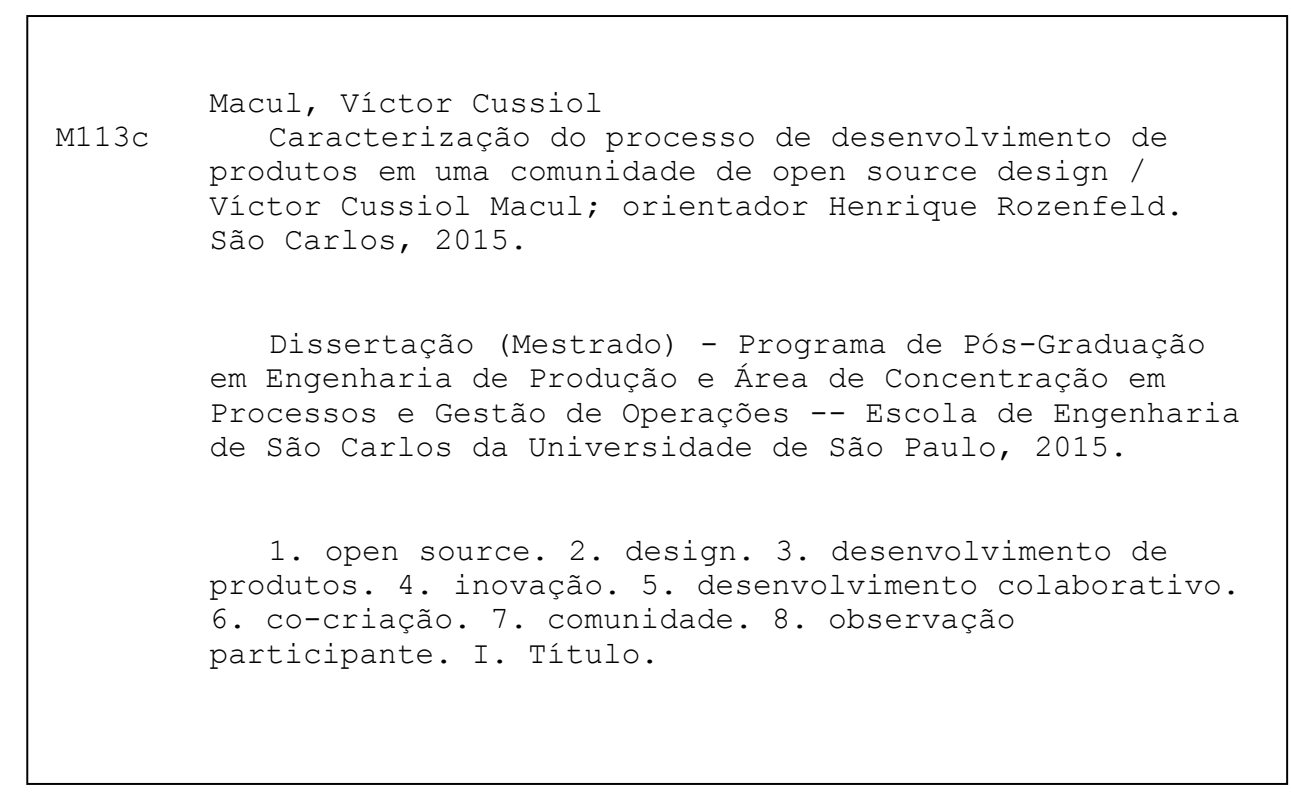




\section{FOLHA DE JULGAMENTO}

Candidato: Engenheiro VíCTOR CUSSIOL MACUL.

Título da dissertação: "Caracterização do processo de desenvolvimento de produtos em uma comunidade de open source design".

Data da defesa: 20/08/2015

Comissão Julgadora:

Prof. Associado Daniel Capaldo Amaral (Orientador designado)

(Escola de Engenharia de São Carlos/EESC)

Prof. Dr. Eduardo de Senzi Zancul

(Escola Politécnica/EP-USP)

Prof. Dr. Aguinaldo dos Santos

(Universidade Federal do Paraná/UFPR)
Resultado:

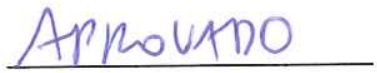

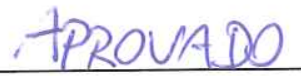

Apruvano

Coordenadora do Programa de Pós-Graduação em Engenharia de Produção:

Profa. Associada Daisy Aparecida do Nascimento Rebelatto

Presidente da Comissão de Pós-Graduação:

Prof. Associado Paulo César Lima Segantine 



\title{
DEDICATÓRIA
}

\author{
A todos \\ que criam, \\ que colaboram, \\ que experimentam, \\ que melhoram, e \\ que sustentam
} um design consciente. 



\section{AGRADECIMENTOS}

Aos meus pais, pela educação que me foi dada e pelos valores que me foram transmitidos. Por sempre me lembrarem das minhas responsabilidades, e por me concederem a liberdade para que eu tomasse minhas próprias escolhas.

À minha bisavó, pelo carinho, e por todos ensinamentos transmitidos, com toda paciência do mundo, naquelas longas tardes que passei durante boa parte da infância.

Ao meu orientador, por ser, para mim, um exemplo de pessoa e profissional. Pela liberdade e confiança concedida. Por toda atenção e dedicação durante o mestrado. Pela cobrança, encorajadora.

Ao fundador e diretor executivo da Open Source Ecology, por inspirar esta pesquisa, com a apresentação "Open-sourced blueprints for civilization" no TED Talk, e pela oportunidade concedida para realização do estudo de caso.

A todos os amigos e companheiros de trabalho durante o período de observação participante junto à comunidade Open Source Ecology, pelas conversas inspiradoras, trocas de conhecimento, e momentos de diversão. Por me mostrarem um mundo mais cooperativo e igualitário.

Aos meus amigos de república, por serem minha família durante os anos de universidade. Por todos os papos-cabeça, jantares, viagens e festas.

A um grande amigo, e companheiro em diversos projetos, desde consultoria de logística a trabalhos em educação, por todas as conversas e conselhos. Por compartilhar comigo sua experiência, e sua paixão, por sustentabilidade e empreendedorismo.

Aos colegas de laboratório, pelo companheirismo. Em especial, àqueles que me acolheram e me ajudaram a dar os primeiros passos na pesquisa, e aos professores que contribuíram imensamente em meu processo de formação.

Aos companheiros de equipe no projeto de replicação da impressora 3D Mendel90, realizado entre os meses de Março e Julho de 2015, pelos momentos de diversão, e por contribuírem para um maior entendimento do open source design.

Ao time de polo aquático de São Carlos, por despertar em mim auto superação, determinação e espírito de equipe. Pelos pesados treinos, que me ajudaram a trabalhar 
o corpo, e relaxar a mente. Por me darem a oportunidade de jogar na Chapada dos Veadeiros, em Goiás, um dos lugares mais bonitos que já estive.

À equipe do restaurante Mamãe Natureza, pela simpatia e saborosas refeições. Por me ajudar a manter o corpo e a mente saudável.

A todos aqueles que já me fizerem rir e chorar, por contribuir com a formação de minha personalidade. 


\section{EPÍGRAFE}

"Your potencial to impact the world has more to do with how you influence people to see thigns than by how much you produce" George Kembel 



\section{RESUMO}

MACUL, V. C. Caracterização do processo de desenvolvimento de produtos em uma comunidade de open source design. 2015. 101 f. Dissertação (Mestrado) Escola de Engenharia de São Carlos, Universidade de São Paulo, São Carlos, 2015.

O open source design ainda é um fenômeno nascente, no entanto representa um movimento que caminha em direção a mudanças radicais na maneira como nós adquirimos uma grande variedade de produtos. Baseado no conceito Do-It-Yourself, os usuários, ou seja, os indivíduos ou organizações que esperam se beneficiar do uso de um design, produto ou serviço, possuem um papel ativo e central no desenvolvimento de novos produtos. Por meio de comunidades auto-organizadas, os colaboradores compartilham esforços para geração de produtos, e os tornam disponíveis para que qualquer pessoa possa utilizá-los livremente. Embora as comunidades open source sejam mais conhecidas para o desenvolvimento de software, elas não estão restritas ao software. No entanto, são poucas as iniciativas que aplicam esse conceito para produtos físicos. A literatura apresenta um grande número de estudos relacionados ao processo de desenvolvimento de produtos, porém, o open source design apresenta um ambiente diferente do tradicional. $O$ envolvimento de um grande número de pessoas auto-organizadas pode provocar efeitos negativos no processo de desenvolvimento de produtos, quando soluções ruins influenciarem significativamente na convergência para uma solução final. Pesquisas indicam a necessidade de um melhor entendimento do processo de desenvolvimento de produtos nesse ambiente, assim como das ferramentas utilizadas para apoiar às organizações na gestão de seus processos de forma eficiente. Alguns autores apontam a falta de estudos de caso como uma das grandes barreiras para o desenvolvimento das pesquisas neste campo. Com base nessas lacunas, o objetivo deste estudo é contribuir com a caracterização do desenvolvimento de produtos no open source design. Para atingir esse objetivo, são realizados uma revisão de literatura no tema e um estudo de caso de caráter etnográfico, apoiado em mais de 800 horas de observação participante, e na análise de documentos da comunidade Open Source Ecology, nos Estados Unidos. Como 
resultado, é apresentado um relato das experiências vivenciadas junto à comunidade, que permitiram o levantamento de características do processo de desenvolvimento de produtos no open source design, assim como algumas reflexões sobre os demais elementos deste fenômeno: a plataforma de colaboração, a comunidade, os fatores que motivam os colaboradores a se envolverem no open source design, e o modelo de negócio dessas organizações. Estes resultados nos levam a crer que, embora muito trabalho tenha sido feito nas comunidades de open source design, este movimento ainda possui um baixo nível de maturidade com relação à gestão do processo de desenvolvimento de produtos, e está longe de mostrar seu todo o seu potencial.

Palavras-chave: open source, design, desenvolvimento de produtos, inovação, desenvolvimento colaborativo, co-criação, comunidade, observação participante. 


\section{ABSTRACT}

MACUL, V. C. Characterization of the product development process in an open source design community. 2015. 101 f. Dissertação (Mestrado) - Escola de Engenharia de São Carlos, Universidade de São Paulo, São Carlos, 2015.

The open source design is still a nascent phenomenon, but is it represents a movement that goes toward radical changes in how we acquire a wide variety of products. Based on the Do-It-Yourself concept, the users, i.e. individuals or organizations who expect to benefit from the use of a design, product or service, have an active and central role in the development of new products. Through self-organized communities, contributors share efforts to generate product designs, and make them available so that anyone can make free use of them. Although the open source communities are best known for software development, they are not restricted to software. However, there are few initiatives that apply this concept to physical products. The literature shows a large number of studies related to the design process, however, the open source design has a different environment than traditional one. The involvement of a large number of selforganized people can result in negative effects on the design process, when bad solutions dominate and greatly influence the convergence to a solution. Some researches indicate the necessity of better understand the design process in this environment, as well as the tools that aid organizations and individuals to manage this process effectively. Some authors point out the lack of case studies as one of the major barriers to the development of research in this field. Based on these gaps, the objective of this study is to contribute to the characterization of the design process in the open source design. To achieve this goal, there are conducted a literature review on this topic and an ethnographic case study, supported by more than 800 hours of participant observation, and document analysis the Open Source Ecology community, in the United States. As a result, an account of experiences with this community is presented, which support the characterization of the design process in open source design, as well as some reflections on other elements of this phenomenon: the collaboration platform, the 
community, the drive that motivates participation, and the business models of these organizations. Our findings indicate that, even though many accomplishments have been achieved, the open source design movement still has a low level of maturity, and is far from showing its full potential.

Keywords: open source, design, product development, innovation, collaborative design, co-creation, community, participant observation. 


\section{LISTA DE FIGURAS}

Figura 1 - Modelo conceitual do open source design (adaptado de Fjeldsted et al., 2012)

Figura 2 - Distribuição dos projetos de open source design de acordo com os estágios de desenvolvimento (BALKA et al., 2009, p. 8) .43

Figura 3 - PDP utilizado no TestBed Botnia living lab (ALMIRALL et al., 2012, p. 13) ..44 Figura 4 - PDP utilizado no Helsink Living Labs (ALMIRALL et al., 2012, p. 15).... .46

Figura 5 - Processo lógico da plataforma proposta por Fathianathan et al. (2009, p. 129)

Figura 6 - Distribuição dos meios de comunicação utilizados em projetos de open source design (BALKA et al., 2009, p. 9) .50

Figura 7 - Distribuição dos colaboradores nos projetos de open source design de acordo com o background (BALKA et al., 2009, p. 6) . .53

Figura 8 - Relação entre o número de colaboradores e os estágios de desenvolvimento (BALKA et al., 2009, p. 10) .53

Figura 9 - Distribuição do número de colaboradores nos projetos de open source design (BALKA et al., 2009, p. 6) ... .54

Figura 10 - Estruturação de uma comunidade de colaboradores em um projeto open source (adaptado de Gacek e Arief, 2004, p. 36). .55

Figura 11 - Distribuição dos principais coordenadores do processo de desenvolvimento (esquerda) e dos principais produtores (direita) nos projetos de open source design (BALKA et al., 2009, p. 8). .56

Figura 12 - Modelo de negócio arquetípico do OSD (adaptado de FJELDSTED et al., 2012, p. 5) 62

Figura 13 - Distribuição dos TechShops ao redor do mundo, sendo que os pontos vermelhos representam as unidades já existentes, enquanto os pontos em branco representam as unidades planejadas (TECHSHOP) .68 Figura 14 - Distribuição dos Fab Labs ao redor do mundo, sendo que os números em destaque no mapa representam a quantidade de Fab Labs por região (FABLAB) 69 
Figura 15 - Distribuição dos Hackerspaces ao redor do mundo, sendo que os números em destaque no mapa representam a quantidade de hackerspaces por região

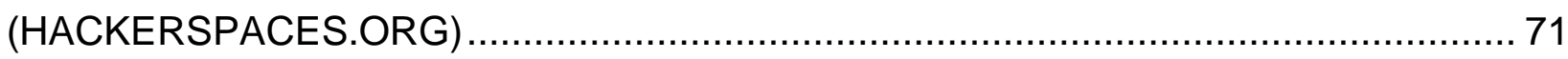

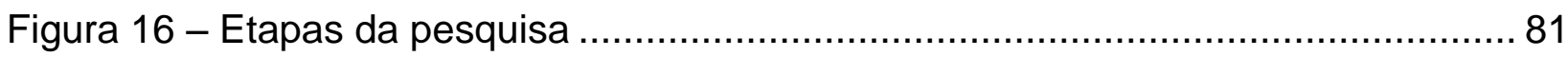

Figura 17 - Estágios da etapa de análise de evidências do caso …........................... 85 Figura 18 - Correspondência entre a metodologia adotada e a apresentação dos resultados de acordo com a estrutura deste documento ............................................. 89 Figura 19 - Material de divulgação do programa em vigor durante o período de

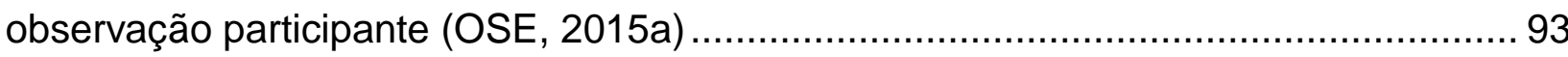

Figura 20 - Projetos planejados vs. projetos executados durante o período de observação participante (adaptado de OSE, 2014a) .................................................. 96 Figura 21 - Evolução do número de protótipos do GVCS construídos entre o período de

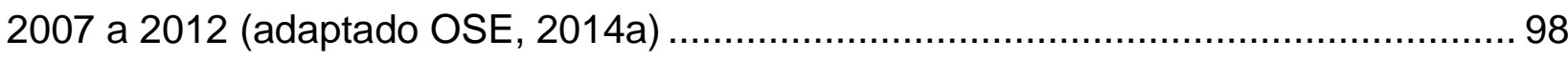

Figura 22 - Vista aérea da FeF (imagens retiradas do Google Maps) ...................... 100 Figura 23 - Variação do número de estagiários durante o período de observação participante e períodos dos workshops. 101

Figura 24 - Distribuição das edições dos usuários ativos na wiki (OSE, 2015a): (1) indica o número de edições dos quatro colaboradores que possuem papel de liderança, enquanto que (2) indica o número de contribuições dos demais colaboradores, sendo que cada fatia da pizza representa um colaborador e seu respectivo número de edições 103

Figura 25 - Descrição da CEB Press (OSE, 2015a) 105

Figura 26 - llustração das instruções para a monagem de um dos módulos da $C E B$ Press (OSE, 2015a) 106

Figura 27 - Exemplo da separação das peças por módulos e identificação conforme as instruções (OSE, 2015a, 2015b). 107

Figura 28 - Registros fotográficos do workshop da CEB Press em Wisconsin: (1) participantes reunidos; (2) montagem de um dos módulos; (3) montagem final e ajustes da máquina; (4) produção de tijolos para teste (OSE, 2015b) ................................. 108 Figura 29 - Descrição do Power Cube .................................................................. 111 
Figura 30 - Participantes trabalhando na documentação das instruções de montagem do Power Cube (OSE, 2015b).

Figura 31 - Registros fotográficos do workshop do Power Cube: (1) participantes trabalhando na montagem dos módulos; (2) documentação da montagem; montagem final e ajustes da máquina; (4) teste do Power Cube no trator (adaptado de OSE, 2014). 113

Figura 32 - Template para elaboração de um índice para os módulos da máquina (OSE, 2015a) 115

Figura 33 - Template para elaboração da lista de matérias de um dos módulos da máquina (OSE, 2015a). 115

Figura 34 - Template para descrição do passo-a-passo de um dos módulos da máquina (OSE, 2015a)

Figura 35 - Registro fotográfico do workshop da CEB Press na FeF, em que mostra os participantes trabalhando na montagem dos módulos e se preparando para montagem final da máquina (OSE, 2015b) 117

Figura 36 - Descrição do MicroCar (OSE, 2015a) 118

Figura 37 - Parte da lista de materiais utilizadas no inventário para o workshop do MicroCar (OSE, 2015a). 120

Figura 38 - Registros fotográficos do workshop do MicroCar: (1) usinagem dos moldes da roda; (2) preparação dos moldes; (3) prototipagem das rodas; e (4) apresentação do protótipo das rodas (acabada na esquerda e com rebarbas na direita) (OSE, 2015b) 121 Figura 39 - Exemplo de parte das instruções elaboradas para um dos módulos da MicroHouse 3 (OSE, 2015c). 123 Figura 40 - Registros fotográficos do workshop da MicroHouse 3: (1) participantes trabalhando na produção dos tijolos ao lado da fundação da casa; (2) construção das paredes usando os tijolos produzidos pela CEB Press; (3) montagem dos módulos de madeira; (4) instalação dos apoios para as janelas; e (5) LifeTrac 4 quebrado (OSE, 2015b) 125

Figura 41 - Prototipagem de parte do mobiliário open source para a MicroHouse 4 utilizando fabricação digital (OSE, 2015b) 128 
Figura 42 - Registros fotográficos do workshop da MicroHouse 4: (1) participantes trabalhando no primeiro dia de workshop; e (2) estágio do protótipo ao final do workshop (OSE, 2015b). 129

Figura 43 - Resultado obtido após a finalização do interior da MicroHouse 4 (OSE, 2015b) 129

Figura 44 - Receitas e despesas da OSE em 2014 (OSE, 2015a) .......................... 141

Figura 45 - Representação lógica da relação causa-e-efeito..................................... 158

Figura 46 - Processo para a construção da Árvore da Realidade Atual (RENTES, 2000, p. 127) 159

Figura 47 - Representação de parte do processo de construção da Árvore de Causa e Efeito 160

Figura 48 - Árvore de causa e efeito da OSE 171

Figura 49 - Relação entre modelos de referência genéricos e específicos (adaptado de Amigo, 2013) 175

Figura 50 - Versão atual do modelo de referência para o processo de desenvolvimento de produto da OSE (OSE, 2015a) 178 Figura 51 - Versão anterior do modelo de referência para o processo de desenvolvimento de produto da OSE (OSE, 2015a) 182 


\section{LISTA DE TABELAS}

Tabela 1 - Definições relacionadas ao fenômeno estudado (adaptada de Macul et al., 2014, p. 7)

Tabela 2 - Características típicas de uma etnografia pura (BALL; ORMEROD, 2000, p. 406) .79

Tabela 3 - Pontos fortes e fracos da análise de documentos (YIN, 2005, p. 113) ........82 Tabela 4 - Pontos fortes e fracos da observação participante (YIN, 2005, p. 113)........84

Tabela 5 - Exemplo da identificação de um incidente a partir da narrativa .86

Tabela 6 - Websites administrados pela organização. As linhas em destaque correspondem aos websites selecionados para a análise de documentos .94

Tabela 7 - Agenda dos eventos programados para a observação participante. .95

Tabela 8 - Estatísticas da wiki (OSE, 2015a) 102

Tabela 9 - Efeitos principais e causas-raiz do PDP da OSE. Legenda: PDP - Processo de desenvolvimento de produtos, COM - Comunidade, MOT - Motivadores; P Prototipagem, D - Design, T - Teste; ND - Detalhado; MD - Método de design; N/A Não se aplica.

Tabela 10 - Correspondência entre os problemas recorrentes do PDP com os efeitos indesejados identificados no PDP da OSE 133

Tabela 11 - Lista de problemas relevantes do PDP (COSTA et al., 2013, p. 26) 161

Tabela 12 - Categorias, opções e códigos utilizados na classificação dos incidentes 163

Tabela 13 - Os incidentes que facilitam o OSD na OSE 165

Tabela 14 - Os efeitos indesejados da OSE que se tornam uma barreira para o OSD 168

Tabela 15 - Propósitos estratégicos dos modelos de referência do PDP (AMIGO, 2013, p. 99)

Tabela 16 - Principais entregas do processo de desenvolvimento de produtos da OSE 183 



\section{LISTA DE ABREVIATURAS E SIGLAS}

$\begin{array}{ll}\text { AD } & \text { Análise de documentos } \\ \text { APQP } & \text { Advanced Product Quality Planning } \\ \text { BOM } & \text { Bill of Materials } \\ \text { CAD } & \text { Computer Aided Design } \\ \text { CAE } & \text { Computer Aided Engineering } \\ \text { CAM } & \text { Computer Aided Manufacturing } \\ \text { CNC } & \text { Computer Numeric Control } \\ \text { DPV } & \text { Dedicated Project Visits } \\ \text { DIY } & \text { Do-it-Yourself } \\ \text { EI } & \text { Efeito Indesejado } \\ \text { GDP } & \text { Gestão do Desenvolvimento de Produto } \\ \text { OP } & \text { Observação Participante } \\ \text { OSD } & \text { Open Source Design } \\ \text { OSE } & \text { Open Source Ecology } \\ \text { OSS } & \text { Open Source Software } \\ \text { PDP } & \text { Processo de Desenvolvimento de Produtos } \\ \text { PMI } & \text { Project Management Institute } \\ \text { PSS } & \text { Product-Service System } \\ \text { TI } & \text { Tecnologia de Informação } \\ \text { 4Ps } & \text { Parcerias Público-Privada-Pessoal }\end{array}$





\section{SUMÁRIO}

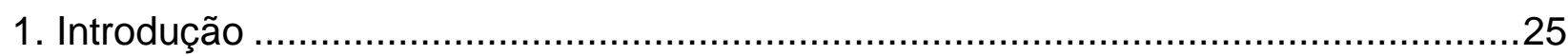

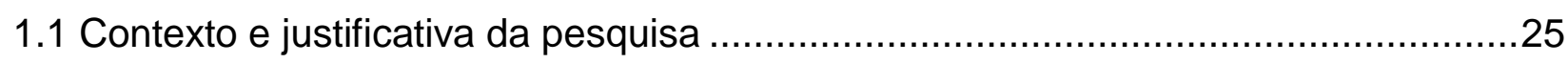

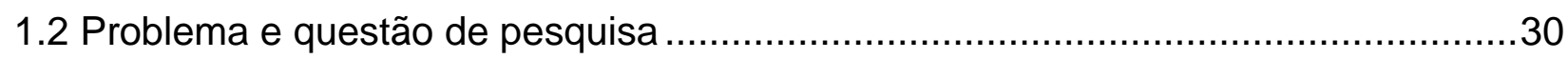

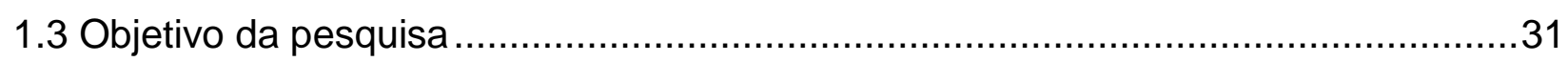

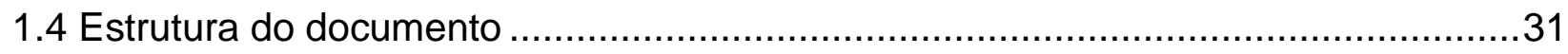

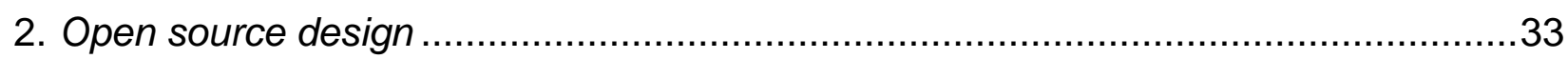

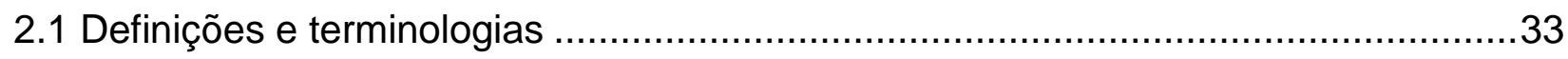

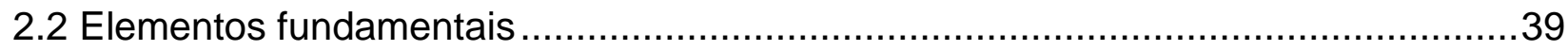

2.2.1 Processo de desenvolvimento de produtos ..........................................40

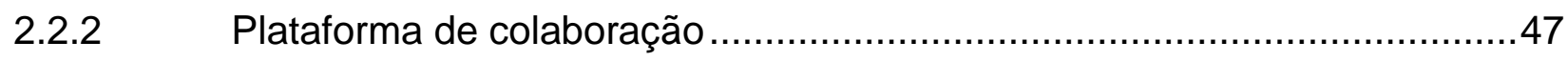

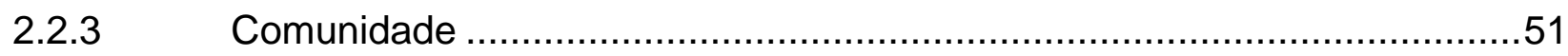

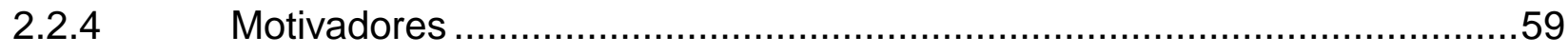

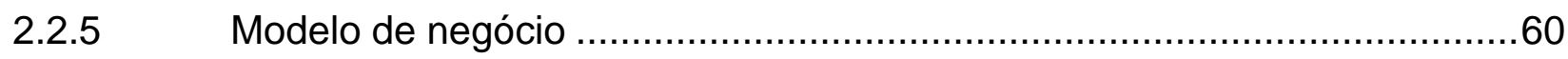

2.3 Oportunidades e ameaças para o open source design .........................................65

2.4 Oportunidades e ameaças para as indústrias existentes .....................................72

2.5 Um caso de open source design: o projeto RepRap ...........................................74

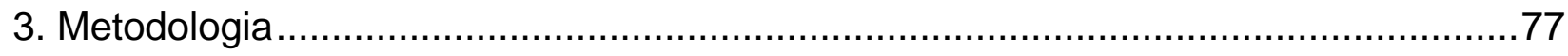

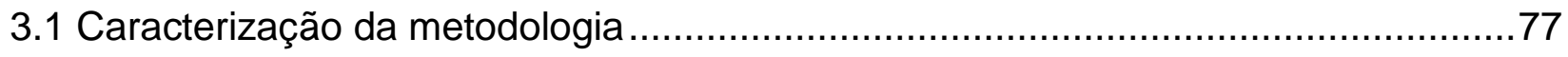

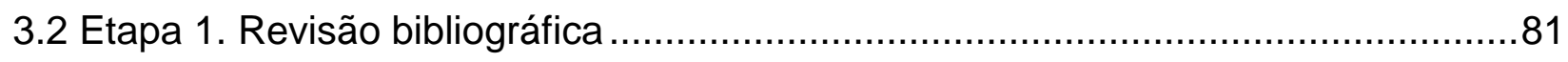

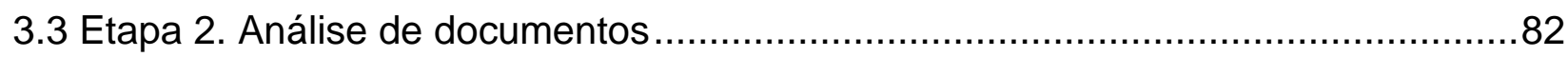

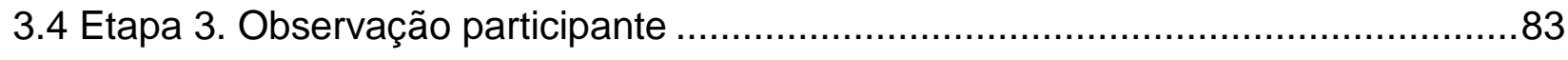

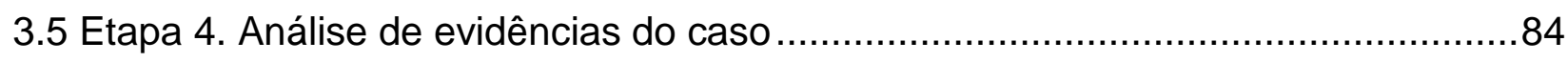

3.5.1 Redução dos dados e narrativa do caso ............................................. 85

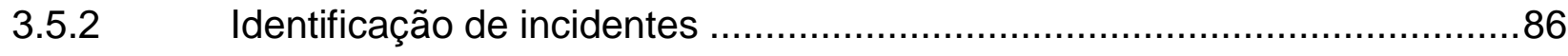

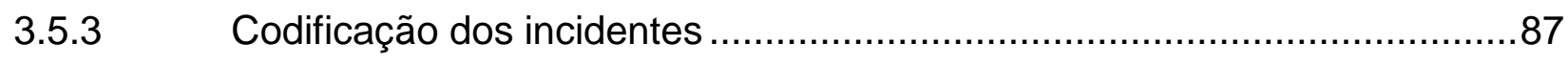

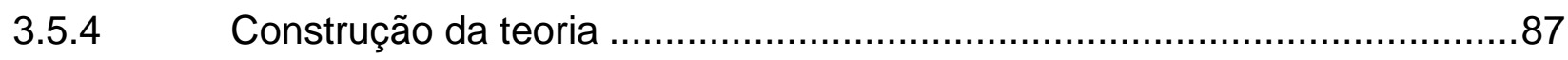

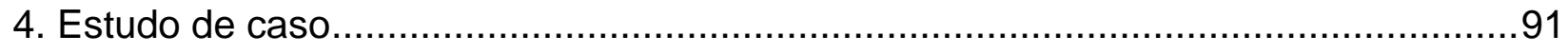

4.1 Seleção do caso e identificação das fontes de evidência.......................................91 
4.2 Um relato das experiências vivenciadas na comunidade Open Source Ecology..... 96

4.2.1 CEB Press Workshop em Wisconsin .................................................. 104

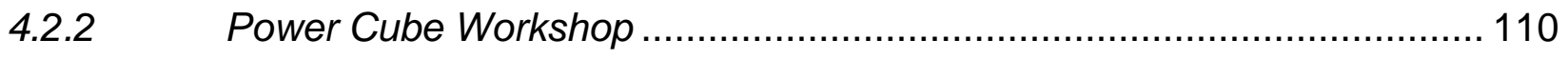

4.2.3 CEB Press Workshop na Factor e Farm ................................................ 114

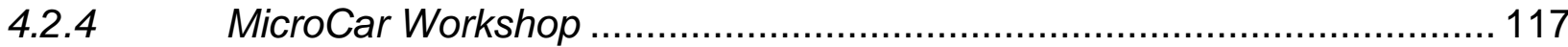

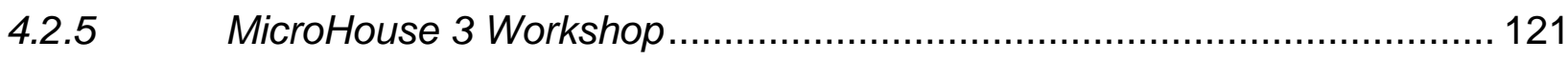

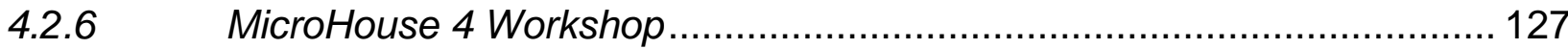

4.3 Análise dos principais incidentes observados no PDP da Open Source Ecology.. 129

4.4 Características do PDP no open source design ............................................... 134

4.5 Reflexões sobre os demais elementos do open source design ............................ 137

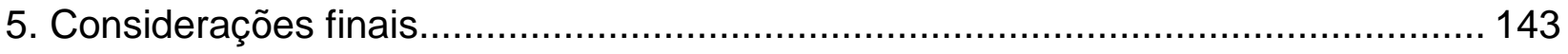

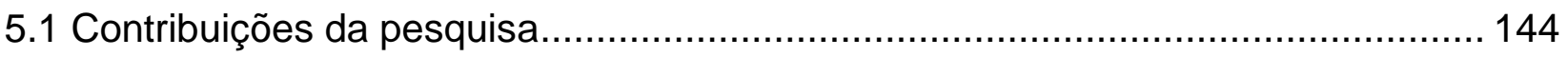

5.2 Limitações da pesquisa e sugestão de trabalhos futuros .................................... 146

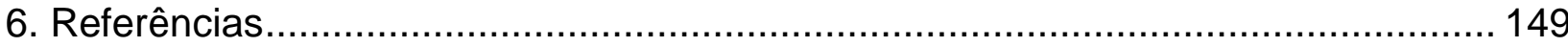

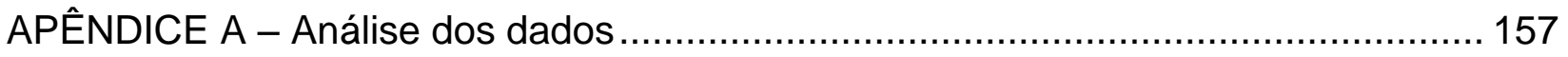

APÊNDICE B - Modelagem de processos para o desenvolvimento de produto e 0

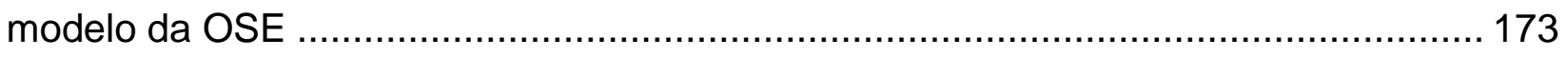

ANEXO I - Árvore da evolução da família de produtos da comunidade RepRap entre

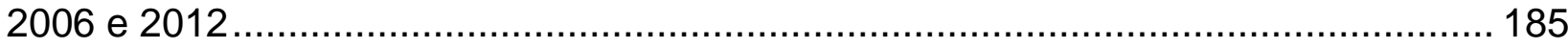

ANEXO II - Global Village Construction Set......................................................... 187

ANEXO III - Exemplo das instruções de montagem da CEB Press ........................... 191 


\section{Introdução}

Neste capítulo é apresentado o contexto em que se insere a pesquisa, acompanhado da justificativa para escolha do tema (seção 1.1); o problema e a questão de pesquisa (seção 1.2); os objetivos da pesquisa (seção 1.3) e a forma que este documento está estruturado (seção 1.4).

\subsection{Contexto e justificativa da pesquisa}

A natureza do relacionamento entre os usuários e as empresas vem mudando, levando a uma mudança de paradigma nos modos de inovação ${ }^{1}$. A visão de uma organização que desenvolve produtos para usuários passivos, ou seja, que apenas compram e consomem os produtos criados pelos produtores, está sendo substituída. Nesse novo paradigma, os usuários, ou seja, os indivíduos ou organizações que esperam se beneficiar do uso de um design, produto ou serviço, são vistos como inovadores, co-designers, co-produtores, e empreendedores, e possuem um papel ativo e central no desenvolvimento de produtos, podendo chegar ao ponto em que múltiplos usuários colaboram entre si, e compartilham, abertamente, os resultados gerados (PRAHALAD; KRISHNAN, 2008, p. 3; ABEL et al., 2011; BALDWIN; von HIPPEL, 2011, p. 1399; von HIPPEL et al., 2011, p. 27; ILAN, 2011, p. 46; TROXLER, 2011; PASCU; van LIESHOUT, 2009 apud LEMINEN et al., 2012, p. 6; SEND et al., 2013, p. 542).

Estudos empíricos confirmam essa mudança de paradigma, e mostram que muitas das inovações em produtos vêm sendo desenvolvidas por usuários em diferentes segmentos de mercado: equipamentos esportivos (SHAH, 2000; HIENERTH, 2006), instrumentos musicais (ILAN, 2011), impressão 3D (BRUIJN, 2010; JONG; BRUIJN, 2013), maquinários para construção civil, agricultura e manufatura (THOMSON; JAKUBOWSKI, 2012).

\footnotetext{
${ }^{1}$ Um modo de inovação consiste na maneira de se organizar esforços e investimentos a fim de gerar valiosas inovações (BALDWIN; von HIPPEL, 2011, p. 1399). Nesta pesquisa o termo inovação se refere à inovação de produto, ou seja, à introdução de bens ou serviços novos, ou com melhorias significativas nas características funcionais ou de uso, em relação às ofertas existentes (OECD, 2005, p. 48).
} 
O movimento do software livre, também chamado de open source software (OSS), provou que uma rede de voluntários poderia escrever um código fonte de um software tão bem como os desenvolvidos pelas grandes empresas. A Wikipedia ${ }^{2}$ mostrou que este modelo poderia ser usado para criar uma extensa enciclopédia online. E empresas como de comércio eletrônico, como o eBay ${ }^{3}$, e redes sociais, como o $\mathrm{MySpace}^{4}$, têm construído negócios lucrativos que não poderiam existir sem as contribuições dos usuários (HOWE, 2006). Ao invés de apenas receberem passivamente informações por meio da web, a participação dos usuários tem evoluído, e eles estão passando a desempenhar um papel ativo, organizando-se em comunidades, interagindo com os pares, compartilhando informações, e gerando conteúdo público na Internet como resultado de suas interações (PANCHAL; FATHIANATHAN, 2008, p. 1).

O envolvimento em massa dos usuários no processo de desenvolvimento de produtos (PDP) somente foi possível graças a avanços tecnológicos que, segundo Howe (2006, p. 2), estão contribuindo para a quebra das barreiras de custo que separam os 'amadores' dos 'profissionais'. Essas tecnologias incluem computadores pessoais de alto desempenho; ferramentas de comunicação de baixo custo via Internet; e arquiteturas modulares (BALDWIN; von HIPPEL, 2011, p. 1410). Em uma arquitetura modular, os módulos representam os elementos da estrutura do produto que proporcionam uma ou mais funções independentemente, e estão associados a outros módulos por meio de interfaces (SCHUH et al., 2006, p. 394). Desse modo, alterações realizadas em um módulo não implicam em alterações nos demais, e diferentes pessoas podem trabalhar no desenvolvimento de diferentes módulos independentemente e em paralelo, permitindo a divisão de um projeto em múltiplas tarefas (BALDWIN; von HIPPEL, 2011, p. 1402). Com a web se torna ainda mais fácil agregar ideias diversas e independentes, sem os perigos da comunicação excessiva e da obrigação de se chegar a um acordo (SUROWIECKI, 2005, p. 10). A

${ }^{2}$ Wikipedia é um projeto de enciclopédia coletiva universal e multilíngue estabelecido na Internet sob o princípio wiki. A Wikipédia tem como objetivo fornecer um conteúdo reutilizável livre, objetivo e verificável, que todos possam editar e melhorar. Disponível em: http://pt.wikipedia.org/wiki/Wikip\%C3\%A9dia:P\%C3\%A1gina principal, acessado em 09/06/2015.

${ }^{3}$ eBay é uma empresa de comércio eletrônico fundada, em 1995, nos Estados Unidos. Atualmente é o maior site do mundo para a venda e compra de bens. Disponível em: http://pt.wikipedia.org/wiki/EBay, acessado em 09/06/2015.

${ }^{4}$ MySpace é uma rede social que utiliza a Internet para comunicação online através de uma rede interativa de fotos, blogs e perfis de usuário. Foi uma das precursoras entre as redes sociais, chegando a ser a mais popular do mundo. Disponível em: http://pt.wikipedia.org/wiki/Myspace, acessado em 09/06/2015. 
diversidade e a independência são importantes para a colaboração, pois, segundo Surowiecki (2005), as melhores decisões coletivas são frutos do desacordo e da contestação, não do consenso e da harmonia.

Baldwin e von Hippel (2011, p. 1410) incluem também o design digital como um dos impulsionadores para o aumento da colaboração nos projetos de desenvolvimento de produtos. Muitas atividades que antes eram realizadas fisicamente passaram a ser executadas no mundo virtual, e a geração de objetos físicos se tornou uma simples etapa ao final de uma série de manipulações de dados de forma digital (SHIRKY, 2007). A fabricação digital, isto é, o uso de máquinas como impressoras 3D, laser cutters ${ }^{5}$, e $C N C$ routers ${ }^{6}$, que permitem a criação remota de objetos por meio de modelos digitais, se tornou mais acessível à população, deixando de ser um privilégio de grandes empresas (ATKINSON, 2009, p. 32). TechShops, Hackerspaces e Fab Labs ${ }^{7}$ vêm ocupando um papel de destaque ao facilitar o acesso a essas tecnologias (TROXLER, 2011).

Jong e Bruijn (2013) ainda acrescentam como impulsionador desse fenômeno, uma melhor formação dos cidadãos, os tornando aptos a se articularem em comunidades e se envolverem em atividades de inovação. Embora as comunidades de inovação sejam mais conhecidas para o desenvolvimento de software, como por exemplo, Linux ${ }^{8}$, Apache $^{9}$ e Mozilla Firefox ${ }^{10}$, elas não estão restritas ao software (JONG; BRUIJN, 2013, p. 45). Balka, Raasch e Herstatt realizaram um importante trabalho ao listar no website open-innovation-projects.org projetos de desenvolvimento de produtos físicos sob o paradigma open source,

\footnotetext{
${ }^{5}$ Um laser cutter é uma máquina de corte a laser controlado pelo computador, usada para o corte de vários materiais, com alta qualidade de acabamento superficial. Disponível em http://en.wikipedia.org/wiki/Laser cutting, acessado em 09/06/2015.

${ }^{6}$ Uma CNC router é uma máquina de corte controlado pelo computador, usada para o corte de vários materiais duros, como madeira, materiais compósitos, alumínio, aço, plásticos e espumas. Disponível em http://en.wikipedia.org/wiki/CNC router, acessado em 06/06/2015.

${ }^{7}$ Para maiores informações, consulte a seção 2.3.

${ }^{8}$ Linux é um sistema operacional livre, cujo código fonte está disponível para que qualquer pessoa o possa utilizar, estudar, modificar e distribuir livremente de acordo com os termos da licença GPL. Disponível em http://pt.wikipedia.org/wiki/Linux, acessado em 09/06/2015.

9 Apache é um servidor web livre, cujo código fonte está disponível para que qualquer pessoa o possa utilizar, estudar, modificar e distribuir livremente de acordo com os termos da licença Apache. Disponível em http://pt.wikipedia.org/wiki/Apache, acessado em 09/06/2015.

${ }^{10}$ Mozilla Firefox é um navegador livre, cujo código fonte está disponível para que qualquer pessoa o possa utilizar, estudar, modificar e distribuir livremente de acordo com os termos da licença GPL. Cerca de $40 \%$ do código do programa foi totalmente escrito por voluntários. Disponível em http://pt.wikipedia.org/wiki/Firefox, acessado em 09/06/2015.
} 
denominados nesse trabalho open source design (OSD) ${ }^{11}$. Em Março de 2015, essa lista apresentava 161 projetos, incluindo projetos como: RepRap ${ }^{12}$, Zoybar ${ }^{13}$ e Open Source Ecology ${ }^{14}$.

A literatura apresenta um grande número de estudos relacionados ao processo de desenvolvimento de produtos, porém, o open source design apresenta um ambiente fundamentalmente diferente do tradicional. $O$ envolvimento de um grande número de pessoas auto-organizadas pode provocar efeitos negativos no processo de desenvolvimento de produtos, por exemplo, quando soluções ruins influenciarem significativamente na convergência para uma solução final (PANCHAL; FATHIANATHAN, 2008, p. 5). Segundo Panchal e Fathianathan (2008, p. 4), é necessário um melhor entendimento do processo de desenvolvimento de produtos nesse ambiente, assim como das ferramentas utilizadas para apoiar às organizações na gestão de seus processos de forma eficiente. Fjeldsted et al. (2012, p.2) corroboram com essa visão, e apontam a falta de estudos de caso como uma das grandes barreiras para as pesquisas em open source design. Esses autores também apontam a necessidade de uma metodologia de design específica para 0 desenvolvimento open source de produtos físicos, assim como, a necessidade de diferentes modelos de negócio que apoiem o OSD.

A fim de contribuir para o entendimento desse fenômeno, Fjeldsted et al. (2012) propõem um modelo conceitual para o open source design ${ }^{15}$ (Figura 1),

11 Optou-se por não traduzir o termo open source design neste trabalho, a fim de evitar a criação de mais um termo para se referir ao fenômeno de interesse. Para maiores detalhes sobre terminologia, consultar seção 2.1.

${ }_{12}$ RepRap é organização com o objetivo de desenvolver uma impressora 3D que possa imprimir a maior parte dos seus próprios componentes, permitindo sua auto-replicação. A documentação de projeto gerada está disponível para que qualquer pessoa possa utilizar, estudar, modificar e distribuir livremente de acordo com a licença GNU. Disponível em http://en.wikipedia.org/wiki/RepRap Project, acessado em 09/06/2015. Para maiores detalhes, consultar seção 2.5 .

13 Zoybar é um laboratório de P\&D para acadêmicos, hobbyistas, e desenvolvedores comerciais para customizar e fabricar instrumentos musicais e acessórios. Disponível em http://www.zoybar.net/, acessado em 09/06/2015.

${ }^{14}$ Open Source Ecology é uma organização com o objetivo de desenvolver uma plataforma que permita a fabricação de 50 máquinas industriais capazes de construir uma pequena civilização sustentável nos padrões de conforto atualmente difundidos. A documentação de projeto gerada está disponível para que qualquer pessoa possa utilizar, estudar, modificar e distribuir livremente de acordo com a licença OSE Licency for Distributive Economics. Disponível em http://opensourceecology.org/wiki/Main Page, acessado em 09/06/2015. Para maiores detalhes, consultar capítulo 4.

${ }^{15} \mathrm{O}$ modelo para o open source design proposto por Fjeldsted et al. (2012) é originalmente chamado pelos autores de open source development process model, e possui como elementos fundamentais: plataforma, comunidade, motivadores, desenvolvimento e negócio. Nesta pesquisa, discorda-se da utilização do termo 'modelo de processo' para se referir ao modelo proposto, e opta-se 
destacando seus principais elementos: plataforma de colabroação, comunidade, motivadores, processo de desenvolvimento de produtos, e modelo de negócio.

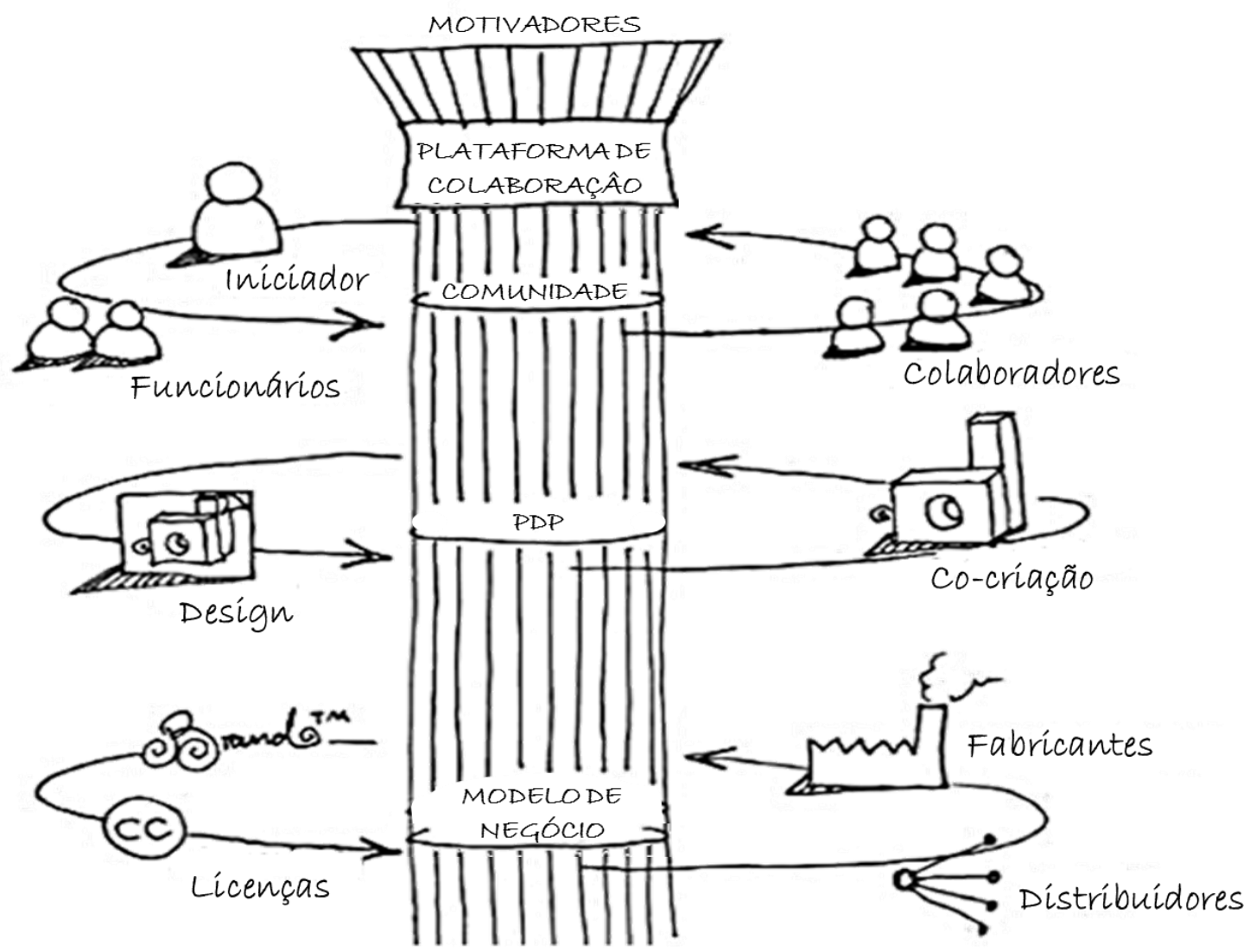

Figura 1 - Modelo conceitual do open source design (adaptado de Fjeldsted et al., 2012)

Neste modelo conceitual, a plataforma de colaboração é o elemento central do open source design, pois possibilita, e facilita as interações entre os participantes, culminando no desenvolvimento colaborativo dos produtos. De acordo com os casos estudados por Fjeldsted et al. (2012), geralmente a plataforma de colaboração é criada pelo iniciador do projeto de OSD. No entanto, essa plataforma necessita da presença de interessados em participar diretamente no desenvolvimento, ou na gestão do processo de desenvolvimento de produtos. Essas duas partes interagem e desenvolvem em cima das soluções e feedback por eles gerados, e assim, formase ao redor da plataforma uma comunidade de colaboradores atraídos por motivadores comuns. O processo de desenvolvimento de produtos tem início com a 'desenvolvimento' e 'negócio' também são modificados, de forma que nesta pesquisa, refere-se a eles como 'plataforma de colaboração', 'processo de desenvolvimento de produtos' e 'modelo de negócio', respectivamente. Com isso, espera-se reduzir as dúvidas causadas pela utilização de termos com amplo significado, tornando-os mais específicos. 
publicação de um "desafio" na plataforma de colaboração, com informações que permitam aos colaboradores criarem em cima do que proposto pelo iniciador. Dessa forma, inicia-se um ciclo de desenvolvimento contínuo, na maioria dos casos, com o apoio de uma equipe pertencente à organização que iniciou o projeto. Para que isso seja possível, é necessário um modelo de negócio que torne o open source design uma opção viável e atraente para o desenvolvimento de produtos. Aspectos legais relacionados à propriedade intelectual, marca, e regulação do mercado são importantes e devem ser considerados. Por exemplo, no caso de fabricantes e distribuidores desejarem gerar receita com os produtos desenvolvidos pelo open source design, é necessário garantir que as práticas estabelecidas pela comunidade sejam respeitadas.

\subsection{Problema e questão de pesquisa}

Com base no contexto apresentado na seção anterior, observa-se um aumento no número de iniciativas relacionadas ao open source design. No entanto, na literatura ainda são poucos os estudos de caso que descrevam este fenômeno, e não existem metodologias de design específicas para o open source design (FJELDSTED et al., 2012). Para que a teoria possa evoluir é necessário que haja um amadurecimento sobre questões referentes à base do conhecimento teórico do open source design, proporcionando um maior entendimento deste fenômeno entre pesquisadores e comunidade prática.

Um importante passo foi dado por Fjeldsted et al. (2012), ao proporem um modelo conceitual para o open source design, identificando os elementos fundamentais deste fenômeno (Figura 1). No entanto, o modelo conceitual proposto não está acompanhado de uma descrição detalhada de cada um dos elementos apresentados, possibilitando apenas um entendimento superficial do open source design. Surge, portanto, como questão para essa pesquisa: "como são caracterizados os elementos fundamentais do open source design?". 


\subsection{Objetivo da pesquisa}

Para responder à questão de pesquisa de forma abrangente e profunda, seriam necessários diversos estudos. O escopo desse trabalho se concentra no elemento referente ao processo de desenvolvimento de produtos, a fim de fortalecer as bases teóricas para que sejam desenvolvidas metodologias de design específicas para o open source design. Portanto, o objetivo principal deste estudo é caracterizar o processo de desenvolvimento de produtos dentro do contexto do open source design, contribuindo para aprimorar o modelo conceitual proposto por Fjeldsted et al. (2012).

\subsection{Estrutura do documento}

Este documento está estruturado da seguinte forma:

Capítulo 1 - Introdução: apresenta o contexto, justificativa, problema, questão e objetivo da pesquisa.

Capítulo 2 - Open source design: apresenta o estado da arte sobre 0 fenômeno estudado nesta pesquisa com destaque para as características dos elementos fundamentais do OSD: processo de desenvolvimento de produtos, plataforma de colaboração, comunidade, motivadores e modelo de negócio.

Capítulo 3 - Metodologia: apresenta a caracterização da metodologia adotada e as etapas da pesquisa.

Capítulo 4 - Estudo de caso: apresenta o processo de seleção do caso e identificação das fontes de evidência, e os resultados obtidos no estudo de caso.

Capítulo 5 - Considerações finais: discute as contribuições da pesquisa e apresenta os próximos passos para condução deste estudo.

Capítulo 6 - Referências: apresenta as referências bibliográficas que embasam a pesquisa, e que estão citadas ao longo do texto.

Apêndices: reúne os apêndices deste estudo, ou seja, documentos criados para apoiar a realização desta pesquisa.

Anexos: reúne os anexos deste estudo, ou seja, documentos identificados na literatura que são úteis para realização desta pesquisa. 


\section{Open source design}

Este capítulo apresenta o estado da arte sobre o open source design. $\mathrm{Na}$ seção 2.1 são apresentadas as definições e terminologias identificadas na literatura que abordam o fenômeno estudado; a justificativa pela escolha do termo open source design; e a definição adotada para este termo. Na seção 2.2 é apresentada uma revisão bibliográfica sobre os elementos fundamentais do OSD, sendo uma subseção para cada elemento: processo de desenvolvimento de produtos, plataforma de colaboração, comunidade, motivadores e modelo de negócio. $\mathrm{Na}$ seção 2.3, são apontadas as oportunidades e ameaças para o open source design. Já na seção 2.4, são discutidas as oportunidades e ameaças para as indústrias existentes, acarretadas pelo fortalecimento desse fenômeno. Por fim, na seção 2.5, um caso de open source design aplicado à indústria de impressão 3D é apresentado.

\subsection{Definições e terminologias}

Há algumas décadas a opinião dos usuários vem ganhando importância, principalmente com o surgimento de processos de design centrado no usuário. $O$ levantamento de requisitos dos usuários pela equipe de desenvolvimento é uma atividade presente no início da maioria dos processos de desenvolvimento de produtos. Mais recentemente, os usuários passaram a se envolver mais profundamente no processo criativo por meio da co-criação ${ }^{16}$ (ATKINSON, 2011). Hoje, os usuários podem ser vistos como inovadores, co-designers, co-produtores, e empreendedores no que diz respeito ao desenvolvimento de novos produtos e serviços (PASCU; van LIESHOUT, 2009 apud LEMINEN et al., 2012, p. 6).

O fenômeno estudado nesse trabalho representa o próximo passo nessa trajetória em busca de um maior envolvimento dos usuários, visando possibilitar que os usuários assumam inteiramente a responsabilidade pela criação e produção de produtos (ATKINSON, 2011). Esse fenômeno tem como ambição quebrar as

${ }^{16}$ Kambil et al. (1999) definem co-criação como o "engajamento direto dos consumidores na produção ou distribuição de valor". 
barreiras entre os desenvolvedores de um produto e seu usuário final, transformando um usuário no desenvolvedor dos produtos que ele necessita, e até mesmo no produtor desses produtos, eliminado alguns intermediários na cadeia de valor (STAPPERS et al., 2011).

Por se tratar de um fenômeno recente, não há consenso na literatura com relação a uma definição, assim como o termo utilizado para se referir a esse fenômeno. A Tabela 1 reúne as definições encontradas na literatura pesquisada, que serviram de base para a caracterização do fenômeno estudado nesta pesquisa.

Tabela 1 - Definições relacionadas ao fenômeno estudado (adaptada de Macul et al., 2014, p. 7)

\begin{tabular}{|c|c|c|}
\hline Termo & Definição & Autor \\
\hline $\begin{array}{l}\text { Open source } \\
\text { hardware }\end{array}$ & $\begin{array}{l}\text { Um hardware cujo design está sob domínio público de } \\
\text { modo que qualquer um possa estudar, modificar, } \\
\text { distribuir, produzir, e vender o design ou o hardware } \\
\text { baseado nesse design. A fonte do hardware, ou seja, o } \\
\text { design com o qual ele foi feito, é disponibilizada } \\
\text { preferencialmente em um formato que possibilite que } \\
\text { Ihe sejam feitas modificações. Idealmente, um open } \\
\text { source hardware utiliza componentes e materiais de } \\
\text { fácil acesso, processos padronizados, infraestrutura } \\
\text { aberta, conteúdo não restrito, e ferramentas open } \\
\text { source para maximizar a capacidade de indivíduos } \\
\text { produzirem e utilizarem o hardware. O open source } \\
\text { hardware dá às pessoas liberdade para controlar sua } \\
\text { tecnologia, enquanto compartilham conhecimento e } \\
\text { encorajam o comércio por meio da troca de designs }\end{array}$ & $\begin{array}{l}\text { Open Source } \\
\text { Hardware } \\
\text { Definition } \\
(2014)\end{array}$ \\
\hline $\begin{array}{l}\text { Commons-based } \\
\text { peer production }\end{array}$ & $\begin{array}{l}\text { Possui características de empreendimentos } \\
\text { cooperativos, em que as entradas e saídas do processo } \\
\text { são compartilhadas livremente e condicionalmente em } \\
\text { um sistema de produção que depende das ações dos } \\
\text { indivíduos que é auto selecionada e descentralizada }\end{array}$ & Benkler (2006) \\
\hline $\begin{array}{l}\text { Product-oriented } \\
\text { web-based } \\
\text { interactive } \\
\text { innovation }\end{array}$ & $\begin{array}{l}\text { Os mecanismos pelos quais ideias ou designs } \\
\text { inovadores, sem proteção da propriedade intelectual, } \\
\text { provêm dos consumidores, via web }\end{array}$ & Wei (2013) \\
\hline $\begin{array}{l}\text { Mass } \\
\text { collaborative } \\
\text { product } \\
\text { realization }\end{array}$ & $\begin{array}{l}\text { Uma atividade coletiva de um grande número de } \\
\text { pessoas para desempenhar uma tarefa para realização } \\
\text { de um produto. [...] Está baseada no conceito de open } \\
\text { innovation e comunidades auto-organizadas. [...] } \\
\text { Empresas influenciadas pelo paradigma da colaboração } \\
\text { em massa se baseiam em abertura, compartilhamento, } \\
\text { e ações globais }\end{array}$ & $\begin{array}{l}\text { Panchal; } \\
\text { Fathianathan } \\
\text { (2008, p. } 1 ; 3)\end{array}$ \\
\hline $\begin{array}{l}\text { Open source } \\
\text { innovation }\end{array}$ & $\begin{array}{l}\text { Caracterizado pela revelação gratuita de um novo } \\
\text { design com a intenção de desenvolvimento colaborativo } \\
\text { de um único design ou um número limitado de designs } \\
\text { relacionados com, ou sem, exploração de mercado }\end{array}$ & $\begin{array}{l}\text { (RAASCH et } \\
\text { al., 2009, p. } \\
383 \text { ) }\end{array}$ \\
\hline $\begin{array}{l}\text { Open source } \\
\text { development }\end{array}$ & $\begin{array}{l}\text { O desenvolvimento de produtos tangíveis, bem como } \\
\text { intangíveis, por meio de uma plataforma acessível e } \\
\text { compartilhável, em que comunidades motivadas, com } \\
\text { práticas comuns compartilham, adotam, produzem e } \\
\text { desenvolvem continuamente soluções inovadoras sob } \\
\text { os créditos e licenças estabelecidas em comum acordo }\end{array}$ & $\begin{array}{l}\text { Fjeldsted et al. } \\
(2012, \text { p. 1) }\end{array}$ \\
\hline
\end{tabular}


Tabela 1 - Definições relacionadas ao fenômeno estudado (adaptada de Macul et al., 2014, p. 7) (continuação)

\begin{tabular}{|c|c|c|}
\hline Termos & Definições & Autores \\
\hline Open design & $\begin{array}{l}\text { Acesso livre a blueprints" digitais que podem ser } \\
\text { adaptados à vontade para atender a requisitos } \\
\text { individuais, e logo podem ser usados por consumidores } \\
\text { na fabricação de produtos sob demanda, por meio de } \\
\text { métodos de produção convencionais. O modelo do open } \\
\text { design achata a cadeia de valor tradicional, formada } \\
\text { pela relação desenvolvedor-fabricante-distribuidor- } \\
\text { consumidor, e oferece como alternativa uma teia aberta } \\
\text { de relações diretas entre desenvolvedores e } \\
\text { consumidores. Como resultado, as relações (direta, } \\
\text { transitória, e não hierárquica) criam uma rede dinâmica } \\
\text { e flexível de design blueprints não somente centrada no } \\
\text { usuário, mas também direcionada pelo usuário }\end{array}$ & Avital (2011) \\
\hline $\begin{array}{l}\text { Open } \\
\text { collaborative } \\
\text { innovation }\end{array}$ & $\begin{array}{l}\text { Envolve colaboradores que compartilham o trabalho } \\
\text { para gerar um design, e revelam abertamente os } \\
\text { resultados de seus esforços individuais e coletivos para } \\
\text { que qualquer pessoa possa usar. Desse modo, os } \\
\text { colaboradores não são remunerados por suas } \\
\text { contribuições. Esses projetos devem possuir duas } \\
\text { características essenciais: (1) os participantes não } \\
\text { podem ser competidores com respeito à geração do } \\
\text { design, e (2) eles não podem, individualmente ou } \\
\text { coletivamente, planejar vender produtos ou serviços que } \\
\text { incorporem a inovação gerada, ou os direitos de } \\
\text { propriedade intelectual relacionadas a ela }\end{array}$ & $\begin{array}{l}\text { Baldwin; von } \\
\text { Hippel (2011, p. } \\
\text { 1403) }\end{array}$ \\
\hline
\end{tabular}

É possível observar similaridades entre as definições apresentadas na Tabela 1. Todas estão amparadas no conceito de abertura e contemplam o desenvolvimento de produtos físicos. Segundo Balka et al. (2010, p. 249), abertura é um conceito gradual e multidimensional, baseado em três aspectos: (1) transparência, relacionada à quantidade e qualidade de informações livremente reveladas; (2) acessibilidade, relacionada à possibilidade de um membro da comunidade participar ativamente do desenvolvimento do produto, e (3) replicabilidade, relacionada à disponibilidade dos componentes utilizados no produto, e logo, na possibilidade de replicar a montagem destes produtos por conta própria. Projetos open source são entendidos como casos extremos de abertura (GASSMANN, 2006, p. 227), já que possuem como requisito básico a disponibilização do "código fonte" desenvolvido (GACEK; ARIEF, 2004, p. 34), que

${ }^{17} \mathrm{O}$ termo blueprint se refere a um desenho técnico, documentando um projeto de arquitetura ou engenharia, e também pode ser usado para se referir a qualquer plano. Disponível em http://en.wikipedia.org/wiki/Blueprint, acessado em 09/06/2015.

${ }^{18}$ A expressão 'direcionada pelo usuário' é uma tradução do termo 'user driven', em inglês. 
no caso de produtos físicos são os designs gerados ao longo do processo de desenvolvimento. Neste trabalho, o termo design remete a "um conjunto de instruções que especificam como produzir um novo produto ou serviço" (SIMON, 1981; ROMER, 1990; SUH, 1990; BALDWIN; CLARK, 2000; BALDWIN; CLARK, 2006 apud BALDWIN; von HIPPEL, 2011, p. 1403).

Embora as definições sejam semelhantes em sua maioria, há uma contradição explícita entre open source hardware e open collaborative innovation com relação à venda do design ou o produto desenvolvido. Baldwin e von Hippel (2011) apontam como característica do fenômeno que os participantes de um projeto de open collaborative innovation não planejem vender produtos ou serviços que incorporem a inovação gerada, ou os direitos de propriedade intelectual relacionadas a ela. No entanto, comunidades como RepRap e Open Source Ecology, nas quais esse estudo está focado, praticam a venda de produtos desenvolvidos por seus participantes. Outro ponto a ser observado nas definições apresentadas na Tabela 1, é com relação o termo mass collaborative product realization, que embora esteja baseado no conceito de abertura, não especifica o grau de abertura desejado, e contempla além de projetos open source, projetos com um grau inferior de abertura.

Os demais termos e definições (open source hardware; commons-based peer production; product-oriented web-based interactive innovation; open source innovation; open source development; e open design) comtemplam em sua totalidade o fenômeno estudado neste trabalho. Dentre esses termos não há um consenso na literatura sobre qual deles se tornará tendência. Em 2013, a Design Society $^{19}$ lançou na lista de palavras chave de seu principal congresso, o International Conference on Engineering Design (ICED), o termo open source design, que voltou a aparecer dentre as palavras chaves da edição de 2015. Sendo assim, opta-se por utilizar o termo open source design (OSD) para se referir ao fenômeno abordado nessa pesquisa. Espera-se com isso, contribuir para que as obras referentes a esse fenômeno sejam encontradas com maior facilidade na literatura.

Para este trabalho foi estabelecida uma definição para o termo open source design combinando as definições de open source development, open source

19 A Design Society é uma organização internacional, não governamental e sem fins lucrativos, cujos membros compartilham interesses comuns na área do design. Disponível em www.designsociety.org, acessado em 09/06/2015. 
hardware e open design. Desse modo, buscou-se restringir o termo open source design ao desenvolvimento de produtos físicos, contemplar os elementos fundamentais identificados por Fjeldsted et al. (2012), esclarecer como devem ser as licenças associadas aos produtos resultantes do OSD, e enaltecer as características da cadeia de valor formada neste modo de inovação. Portanto, nesta pesquisa, "open source design é uma estratégia de desenvolvimento de produtos físicos por meio de uma plataforma de colaboração acessível e compartilhável, em que comunidades motivadas compartilham de forma transparente, adotam, produzem e desenvolvem continuamente soluções inovadoras sob os créditos e licenças estabelecidas em comum acordo, desde que essas licenças permitam que qualquer pessoa possa estudar, modificar, distribuir, produzir, e vender o design ou o produto baseado nesse design, formando uma cadeia de valor caracterizada pela co-criação e comunicação contínua".

Um dos fatores que pode corroborar para essa diversidade de termos e definições é o fato de o open source design compreender uma variedade de disciplinas, por exemplo, design, fabricação, ação colaborativa, gestão da cadeia de suprimentos, modelos de negócio, aspectos legais, infraestrutura tecnológica, e valores de conduta (AVITAL, 2011). Durante a revisão de literatura foram mapeados outros modos de inovação semelhantes ao open source design, que se diferenciam, porém, em alguns aspectos, e por isso, não devem ser confundidos com o fenômeno estudado neste trabalho. Dentre eles, destacam-se o crowdsourcing e os living labs.

Define-se o crowdsourcing como:

"um tipo de atividade online participativa, em que um indivíduo, uma instituição, uma organização sem fins lucrativos, ou uma empresa (iniciador) propõe a um grupo de indivíduos com diferentes graus de conhecimento, heterogeneidade $e$ número, por meio de uma chamada aberta e flexível, um acordo voluntário para realização de uma tarefa. A realização da tarefa, modular e de complexidade variada, cabe à multidão, que participa trazendo seu trabalho, dinheiro, conhecimento e/ou experiência, implicando sempre em benefício mútuo. $O$ usuário, ao contribuir com a tarefa, recebe como recompensa $o$ atendimento a um determinado tipo de necessidade, seja ela econômica, reconhecimento social, autoestima, ou o 
desenvolvimento de habilidades individuais, enquanto 0 iniciador obtêm e utiliza a seu favor o que o usuário traz para a organização, cuja forma depende do tipo de atividade específica" (ESTELLES-AROLAS; GONZALEZ-LADRON-DEGUEVARA, 2012, p. 197).

Segundo Baldwin; von Hippel (2011, p. 1412), o crowdsourcing pode ser considerado um modo de inovação colaborativa fechada. Nesse caso, os iniciadores têm o direito de propriedade intelectual sobre as inovações geradas. Além disso, esse modo de inovação se diferencia do open source design por possibilitar que as contribuições de um colaborador não sejam acessadas pelos demais. Assim, os colaboradores ao invés de construírem em cima das soluções propostas, competem entre si pela melhor solução, que será utilizada pelo iniciador. Isso só é possível nos casos em que os iniciadores são capazes de planejar tarefas com modularidade extrema, de modo que os colaboradores não necessitam saber o que os outros estão fazendo para conseguir realizar o seu trabalho (BALDWIN; HIPPEL, 2011, p. 1413).

Os living labs, por sua vez, são definidos como um ambiente, físico ou virtual, no qual interessados em "parcerias público-privada-pessoal" (4Ps) entre empresas, agências públicas, universidades e usuários, colaboram para a criação, prototipagem, validação e teste de novas tecnologias, produtos, serviços e sistemas, no contexto da vida-real. Os living labs são usados para o desenvolvimento de comunidades em um ambiente experimental, no qual os usuários são imersos em um espaço social criativo para o desenvolvimento e experimentação de seu próprio futuro. Portanto, os usuários se tornam co-criadores de valor ao explorar conceitos inovadores. (MCPHEE et al., 2012, p. 3). O termo living labs é frequentemente usado para se referir tanto a metodologia, quanto ao instrumento ou agência criada para essa prática (ALMIRALL et al., 2012, p. 12).

Assim como no open source design, o processo de inovação utilizado nos living labs é direcionado pelos usuários (ALMIRALL et al., 2012, p. 18). No entanto, os usuários que participam dos living labs fazem parte de um grupo selecionado pelo iniciador (ALMIRALL et al., 2012, p. 15), e há diferentes perspectivas com relação aos direitos de propriedade intelectual (NIITAMO et al., 2012, p. 47). Embora os living labs sejam baseados em uma filosofia de abertura, as empresas participantes enfatizam o interesse em deter os direitos de propriedade intelectual, enquanto os 
pesquisadores das universidades envolvidas, pressionam pela publicação dos resultados gerados (NIITAMO et al., 2012, p. 48). Dessa forma, em um living lab a disponibilização dos designs gerados não está garantida, e isso descaracteriza um open source design.

Nessa seção foram apresentadas as terminologias e definições encontradas na literatura sobre o fenômeno analisado, a justificativa pela escolha do termo open source design, assim como a definição adotada nesta pesquisa. Também foram apresentados outros modos de inovação que se assemelham ao OSD, porém, que não devem ser confundidos com o fenômeno estudado. Na seguinte seção, são explorados na literatura os trabalhos que contenham informações relevantes para a caracterização dos elementos fundamentais do open source design.

\subsection{Elementos fundamentais}

Essa seção está dividida de acordo com os o modelo conceitual proposto por Fjeldsted et al. (2012) (Figura 1), possuindo uma subseção para cada um dos elmentos fundamentatais do open source design. Conforme mencionado na introdução deste trabalho (seção 1.1), Fjeldsted et al. (2012) consideram a plataforma de colaboração o elemento central do open source design. Certamente esse elemento é importante, pois além de um repositório de informações, é o meio pelo qual os participantes do open source design entram em contato com o projeto e se relacionam entre si. Acredita-se que a arquitetura das plataformas de colaboração esteja diretamente relacionada ao processo de desenvolvimento de produtos, já que é ele que determina as atividades que serão executadas, e logo, o fluxo de informação no qual a plataforma deverá se basear. Em vista disso, opta-se por iniciar a revisão da literatura pelo elemento processo de desenvolvimento de produtos (subseção 2.2.1), seguido pelos elementos plataforma de colaboração (subseção 2.2.2), comunidade (subseção 2.2.3), motivadores (subseção 2.2.4) e modelo de negócio (subseção 2.2.5). 


\subsubsection{Processo de desenvolvimento de produtos}

Diversos autores encaram o desenvolvimento de produtos como um processo de negócio (COOPER, 2001; BROWNING et al., 2006; CRAWFORD; BENEDETTO, DI, 2006; ROZENFELD et al., 2006; ULRICH; EPPINGER, 2007). Um processo de negócio pode ser definido como um conjunto de atividades que entregam valor para um grupo de interessados (BURLTON, 2011 apud JESTON; NELIS, 2006, p. 10; BALDAM et al., 2014, p. 5). No caso do PDP, essas entregas consistem em um conjunto de especificações de projeto de um produto e de seu processo produtivo, envolvendo também o acompanhamento do produto no mercado, de modo a possibilitar a realização de eventuais mudanças necessárias, o planejamento da descontinuidade do produto e a incorporação de lições aprendidas ao longo do ciclo de vida do produto (ROZENFELD et al., 2006, p. 3). Com isso, as informações geradas ao longo do PDP permitem que a cadeia de valor produza, comercialize, distribua, e de assistência técnica aos produtos desenvolvidos, ou seja, entreguem valor para os interessados.

O open source design fornece uma alternativa à cadeia de valor tradicional, normalmente formada pela relação desenvolvedor-fabricante-distribuidorconsumidor. Com as informações geradas durante o PDP disponíveis online, é comum que os usuários se envolvam na fabricação dos produtos, encurtando a cadeia de valor em uma relação direta desenvolvedor-consumidor (AVITAL, 2011).

Durante o desenvolvimento, as relações entre os membros da cadeia de valor também sofrem alterações. No desenvolvimento colaborativo tradicional, também chamado de co-desenvolvimento, geralmente uma empresa montadora ${ }^{20}$ trabalha em conjunto com um grupo de parceiros estratégicos para o desenvolvimento de um produto. Nesses casos, ocorre uma decomposição hierárquica (top-down) do produto (problema), e cada empresa parceira fica responsável pelo desenvolvimento de um determinado item ${ }^{21}$ (subproblema) (ROZENFELD et al., 2006, p. 84; PANCHAL; FATHIANATHAN, 2008, p. 3). No processo de desenvolvimento

\footnotetext{
${ }^{20}$ A empresa montadora fornece os produtos para o mercado de consumo final e possui contato com os consumidores

${ }^{21} \mathrm{O}$ termo item é utilizado como uma designação genérica dos elementos, em diferentes níveis hierárquicos (sistemas, subsistemas e componentes), que compõe um determinado produto (ROZENFELD et al., 2006, p. 539).
} 
colaborativo tradicional, o fluxo de informação é direto e está baseado na relação entre os subproblemas (PANCHAL; FATHIANATHAN, 2008, p. 3).

Diferentemente do desenvolvimento colaborativo tradicional, os participantes do open source design não se organizam necessariamente de maneira hierárquica, podendo contribuir com soluções para diferentes níveis do problema. Os próprios participantes são responsáveis por escolher o problema que desejam colaborar (auto-organização), podendo ocorrer, dependendo do número de interessados, o envolvimento de mais de um participante na solução de um mesmo problema. Os objetivos do PDP no open source design também são significativamente diferentes dos objetivos de empresas tradicionais, cuja ênfase está no cumprimento dos requisitos desejados, o mais próximo possível. No OSD, as abertura e flexibilidade são as características chave para co-criações de sucesso nos produtos (PANCHAL; FATHIANATHAN, 2008, p. 8). Nesses casos, o fluxo de informação é baseado no modelo de "inscrição e publicação", no qual todos os participantes que estiverem trabalhando em um mesmo problema, se inscrevem para receber notificações sempre que houver uma nova publicação.

Michel Bauwens (2010) encara o open source design como um processo iterativo que necessita como entrada apenas um grupo de colaboradores voluntários, que não precisam pedir permissão para participar, com acesso a um conjunto de informações livres de direito autoral, que possam ser modificadas. $O$ processo é baseado em tarefas modulares disponibilizadas abertamente (ao invés de uma separação funcional do trabalho), e a qualidade dos resultados é validada pela própria comunidade. Dessa forma, a saída do processo gera uma nova versão das informações iniciais, que possam ser usadas em uma próxima iteração. Por se tratarem de produtos físicos, que precisam ser testados no mundo real, é necessária uma série de iterações entre as fases de design e produção. Para isso, é essencial o uso de ferramentas de design baseadas em 3D, como CAD/CAM, e de vídeos que mostrem os aspectos práticos de uso. Também é essencial que ocorra muita colaboração remota em tempo real (BAUWENS, 2010).

Em um levantamento do tipo survey realizado por Balka et al. (2009) com 85 projetos de open source design, foram levantadas algumas informações interessantes acerca dos tipos de projeto de open source design. Foi identificado que a maioria dos projetos pertence à indústria de produtos eletrônicos e equipamentos de $\mathrm{TI}$, e que aproximadamente $80 \%$ dos projetos de open source 
design necessitam de desenvolvimento de software. Ao serem questionados sobre o público alvo dos projetos, em torno de $73 \%$ dos respondentes disseram ser os usuários finais dos produtos, sendo que desses, aproximadamente $38 \%$ acreditavam que $\mathrm{o}$ uso dos produtos exigiam conhecimentos específicos (usuários avançados). Os demais projetos ( 27\%) não estariam destinados aos usuários finais, mas sim aos desenvolvedores, por necessitarem elevado conhecimento dos produtos/tecnologias.

Com relação ao grau de inovação, foram identificados projetos de todos os tipos, desde inovações incrementais (que resultam na melhoria de uma tecnologia existente em um mercado também existente) a inovações radicais (que resultam em uma nova tecnologia capaz de criar uma demanda previamente não reconhecida no mercado). No entanto, há uma maior proporção de projetos de inovação incremental, seguido por projetos que apresentam níveis intermediários de inovação (BALKA et al., 2009, p. 9).

Essa pesquisa também levantou o estágio de desenvolvimento dos projetos de open source design. Para isso, os projetos foram divididos em cinco estágios (BALKA et al., 2009, p. 15): (1) Planejamento/desenvolvimento virtual, abrangendo desde ideias ao desenvolvimento digital dos produtos; (2) Prototipagem iniciada, quando houver protótipos físicos montados, em fase de teste; (3) Primeiros protótipos em funcionamento, quando houver protótipos funcionais disponíveis à comunidade, porém, com necessidade de desenvolvimento futuro; (4) Produção estável, quando houver produtos completamente funcionais disponíveis no mercado, porém, com possibilidade de desenvolvimento futuro; e (5) Maturidade, quando for alcançado o desenvolvimento final, sem necessidade de desenvolvimento futuro. A Figura 2 apresenta a distribuição dos projetos de open source design pesquisados de acordo com os estágios de desenvolvimento. 


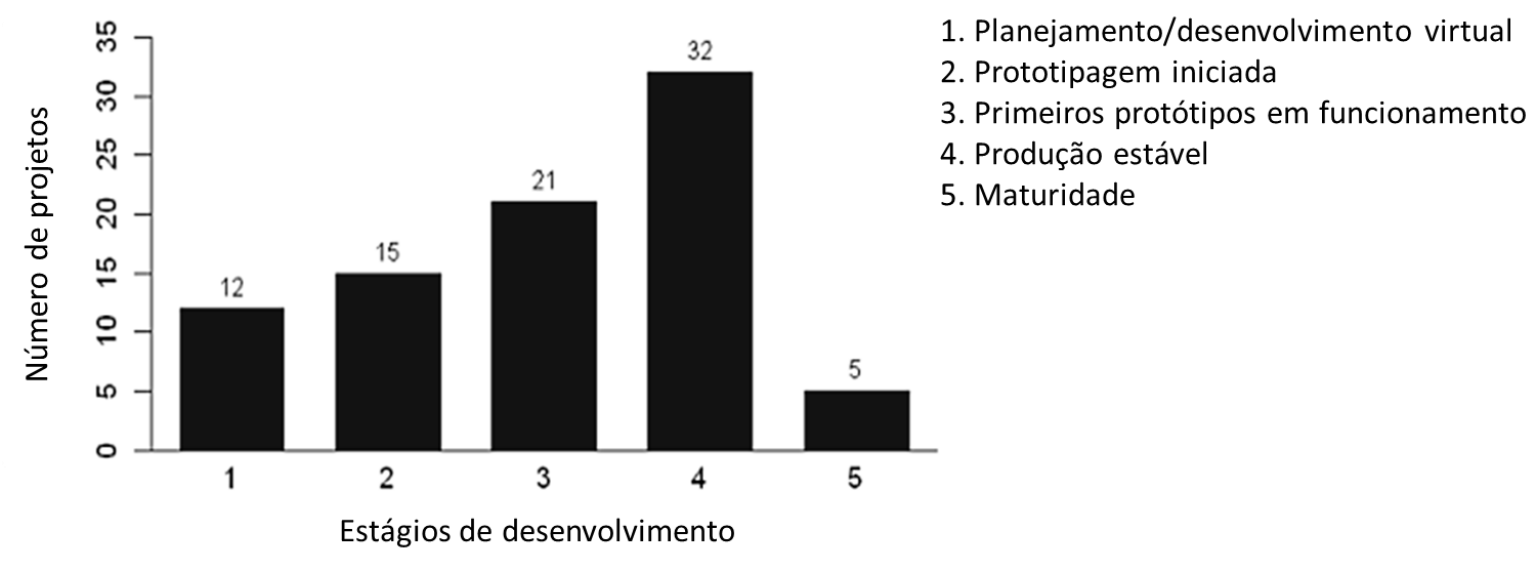

Figura 2 - Distribuição dos projetos de open source design de acordo com os estágios de desenvolvimento (BALKA et al., 2009, p. 8)

Os dados apresentados na Figura 2 mostram que a maioria dos projetos de open source design ainda não haviam sido finalizados completamente no momento em que foi realizada a pesquisa, e que aproximadamente $45 \%$ dos projetos pesquisados já haviam atingido o estágio de produção estável. Esses dados, analisados isoladamente, apresentam um indicativo de que o open source design, se encontra em estágios iniciais. Observa-se, também, a importância da evolução dos protótipos físicos como responsável por demarcar a transição entre os estágios de desenvolvimento definidos por Balka et al. (2009).

Ao estabelecer estágios de desenvolvimento, Balka et al. (2009) buscaram um meio genérico de medir o avanço dos projetos de open source design ao longo do processo de desenvolvimento de produtos. Esse foi o caso mais próximo encontrado na literatura pesquisada de uma representação do processo de desenvolvimento de produtos para o open source design. No entanto, dentro do contexto dos living labs, foi identificada uma preocupação com a estruturação do PDP visando auxiliá-los no cumprimento de seu papel como um catalizador de redes de inovação (SCHAFFERS; TURKAMA, 2012, p. 26).

Devido às semelhanças existentes entre os living labs e o open source design, principalmente pelo fato de ambos terem como característica um processo de inovação direcionado pelos usuários, são explorados nessa subseção dois modelos para o processo de desenvolvimento de produtos utilizados por living labs. Com isso, pretende-se utilizar os living labs com uma fonte de benchmarking para auxiliar no entendimento sobre processos de desenvolvimento de produtos direcionados pelos usuários. 
Segundo Katzy (2012), para que os usuários sejam capazes de influenciar o PDP, é necessário que os living labs possuam novos modelos de processo, que permitam a prototipagem rápida das ideias e conceitos apresentados pelos usuários. Os living labs também devem fornecer proficiência em práticas, métodos e técnicas que reduzam os custos e o tempo de aprendizagem, como por exemplo, práticas ágeis $^{22}$. Além disso, cabe a cada living lab se especializar nas competências técnicas que são de seu interesse, de modo que cada um tenha um perfil único (KATZY, 2012, p. 22).

O primeiro modelo de processo explorado é utilizado pelo TestBed Botnia living lab no desenvolvimento de produtos e serviços. Conforme apresentado na Figura 3, o PDP utilizado no TestBed Botnia living lab possui três fases: (1) Projetar Conceitos, (2) Projetar Protótipos e (3) Projetar Sistema Final (BERGVALLKÅREBORN et al., 2006 apud ALMIRALL et al., 2012, p. 13).

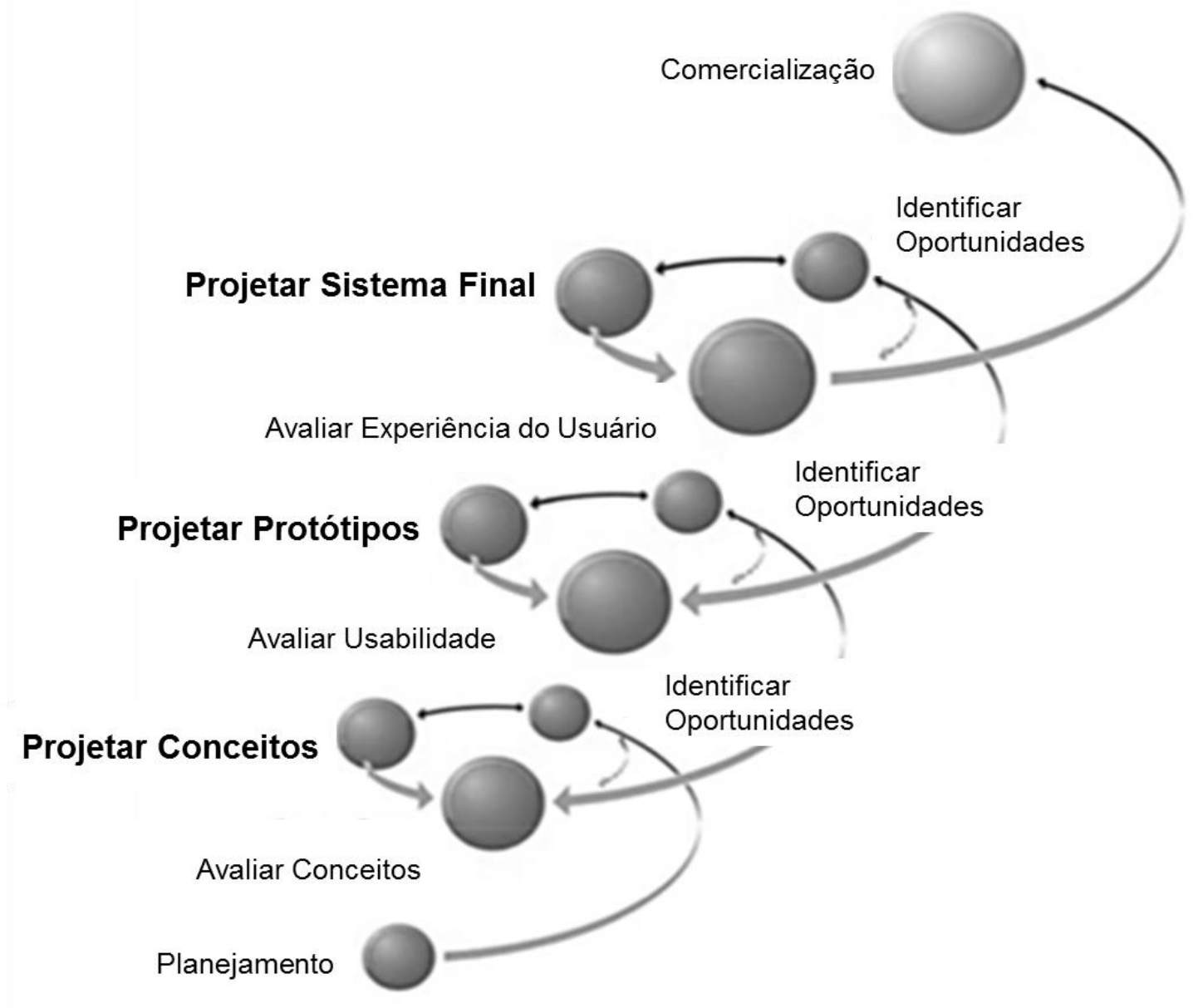

Figura 3 - PDP utilizado no TestBed Botnia living lab (ALMIRALL et al., 2012, p. 13)

${ }^{22}$ Práticas ágeis consistem em "práticas que tragam mais agilidade, flexibilidade, capacidade para absorver mudanças com baixo custo e risco" (CONFORTO, 2013, p. 22). 
O objetivo da primeira fase (Projetar Conceitos) é identificar e priorizar as necessidades dos usuários, por meio da construção de narrativas elaboradas pelos próprios usuários. Nessas narrativas, eles enaltecem o que há de melhor no estado atual, e sonham com uma situação futura por eles desejada. A partir das necessidades dos usuários, priorizadas, são desenvolvidos os primeiros conceitos, que são prototipados na segunda fase (Projetar Protótipos). Na terceira fase (Projetar Sistema Final), os protótipos são testados em casos reais e melhorados. O processo iterativo faz com que os resultados de cada fase sejam refinados por meio de um desenvolvimento colaborativo, até se chegar ao produto ou serviço final, ou seja, até que os resultados gerados sejam considerados satisfatórios (ALMIRALL et al., 2012, p. 13).

Uma abordagem semelhante é utilizada pelo Helsinki Living Labs para estimular o desenvolvimento colaborativo (Figura 4). Neste caso é dada uma ênfase maior na seleção dos usuários que participam do processo. O Helsinki Living Labs também segue um modelo de processo iterativo composto por três fases: (1) Fundamentação, (2) Co-Design Interativo e Iterativo, e (3) Apropriação e Implementação. Após a definição do foco do projeto, se inicia a fase de Fundamentação, na qual são identificados os stakeholders do projeto e selecionados os usuários participantes. Na segunda fase (Co-Design Interativo e Iterativo) os usuários exploram conceitos potenciais e trabalham colaborativamente, por meio de workshops, na prototipagem desses conceitos. Na última fase (Apropriação e Implementação), os protótipos são testados e são coletados feedback visando a melhoria dos resultados obtidos (ALMIRALL et al., 2012, p. 14). 
workshops e prototipagem

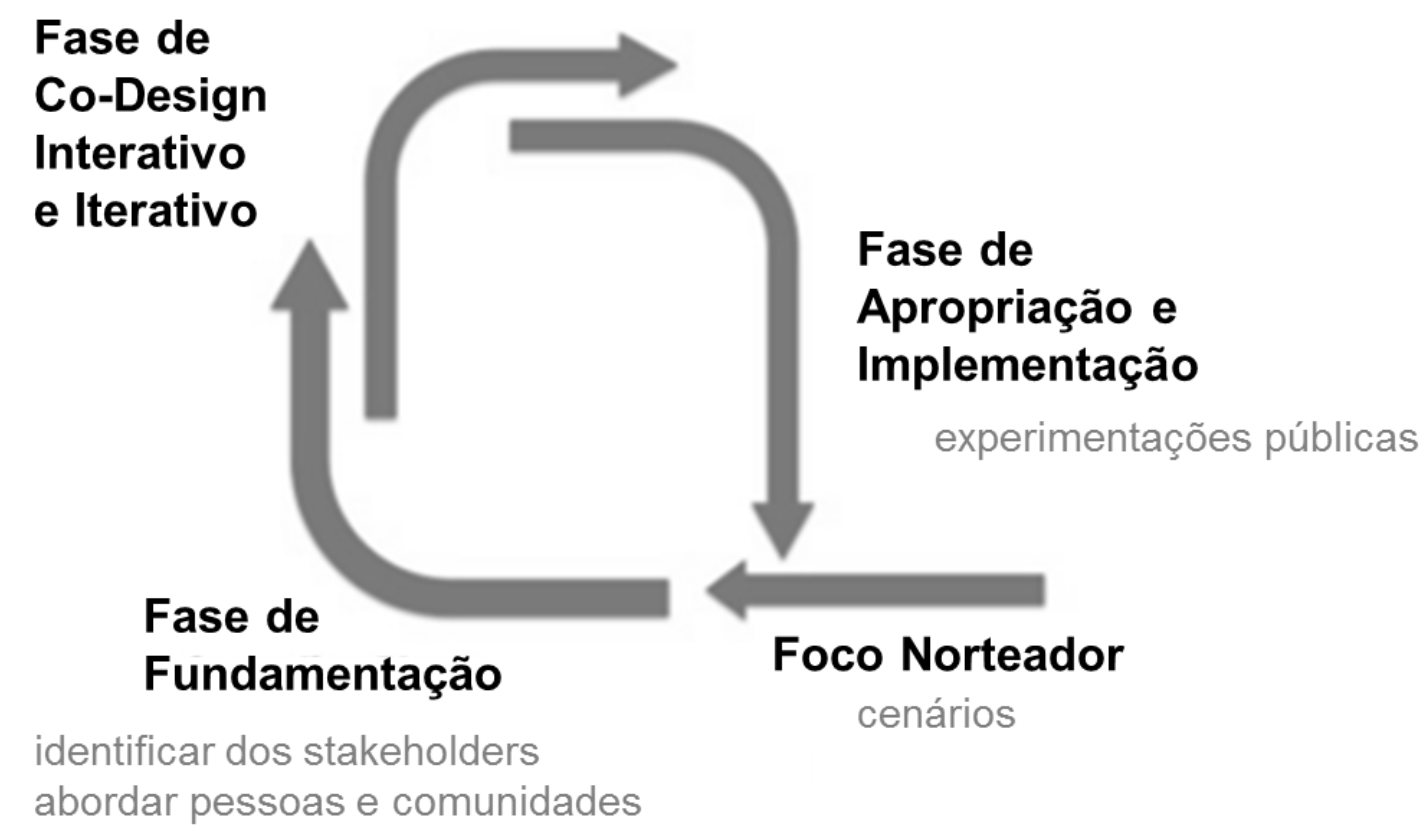

Figura 4 - PDP utilizado no Helsink Living Labs (ALMIRALL et al., 2012, p. 15)

Ao analisar os dois modelos de processo apresentados, observa-se que ambos são processos iterativos e estão de acordo com as recomendações de Katzy (2012) no que diz respeito à prototipagem rápida dos conceitos apresentados pelos usuários. No PDP utilizado no TestBed Botnia living lab há uma fase exclusiva para o projeto dos protótipos, enquanto que no Helsink Living Labs, a prototipagem está incluída na fase de Co-Design Interativo e Iterativo, juntamente com 0 desenvolvimento de conceitos, que são posteriormente testados na fase de Apropriação e Implementação.

Nesta subseção foi realizada uma revisão da literatura sobre o processo de desenvolvimento de produtos no open source design. Como foram encontrados poucos trabalhos abordando esse tema, realizou-se um benchmarking na literatura sobre living labs, devido às similaridades entre ambos os processos. Com base nos estudos revisados, é possível identificar algumas características desse elemento:

- processo iterativo;

- colaborativo, com fluxo de informação baseado no modelo de "inscrição e publicação";

- direcionado pelo usuário;

- auto-organizado;

- baseado em tarefas modulares; 
- permite o desenvolvimento de soluções concorrentes;

- permite a prototipagem rápida das ideias e conceitos, por exemplo por meio de workshops;

- a qualidade dos resultados é validada pela própria comunidade;

- deve apoiar projetos de diferentes graus de inovação, desde inovações incrementais a inovações radicais;

- deve apoiar, também, o desenvolvimento de softwares; e

- deve fornecer proficiência em práticas, métodos e técnicas que reduzam os custos e o tempo de aprendizagem.

$\mathrm{Na}$ próxima subseção é apresentada uma revisão da literatura sobre o elemento plataforma.

\subsubsection{Plataforma de colaboração}

Avital (2011), ao tratar de plataformas de colaboração para apoiar o open source design, sugere alguns requisitos de alto nível que as plataformas devem atender. Para ele, as plataformas de colaboração devem ser transparentes, permitir o compartilhamento de informação e encorajar o diálogo sem impor limites culturais ou institucionais, de modo a reforçar a colaboração, reciprocidade, tolerância, igualdade, justiça e liberdade. Ele ressalta a importância de plataformas de colaboração flexíveis para garantir um fluxo contínuo de novas ideias e configurações, e defende a existência de funcionalidades que permitam a adaptação e customização. Segundo Avital (2011), essas funcionalidades deveriam gerar automaticamente extensões complementares às modificações feitas por um colaborador, de modo a evitar potenciais "imprevistos", embora o autor não mencione quais seriam esses potenciais imprevistos, nem como seriam essas funcionalidades em detalhes.

Conforme apresentado na seção 2.2.1, Panchal e Fathianathan (2008) defendem um fluxo de informação para o open source design baseado em um modelo de "inscrição e publicação", e em vista disso, apontam a necessidade de um sistema de informação capaz de apoiar: (1) a estruturação de uma comunidade, possibilitando que os usuários criem seus próprios perfis, com informações relacionadas à formação, habilidades e experiências; (2) a descrição online dos 
problemas; (3) a submissão online de soluções e comentários, permitindo a coexistência de múltiplas soluções; (4) a comunicação, permitindo o recebimento de notificações quando houver uma nova publicação em um tópico no qual o participante estiver inscrito; e (5) a tomada de decisão descentralizada, por exemplo, por meio de pesquisas de opinião (FATHIANATHAN et al., 2009, p. 128).

Visando atender a estas necessidades, Fathianathan et al. (2009) propõem uma plataforma de colaboração na qual os projetos são gerenciados como uma rede, por meio da criação de "nós" (nó de projeto, nó de solução e nó de análise), e dos relacionamentos entre os "nós". A Figura 5 apresenta o processo lógico dessa plataforma, detalhado nos paragráfos seguintes.

6. Criar nós de projetos filhos

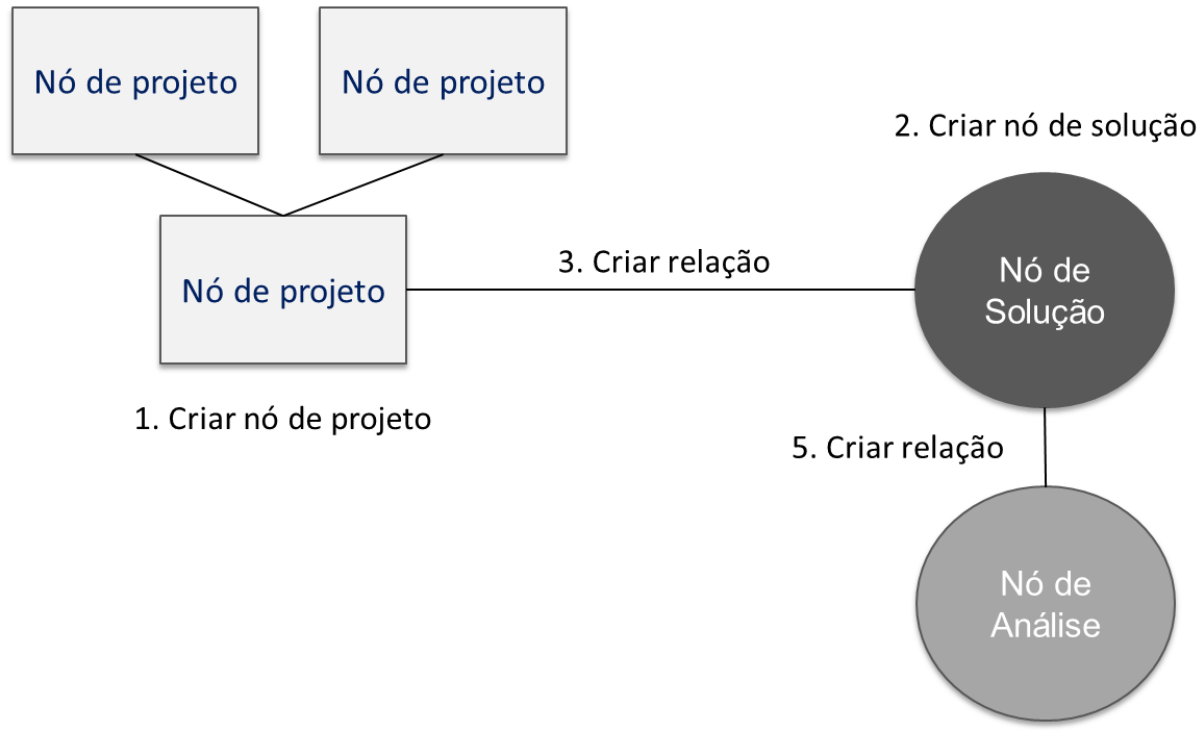

4. Criar nó de análise

Figura 5 - Processo lógico da plataforma proposta por Fathianathan et al. (2009, p. 129)

Ao utilizar a plataforma de colaboração com uma abordagem top-down, em que ocorre a decomposição hierárquica do problema, o primeiro passo consiste na criação de um nó de projeto (1), que pode ser, posteriormente, decomposto em nós de "projetos-filho". Cada nó de projeto possui campos para inclusão da data de início e da data de conclusão prevista para o projeto, e os requisitos do projeto. Para cada projeto, são propostas soluções, por meio da criação de um nó (2) de solução e do relacionamento deste nó com o projeto para qual a solução foi proposta (3). Esse nó é composto pela descrição da solução, permitindo o anexo de arquivos, como por exemplo, arquivos CAD e esquemáticos. As soluções propostas podem ser analisadas, por meio da criação de um nó de análise (4) e do relacionamento deste 
nó com a solução analisada (5). O nó de análise contém as informações sobre o método e métricas utilizados, acompanhados do resultado da análise. Assim como ocorre no nó de solução, o nó de análise permite que sejam anexados arquivos, como por exemplo, simulações de elementos finitos. Após a inclusão de diversas soluções e análises, é selecionada a solução mais adequada para o projeto, e caso necessário, são adicionados mais projetos-filho (6). Para garantir uma tomada de decisão descentralizada, a plataforma de colaboração oferece a possibilidade de que seja realizada uma pesquisa de opinião, na qual os usuários podem dar notas para as soluções, seguindo uma escala de 1-10. Além disso, em cada nó há um espaço para discussões entre os usuários (FATHIANATHAN et al., 2009, p. 129).

Ao testar a plataforma de colaboração em um estudo de caso, Fathianathan et al. (2009) observaram que usuários utilizaram distintos formatos para descrever as soluções (texto, desenhos em CAD, e rascunhos escaneados um papel), e que os criadores dos nós de solução assumiram um papel de líder nas discussões, coordenando as contribuições dos demais membros da comunidade, e curiosamente, mostraram uma tendência em não contribuir com outras soluções propostas. Já os membros que não propuseram soluções, participaram ativamente, contribuindo com diversas soluções. Com relação à análise das soluções, os pesquisadores observaram que as discussões informais podem contribuir na redução do tempo gasto com a validação das soluções, baseada nos problemas levantados e nas melhorias sugeridas pela comunidade. Os autores também destacaram que as soluções propostas foram em sua maioria inovações incrementais (FATHIANATHAN et al., 2009, p. 129), corroborando com os resultados obtidos na survey realizada por Balka et al. (2009).

A plataforma de colaboração proposta por Fathianathan et al. (2009) foi a única plataforma identificada na literatura pesquisada, criada para apoiar projetos de desenvolvimento de produtos físicos no contexto do open source design. A survey realizada por Balka et al. (2009), embora não tenha investigado diretamente as plataformas de colaboração utilizadas para apoiar o open source design, explora quais são os principais meios de comunicação adotados, e aponta para uma ampla utilização de fóruns, wikis, ambientes virtuais de trabalho, blogs, redes sociais e provedores de hospedagem (por exemplo, Sourceforge $e^{23}$ e GitHub ${ }^{24}$ ) para facilitar o

${ }^{23}$ O Sourceforge consiste em um repositório para códigos fonte focado em projetos open source. Disponível em http://sourceforge.net/, acessado em 09/06/2015. 
compartilhamento de informações e a co-criação entre um grande grupo de participantes geograficamente distribuídos (BALKA et al., 2009, p. 9). A Figura 6 apresenta a distribuição dos meios de comunicação utilizados em projetos de open source design, sendo que os meios de comunicação destacados anteriormente (wikis, ambientes virtuais de trabalho, blogs, redes sociais e provedores de hospedagem) estão agrupados na opção "Outros".

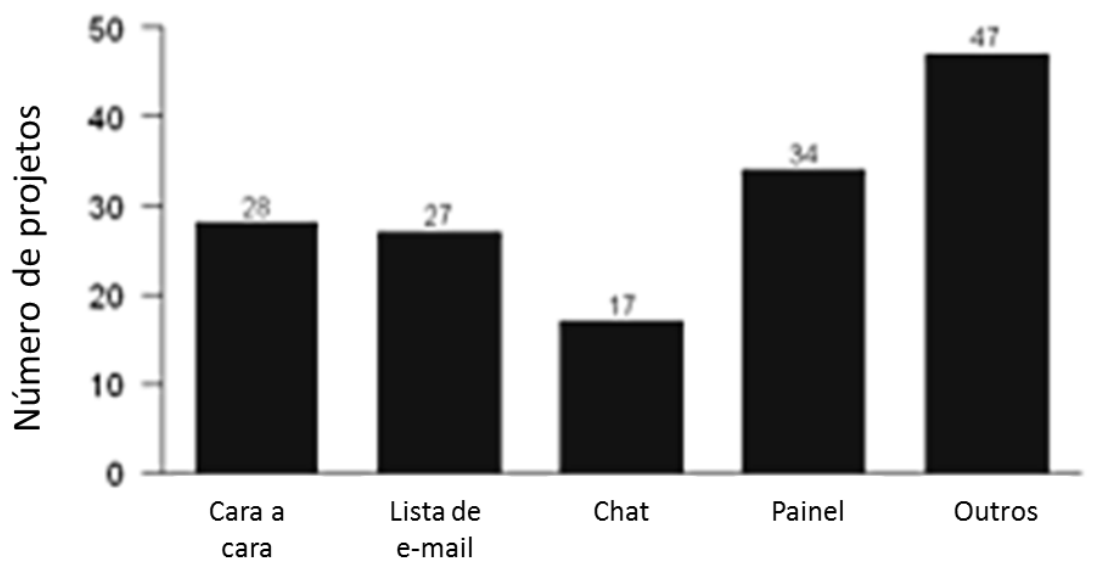

Meios de comunicação

Figura 6 - Distribuição dos meios de comunicação utilizados em projetos de open source design (BALKA et al., 2009, p. 9)

No ambiente empresarial, normalmente são utilizados sistemas de gestão do ciclo de vida de produtos (em inglês, Product Lifecycle Management - PLM) para apoiar a gestão do PDP. Os sistemas PLM são definidos como um conceito para a gestão integrada do das informações relacionadas ao produto durante todo o seu ciclo de vida (SAAKSVUORI, IMMONEN, 2004 apud SCHUH et al., 2008, p. 210). Estudos indicam que mesmo nas empresas tradicionais o nível de maturidade em PLM ainda se encontra em estágios iniciais, com foco em aspectos parciais e, na maioria dos casos, baseados apenas em softwares de gestão eletrônica de documentos (em inglês, Product Data Management - PDM) (SCHUH et al., 2008, p. 211). Na maioria dos casos, a implantação desses sistemas requer um grande esforço por parte da empresa, principalmente na customização e integração do novo sistema com os demais sistemas utilizados. No open source design a gestão das informações referentes ao processo de desenvolvimento de produtos é um desafio ainda maior, devido à grande diversidade entre os softwares e hardwares utilizados

${ }^{24} \mathrm{O}$ GitHub consiste em um repositório para códigos fonte com um sistema de controle de versionamento, e uma rede social. Disponível em https://github.com/, acessado em 09/06/2015. 
pelos diversos colaboradores. O desenvolvimento de padrões para a troca de informações entre essas diferentes ferramentas é um ponto crítico, e a integração entre as ferramentas open source existentes, como as ferramentas de CAD, modelagem de elementos finitos, planejamento de processos de fabricação, otimização, etc., ainda é muito fraca. São necessárias novas abordagens que permitam a integração dinâmica entre os sistemas, de maneira automatizada (PANCHAL; FATHIANATHAN, 2008, p. 8). Balka et al. (2009) também destacam a importância de ferramentas open source para o desenvolvimento digital dos produtos desenvolvidos no open source design, e relatam terem observado como a falta de ferramentas necessárias desacelera o processo de desenvolvimento (BALKA et al., 2009, p. 12).

Nesta subseção, foram explorados os trabalhos identificados na literatura que contribuem para a um melhor entendimento da plataforma de colaboração dentro do contexto do open source design. Por meio da revisão desses trabalhos, é possível identificar algumas características deste elemento:

- permite a estruturação de uma comunidade;

- permite o compartilhamento de informações de maneira transparente, em diversos formatos;

- encoraja o diálogo;

- permite a coexistência de múltiplas soluções;

- deve facilitar a co-criação entre um grande grupo de participantes geograficamente distribuídos;

- deve permitir a integração dinâmica entre sistemas, de maneira automatizada; e

- deve facilitar a tomada de decisão descentralizada.

Na próxima subseção é apresentada a revisão da literatura sobre o elemento comunidade, incluindo também as características dos membros dessas comunidades.

\subsubsection{Comunidade}

Ao revelar gratuitamente um design, os desenvolvedores frequentemente se deparam com outros interessados, que melhoram ou sugerem melhorias nos 
designs gerados, proporcionando um benefício mútuo (Raymond, 1999 apud Baldwin; von Hippel, 2011, p. 1401). Esses interessados são em sua maior parte usuários, porém, o open source design também pode atrair participantes que não sejam usuários dos designs criados, motivados por aprendizado, diversão e reputação (BALDWIN; HIPPEL, 2011, p. 1408). Os usuários são definidos como indivíduos ou organizações que esperam se beneficiar do uso de um design, produto ou serviço (BALDWIN; HIPPEL, 2011, p. 1400). Nesta pesquisa, utiliza-se o termo colaborador para se referir aos indivíduos que participam do open source design, independentemente, se esse indivíduo é ou não, um usuário dos designs gerados. Colaboradores podem inclusive serem pagos, ou trabalhar para uma organização tradicional. O importante é que eles contribuam com o projeto, e disponibilizem seus resultados para que outros colaboradores possam construir em cima (von HIPPEL, 2005, p. 96; BAUWENS, 2010).

Von Hippel (2005, p. 96) refere-se a essas comunidades como "comunidades de inovação", e as define como um grupo de indivíduos ou empresas interconectados por relações de transferência de informações, as quais podem ocorrer por meio de encontros presenciais, eletrônicos, ou outros meios de comunicação. Elas podem, porém não necessitam ser reguladas por meio de associações, e normalmente incorporam o conceito de comunidade proposto por Wellman et al. (2002, p. 153), no qual uma comunidade é definida como "uma rede de laços interpessoais que proporciona sociabilidade, apoio, informação, sentimento de fazer parte de um grupo, e identidade social".

A survey realizada por Balka et al. (2009) corrobora com a literatura, apontando para uma predominância de envolvimento de usuários nos projetos de open source design. Aponta também para uma participação significativa de membros da indústria nesses projetos, superior à participação de pesquisadores. $O$ gráfico apresentado na Figura 7 apresenta a distribuição dos colaboradores nos projetos de open source design de acordo com o background de cada um (usuário, profissional da indústria, e pesquisador). Vale ressaltar que neste caso, foi permitida aos respondentes a marcação de múltiplas alternativas. Sendo assim, dos 85 projetos investigados, 12 disseram ter recebido contribuição dos três tipos de colaboradores, 41 combinaram contribuições de usuários e profissionais da indústria, 17 de usuários e pesquisadores, e 14 de profissionais da indústria e pesquisadores (BALKA et al., 2009, p. 6). 


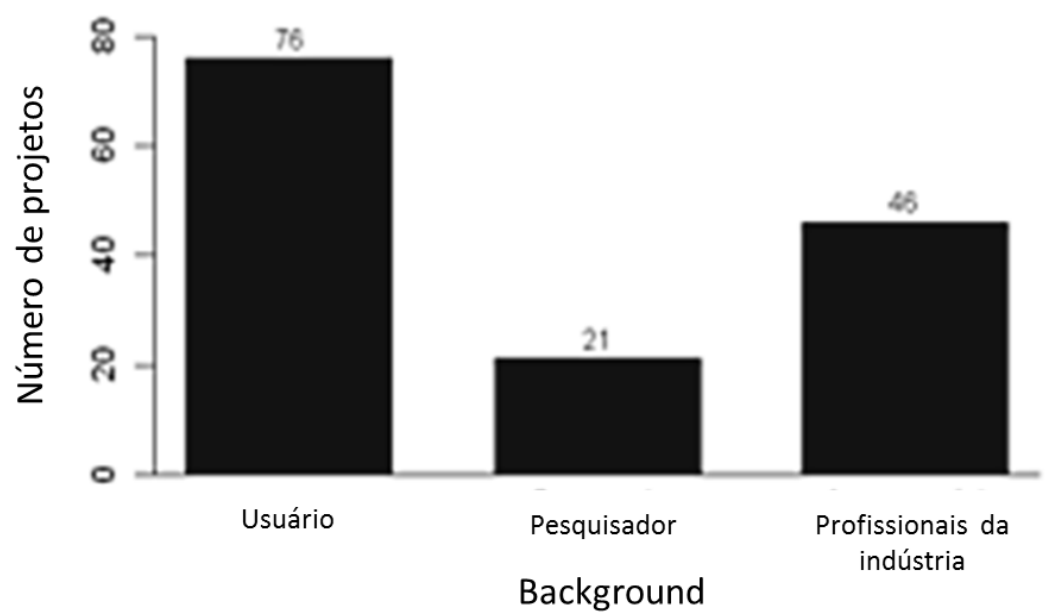

Figura 7 - Distribuição dos colaboradores nos projetos de open source design de acordo com o background (BALKA et al., 2009, p. 6)

Segundo Balka et al. (2009, p. 11), são poucos os projetos que conseguem, em seu início, atrair um número alto o suficiente de colaboradores ativos, com diferentes backgrounds, de modo a construir uma comunidade e avançar rapidamente nas fases do processo de desenvolvimento de produtos. Seus estudos apontam haver uma relação positiva entre o número de colaboradores e o estágio de desenvolvimento dos projetos de open source design. No entanto, não é claro quem vem primeiro: se projetos em estágios mais avançados atraem mais colaboradores, ou se mais colaboradores fazem com que os projetos avancem mais rápido (BALKA et al., 2009, p. 9). O gráfico apresentado na Figura 8 demonstra essa relação positiva entre o número de colaboradores e os estágios de desenvolvimento, discutidos na subseção 2.2.1.

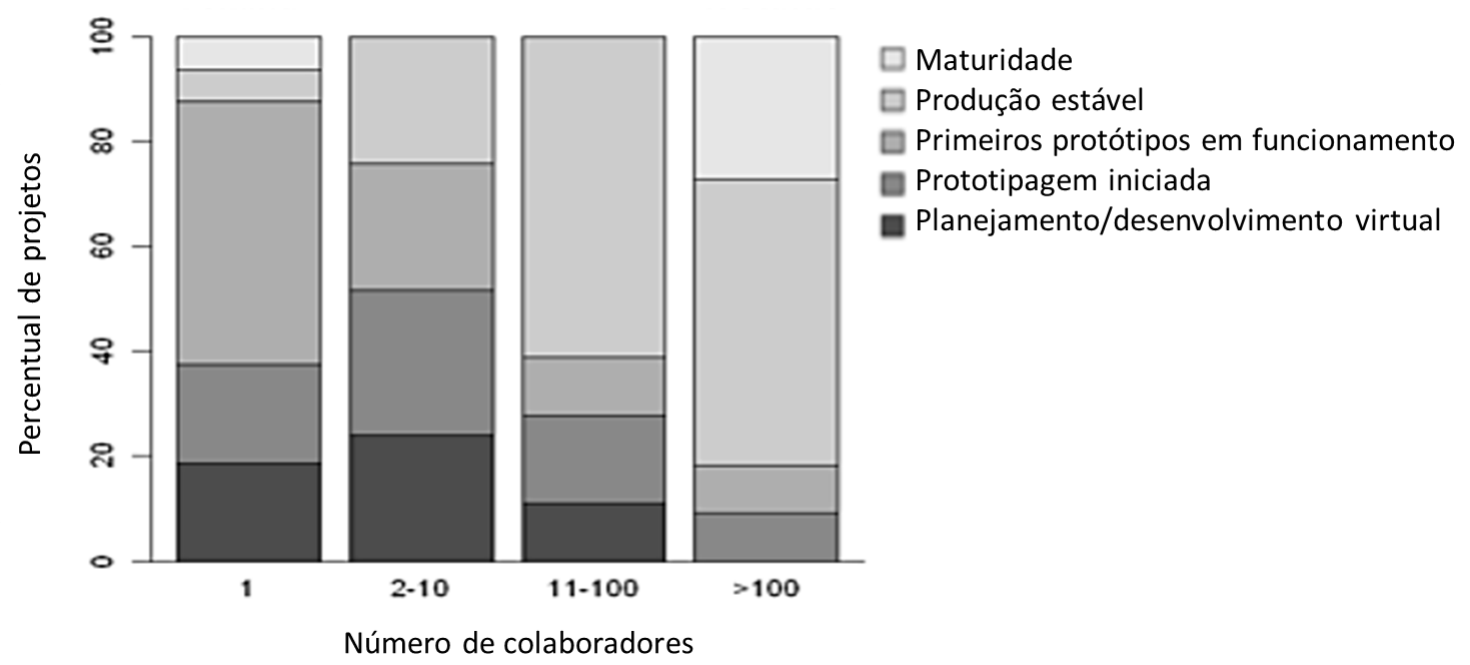

Figura 8 - Relação entre o número de colaboradores e os estágios de desenvolvimento (BALKA et al., 2009, p. 10) 
Projetos open source ativos geralmente possuem uma comunidade bem definida com interesses comuns tanto com relação à evolução dos produtos, quanto ao uso dos resultados gerados. Ainda assim, há muitos projetos open source que não possuem uma comunidade claramente estruturada, ou que envolvem somente uma pessoa (GACEK; ARIEF, 2004, p. 36), conforme pode ser observado no gráfico apresentado na Figura 9.

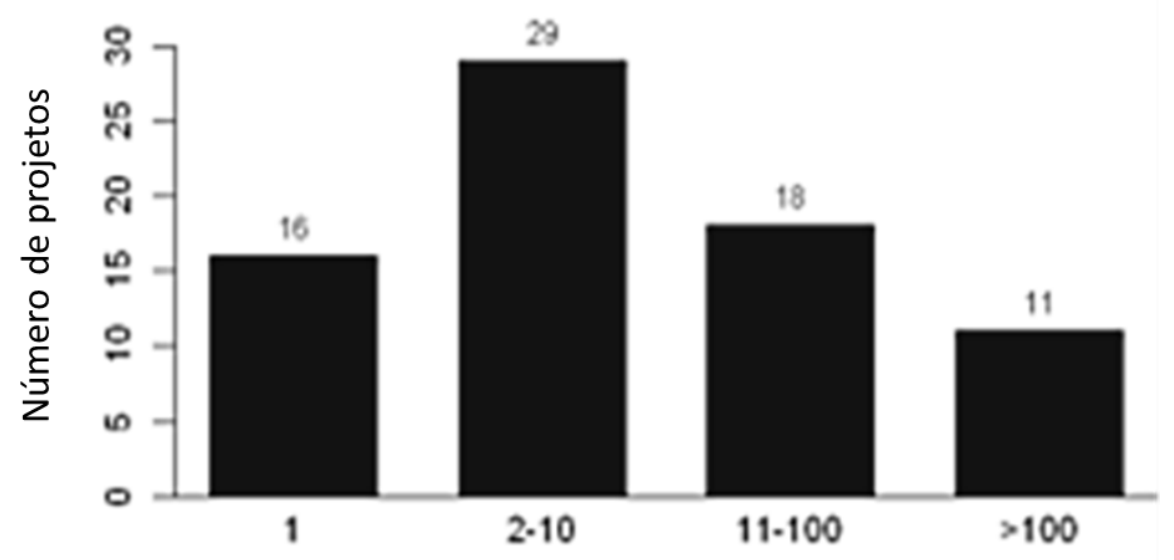

Número de colaboradores por projeto

Figura 9 - Distribuição do número de colaboradores nos projetos de open source design (BALKA et al., 2009, p. 6)

Para Gacek e Arief (2004), a estruturação de uma comunidade depende basicamente de dois fatores: o balanço entre centralização e descentralização, e a meritocracia. $O$ balanço entre centralização e descentralização está relacionado à estrutura hierárquica da comunidade. No caso das comunidades mais centralizadas há uma diferenciação explícita entre os níveis de desenvolvedores, e aqueles que possuem um nível mais alto são responsáveis pela tomada de decisão. Já em comunidades mais descentralizadas, todos estão em um mesmo nível, e a tomada de decisão ocorre por meio do consenso entre os colaboradores (GACEK; ARIEF, 2004, p. 36). A meritocracia está associada à forma como ocorre a transição entre os diferentes níveis dentro de uma estrutura hierárquica de uma comunidade. Em uma comunidade meritocrática, o conhecimento que um colaborador demonstra por meio de suas contribuições determina a posição que ele ocupa dentro da comunidade, e logo, sua influência na tomada de decisões. O tempo para ocorrer uma ascensão hierárquica varia de comunidade para comunidade, assim como os obstáculos enfrentados. Transições também podem ocorrer no outro sentido, por exemplo, pela falta de participação ou desentendimentos com outros colaboradores 
(GACEK; ARIEF, 2004, p. 37). Por isso, valores como confiança, responsabilidade e reciprocidade são importantes para criação de uma cultura de compartilhamento (van ABEL et al., 2011).

A Figura 10 ilustra uma comunidade de colaboradores em um projeto open source design, em que se pode notar a divisão hierárquica entre seus membros e as transições que ocorrem entre os diferentes níveis hierárquicos. Cada um dos níveis hierárquicos está associado a atividades específicas, e de acordo com a ascensão dentro da comunidade, aumentam-se as responsabilidades e a influência na tomada de decisões.

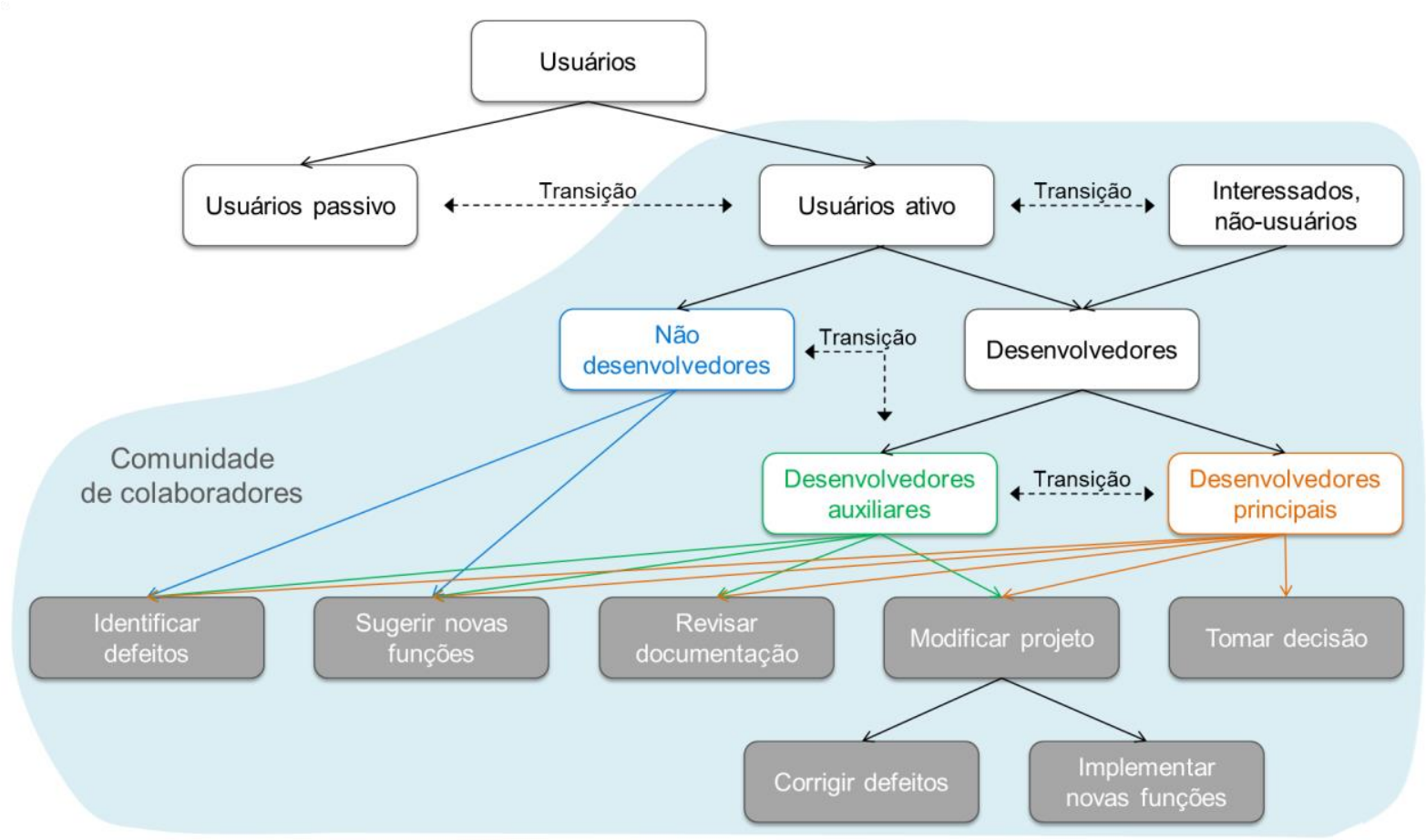

Figura 10 - Estruturação de uma comunidade de colaboradores em um projeto open source (adaptado de Gacek e Arief, 2004, p. 36).

A estrutura hierárquica de uma comunidade tende a estar relacionada aos interesses de seu iniciador. O iniciador de um projeto geralmente se torna o "dono" do projeto, ou líder, e assume a responsabilidade pela gestão do projeto, assim como o desenvolvimento da primeira versão e o estabelecimento da infraestrutura necessária. Conforme o projeto atrai colaboradores, ele começa a evoluir, levando a estruturação de uma comunidade (von HIPPEL, 2005, p. 100). Quando os projetos de open source são iniciados por empresas, com o intuito de patrocinar atividades de co-criação, as comunidades formadas são chamadas de comunidades patrocinadas. Por outro lado, quando as comunidades se formam sem o patrocínio 
de uma empresa, são denominadas comunidades autônomas (WEST; O'MAHONY, 2008, p. 2).

O gráfico apresentado na Figura 11 apresenta indícios de que grande parte das comunidades possui uma estrutura hierárquica mais centralizada, apontando os líderes dos projetos, as empresas e os desenvolvedores principais como os coordenadores preponderantes do processo de desenvolvimento de produtos. Quando o projeto atinge o estágio de produção, as empresas se tornam o principal agente.
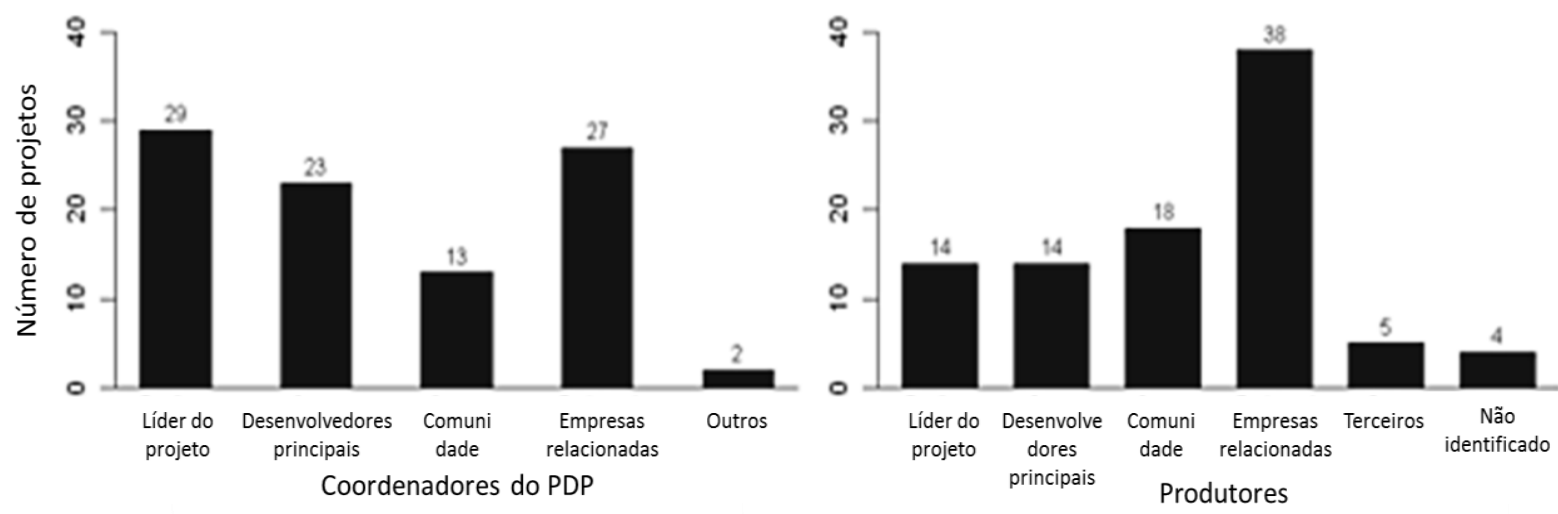

Figura 11 - Distribuição dos principais coordenadores do processo de desenvolvimento (esquerda) e dos principais produtores (direita) nos projetos de open source design (BALKA et al., 2009, p. 8)

Embora o open source design não forneça barreiras diretas à participação, muitas das atividades executadas durante o processo de desenvolvimento de produtos exigem que o colaborador seja extremamente experiente. Além de habilidades técnicas, a co-criação exige habilidades sócias (van ABEL et al., 2011), principalmente de colaboradores que possuem papeis de maior responsabilidade dentro das comunidades. Segundo Surowiecki (2005, p. 10), as comunidades devem compreender pessoas com os mais diversos conhecimentos e habilidades. Fathianathan et al. (2009, p. 128) acrescentam que a diversidade auxilia na concepção de inovações multidisciplinares e na validação de soluções por diferentes perspectivas.

Dentro desta lógica de diversidade, Schuurman e Marez (2012, p. 32), ao pesquisar as características dos usuários nos living labs, propuseram quatro dimensões principais para caracterização de usuários: (1) expertise; (2) intensidade de uso; (3) novas necessidades; e (4) originalidade ${ }^{25}$. Adaptando essas dimensões para o contexto das comunidades de open source design, na caracterização dos

\footnotetext{
${ }^{25}$ Utiliza-se o termo innovativeness, em inglês, para se referir a essa dimensão.
} 
colaboradores, expertise está relacionada aos conhecimentos que o colaborador possui do produto, do seu processo de fabricação, de métodos, técnicas e ferramentas utilizadas no desenvolvimento de produtos, e também aos conhecimentos que o colaborador possui da experiência dos usuários ${ }^{26}$; intensidade de uso se refere às experiências dos colaboradores como usuários, incluindo a quantidade de tempo gasta usando o produto, assim como a diversidade de usos; novas necessidades consistem no fato de os colaboradores terem identificado necessidades que não possam ser atendidas pelas soluções oferecidas atualmente no mercado; e originalidade está relacionada à adoção de inovações por parte do colaborador. Caberia aqui também uma dimensão referente à

Além de habilidades técnicas e sociais, e de conhecimento sobre o produto e suas experiências de uso, os colaboradores também necessitam ter acesso a softwares e ferramentais físicos ao longo do processo de desenvolvimento de produtos, principalmente para o desenvolvimento de protótipos, gerando custos com os quais muitos colaboradores não conseguem arcar (KATZY, 2012, p. 22). Devido a essas dificuldades, Bauwens (2010) defende que as comunidades de open source design necessitam estar muito mais próximas de players já existentes. Nesse contexto, Hummels (2011) sugere que as comunidades se desenvolvam ao redor de um ambiente híbrido de desenvolvimento, que além de um espaço digital - sempre disponível, independentemente da localização geográfica - possua também um espaço físico de trabalho. Um espaço físico comum permita intensa colaboração, a construção de protótipos, e o teste das soluções criadas no contexto de potenciais usuários, de modo a validar ideias e direcionar desenvolvimentos futuros. Fab Labs e TechShops são exemplos de espaços desse tipo, especializados em tecnologias de manufatura para apoiar o desenvolvimento de produtos físicos (KATZY, 2012, p. 21).

Nesta subseção foram explorados estudos que contribuem para a caracterização do elemento comunidade no contexto do open source design, incluindo também as características dos membros dessas comunidades. Com base nesses estudos, foram identificadas as seguintes características para esse elemento:

${ }^{26}$ Segundo a ISO-9241-210:2010, experiência do usuário se refere às percepções e reações de uma pessoa que resultam do uso ou utilização prevista de um produto, sistema ou serviço, incluindo todas as emoções, crenças, preferências, percepções, respostas físicas e psicológicas, comportamentos e realizações do usuário que ocorrem antes, durante e após o uso. 
- não fornecem barreiras diretas à participação;

- geralmente, no início dos projetos, possuem um pequeno número de colaboradores ativos;

- possui uma relação positiva entre o número de colaboradores e o estágio de desenvolvimento dos projetos de open source design;

- em alguns projetos, a comunidade não está claramente estruturada, ou envolve somente uma pessoa

- normalmente são formadas principalmente por usuários do(s) produto(s) em desenvolvimento;

- permitem que os colaboradores sejam remunerados;

- devem compreender pessoas com os mais diversos conhecimentos e habilidades (técnicas e sociais), além de conhecimento sobre o(s) produto(s) e de suas experiências de uso;

- estão baseadas nas relações de transferência de informações;

- normalmente proporcionam aos colaboradores sociabilidade, apoio, sentimento de fazer parte de um grupo, e identidade social;

- permitem o balaço entre centralização e descentralização;

- no caso de comunidades mais centralizadas, normalmente há diferenciação explícita entre os níveis de desenvolvedores, e uma cultura meritocrática;

- podem ser iniciadas/coordenadas por indivíduos ou empresas;

- o iniciador de um projeto geralmente assume o papel de líder, e assume a responsabilidade pela gestão do projeto, assim como o desenvolvimento da primeira versão e o estabelecimento da infraestrutura necessária;

- devem se aproximar de players já existentes; e

- devem se desenvolver ao redor de um ambiente híbrido, ou seja, tanto digital quanto físico.

$\mathrm{Na}$ subseção a seguir é apresentada uma revisão da literatura sobre o elemento que motiva os colaboradores a se envolverem no open source design. 


\subsubsection{Motivadores}

Os colaboradores, ao participar de um projeto open source, são motivados tanto por retornos imediatos como por retornos a médio/longo prazo (LERNER; TIROLE, 2002, p. 213). Os retornos imediatos vão desde aprendizado e diversão, ao atendimento de crenças filosóficas e o senso de controle sobre o próprio trabalho (von HIPPEL; von KROGH, 2003; PANCHAL; FATHIANATHAN, 2008; BRUIJN, 2010). Por sua vez, os retornos a médio/longo prazo incluem a possibilidade de uso do design gerado para atender a necessidades individuais, participação na construção de uma comunidade (BRUIJN, 2010; von HIPPEL; von KROGH, 2003), expectativa de reciprocidade (von HIPPEL; von KROGH, 2003), e vantagens na carreira profissional e reputação (LERNER; TIROLE, 2002; TROXLER, 2011a; JONG; BRUIJN, 2013), podendo levar a contratos para o oferecimento de consultoria, customização, manutenção ou outros serviços associados aos produtos desenvolvidos (TROXLER, 2011).

Estudos indicam que pessoas do sexo masculino, com alguma formação técnica (por ex. engenheiros e cientistas), têm maior probabilidade de se sentirem atraídos a participar de projetos de open source design (von HIPPEL et al., 2011, p. 16). Thomson e Jakubowski (2012) destacam o envolvimento de engenheiros aposentados, que após trabalharem muitos anos com o desenvolvimento de produtos, se sentem incentivados a utilizar o conhecimento adquirido ao longo da carreira para contribuir com os projetos open source. O open source design atrai a atenção, não somente de indivíduos, como também de organizações. Na seção 2.4 são apresentadas as oportunidades e ameaças que direcionam a maneira pela qual as empresas existentes podem se relacionar com as comunidades de colaboradores.

Por meio dos estudos explorados nesta subseção, foram identificadas características do elemento responsável por motivar os colaboradores a participar de projetos de open source design:

- podem estar relacionados tanto a retornos imediatos, quanto a retornos de médio/longo prazo;

- podem estar relacionados a crenças filosóficas, ganhos pessoais, ou oportunidades de geração de novos negócios. 
Na próxima subseção são apresentados o estado da arte sobre os modelos de negócio que viabilizam a prática do open source design.

\subsubsection{Modelo de negócio}

Mesmo que o open source design disponibilize os designs gerados gratuitamente na Internet, sua prática ainda sim pode gerar receita. No open source software a principal fonte de receita está frequentemente associada à publicidade $\mathrm{e}$ cobrança por funcionalidades avançadas (FJELDSTED et al., 2012, p. 6). No open source design, ganhos com publicidade também são uma alternativa, além disso, a venda de produtos, a cobrança de taxas para se associar a uma comunidade, o oferecimento de cursos, e serviços de manufatura também são opções de receita viáveis (TROXLER, 2011). Segundo Troxler (2011), o "selo" open source nos produtos representa um diferencial em alguns círculos. De acordo com Klaassen e Troxler (2011), ao invés de comprar um produto já pronto, alguns clientes preferem pagar para ter um design open source adaptado a suas necessidades individuais. Fjeldsted et al. (2012) ainda sugerem o fechamento de contratos com o governo e o recebimento de doações como uma possível fonte de receita.

No geral, os modelos de negócio tradicionais são baseados em uma cadeia de valor top-down, na qual os produtos produzidos em massa são amplamente distribuídos. Ao contrário, os modelos de negócio do open source design são baseados em uma cadeia de valor bottom-up, na qual produtos configurados pelos usuários são distribuídos individualmente. Enquanto o primeiro tipo de modelo de negócio, denominado de modelo de negócio empurrado, apresenta ganhos de economia de escala e foca na eficiência de custos, o segundo tipo, denominado de modelo de negócio puxado, se baseia em uma manufatura flexível e foca na customização em massa (AVITAL, 2011).

Um caso interessante é o RiverSimple ${ }^{27}$, um ambicioso projeto de open source design com o objetivo de desenvolver um pequeno carro urbano que utiliza células combustíveis de hidrogênio como fonte de energia para seus motores elétricos (KATZ, 2011). Por se tratar de um novo integrante no mercado automotivo, com uma nova tecnologia, o RiverSimple tem apostado em um novo modelo de

\footnotetext{
${ }^{27}$ Disponível em http://riversimple.com/, acessado em 12/09/2015.
} 
negócio, de modo a repensar sua cadeia de fornecedores e distribuidores. $O$ primeiro diferencial está no fato de que seus carros não serão vendidos aos consumidores. Eles oferecerão mobilidade como um serviço, assumindo todos os custos relacionados à posse do automóvel, incluindo manutenção e combustível, de modo que os consumidores serão cobrados pela distância percorrida (TAN, 2010, p. 148). Esse modelo de negócio orientado a serviços é conhecido na comunidade acadêmica como PSS (product-service system).

A RiverSimple tem encorajado seus fornecedores a adotarem o mesmo modelo de negócio, e fornecerem a eles os componentes necessários para a fabricação do veículo por meio de leasing. Isso contribuiria para o desenvolvimento colaborativo de um produto mais durável e com responsabilidade compartilhada, de modo a se buscar uma redução do custo de manutenção e maior eficiência energética. Com relação à cadeia de distribuição, pretende-se que o produto tenha uma fabricação distribuída, em pequenas unidades fabris que estejam próximas aos consumidores (TAN, 2010, p. 150). O OSD pode contribuir para essa estratégia de compartilhamento das responsabilidades entre a cadeia de valor, acelerando o desenvolvimento e a adoção de carros movidos a hidrogênio (TAN, 2010, p. 221). Ao se apoiar no open source design, espera-se a redução dos custos de desenvolvimento, assim como dos riscos, enquanto que a qualidade e eficiência aumentem. No entanto, como este projeto ainda não está em fase de comercialização, esta abordagem ainda não foi testada no mercado.

Fjeldsted et al. (2012, p. 5) propõem um modelo de negócio arquetípico do OSD, construído por meio do método Business Model Canvas (OSTERWALDER; PIGNEUR, 2010). Este método explora um modelo de negócio sob a ótica de nove dimensões, descritas a seguir. A Figura 12 apresenta uma adaptação do modelo de negócio proposto por Fjeldsted et al. (2012), complementado com os resultados da revisão bibliográfica apresentados nas subseções anteriores. 


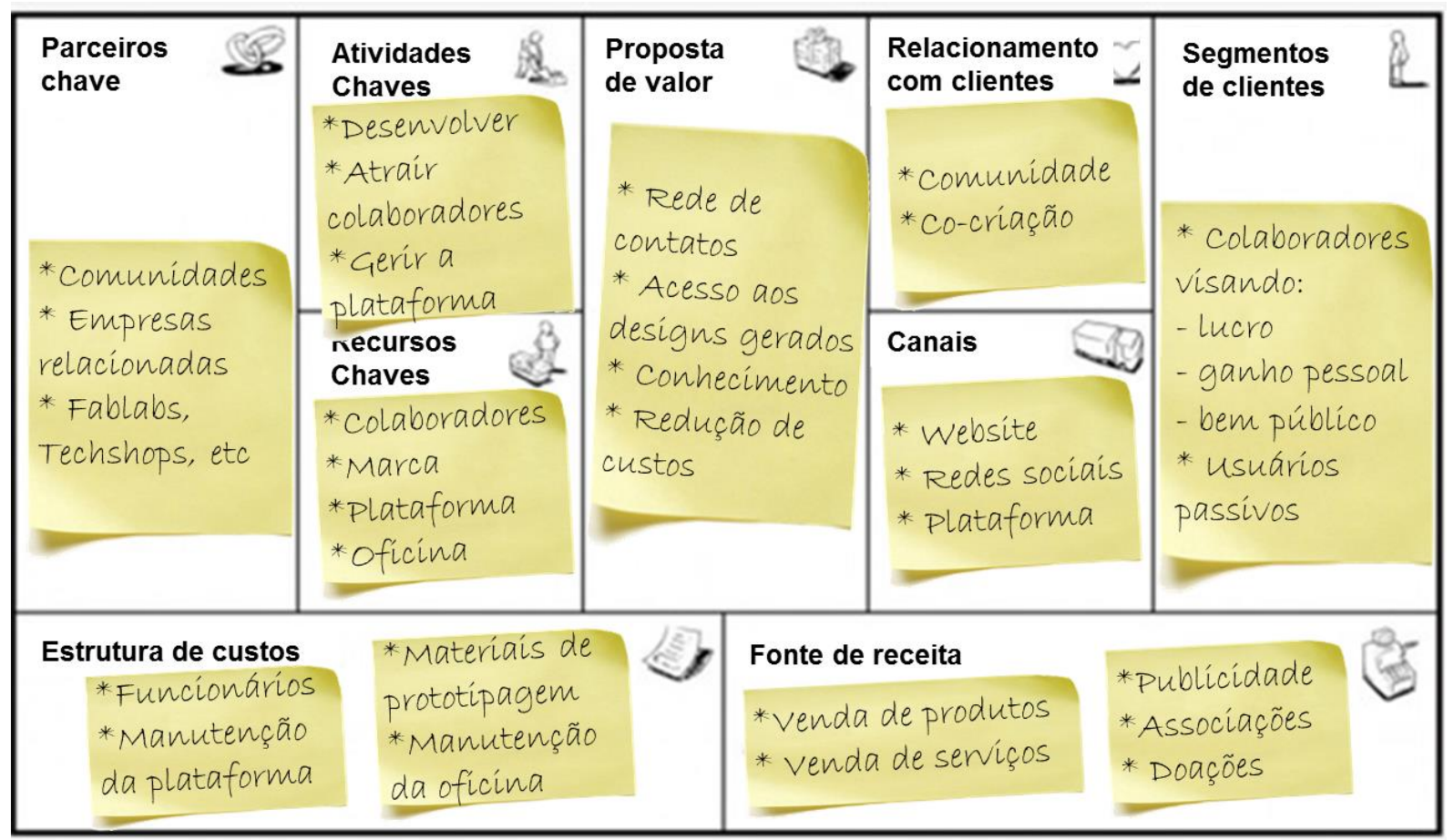

Figura 12 - Modelo de negócio arquetípico do OSD (adaptado de FJELDSTED et al., 2012, p. 5)

- Segmentos de clientes: define os diferentes segmentos de clientes que a organização deseja atender. Um segmento de clientes é caracterizado por possuir as mesmas necessidades, ser atendido pelos mesmos canais de distribuição, possuir os mesmos tipos de relacionamento, apresentar o mesmo rendimento e estar disposto a pagar pelos mesmos aspectos do produto/serviço ofertado. No caso do OSD, os segmentos de clientes identificados foram: colaboradores visando lucro, por exemplo, com a venda de produtos e serviços associados; colaboradores visando ganhos pessoais, por exemplo, com a satisfação de necessidades específicas (customização), aprendizagem e diversão; colaboradores visando um bem público, buscando contribuir com uma boa causa; e os usuários finais dos produtos gerados, mesmo os que não estão envolvidos diretamente no projeto (usuários passivos), pois estes podem se interessar por comprar os produtos desenvolvidos.

- Proposta de valor: define o pacote de produtos e serviços que criam valor para cada segmento de clientes especificado. É aquilo que atende às necessidades dos clientes, seja pelo preço, desempenho, 
capacidade de customização, estética, baixo risco, usabilidade, status, durabilidade, etc. No caso do OSD, as propostas de valor identificadas foram: a rede de contatos proporcionada pela comunidade; o acesso aos designs gerados; o compartilhamento de conhecimentos; e a redução do custo dos produtos.

- Canais: define os meios pelos quais a empresa se comunicará e alcançará os clientes para entregar a proposta de valor. Inclui como a empresa sensibilizará o mercado, como receberá feedback, como permitirá a compra de produtos e serviços, como efetuará as entregas e, por fim, como proverá o serviço de pós venda aos seus clientes. No caso do OSD, os canais identificados foram: websites, redes sociais e as plataformas de colaboração.

- Relacionamento com clientes: define a forma como a empresa se relacionará com cada segmento de clientes especificado. Envolve o nível de atenção que os clientes receberão, assim como o nível de liberdade que terão na interação com os produtos e serviços, apresentando forte influência nas experiências vivenciadas por eles. No caso do OSD, as formas de relacionamento com o cliente identificadas foram: as interações que ocorrem nas comunidades, com destaque para a co-criação ao longo do processo de desenvolvimento de produtos.

- Fonte de receita: define quais serão os mecanismos, por meio dos quais a empresa gerará renda ao atender a cada segmento de cliente especificado. Pode incluir mais de um mecanismo, como por exemplo: venda direta, taxa de assinatura (diárias, mensalidades, anuidades, etc.), aluguel, venda de licença, juros, corretagem (percentual da operação realizada) e venda de espaço publicitário. No caso do OSD, as fontes de receita identificadas foram: a venda direta de produtos, a venda de serviços associados, como por exemplo, serviços de manufatura e treinamentos; ou mesmo a venda dos resultados provenientes do uso dos produtos como um serviço (como no caso RiverSimple); a venda de espaços publicitários na plataforma de colaboração; taxas de associação das comunidades, e doações. 
- Recursos chave: define os mais importantes ativos necessários para que o modelo de negócios funcione. Inclui recursos físicos (fábricas, máquinas, veículos, pontos-de-venda, redes de distribuição, etc.), recursos intelectuais (registros ou licenciamento de patentes, registros de marca, compra de banco de dados de clientes, etc.), recursos humanos e financeiros. No caso do OSD, os recursos chave identificados foram: os colaboradores; uma marca associada à comunidade, ao projeto ou ao produto desenvolvido; a plataforma digital no na qual ocorrem as interações entre os colaboradores; e um espaço físico (oficina) que permita a prototipagem e o teste dos produtos em desenvolvimento.

- Atividades chave: define as atividades mais importantes que a empresa tem que cumprir para que o modelo de negócios funcione. Inclui o desenvolvimento de produtos e serviços, a produção de bens, a prestação de serviços, o estabelecimento de contatos, campanhas publicitárias, etc. No caso do OSD, as atividades chave identificadas foram: desenvolver os produtos; atrair colaboradores para o projeto; e gerir a plataforma de colaboração, de modo a facilitar as interações entre os colaboradores.

- Parceiros chave: define os principais fornecedores e parceiros necessários para que o modelo de negócios funcione. Na busca de parceiros, deve-se atentar para a obtenção de economias de escala, redução de riscos e incertezas e estabelecimento de parcerias com empresas diretamente relacionadas aos recursos e atividades chave para o sucesso do modelo de negócio. No caso do OSD, os parceiros chave identificados foram: as próprias comunidades, compostas por usuários, pesquisadores e profissionais da indústria; empresas relacionadas, principalmente quando os projetos atingem o estágio de produção; e espaços especializados em tecnologias de manufatura para apoiar o desenvolvimento de produtos físicos, como os Fab Labs e os TechShops.

- Estrutura de custos: define todos os custos associados ao modelo de negócios, a maior parte deles, relacionada aos recursos e atividades chave. Os modelos de negócio podem ser divididos em duas 
categorias, de acordo com a estrutura de custo adotada: "Determinado pelo Custo" e "Determinado pelo Valor". A primeira consiste em modelos de negócio em que o baixo custo é o principal atrativo para os consumidores, já na segunda, a proposta de valor é o mais importante, permitindo a esses produtos e serviços, maiores preços. No caso do OSD, os principais custos identificados foram: os custos com funcionários, principalmente para administração da plataforma de colaboração e gestão dos projetos; os custos com a manutenção da plataforma; os custos com matérias para a prototipagem dos produtos; e os custos com a manutenção da oficina, também para apoiar a prototipagem dos produtos.

Na seção a seguir são exploradas as oportunidades e ameaças para o open source design, baseada na revisão da literatura, e tomando como base o modelo de negócio apresentado nesta subseção.

\subsection{Oportunidades e ameaças para o open source design}

Por meio de um levantamento do tipo survey realizado com consumidores do Reino Unido, estima-se que 6,1\% dos residentes do Reino Unido, maiores de 18 anos, (aproximadamente 2,9 milhões de pessoas) têm criado ou modificado os produtos por eles utilizados durante os três anos anteriores à realização da pesquisa. Isso representa um esforço aproximado de 97.800 pessoas-ano, e um orçamento anual de $£ 3,2$ bilhões (mais de $140 \%$ da soma dos gastos em P\&D de todas as empresas de bens de consumo do Reino Unido) (von HIPPEL et al., 2011, p. 2). Estes mesmos autores também identificaram que são raras as vezes em que os usuários protegem suas inovações por meio de propriedade intelectual, e que $17 \%$ deles compartilham suas criações com outras pessoas.

Essa pesquisa apresenta indícios de um potencial mercado para o open source design, representado pelo número de consumidores britânicos que têm criado ou modificado produtos por eles utilizados, pelo montante de capital por eles movimentado, e pelo percentual de consumidores que compartilham suas criações com outras pessoas. No entanto, incentivar a participação de colaboradores tem 
sido um dos maiores desafios dos projetos de open source software. Muitos projetos têm enfrentado dificuldade em atrair colaboradores suficientemente qualificados e motivados, tornando-se ainda mais difícil mantê-los envolvidos. Nos casos de maior sucesso no open source software, o Linux e o Apache, de 1,5 bilhão de usuários, apenas em torno de 1600 (0,0001\%) são colaboradores ativos (BERT MULDER, 2011). A pesquisa realizada por von Hippel et al. (2011), mesmo que restrita ao mercado britânico, mostra um cenário mais otimista para o open source design. Dos 6,1\% dos residentes do Reino Unido, maiores de 18 anos, que disseram ter criado ou modificado os produtos por eles utilizados durante os três anos anteriores, $17 \%$ compartilham suas criações com outras pessoas, ou seja, 0,01\% dos usuários analisados.

Já o alto montante de capital movimentado, abre oportunidades para interpretações tanto de um mercado atrativo em torno do open source design, quanto de uma alta barreira de entrada para os interessados se envolverem nesses projetos (segundo os dados apresentados nessa pesquisa, estima-se um orçamento médio de aproximadamente $£ 32.720$ por pessoas por ano). O desenvolvimento de produtos físicos, quando comparado ao desenvolvimento de software (em que um simples computador com a acesso internet é suficiente para rodar o Linux e acessar projetos open source em provedores de hospedagem com o Sourceforge e GitHub), requer um investimento mais intenso em equipamentos, assim como, um espaço físico para o desenvolvimento e teste dos produtos (KATZ, 2011). O investimento na prototipagem de produtos físicos é mais alto e os componentes são mais difíceis de serem compartilhados (MUL, 2011; SEND et al., 2013, p. 543). A indústria de produtos eletrônicos, como os microcontroladores Arduino, é a que mais se assemelha ao open source software, já que apresenta as menores barreiras de entrada dentre os casos de open source design. Com um capital inicial em torno de US\$30,00 é possível se aventurar em alguns projetos (KATZ, 2011).

Outro ponto significativo é a falta de acesso a ferramentas de design (CAD) de baixo custo. Diferentemente, no open source software os colaboradores têm acesso a um conjunto de ferramentas open source de alta qualidade para thes apoiar no processo de desenvolvimento (KATZ, 2011). No open source design as ferramentas disponíveis em geral são caras e exigem usuários habilidosos. Para alcançar um maior público, as ferramentas atuais necessitam de interfaces mais amigáveis para os usuários e sistemas mais intuitivos para auxiliar na criação de 
designs tridimensionais (ATKINSON, 2011). Há também outra vertente de ferramentas $C A D$ em desenvolvimento, tendo como público alvo programadores interessados em programar de forma dinâmica objetos paramétricos. O openSCAD ${ }^{28}$ é o sistema mais desenvolvido nesse sentido. Um projeto open source que permite transformar linhas de código em um objeto tridimensional (PETTIS, 2011).

Quanto mais desenvolvidas forem as ferramentas de design, principalmente na parte de simulação, mais protótipos poderão ser construídos e testados em ambiente virtual (KATZ, 2011), e quando conectadas às ferramentas de manufatura, um rascunho pode se tornar facilmente um produto final (DICK RIJKEN, 2011). A introdução de impressoras 3D, como os projetos open source desenvolvidos pela comunidade RepRap, encurtou a distância entre o mundo físico e virtual, facilitando a materialização dos design digitais (KATZ, 2011). Graças às impressoras 3D, a dificuldade em se compartilhar componentes físicos também está deixando de ser um grande problema (MUL, 2011), já que, dependendo dos componentes (dimensão, precisão e material), sua replicação se torna muito mais fácil. Plataformas online como o MakerBot Thingiverse ${ }^{29}$ e o Google 3D Warehouse ${ }^{30}$, têm se mostrado muito úteis no compartilhamento de arquivos 3D, muitos já prontos para impressão.

Porém, no open source design nem tudo pode ser feito em um ambiente virtual. Definitivamente, ainda há a necessidade de encontros presencias entre os envolvidos, possibilitando a troca, principalmente, entre designers amadores e designers mais experientes, professores e instrutores (DICK RIJKEN, 2011). Se os designs gerados nos projetos de open source design pudessem ser comparados a livros, então os TechShops, Fab Labs e os hackerspaces seriam as bibliotecas (TROXLER, 2011).

Com o slogan "Come and build your dream?" ("Venha e construa seus sonhos!"), os TechShops correspondem a uma rede americana de oficinas equipadas com um conjunto de máquinas e softwares necessários para a prototipagem e até mesmo a produção de pequenos lotes de uma grande gama de

\footnotetext{
${ }^{28}$ Disponível em http://www.openscad.org/, acessado em 15/06/2015.

${ }^{29}$ Disponível em http://www.thingiverse.com/, acessado em 12/06/2015.

${ }^{30}$ Disponível em https://3dwarehouse.sketchup.com/?hl=pt-BR, acessado em 12/06/2015.
} 
produtos $^{31}$. Assim como ocorre em academias de ginástica, por uma taxa mensal ou anual, os membros podem utilizar os equipamentos disponíveis, tendo apenas que realizar os treinamentos de segurança e de usos básicos para cada operação. Além dos treinamentos básicos, são também oferecidos cursos mais avançados, e uma equipe de instrutores está sempre à disposição para auxiliar os membros no desenvolvimento de suas ideias e no aperfeiçoamento de suas habilidades técnicas. No entanto, os TechShops operam em um ambiente estritamente comercial, e as iniciativas de open source design, mesmo que eventualmente ocorram, não são oficialmente incentivadas. Ainda assim, os TechShops oferecem uma oportunidade para que tanto a prototipagem quanto a produção ocorram de maneira descentralizada (TROXLER, 2011). A Figura 13 apresenta a distribuição dos TechShops, atualmente localizados apenas nos Estados Unidos.

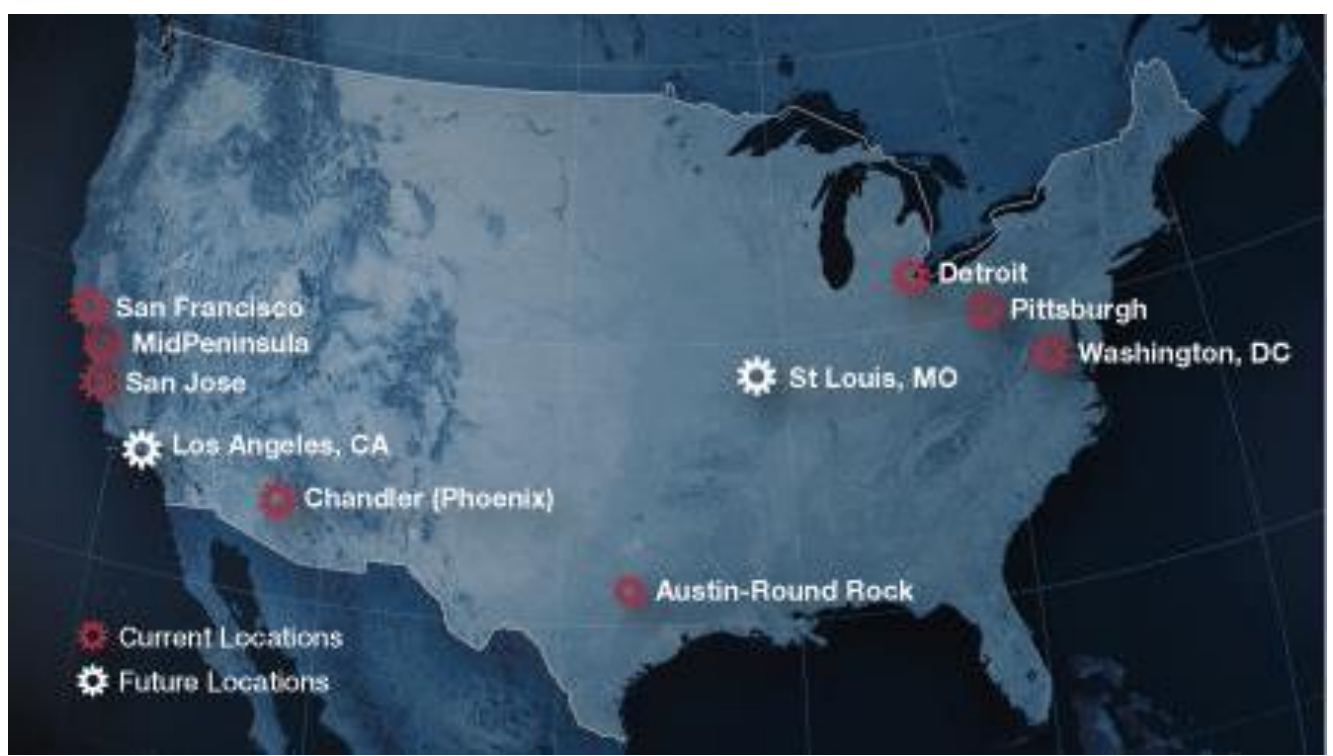

Figura 13 - Distribuição dos TechShops ao redor do mundo, sendo que os pontos vermelhos representam as unidades já existentes, enquanto os pontos em branco representam as unidades planejadas (TECHSHOP)

Os Fab Labs, um acrônimo para Fabrication Laboratory (Laboratório de Fabricação), formam uma rede global de oficinas de fabricação digital. Ao contrário dos TechShops, os Fab Labs têm um foco maior na comunidade de pessoas, e muitas vezes consistem em organizações sem fins lucrativos. A iniciativa surgiu de um curso do $\mathrm{MIT}^{32}$ intitulado "How to make (almost) anything" ("Como fazer (quase)

${ }^{31}$ Os TechsShops possuem desde cortadoras a laser, impressoras 3D, centros de usinagem, e estações de soldagem, até serras para madeira, e máquinas de costura. Disponível em http://www.techshop.ws/, acessado em 12/06/2015.

${ }^{32}$ A sigla MIT corresponde ao Massachusetts Institute of Technology. Disponível em http://web.mit.edu/, acessado em 12/06/2015. 
qualquer coisa"). Embora não haja um procedimento formal para criar um Fab Lab, esse processo é apoiado pela Fab Foundation ${ }^{33}$, que possui como principais linhas de atuação a educação, a capacitação organizacional, e oportunidades de negócio.

$\mathrm{Na}$ linha relacionada à educação, a Fab Foundation está focada em levar as ferramentas e processos de fabricação digital a pessoas de todas a idades por meio do desenvolvimento de currículos formais e informais, e treinamentos para professores, gestores dos Fab Labs e demais profissionais interessados. Na linha de capacitação organizacional, busca-se facilitar o desenvolvimento dos Fab Labs, e disseminar boas práticas de fabricação digital por meio de treinamentos e consultorias, assim como pela organização de encontros que possibilitem uma maior integração entre a rede de Fab Labs. Já a linha de oportunidades de negócio visa fomentar o desenvolvimento de novos negócios e novos produtos dentro da comunidade dos Fab Labs, por meio de apoio na busca por financiamento. A Figura 14 apresenta a distribuição dos Fab Labs ao redor do mundo. Destaca-se o pequeno número de Fab Labs presentes no Brasil, comparado principalmente à Europa e aos Estados Unidos.

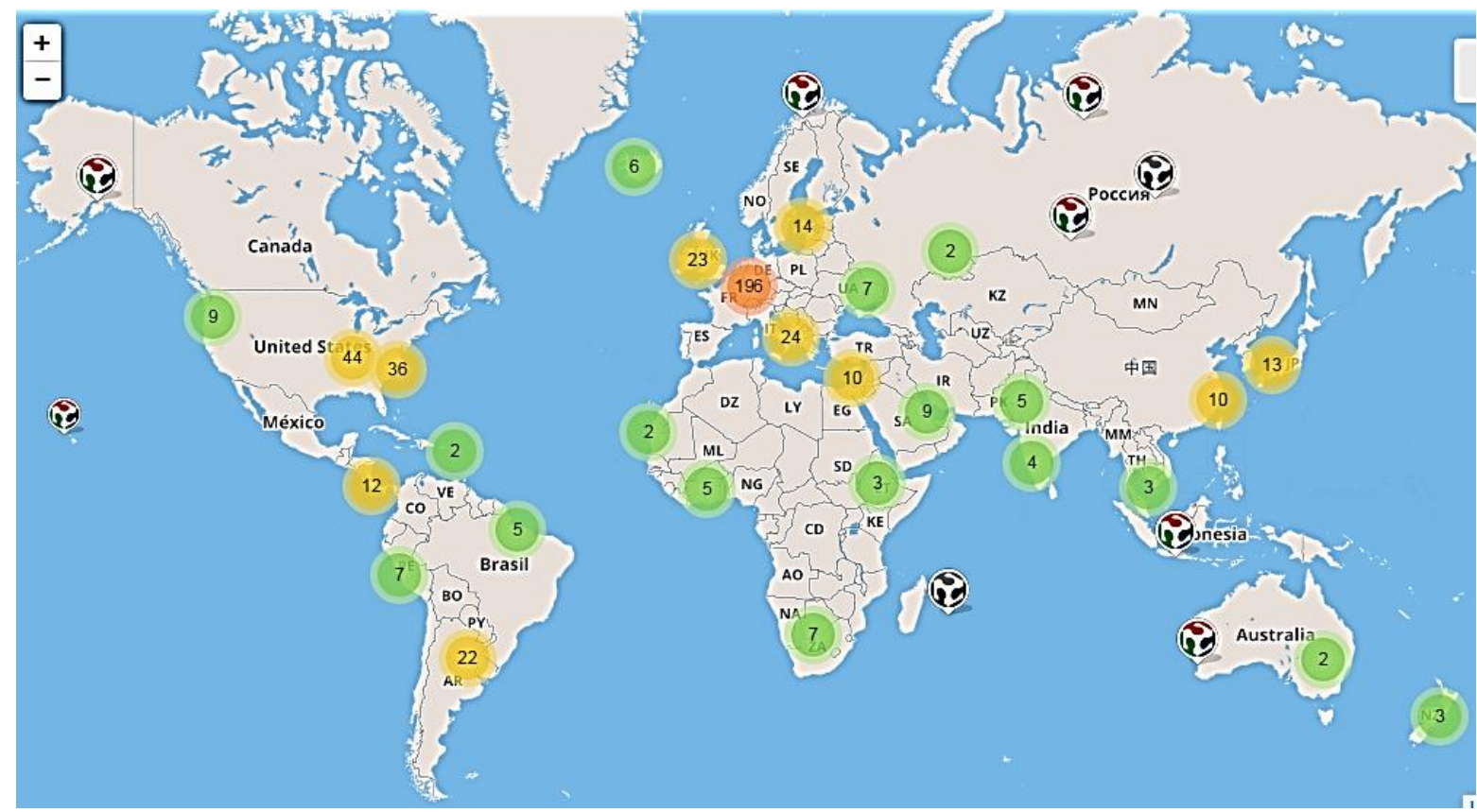

Figura 14 - Distribuição dos Fab Labs ao redor do mundo, sendo que os números em destaque no mapa representam a quantidade de Fab Labs por região (FABLAB)

${ }^{33}$ A Fab Foundation consiste em uma organização sem fins lucrativos americana, fundada a partir do MIT's Center for Bits \& Atoms Fab Lab Program em fevereiro de 2009, com o intuito de facilitar e apoiar o crescimento da rede internacional de Fab Labs por meio do desenvolvimento de Fab Foundations regionais e organizações. Disponível em http://www.fabfoundation.org/about-us/, acessado em 29/04/2015. 
Os hackerspaces, também chamados de hacklabs, makerspaces e hackspaces, consistem em um espaço físico operado de forma comunitária de modo que pessoas com interesses comuns (normalmente em tecnologia), possam se reunir, socializar e colaborar em projetos comuns. Por terem surgido dentro do movimento de contracultura, os hackerspaces possuem valores como liberdade, no sentido de autonomia; livre acesso e livre circulação de informações; aprendizado pela prática ("learn by doing”); e cooperação. É comum que esses espaços possuam uma agenda de eventos que promovam o aprendizado, como palestras e oficinas; o desenvolvimento de projetos em grupo, como os hackathons ${ }^{34}$; e também a socialização entre seus membros, como confraternizações e noites de jogos. Esses eventos são responsáveis pela arrendação de parte do capital necessário para operação de um hackerspace, aliados a cobrança de taxas mensais de seus membros e doações. Os equipamentos disponíveis nos hackerspaces variam muito de um espaço para outro, dependendo também das necessidades específicas de seus membros, podendo ir desde algumas ferramentas básicas, até oficinas completas como nos TechShops ${ }^{35}$. O website hackerspaces.org apresenta uma lista dos hackerspaces existentes, elaborada por meio de uma auto-inscrição. Com base nessa lista, estima-se haver em torno de 1150 hackerspaces ativos no mundo, dentre eles, alguns Fab Labs também estão inscritos. A Figura 15 apresenta a distribuição dos hackerspaces ao redor do mundo. Outra vez, destaca-se o pequeno número de hackerspaces presentes no Brasil.

${ }^{34}$ Eventos focados no desenvolvimento de softwares e também hardwares, com normalmente com duração entre um dia e uma semana, que atraia muitos colaboradores para trabalharem de forma colaborativa. Disponível em https://en. wikipedia.org/wiki/Hackathon, acessado em 12/06/2015.

${ }^{35}$ Disponível em http://en.wikipedia.org/wiki/Hackerspace, acessado em 07/05/2015. 


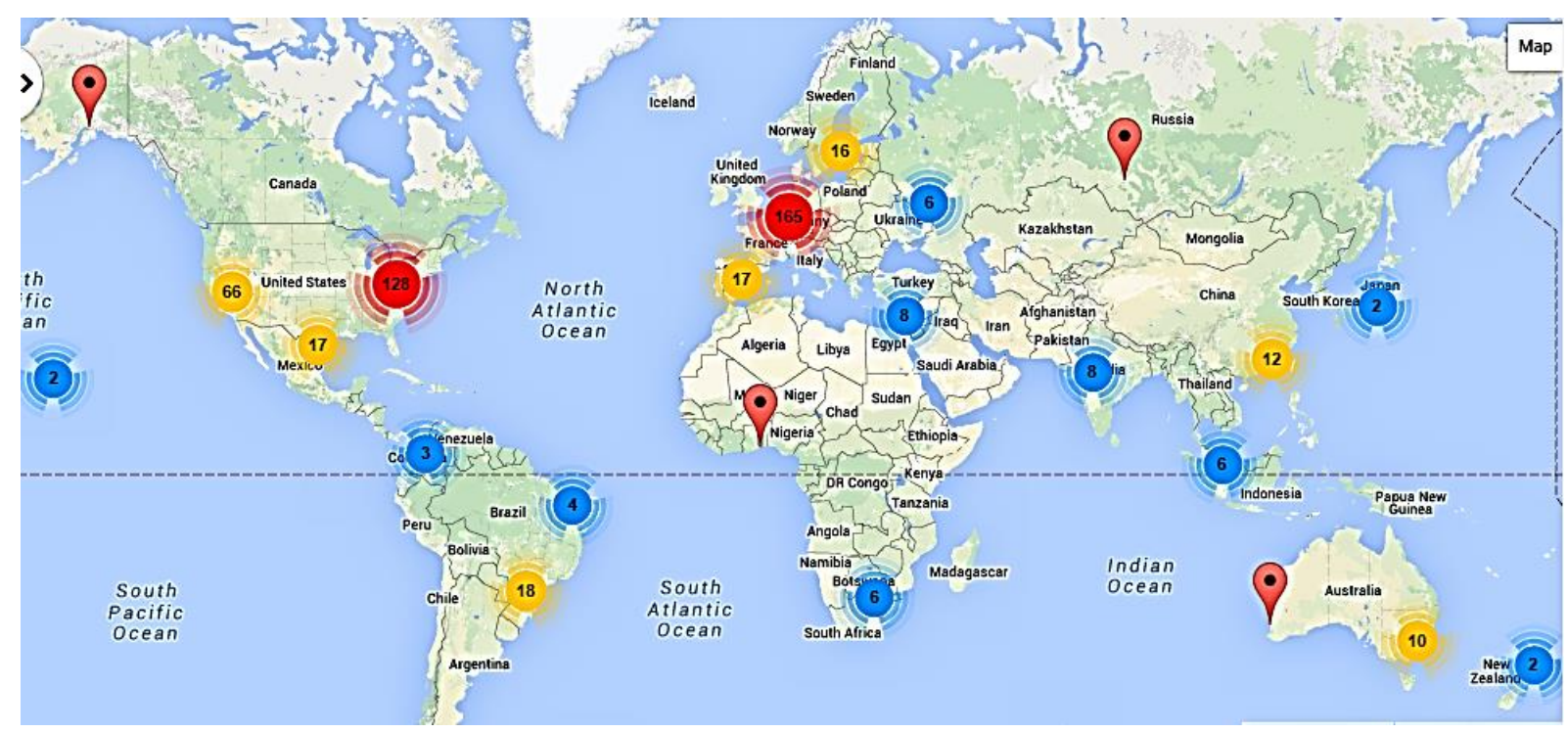

Figura 15 - Distribuição dos Hackerspaces ${ }^{36}$ ao redor do mundo, sendo que os números em destaque no mapa representam a quantidade de hackerspaces por região (HACKERSPACES.ORG)

Dentro desse novo paradigma de inovação proporcionado pelo open source design, talvez os designers tenham que adaptar seu papel, e atuar como se fossem "maestros de uma orquestra de colaboradores". Para acompanhar essa transformação, o currículo dos designers também deverá ser atualizado (ATKINSON, 2011). O designer do futuro deverá se tornar um "meta-designer", de modo que sua função principal não será projetar produtos, mas preparar ambientes amigáveis para que usuários com habilidades limitadas e sem experiência em design possam desenvolver os próprios produtos (MUL, 2011). No entanto, caso essa facilitação do processo de desenvolvimento de produtos não seja bem executada, o open source design pode resultar em uma grande quantidade de produtos indesejáveis (KLAASSEN; TROXLER, 2011; THACKARA, 2011).

O OSD ainda é um fenômeno nascente, no entanto representa um movimento que caminha em direção a mudanças radicais na maneira como nós adquirimos uma grande variedade de produto. Baseado no conceito Do-lt-Yourself ${ }^{37}$ (DIY), o open source design traz benefícios além da redução de custos e diversão. Ele dá aos usuários a oportunidade de uma customização completa de um produto, incluindo a escolha sobre as funcionalidades e materiais. Também representa um grande incentivo para a produção local de bens, criando uma excelente oportunidade para

\footnotetext{
${ }^{36}$ Por limitações da ferramenta utilizada para indicar a distribuição dos hackerspaces, este mapa apenas apresenta a localização dos 500 hackerspaces mais ativos, determinados com base na quantidade de atualizações em seus websites.

${ }^{37}$ Termo inglês utilizado para se referir à atividade amadora de desenvolvimento e produção de produtos, auto-orientada e auto-dirigida (ATKINSON, 2006, p. 1).
} 
os consumidores de países em desenvolvimento, que muitas vezes sofrem com altas taxas alfandegárias e elevados custos logísticos na aquisição, principalmente, de produtos tecnológicos. Esse fenômeno também gera oportunidades para o desenvolvimento de novos modelos organizacionais, novos modelos de negócio, novas estruturas para as cadeias de suprimento e uma nova variedade de produtos e serviços. Dentro desse contexto, na próxima seção serão exploradas as oportunidades e ameaças que o open source design traz para as indústrias existentes.

\subsection{Oportunidades e ameaças para as indústrias existentes}

As comunidades de inovação que atuam em projetos de open source design podem competir com as empresas existentes fornecendo soluções que melhor atendam às necessidades dos usuários, com um custo inferior (BALDWIN; von HIPPEL, 2011, p. 1409; JONG; BRUIJN, 2013, p. 47). Isso faz com que a OSD represente uma ameaça para as indústrias existentes, pressionando a queda dos preços dos produtos, podendo até mesmo quebrar com o monopólio dos produtores. No entanto, o open source design também pode trazer algumas oportunidades para as empresas existentes.

A forma com que as empresas existentes encaram a OSD é determinada pela situação em que a indústria se encontra, e pela maneira pela qual as empresas se relacionam com as comunidades de inovação. Foram identificadas três situações (ou fases) em que há uma maior probabilidade do open source design ocorrer: (1) em indústrias nascentes; (2) em indústrias nas quais potenciais usuários ainda não são atendidos; e (3) em indústrias nas quais alguns usuários não são devidamente atendidos (von HIPPEL; OGAWA; et al., 2011, p. 29; JONG; BRUIJN, 2013, p. 46).

Muitas inovações provenientes dos usuários ocorrem em indústrias nascentes, quando o mercado ainda é pequeno e as empresas já estabelecidas não se sentem atraídas em explorá-lo. Após um período de experimentação das inovações pelos usuários e aumento da previsibilidade da demanda do novo mercado, algumas empresas aproveitam a oportunidade e dão início a produção comercial de produtos que atendam às necessidades desses usuários. Essa 
situação é facilmente percebida quando novos esportes são criados, como aconteceu com o kitesurfing e o snowbording (JONG; BRUIJN, 2013, p. 46).

Após o surgimento de uma nova indústria, continuam a existir potenciais usuários que ainda não são atendidos pelas empresas estabelecidas, principalmente devido ao alto custo dos produtos. Normalmente, isso ocorre em indústrias de alta tecnologia. Nesta situação, as comunidades de inovação podem desenvolver suas próprias versões DIY desses produtos. A indústria de impressoras 3D é um exemplo desta situação (JONG; BRUIJN, 2013, p. 46).

Mesmo em uma indústria madura, algumas empresas estabelecidas tendem a tratar o mercado de maneira homogênea, e focar nas necessidades de um grande número de usuários. Desta forma, os produtos comercializados podem apresentar poucas variações, deixando de atender às necessidades de alguns usuários. Um exemplo clássico dessa situação ocorreu no início da indústria automobilística, com a comercialização de apenas uma variedade de automóvel, o Ford T. Muitos usuários passaram a modificar seus próprios carros para melhor atendê-los, chegando a construir, a partir do Ford T, veículos para neve e tratores. Ao perceber essa demanda a Ford lançou um kit de ferramentas para facilitar as modificações, aumentando assim seu lucro (JONG; BRUIJN, 2013, p. 48).

Em indústrias nascentes, as comunidades de inovação revelam às empresas mercados promissores. Em indústrias existentes, as inovações desenvolvidas pelas comunidades de inovação podem apontar os pontos fracos dos produtos desenvolvidos pelas empresas, e até mesmo representar importantes complementos para os seus produtos (JONG; BRUIJN, 2013, p. 47). Além disso, os produtores que buscarem sistematicamente por inovações desenvolvidas pelos usuários podem utilizar os conceitos e os protótipos gerados como inputs para o desenvolvimento de novos produtos (von HIPPEL; JONG; et al., 2011, p. 21).

Portanto, conforme explorado nessa seção, caso as empresas estejam abertas para encarar o open source design como uma oportunidade, elas conseguirão se beneficiar do desenvolvimento de comunidades de inovação. $\mathrm{Na}$ próxima seção é apresentado um caso de OSD em que é possível observar diferentes reações que as empresas existentes tiveram na indústria de impressão 3D. Algumas encararam o open source design como uma ameaça, enquanto outras aproveitaram as oportunidades provenientes desse projeto para se desenvolverem. 


\subsection{Um caso de open source design: o projeto RepRap}

O rápido crescimento do movimento open source em impressões 3D é um típico exemplo de open source design (JONG; BRUIJN, 2013, p. 45). Inserido nesta indústria, o projeto RepRap possui o objetivo de desenvolver colaborativamente uma impressora 3D de baixo custo $^{38}$, capaz de se auto-replicar. Baseado em arquivos de design digital, essas máquinas podem ser utilizadas na fabricação de uma grande quantidade de objetos. Frequentemente, os designs produzidos pelos membros da comunidade RepRap são abertamente disponibilizados sob licenças open source, incluindo os designs da própria máquina (BRUIJN, 2010, p. 18). Estima-se existir em torno de 400 projetos diferentes de impressoras $3 D^{39}$, desenvolvidos pelos membros desta comunidade. O ANEXO I apresenta a árvore da evolução da família de produtos da comunidade RepRap de 2006 a 2012 , na qual é possível observar a existência de diversas soluções concorrentes dentro da comunidade.

A tecnologia utilizada nas impressoras 3D é conhecida há mais de 20 anos, no entanto, devido aos preços elevados, essas máquinas ainda não são consideradas atrativas para o uso doméstico (BRUIJN, 2010, p. 18). Essa situação caracteriza este caso como um típico exemplo de uma indústria na qual potencias usuários ainda não são atendidos, conforme apresentado na seção 2.4.

No caso das impressoras 3D, alguns produtores encararam os projetos de open source design como uma oportunidade, e passaram a monitorar a evolução da RepRap, incentivando que seus funcionários participassem da comunidade. Com isso, muitos funcionários de fabricantes de impressoras 3D passaram a contribuir com os projetos de OSD durante o trabalho ou durante o tempo livre. Algumas empresas incorporam em seus produtos inovações desenvolvidas pela comunidade. Em alguns casos, colaboradores foram contratados pelos produtores, e empresas startups fundadas por membros da comunidade foram adquiridas. Outros produtores, no entanto, se sentiram ameaçados pela comunidade de inovação, e abriram processos judiciais contra alguns membros (JONG; BRUIJN, 2013, p. 48$50)$.

${ }^{38}$ Em 2010, uma impressora 3D desenvolvida pelo projeto RepRap podia ser construída menos de 500 euros ( $5 \%$ do valor de um produto equivalente, disponível no mercado).

${ }^{39}$ Disponível em http://reprap.org/wiki/RepRap Family Tree, acessado em 30/06/2015. 
Em um levantamento do tipo survey, realizado com os membros da comunidade $\operatorname{RepRap}{ }^{40}$, foi encontrado que há uma maior probabilidade de inovação quando os colaboradores: (1) possuem experiência na construção das impressoras 3D; (2) são mais habilidosos tecnicamente; (3) mantêm contato pessoal com outros colaboradores; e (4) utilizam seu tempo de dedicação à impressão 3D para o desenvolvimento de melhorias na máquina. Além disso, foi identificado que as inovações têm maior probabilidade de serem adotados por outros membros quando: (1) são abertamente reveladas pelos desenvolvedores; (2) estão relacionadas ao software, ao invés do hardware; (3) são desenvolvidas por membros bem relacionados dentro da comunidade; e (4) utilizam seu tempo de dedicação à impressão 3D para a impressão de objetos (JONG; BRUIJN, 2013, p. 49).

Os resultados dessa pesquisa mostram que os colaboradores que passam mais tempo tentando melhorar as máquinas, têm maior probabilidade de criar uma inovação, no entanto, eles não possuem as melhores chances de difundir suas inovações. Já os colaboradores que passam a maior parte do tempo imprimindo objetos não possuem as melhores chances de inovar, porém, quando o fazem, suas inovações têm maior probabilidade de serem adotadas por outros membros (JONG; BRUIJN, 2013, p. 50). Esses resultados apontam de indícios de que quanto mais tempo de uso dos produtos, maior a probabilidade de se identificar necessidades comuns a outros usuários, e atendê-las de forma inovadora.

No caso do projeto RepRap, os fatores que levam os membros da comunidade se sentirem motivados a participar nos projetos de OSD são semelhantes aos fatores descritos na seção 2.2.4. Por meio de um estudo de caso realizado nesta comunidade, Bruijn (2010) identificou a autonomia dos membros, o aprendizado e diversão, o relacionamento entre os membros, e a significância do projeto como sendo os fatores motivacionais de maior destaque (BRUIJN, 2010, p. 20).

As pesquisas apresentadas nessa seção sobre o projeto RepRap foram as únicas identificadas na literatura pesquisada em que se descreve de forma mais detalhada um projeto de open source design. Esses estudos corroboram com a mudança de paradigma que está ocorrendo nos modos de inovação (PRAHALAD; KRISHNAN, 2008, p. 3; BALDWIN; HIPPEL, 2011, p. 1399; HIPPEL, VON; OGAWA;

\footnotetext{
${ }^{40}$ Amostra de 384 colaboradores, dos quais 202 foram responsáveis por 246 inovações.
} 
et al., 2011, p. 27), mostrando um caso real em que o open source design é viável, e ocupa um papel importante no desenvolvimento da indústria de impressão 3D. 


\section{Metodologia}

Este capítulo caracteriza a metodologia utilizada e apresenta as etapas propostas para realização desta pesquisa.

\subsection{Caracterização da metodologia}

A estratégia metodológica a ser adotada depende do volume e da maturidade das pesquisas na área de conhecimento explorada. Normalmente, as primeiras pesquisas tendem a ser de caráter exploratório, de modo a formar uma base que identifique as principais características do fenômeno estudado. Após a realização de estudos exploratórios, com diferentes perspectivas e abordagens, iniciam-se os estudos de caráter descritivo, possibilitando descrições mais ricas, que permitam a identificação de componentes, padrões, sistemas e estruturas. Pesquisas descritivas criam uma boa fundação para pesquisas analíticas. Modelos analíticos, por sua vez, direcionam as pesquisas para um melhor entendimento das relações causais que ocorrem no fenômeno analisado. E o entendimento sobre as relações causais permitem ao pesquisador prescrever o que irá ocorrer em certas situações (KARLSSON, 2009, p. 17).

Tendo em vista a sequência que ocorre o desenvolvimento do conhecimento, a estratégia adotada para esta pesquisa é de caráter exploratório, pois, pretende caracterizar o processo de desenvolvimento de produtos do open source design, contribuindo para a fundamentação teórica do OSD e preparando o terreno para pesquisas de caráter descritivo e analítico.

Quanto à abordagem metodológica, as pesquisas podem ser quantitativas ou qualitativas. $\mathrm{Na}$ abordagem quantitativa, conceitos são examinados e testados por meio de uma clara delineação das variáveis, que são observáveis, tangíveis e claramente definidas. O uso de métodos matemáticos e ferramentas estatísticas, para análise numérica dos dados, estão fortemente relacionados a esta abordagem. $\mathrm{Na}$ abordagem qualitativa, a ênfase está na natureza socialmente construída da realidade. Portanto, os métodos qualitativos reconhecem a importância da interpretação, percepção e interação durante o processo de definição, coleta e 
análise de evidências (KARLSSON, 2009, p. 66). Como nesta pesquisa deseja-se um maior entendimento do contexto estudado, de modo a captar as perspectivas e interpretações dos indivíduos em seu ambiente natural, adota-se uma abordagem qualitativa.

Dois procedimentos técnicos são selecionados para esta pesquisa: a revisão bibliográfica e o estudo de caso. A revisão bibliográfica é uma parte fundamental para qualquer pesquisa acadêmica, auxiliando na identificação de lacunas e provendo um conhecimento sobre o estado da arte relacionado ao fenômeno de interesse (KARLSSON, 2009, p. 48). Por se tratar do estudo de um fenômeno contemporâneo em que não é possível a manipulação das variáveis, e a análise das condições contextuais é pertinente, utiliza-se o estudo de caso como procedimento técnico de pesquisa de campo (YIN, 2005, p. 26; IACONO et al., 2009, p. 40). Um estudo de caso é "uma investigação empírica que investiga um fenômeno contemporâneo dentro de seu contexto da vida real, especialmente quando os limites entre o fenômeno e o contexto não são claramente definidos" (YIN, 2005, p. 32). Neste trabalho, opta-se pela realização de um estudo de caso único e holístico, de caráter etnográfico.

A escolha por um caso único é justificada por se tratar de um caso raro e revelador, em que o pesquisador tem a oportunidade de observar e analisar um fenômeno extremo e previamente inacessível à investigação científica (YIN, 2005, p. 63). Outra justificativa é a necessidade de um maior aprofundamento no caso, para uma melhor compreensão do fenômeno analisado. Esse aprofundamento é mais fácil de ser alcançado em um estudo de caso único, no qual o pesquisador geralmente consegue dedicar mais tempo na condução do estudo de caso.

A unidade de análise deste estudo de caso consiste em uma organização que desenvolve projetos de open source design por meio de uma plataforma de colaboração online, possibilitando a formação de uma comunidade de colaboradores. Por se examinar a natureza global da organização, sem que sejam investigadas subunidades de análise, o estudo de caso é classificado como holístico.

A etnografia pura (ou etnografia tradicional) é ideal para estudos antropológicos e sociológicos, no levantamento de informações sobre culturas previamente inexploradas ou práticas sócias ainda não documentadas (BALL; ORMEROD, 2000, p. 404). O crescente número de publicações no campo do design que utilizam técnicas da etnografia tem mostrado que esse procedimento vem 
ganhando importância nesse campo (BALL; ORMEROD, 2000, p. 405). Segundo Cash et al. (2015, p. 1), abordagens observacionais, como a etnografia, têm por objetivo fornecer caracterizações robustas e rigorosas de seus objetos de estudo, que no campo do design, incluem pessoas, processos, artefatos, ambientes, e contextos mais amplos. No entanto, quando aplicada às pesquisas de design, a etnografia normalmente precisa ser adaptada, e acaba por contradizer algumas de suas características típicas, principalmente a relacionada com a independência das observações. A Tabela 2 descreve essa, e as demais características de uma etnografia pura.

Tabela 2 - Características típicas de uma etnografia pura (BALL; ORMEROD, 2000, p. 406)

\begin{tabular}{ll}
\hline Característica & Descrição \\
\hline Contextualização & $\begin{array}{l}\text { Os dados são coletados pelo observador participante que está localizado dentro } \\
\text { do contexto diário de interesse }\end{array}$ \\
\hline Riqueza & $\begin{array}{l}\text { O observador estuda o comportamento em suas várias manifestações de modo } \\
\text { que os dados são coletados por meio de uma ampla variedade de fontes } \\
\text { incluindo entrevistas, discussões em equipe, conversas informais, documentos, } \\
\text { e interações não verbais }\end{array}$ \\
\hline Autonomia dos & $\begin{array}{l}\text { Não é exigido que os observados cumpram qualquer procedimento rígido ou } \\
\text { predeterminado }\end{array}$ \\
\hline Aberturantes & $\begin{array}{l}\text { O observador permanece aberto a novas descobertas ou questões inesperadas } \\
\text { que possam surgir conforme o estudo progride }\end{array}$ \\
\hline Personalização & $\begin{array}{l}\text { O observador toma nota de seus próprios sentimentos em relação às situações } \\
\text { encontradas durante a coleta e análise dos dados }\end{array}$ \\
\hline Reflexividade & $\begin{array}{l}\text { O observador adota uma postura reflexiva e empática ao se esforçar para } \\
\text { entender o ponto de vista dos observados; o observador leva em consideração, } \\
\text { ao invés de se esforçar para eliminar, o próprio efeito sobre o comportamento } \\
\text { dos observados }\end{array}$ \\
\hline Autorreflexão & $\begin{array}{l}\text { O observador tem consciência de que qualquer interpretação é influenciada } \\
\text { pelas tradições as quais ele próprio pertence }\end{array}$ \\
\hline Intensidade & $\begin{array}{l}\text { As observações são intensas e de longo prazo permitindo que o observador seja } \\
\text { imerso na cultura predominante no ambiente dos observados }\end{array}$ \\
\hline Independência & $\begin{array}{l}\text { O observador não tem como objetivo se restringir a qualquer conjunto de metas, } \\
\text { mentalidade, ou teoria predeterminada }\end{array}$ \\
\hline Historicismo & $\begin{array}{l}\text { O observador tem como objetivo conectar suas observações a um pano de } \\
\text { fundo de contingências históricas e culturais }\end{array}$ \\
\hline
\end{tabular}

Ao contrário do que ocorre tipicamente nas pesquisas que utilizam etnografia pura, os projetos de pesquisa em design geralmente necessitam que a coleta de dados seja orientada pela teoria existente (BALL; ORMEROD, 2000, p. 409). Além disso, no campo do design, a intensidade extrema da etnografia tradicional geralmente torna a coleta de dados muito custosa, e ao contrário de estudos antropológicos em que os pesquisadores chegam a passar anos imersos na cultura pesquisada, a intensidade das observações no campo do design normalmente consistem em alguns dias de visita às empresas, e dificilmente se estendem mais do 
que poucos meses (BALL; ORMEROD, 2000, p. 408). Essas contradições justificam o fato de se utilizar neste trabalho um estudo de caso de caráter etnográfico ao invés de uma etnografia pura. Dessa forma, um modelo conceitual teórico é utilizado como guia para as observações, e ainda assim, as demais características típicas da etnografia são incorporadas ao estudo de caso.

$\mathrm{Na}$ área de Gestão de Operações, esse tipo específico de estudo de caso é denominado de estudo longitudinal (KARLSSON, 2009, p. 196). No entanto, diferentemente do estudo realizado nessa pesquisa, os estudos classificados como longitudinais costumam se estender por um longo período de tempo, envolvendo anos de pesquisa. Portanto, para evitar essa confusão, opta-se por adotar o termo estudo de caso de caráter etnográfico para se referir ao procedimento técnico utilizado neste trabalho.

A principal fonte de evidência utilizada é a observação participante, apoiada pela análise de documentos. Opta-se pela adoção de duas fontes de evidência em busca de uma maior validade construtiva da pesquisa, ou seja, o estabelecimento de medidas operacionais corretas para os conceitos que estão sob estudo (YIN, 2005, p. 55). Nenhuma das fontes de evidência possui vantagens indiscutíveis sobre a outra. Ambas possuem pontos fracos e pontos fortes que se complementam quando combinados (YIN, 2005, p. 112). Na análise de documentos, o pesquisador investiga a fenômeno sob uma perspectiva externa, já na observação participante o pesquisador se envolve no processo de pesquisa, adotando uma perspectiva interna para investigação (IACONO et al., 2009, p. 42). É essa perspectiva interna da observação participante que traz para o estudo de caso o caráter etnográfico.

A Figura 16 apresenta as quatro etapas desta pesquisa, assim como as principais atividades de cada uma. A primeira etapa consiste na revisão bibliográfica sobre open source design. Já as três últimas etapas pertencem ao estudo de caso: análise de documentos, observação participante e análise de evidências do caso.

No estudo de caso, a coleta e a análise das evidências formam um processo iterativo ${ }^{41}$ (IACONO et al., 2009, p. 41). Portanto, durante a pesquisa de campo, a análise das evidências coletadas direcionam as próximas coletas, e dependo da necessidade identificada, recorre-se à análise de documentos ou a observação participante.

\footnotetext{
${ }^{41} \mathrm{Na}$ Figura 16, o processo iterativo é representado pelas setas ligando as etapas 2, 3 e 4.
} 


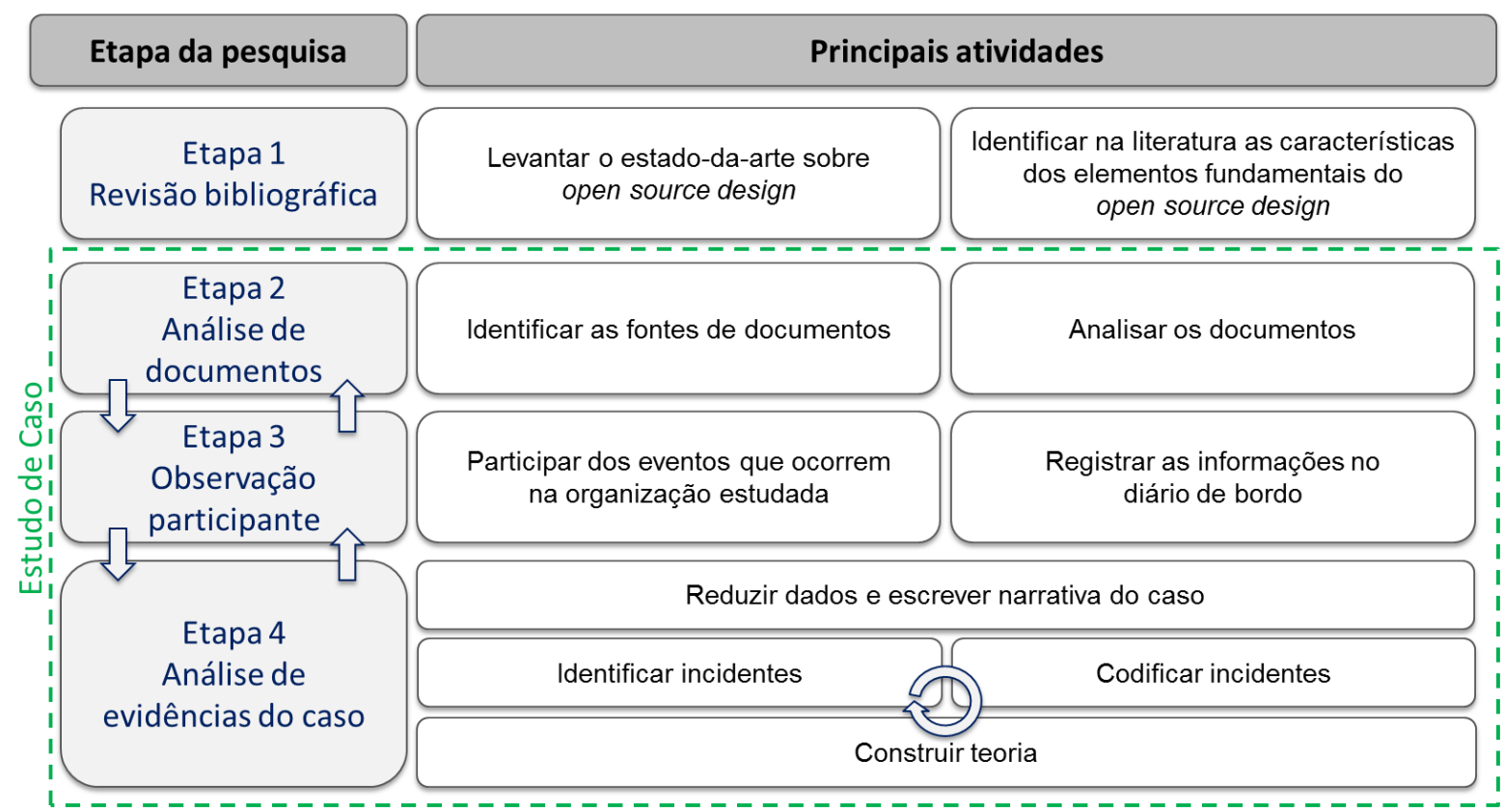

Figura 16 - Etapas da pesquisa

As próximas seções deste capítulo apresentam em maior detalhe cada uma das etapas desta pesquisa, de modo a servir como um protocolo para o estudo de caso. O protocolo, além de um guia, é utilizado para melhorar a confiabilidade da pesquisa, ou seja, demonstrar que as operações do estudo podem ser repetidas, produzindo resultados semelhantes (YIN, 2005, p. 56). No entanto, por se tratar de um estudo de caso de caráter etnográfico, o protocolo elaborado para essa pesquisa é flexível, principalmente com relação à coleta de dados, deixando espaço para autonomia dos participantes, abertura, personalização e autorreflexão (características apresentadas na Tabela 2).

\subsection{Etapa 1. Revisão bibliográfica}

Ao iniciar a revisão bibliográfica, busca-se uma ampla visão da literatura existente. Geralmente, a literatura sobre o tema da pesquisa possui um escopo amplo, de tal modo que somente parte dela trata do fenômeno de interesse (KARLSSON, 2009, p. 52). Nesse sentido, esta etapa tem por objetivo identificar na literatura existente (sem a preocupação em esgotá-la), estudos que tratam do fenômeno de interesse, e extrair desses estudos pontos relevantes para o embasamento desta pesquisa. A revisão bibliográfica concentra-se no open source 
design, e busca identificar nos estudos existentes, características dos elementos fundamentais do OSD: processo de desenvolvimento de produtos, plataforma de colaboração, comunidade, motivadores e modelo de negócio, além das oportunidades e ameaças para este fenômeno, assim como para as indústrias existentes.

Nesta etapa da pesquisa também são delineados os limites do fenômeno estudado, por meio do estabelecimento de uma definição para o open source design, e da identificação das diferentes terminologias utilizadas para se referir a ele. Os resultados desta etapa estão apresentados no capítulo 2.

\subsection{Etapa 2. Análise de documentos}

Nesta etapa, inicia-se a coleta de dados do estudo de caso, por meio da análise de documentos cedidos pela organização pesquisada, sejam eles impressos ou digitais, que contenham informações sobre o os elementos fundamentais do open source design. A análise de documentos é relevante a praticamente todos os estudos de caso, pois é utilizada para corroborar e valorizar as evidências oriundas de outras fontes (YIN, 2005, p. 112). A Tabela 3 apresenta os principais pontos fortes e fracos dessa fonte de evidência. Nesta pesquisa, a análise de documentos contribui também com a preparação do pesquisador para a etapa de observação participante, Ihe proporcionando uma maior familiaridade com o objeto de estudo.

Tabela 3 - Pontos fortes e fracos da análise de documentos (YIN, 2005, p. 113)

\begin{tabular}{lll}
\hline Fonte de evidência & Pontos fortes & Pontos fracos \\
\hline & • Pode ser revisa inúmeras vezes; & \\
& - Não são criadas como resultado & • Pode apresentar uma baixa \\
& do estudo de caso; & capacidade de recuperação; \\
Análise de documentos & - Normalmente contém nomes, & • Pode apresentar uma \\
& referências e detalhes exatos de & seletividade tendenciosa, caso a \\
& um evento; & coleta não seja completa; \\
& - Permite a análise de eventos que & • O acesso aos documentos pode \\
& ocorreram fora do período do & ser negado \\
& estudo de caso. & \\
\hline
\end{tabular}

Uma das características inerente ao fenômeno analisado é a liberação na web dos documentos de projeto elaborados pela organização. A utilização de websites como fonte de evidências faz com que esta pesquisa esteja livre de alguns 
problemas geralmente enfrentados pelos pesquisadores ao realizarem a análise de documentos, como a possibilidade de ter o acesso negado, e a baixa capacidade de recuperação da documentação analisada (YIN, 2005, p. 113).

Para a seleção dos websites utilizados como fontes de evidências utiliza-se como critério o fato de os websites fornecerem informações sobre o processo de desenvolvimento de produtos da organização estudada.

\subsection{Etapa 3. Observação participante}

A observação participante tem suas origens na antropologia, no estudo de costumes e práticas de sociedades pouco conhecidas. Nas últimas décadas, esta fonte de evidência tem se tornado popular entre pesquisadores da área de gestão de operações. Neste caso, as organizações são vistas como uma sociedade, que possuem costumes e práticas particulares, e cabe ao pesquisador participar desta sociedade enquanto registra o que foi observado (IACONO et al., 2009, p. 42).

Ao conviver com os membros da organização, o pesquisador se depara com as limitações do cotidiano. Desse modo, a imersão possibilita um entendimento profundo não só do trabalho, como da cultura da organização estudada, possibilitando, inclusive, a transferência de conhecimentos tácitos (HOWARDGRENVILLE, 2005, p. 621). "Ele vê o mundo em ação e nele insere suas descobertas" (DENZIN; LINCOLN, 2006, p. 24). Durante a observação participante, várias entrevistas informais e não estruturadas são conduzidas com os envolvidos no processo de desenvolvimento de produtos, tanto individuais quanto em grupo. A Tabela 4 apresenta os principais pontos fortes e fracos dessa fonte de evidência. 
Tabela 4 - Pontos fortes e fracos da observação participante (YIN, 2005, p. 113)

\begin{tabular}{|c|c|c|}
\hline Fonte de evidência & Pontos fortes & Pontos fracos \\
\hline Observação participante & $\begin{array}{l}\text { - Trata de acontecimentos em } \\
\text { tempo real; } \\
\text { - Trata do contexto do evento; } \\
\text { - Permite a percepção de } \\
\text { comportamentos e relações } \\
\text { interpessoais. }\end{array}$ & $\begin{array}{l}\text { - Consome muito tempo; } \\
\text { - É seletiva, já que depende dos } \\
\text { eventos que o pesquisador decidiu } \\
\text { participar; } \\
\text { - O acontecimento pode ocorrer de } \\
\text { forma diferenciada por estar sendo } \\
\text { observado; } \\
\text { - Pode gerar altos custos; } \\
\text { - Pode apresentar vieses devido a } \\
\text { manipulações dos eventos por } \\
\text { parte do pesquisador. }\end{array}$ \\
\hline
\end{tabular}

A cada evidência identificada, são realizados breves registros por parte do pesquisador. São também utilizados registros fotográficos para auxiliar na captura de percepções. Ao final de cada dia de trabalho, o pesquisador recupera suas anotações e fotos, e registra detalhadamente em um diário de bordo (instrumento para a coleta de dados) todas as observações capturadas durante o dia. Esse momento de registro também é um momento de reflexão, levando ao processo iterativo de coleta e análise das evidências. Caso surjam dúvidas no momento do registro, os membros da organização são procurados para esclarecê-las. Sempre que necessário, deve-se recorrer à análise de documentos para confirmar ou confrontar alguma evidência.

\subsection{Etapa 4. Análise de evidências do caso}

Nas pesquisas qualitativas, a análise dos dados é muitas vezes um processo subjetivo. No estudo de caso a análise de evidências é um dos aspectos menos desenvolvidos, e diferentemente da análise estatística, há poucas fórmulas ou receitas fixas para auxiliar o pesquisador. Em vista disso, a análise de evidências no estudo de caso depende muito da maneira sistemática de pensar do pesquisador (YIN, 2005, p. 138; IACONO et al., 2009, p. 41). Karlsson (2009, p. 216), também aborda a dificuldade em analisar os dados coletados por meio da observação participante, e alerta que na maioria dos casos, os pesquisadores acabam por desenvolver os próprios métodos de análise, dependendo das especificidades do estudo realizado. 
Neste trabalho, a etapa de análise e evidências do caso está baseada nos estágios propostos por Karlsson (2009) para a análise de dados em estudos longitudinais, e utiliza como método analítico a Árvore de Causa e Efeito. A Figura 17 ilustra os estágios desta etapa, distribuídos de forma cronológica. Cada um dos estágios estão descritos nas subseções a seguir.

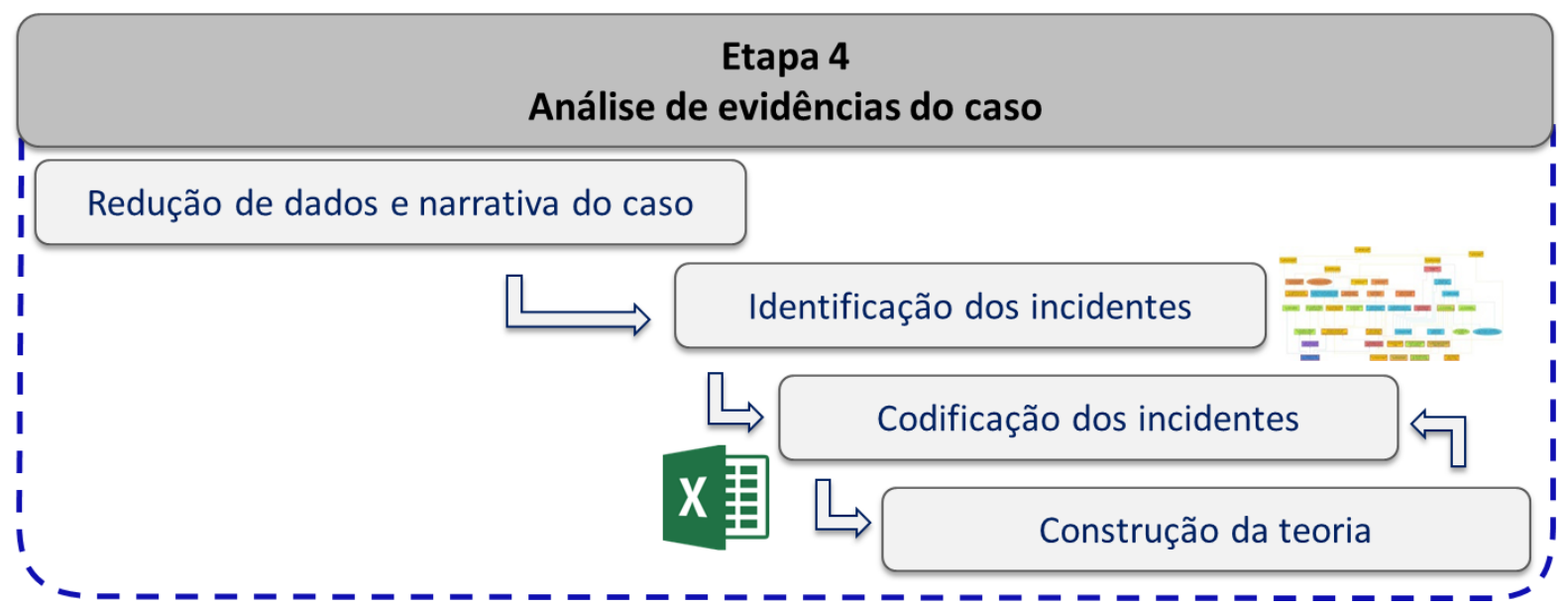

Figura 17 - Estágios da etapa de análise de evidências do caso

\subsubsection{Redução dos dados e narrativa do caso}

A redução de dados é uma atividade recomendada em qualquer estudo qualitativo. Essa atividade pode ser considerada como parte da análise já que ao fazer uma primeira triagem dos dados, determina os tipos de análise que serão possíveis de serem executadas. Na redução dos dados deve-se tomar o cuidado para que eles não sejam distorcidos, nem simplificados ao extremo, deixando espaço para a utilização de uma variedade de abordagens analíticas (KARLSSON, 2009, p. 216). Nesta etapa, o diário de bordo, assim como os documentos coletados são revistos, e os dados relevantes, ou seja, aqueles relacionados aos elementos fundamentais do OSD são incorporados na narrativa do caso.

A narrativa detalha a sequência de eventos observados, em ordem cronológica, de modo a compilar em um único documento os dados coletados em campo. Ao narrar as histórias vivenciadas em campo, o pesquisador deve ser fiel as suas observações, e ter sempre em mente a questão de pesquisa. Nesta etapa da análise, as interpretações do pesquisador devem ser separadas da narrativa, e adicionadas como comentários ao texto (KARLSSON, 2009, p. 217).

Os resultados obtidos nesta etapa estão apresentados na seção 4.2. 


\subsubsection{Identificação de incidentes}

Após a escrita da narrativa, é necessário dividi-la em partes menores para permitir a análise. Esses "pedaços" menores consistem nos elementos básicos da informação sobre um incidente que aconteceu em um momento específico da pesquisa de campo. Cada incidente deve ser posteriormente codificado e classificado como um indicativo de um evento teórico. Um incidente é um dado, que funciona de matéria prima para as análises do pesquisador, já um evento é um constructo teórico. Neste trabalho, um incidente é definido como uma ocorrência que interfere no open source design, podendo tanto facilitar quanto se tornar uma barreira para esse fenômeno.

Os incidentes são identificados por meio da leitura da narrativa, repetidas vezes, de modo que as frases que indicam um incidente vão sendo destacadas no texto. No entanto, os incidentes não precisam ser necessariamente iguais às sentenças da narrativa. Cada incidente identificado deve ser descrito de modo a incluir: a data de ocorrência, o(s) ator(es) ou objeto(s) envolvidos, a ação ou comportamento observado, a consequência da ação, e a fonte da informação (KARLSSON, 2009, p. 218). Nesta pesquisa, as fontes de informação correspondem à observação participante $(\mathrm{OP})$ e à análise de documentos (AD). A Tabela 5 apresenta um exemplo da identificação de um incidente a partir da narrativa.

Tabela 5 - Exemplo da identificação de um incidente a partir da narrativa

\begin{tabular}{|c|c|c|c|c|c|c|}
\hline \multicolumn{3}{|l|}{ Narrativa } & \multicolumn{4}{|c|}{ Incidente } \\
\hline Sentença & Versão & $\begin{array}{l}\text { Pág- } \\
\text { Linha }\end{array}$ & $\begin{array}{l}\text { Data de } \\
\text { ocorrência }\end{array}$ & $\begin{array}{l}\text { Atores ou } \\
\text { objetos }\end{array}$ & $\begin{array}{l}\text { Ação ou } \\
\text { comportamento } \\
\text { observado }\end{array}$ & Fonte \\
\hline $\begin{array}{l}\text { Um dos participantes do grupo } \\
\text { era responsável por } \\
\text { documentar, enquanto que os } \\
\text { demais eram responsáveis pela } \\
\text { construção. Quem ficasse } \\
\text { responsável pela } \\
\text { documentação deveria marcar } \\
\text { o tempo de cada atividade, tirar } \\
\text { foto do passo-a-passo, e tomar } \\
\text { notas que pudessem auxiliar } \\
\text { um leigo na montagem }\end{array}$ & v2.2 & $90-6$ & 17/jun/2014 & Workshop & $\begin{array}{l}\text { Alocação de um } \\
\text { responsável } \\
\text { pela } \\
\text { documentação } \\
\text { durante a } \\
\text { prototipagem }\end{array}$ & OP \\
\hline
\end{tabular}

Os resultados obtidos nesta etapa estão apresentados na terceira seção do APÊNDICE A. 


\subsubsection{Codificação dos incidentes}

A codificação dos incidentes consiste em uma categorização, na qual cada categoria está associada a um determinado código. Existem duas opções para se definir as categorias utilizadas na classificação dos incidentes: retirar as categorias da teoria ou derivá-las dos próprios dados (KARLSSON, 2009, p. 218). No caso de estudos que visam à construção teórica, a segunda opção é mais utilizada. Cada incidente pode ser codificado em mais de uma categoria (van de VEM; POOLE, 1990 apud KARLSSON, 2009, p. 219). Dessa forma, pode-se analisar um evento por diferentes pontos de vista, e extrair dos incidentes um significado mais profundo. A derivação das categorias a partir dos próprios dados (narrativa) ocorre com base na semelhança do conteúdo dos incidentes e de acordo com o conhecimento sobre OSD adquirido pelo pesquisador a fim de definir categorias significativas para caracterização do fenômeno.

Recomenda-se armazenar os incidentes identificados em um banco de dados, a fim de que eles possam ser rastreados de forma mais eficiente (KARLSSON, 2009, p. 219). Com esta finalidade, neste trabalho são utilizadas planilhas eletrônicas com o apoio do software MS Excel. Recursos como esse são de extrema utilidade, visto que, provavelmente, será necessário efetuar diversas rodadas de recodificação das evidências. Em cada rodada, ocorre a busca por incidentes que indicam um evento recorrente, ocasionando na eliminação daqueles incidentes que indicam eventos não-recorrentes. Neste estágio intermediário da análise, é recomendado representar os dados de forma gráfica. Neste ponto, os eventos considerados de maior importância também são destacados. Tudo para auxiliar o pesquisador na identificação de padrões, determinação das relações de causa e efeito entre os incidentes, e levantamento de hipóteses, visando contribuir para o desenvolvimento da teoria (KARLSSON, 2009, p. 221).

Os resultados obtidos nesta etapa estão apresentados na terceira seção do APÊNDICE A.

\subsubsection{Construção da teoria}

Neste estágio, as evidências coletadas são utilizadas como base para o desenvolvimento teórico de hipóteses e modelos. O pesquisador não deve esperar 
que a análise de dados seja algo linear. O processo que ocorre entre a coleta de evidências e a construção da teoria é intencionalmente não linear e iterativo (MARTIN; TURNER, 1986 apud KARLSSON, 2009, p. 222). A análise da ordem, relacionamento e padrões entre os eventos é essencial na análise de estudos que se baseiam na observação participante (VAN DE VEM; POOLE, 1990 apud KARLSSON, 2009, p. 222). Uma vez que um padrão ou sequência entre os eventos é identificado, deve-se se perguntar quais são as causas e consequências desses processos padrões (VAN DE VEM; HUBER, 1990 apud KARLSSON, 2009, p. 222). Neste estágio, são recomendadas ferramentas gráficas para auxiliar o pesquisador na visualização dos dados, padrões e sequências (BERG, 1981 apud KARLSSON, 2009, p. 223).

Um dos métodos utilizados nesse estágio é a Árvore de Causa e Efeito, também chamada de Árvore da Realidade Atual (ARA). Este método faz parte do toolkit da Teoria das Restrições (TOC - Theory of Constraints) desenvolvida por Elyiahu M. Goldratt. Consiste em um diagrama que relaciona os efeitos indesejáveis (Els) identificados em um sistema/processo, permitindo uma análise sistêmica da situação atual de modo que se possa identificar claramente quais são os principais Els que, se eliminados, serão responsáveis por uma melhoria representativa no sistema/processo analisado. Esses Els são denominados causas-raiz (GOLDRATT, 1994; COSTA et al., 2013, p. 22).

Desse modo, a Árvore de Causa e Efeito proporciona um entendimento mais profundo do fenômeno do open source design, possibilitando a análise das dificuldades enfrentadas pelos colaboradores durante 0 processo de desenvolvimento de produtos. Dessa forma, é permitida a formulação de hipóteses sobre as potenciais características que os elementos fundamentais do OSD deveriam possuir para que se tornar um sistema mais eficiente. No APÊNDICE A é apresentada a lógica utilizada na Árvore de Causa e Efeito e o processo para sua construção (seção 1 do apêndice), assim como a Árvore obtida (seção 4 do apêndice).

A construção de uma teoria não se trata de um processo mecânico. Novas descobertas possuem um alto nível de incertezas e ambiguidade e exigem do pesquisador um pensamento criativo na interpretação e análise das evidências coletadas em campo (KARLSSON, 2009, p. 224). Uma atividade essencial na construção de teorias é a comparação dos conceitos, teorias e hipóteses 
emergentes com a literatura existente (Eisenhardt, 1989 apud KARLSSON, 2009, p. 223). Uma revisão da teoria sobre OSD foi apresentada no capítulo 2. A fim de possibilitar, também, uma comparação dos resultados obtidos da aplicação da Árvore de Causa e Efeito com as dificuldades enfrentadas no PDP de empresas tradicionais, ou seja, que não realizam projetos de open source design, é realizada uma revisão da literatura sobre os problemas recorrentes no PDP (seção 2 do APÊNDICE A).

Os resultados obtidos nessa etapa estão apresentados nas seções 4.3 (análise dos principais incidentes identificados), 4.4 (características do PDP da Open Source Ecology) e 4.5 (reflexões sobre os demais elementos do open source design).

A Figura 18 ilustra a correspondência entre a metodologia adotada e a estrutura deste documento, destacando em quais seções são apresentados os resultados obtidos em cada etapa da pesquisa.

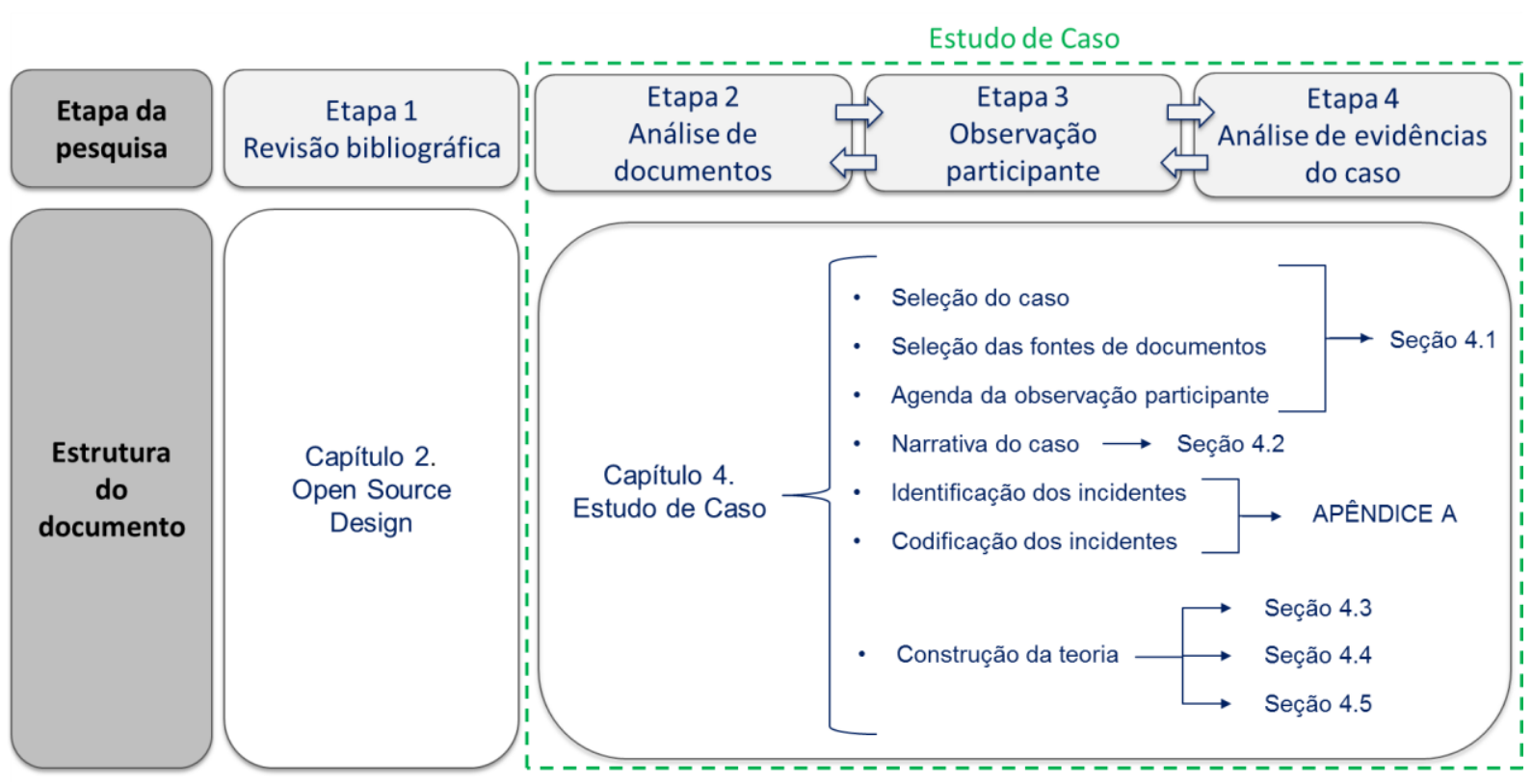

Figura 18 - Correspondência entre a metodologia adotada e a apresentação dos resultados de acordo com a estrutura deste documento 


\section{Estudo de caso}

Este capítulo apresenta o desenvolvimento do estudo de caso (etapas 2 e 3 da metodologia), e os resultados obtidos nas após a análise das evidências do caso (etapa 4). Na seção 4.1 são apresentadas a seleção do caso e a seleção das fontes de evidência utilizadas na análise de documentos, assim como a agenda dos eventos programados para a observação participante. Na seção 4.2, é apresentada a narrativa do caso, visando compilar em um único documento os dados coletados em campo por meio da observação participante da análise de documentos. Esta narrativa visa aproximar os leitores das experiências vivenciadas pelo pesquisador, de modo que eles possam compreender a origem das evidências utilizadas como base para o desenvolvimento teórico de hipóteses e modelos. Essas evidências são explicitadas na seção 4.3, na qual são analisados os principais incidentes observados no PDP da organização estudada. Baseado nesses incidentes, a seção 0 apresenta a caracterização do PDP no open source design, enquanto que na seção 4.5 são realizadas reflexões sobre os demais elementos do OSD, visando contribuir para uma futura caracterização desses elementos. O APÊNDICE A complementa este capítulo, ao apresentar em mais detalhes os resultados obtidos na etapa de análise de evidências.

\subsection{Seleção do caso e identificação das fontes de evidência}

Nesta pesquisa, optou-se por estudar um caso singular cuja identidade já era conhecida desde o início deste trabalho. A singularidade do caso selecionado devese ao fato de a organização, chamada Open Source Ecology (OSE), atuar no contexto do open source design e utilizar um modelo de referência para o processo de desenvolvimento de produtos ${ }^{42}$, descrito na seção 3 do APÊNDICE B. O acesso ao local da pesquisa foi facilitado por meio de um contato prévio por parte do pesquisador com o fundador da organização, que possibilitou ao pesquisador participar de um programa intensivo de desenvolvimento entre os meses de Junho e

B.

$\overline{42}$ Caso o termo "modelo de referência" não seja familiar, consultar a seção 1 do APÊNDICE 
Agosto de 2014, que por se tratarem dos meses de verão no hemisfério norte, passou a ser chamado pelos participantes de "programa de verão". O material de divulgação deste programa é apresentado na Figura 19.

A OSE é uma comunidade que concentra fazendeiros, construtores, e empreendedores, e que atua no desenvolvimento de soluções para reinvenção da produção local. Sua missão é criar uma economia livre ${ }^{43}$, ou seja, uma economia que promova a inovação por meio da colaboração aberta.

A OSE aplica o open source design no setor de construção civil, agricultura e manufatura, e possui uma plataforma de produtos que recebe o nome de Global Village Construction Set (GVCS). O GVCS consiste em uma plataforma de produtos que permite a fabricação no modelo DIY de 50 diferentes máquinas industriais de arquitetura modular, com alto desempenho e baixo custo, consideradas essenciais para a construção de uma pequena civilização sustentável, com os padrões de conforto da vida moderna. O ANEXO II apresenta as máquinas que compõe 0 GVCS. Conforme pode ser observado no ANEXO II, nenhum dos produtos atingiu o estágio de maturidade do desenvolvimento. Dos 50 produtos do GVCS, quatorze encontram-se no estágio de prototipagem iniciada, um no estágio de desenvolvimento virtual, e o demais no estágio de planejamento e pesquisa.

\footnotetext{
${ }^{43}$ Em inglês, open source economy.
} 
Do you know what you're doing this summer?

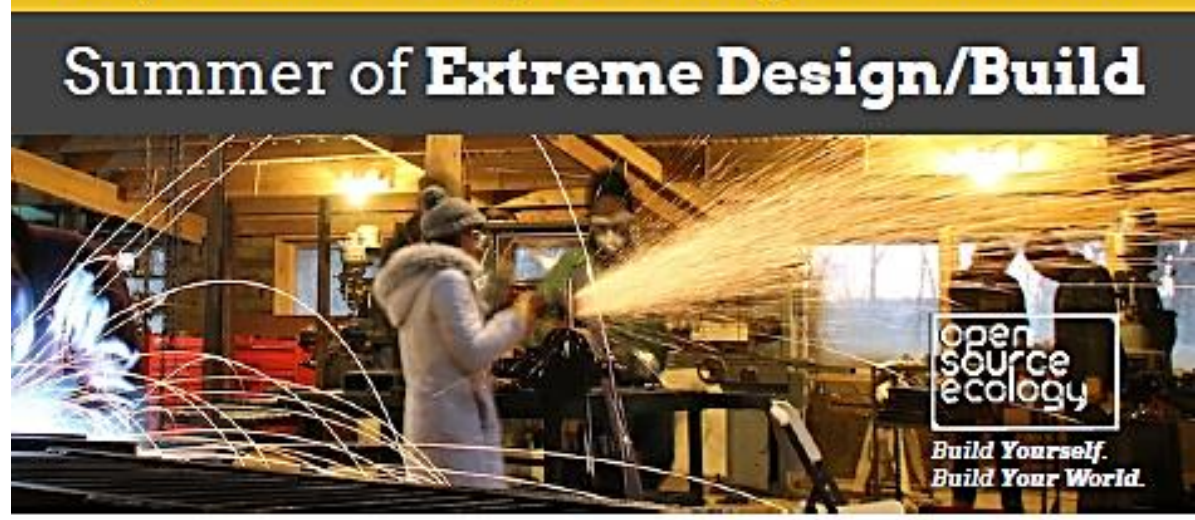

The Global Village Construction Set (GVCS) is a modular, DIY, low-cost, highperformance platform that allows for easy fabrication of the $\mathbf{5 0}$ different Industrial Machines it takes to build a small,|sustainable civilization with modern comforts.

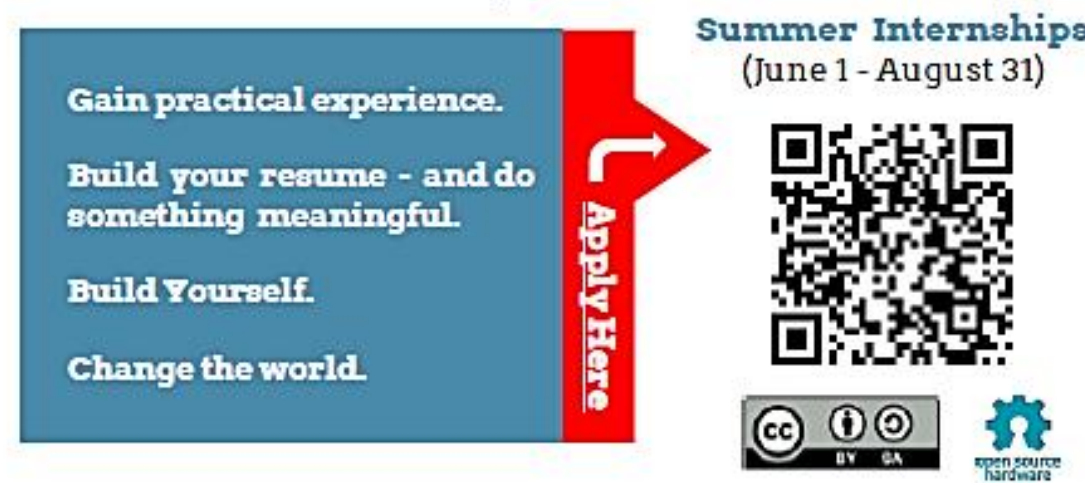

Figura 19 - Material de divulgação do programa em vigor durante o período de observação participante (OSE, 2015a)

Após a seleção do caso, foram identificadas as fontes de evidência utilizadas tanto na etapa de análise de documento quanto na de observação participante. $\mathrm{Na}$ primeira, todos os documentos utilizados foram extraídos dos websites da organização, já que segundo as características do próprio fenômeno estudado, a maior parte das informações referentes ao processo de desenvolvimento de produtos estão disponibilizadas abertamente na internet. A identificação dos websites foi realizada com o auxílio do administrador web da organização pesquisada ${ }^{44}$, seguindo como critério o fato de os websites fornecerem informações sobre o PDP da organização estudada. A Tabela 6 apresenta uma descrição desses websites, assim como o endereço web de cada um deles. Os websites selecionados,

${ }^{44}$ O cargo de administrador web OSE consiste em um trabalho voluntário, realizado remotamente por um brasileiro que nunca teve contato com nenhum funcionário da empresa pessoalmente. 
apresentados em destaque na tabela, são: a homepage, a wiki ${ }^{45}$, o fórum de discussões, e os repositórios de fotos, vídeos e roteiros de fabricação, roteiros de montagem e manuais. Também foi selecionada a ferramenta de pesquisa personalizada nas páginas da organização para realização de buscas por evidências específicas.

Tabela 6 - Websites administrados pela organização. As linhas em destaque correspondem aos websites selecionados para a análise de documentos

\begin{tabular}{ll}
\hline Descrição do website & Endereço web \\
\hline Blog da organização & http://blog.opensourceecology.org/ \\
\hline $\begin{array}{l}\text { Ferramenta do Google de pesquisa } \\
\text { personalizada nas páginas da } \\
\text { organização }\end{array}$ & $\begin{array}{l}\text { https://www.google.com/cse/home?cx=01082324146458313 } \\
6657: \text { hlzpyuunqm }\end{array}$ \\
\hline $\begin{array}{l}\text { Fórum de discussões da } \\
\text { organização }\end{array}$ & http://forum.opensourceecology.org/ \\
\hline Grupo de e-mail da organização & https://groups.google.com/forum/\#!forum/opensourceecology \\
\hline $\begin{array}{l}\text { Página da organização na rede } \\
\text { social Facebook }\end{array}$ & https://www.facebook.com/OpenSourceEcology \\
\hline $\begin{array}{l}\text { Página da organização na rede } \\
\text { social Google+ }\end{array}$ & https://plus.google.com/109167315937284436272/posts \\
\hline $\begin{array}{l}\text { Página da organização na rede } \\
\text { social Linkedlln }\end{array}$ & http://www.linkedin.com/company/open-source-ecology \\
\hline $\begin{array}{l}\text { Página da organização na rede } \\
\text { social MySpace }\end{array}$ & https://myspace.com/opensourceecology \\
\hline $\begin{array}{l}\text { Página da organização na rede } \\
\text { social Twitter }\end{array}$ & https://twitter.com/OSEcology \\
\hline Homepage da organização & http://opensourceecology.org// \\
\hline $\begin{array}{l}\text { Repositório de fotos da } \\
\text { organização }\end{array}$ & https://opensourceecology.trovebox.com/albums/list \\
\hline $\begin{array}{l}\text { Repositório de roteiros de } \\
\text { fabricação, roteiros de montagem e } \\
\text { manuais }\end{array}$ & http://opensourceecology.dozuki.com/ \\
\hline $\begin{array}{l}\text { Repositório de vídeos da } \\
\text { organização no Vimeo }\end{array}$ & http://vimeo.com/opensourceecology \\
\hline $\begin{array}{l}\text { Repositóio de vídeos da } \\
\text { organização no YouTube }\end{array}$ & https://www.youtube.com/user/marcinose \\
\hline \begin{tabular}{l} 
Wiki da organização \\
\hline
\end{tabular} & http://opensourceecology.org/wiki/Main_Page \\
\hline
\end{tabular}

$\mathrm{Na}$ a etapa de observação participante, o pesquisador se aproximou das perspectivas dos membros da organização por meio de uma imersão completa. Além de participar ativamente dos projetos e treinamentos, o pesquisador conviveu em tempo integral com os demais membros da organização por cerca de três meses. Estava prevista uma rotina de trabalho de 40 horas semanais (segunda à sexta, das 9 h00 às $18 \mathrm{~h} 00$, com uma pausa para o almoço das $13 \mathrm{~h} 00$ às $14 \mathrm{~h} 00$ ). No

\footnotetext{
${ }^{45}$ Ambiente virtual no qual um grande número de pessoas podem contribuir para geração e organização de conteúdo.
} 
total, foram mais de 800 horas de observação participante, no período entre 14 de Junho a 30 de Setembro de 2014.

$\mathrm{Na}$ observação participante, uma das dificuldades enfrentadas pelo pesquisador é garantir sua participação e observação em acontecimentos importantes (YIN, 2005, p. 123). A fim de mitigar esse risco, foi planejada uma programação dos eventos nos quais o pesquisador participaria, baseada na programação do programa de verão. A Tabela 7 apresenta a agenda dos eventos programados para participação do pesquisador.

Tabela 7 - Agenda dos eventos programados para a observação participante

\begin{tabular}{ll}
\hline Período & Eventos programados \\
\hline Semana 1 & Design Sprints \\
16 a 20 de Junho & Construção de um trator (Tractor) \\
& Construção de uma pá escavadeira (Backhoe) \\
& Documentação da micro-casa (MicroHouse) \\
\hline Semana 2 & Workshop para construção de um queimador de gás (Gasifier \\
23 a 27 de Junho & Burner) \\
\hline Semana 3 & Construção de um micro-trator (Microtractor) \\
30 de Julho a 04 de Julho & Elaboração do manual para mesa CNC de corte à chama (CNC \\
& Torch Table) \\
\hline Semana 4 & Workshop para construção de um fogão para MicroHouse \\
7 a 11 de Julho & Abertura de um poço \\
& Construção de ferramentais agrícolas \\
& Conexão do poço \\
\hline Semana 5 & Construção de um trator com esteira rolante (Bulldozer) \\
14 a 18 de Julho & Projeto de um trator com esteira rolante \\
& Workshop para construção de um micro-motor (Micro Power Cube) \\
\hline Semana 6 & Construção de uma prensa de tijolos (CEB Press) \\
21 a 25 de Julho & Construção de uma pá escavadeira \\
\hline Semana 7 & Workshop para construção de um micro-carro (Open Source \\
28 de Julho a 1 de Agosto & Automobile) \\
\hline Semana 8 & Documentação do trator \\
4 a 8 de Agosto & Documentação da MicroHouse \\
& Construção de uma pá escavadeira \\
\hline Semana 9 & Workshop para construção de um motor (Power Cube) \\
11 a 15 de Agosto & Projeto e construção de um gerador de energia por biogás \\
\hline Semana 10 & Construção de um granulador (Palletizer) \\
18 a 22 de Agosto & Workshop para construção do trator \\
\hline Semana 11 & Construção do Gasifier Burner \\
25 a 29 de Agosto & Construção da CEB Press em três dias \\
& Construção do trator em três dias \\
\hline
\end{tabular}

No entanto, durante o período de observação participante, apenas parte do que havia sido planejado foi cumprido. A Figura 20 ilustra dentre os projetos planejados, aqueles que foram realmente executados, assim como o número de protótipos construídos em cada projeto. Dos nove protótipos construídos, seis 
contaram com a participação do pesquisador. A prototipagem da Torch Table e de dois Power Cubes ocorreram em paralelo a outros projetos considerados prioritários, inviabilizando a participação do pesquisador em todos os projetos. Os detalhes sobre os projetos e outros eventos vivenciados pelo pesquisador estão relatados na seção 4.2 .

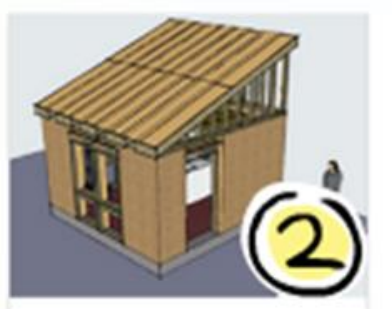

MicroHouse

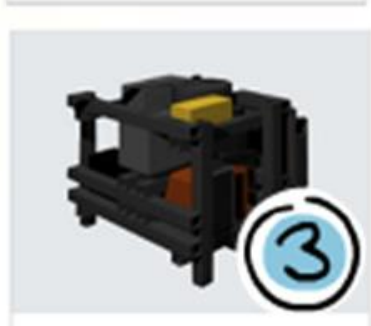

Power Cube

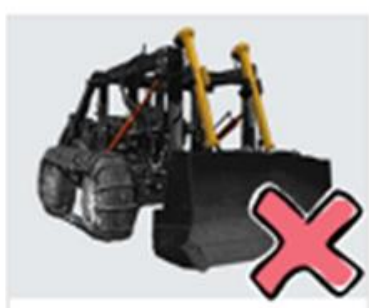

Bulldozer

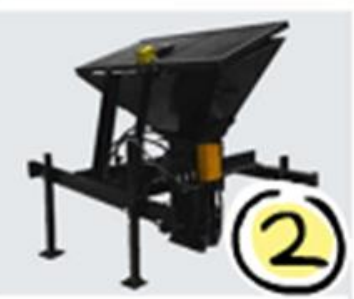

CEB Press

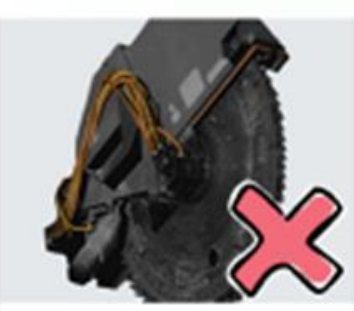

Trencher

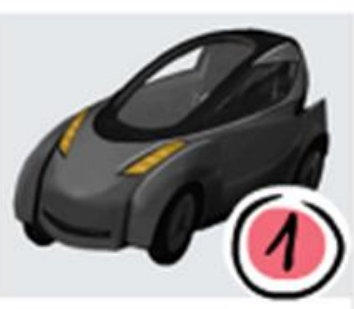

Open Source Automobile

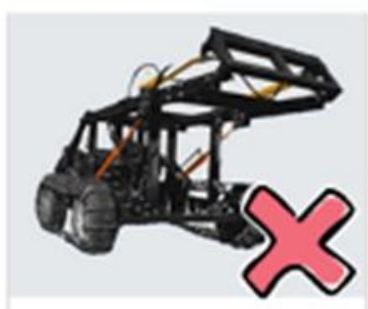

Tractor

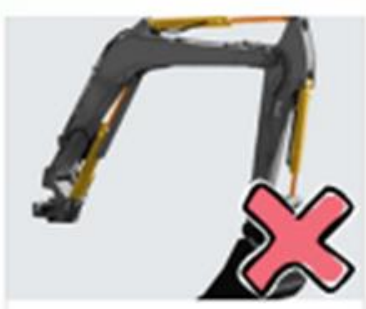

Backhoe

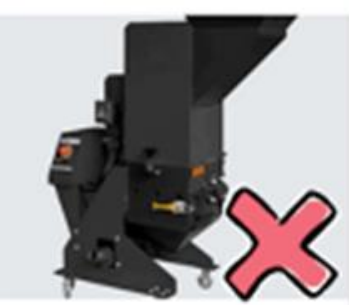

Pelletizer

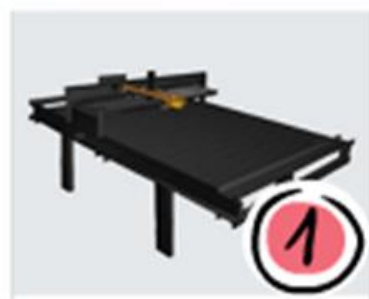

CNC Torch/Router Table

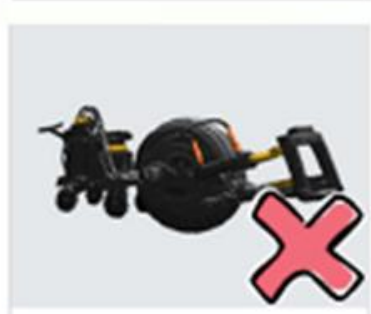

Microtractor

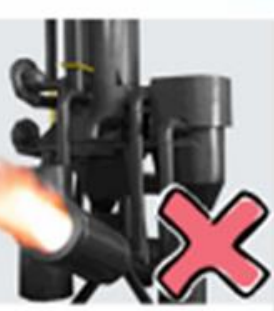

Gasifier Burner

Figura 20 - Projetos planejados vs. projetos executados durante o período de observação participante (adaptado de OSE, 2014a)

\subsection{Um relato das experiências vivenciadas na comunidade Open Source Ecology}

No dia 14 de Junho de 2014 desembarquei no aeroporto de Kansas City, no centro oeste dos Estados Unidos. Esperei em torno de umas duas horas até que minha carona chegasse, para me levar para Factor e Farm (FeF), a fazenda sede da Open Source Ecology. A fazenda ficava nos arredores de uma pequena cidade chamada Maysville, a $100 \mathrm{~km}$ ao norte de Kansas City. Portanto, no caminho tive a 
oportunidade de conversar por cerca de uma hora com o rapaz que havia ido me buscar, o responsável pela hospitalidade durante o programa de verão. Ele tinha 24 anos e estava trabalhando na OSE havia três semanas. Naquele ano, terminara a faculdade de história em Berkeley, e antes de trabalhar ir para OSE estava dando aula para crianças do ensino fundamental. Ele tinha bastante experiência com a gestão de comunidades, pois, durante a faculdade, havia sido gerente geral de uma moradia estudantil cooperativa ${ }^{46}$ onde viviam em torno de 120 estudantes. Sua função na OSE estava diretamente ligada a isso. Ele era responsável por facilitar a vida em comunidade, além de fazer o leva e traz das pessoas para o aeroporto, cozinhar e fazer as compras referentes aos suprimentos necessários para manutenção casa. O que mais me espantou foi que o responsável pela hospitalidade era o único funcionário (temporário) da OSE, e que antes do programa de verão, o iniciador do projeto, chamado Marcin Jakubowski, era a única pessoa com dedicação integral à organização, que estava vivendo sozinho na Factor e Farm, até se casar, e sua esposa se mudar para lá.

Marcin nasceu na Polônia durante um período de guerra, e se mudou para os Estados Unidos ainda novo. Formou-se em Química pela Princeton University (1995) e recebeu o título de Doutor em Física pela University of Wisconsin (2003). Frustrado com o fato de que sua formação não havia the preparado para solucionar os problemas enfrentados pelo mundo, principalmente relacionados à escassez de recursos, decidiu abrir mão da carreira acadêmica e fundou a Open Source Ecology, em 2003. No entanto, foi em 2011 que a OSE alcançou grande repercussão, após Marcin apresentar seus projetos no evento TED Talk. Até o momento, essa apresentação $^{47}$ já foi acessada por mais de 1,2 milhões de pessoas, e rendeu a Marcin alguns prêmios como TED Senior Fellow (2012), melhores invenções de 2012 da revista Time, Shuttleworth Foundation Fellow (2013), e White House Champion of Change (2013).

Antes do TED Talk de Marcin, as colaborações eram menos frequentes. No entanto, após a divulgação do TED Talk de Marcin esse número aumentou drasticamente. $\mathrm{O}$ aumento do número de contribuições pode ser observado pela evolução do número de protótipos das máquinas que compõe o GVCS que foram

\footnotetext{
46 Berkeley Student Cooperative. Disponível em https://www.bsc.coop/, acessado em 10/07/2015.

Marcin Jakubowski: Open-sourced blueprints for civilization. Disponível em: http://www.ted.com/talks/marcin jakubowski?language=pt, acessado em 10/07/2015.
} 
construídos, (Figura 21). Nesse gráfico é possível observar quais máquinas foram prototipadas desde a criação da OSE, assim como as versões dos designs dessas máquinas, e as replicações efetuadas por colaboradores de forma independente. A primeira replicação independente de um protótipo do GVCS ocorreu em 2011, com a construção da prensa de tijolos (CEB Press) por um colaborador do Texas, e representou um grande marco na história da OSE.

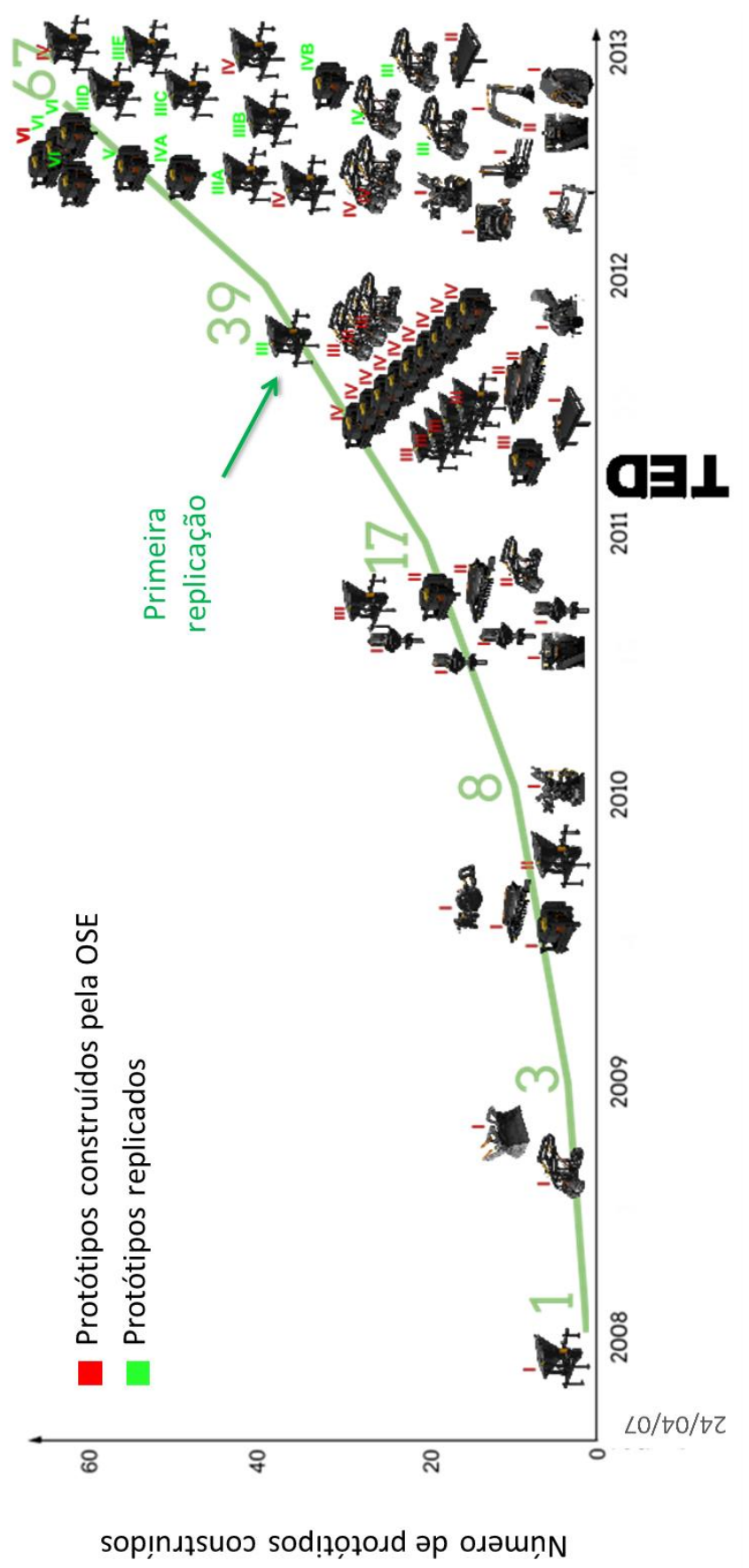

Figura 21 - Evolução do número de protótipos do GVCS construídos entre o período de 2007 a 2012 (adaptado OSE, 2014a) 
Conforme apresentado no gráfico da Figura 21 até o final de 2012, haviam sido construídos um total de 67 protótipos do GVCS, dos quais 16 haviam sido replicados por colaboradores de forma independente. De acordo com os registros da OSE, ao final de 2013 este número subiu para 73, atingindo, no final de 2014, uma marca de 110 protótipos construídos, dos quais 27 provinham de replicações em oito países diferentes: Estados Unidos, Chile, Nicarágua, Guatemala, China, Índia, Itália, Turquia. No entanto, a maioria dos protótipos ainda eram construídos na FeF. Antes do programa de verão, a construção dos protótipos na FeF ocorria principalmente por meio da participação de colaboradores em programas de visitas dedicadas a projetos específicos, chamadas DPVs (do inglês, Dedicated Project Visits). Até o início do período de observação participante, estima-se que a OSE já tenha recebido em torno de 75 colaboradores que participaram dos DPVs na FeF, na pacata Maysville/MO.

Maysville possui por volta de 1500 habitantes, e é cercada por pequenas propriedades rurais, principalmente voltadas para a plantação de milho e soja, com algumas poucas cabeças de gado espalhadas pelo pasto. Cercada pelas plantações de milho e soja, estava a Factor e Farm.

Ao contrário de uma fazenda comum, na FeF não havia grandes plantações nem a criação de animais. Além de um pomar e uma poucas linhas de plantação, a FeF possuía espalhados por seus 30 acres $^{48}$, uma oficina mecânica, utilizada na prototipagem das máquinas do GVCS; uma casa compartilhada chamada Hablab, duas cabanas e uma área de camping, para acomodação dos colaboradores visitantes e estagiários; uma oficina antiga, utilizada como depósito, e os protótipos das MicroHouses construídos com algumas máquinas do GVCS (trator, CEB Press e Power Cube).

O primeiro protótipo da MicroHouse possuía $20 \mathrm{~m}^{2}$ e havia sido ampliado com a construção de um segundo protótipo e uma conexão entre eles, totalizando aproximadamente $60 \mathrm{~m}^{2}$. Ambos já haviam sido construídos quando eu cheguei, e era onde Marcin vivia com sua esposa. No final da minha estadia na FeF, haviam mais dois protótipos iniciados: a MicroHouse 3, que viria a ser utilizada para receber colaboradores, e a MicroHouse 4, que consistia em mais uma ampliação da casa

\footnotetext{
${ }^{48} 30$ acres corresponde a aproximadamente 12 hectares, o equivalente a área de 12 campos de futebol.
} 
onde Marcin morava. A Figura 22 apresenta uma vista aérea da FeF no final do período de observação participante, com a indicação de suas edificações.
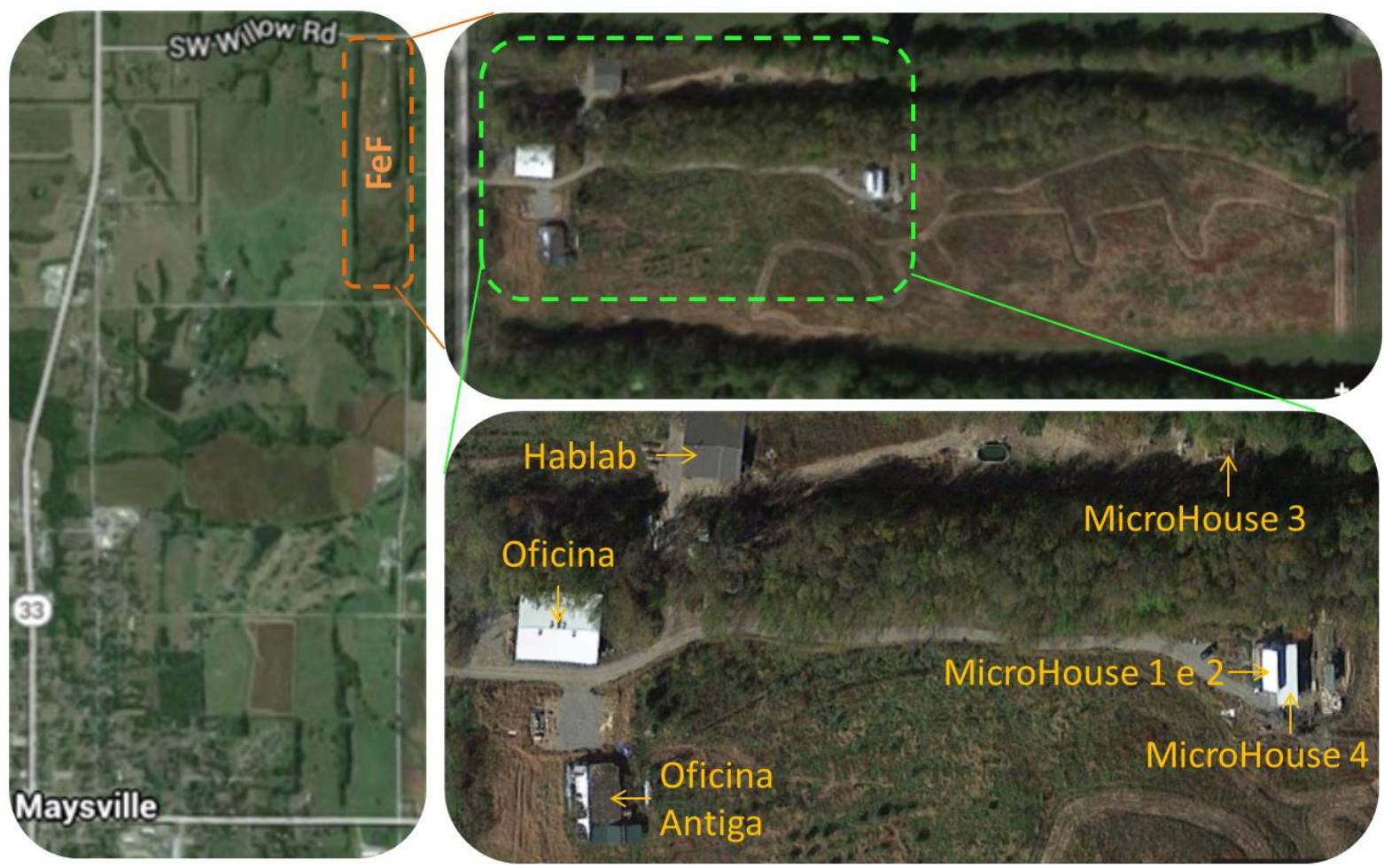

Figura 22 - Vista aérea da FeF (imagens retiradas do Google Maps)

Quando cheguei, compúnhamos um grupo de 14 estagiários voluntários (participantes do programa de verão), a maioria, americanos, universitários e sem muita experiência em desenvolvimento de produtos. Alguns também eram usuários dos produtos com os quais iriamos trabalhar, ou seja, agricultores, construtores e empreendedores. A busca por aprendizado, realização de atividades práticas, diversão e desejo de contribuir com um projeto de impacto social eram motivadores comuns a todos os participantes. Ao longo do período de observação participante, o número de estagiários variou bastante, conforme apresentado no gráfico da Figura 23. No total, circularam pela FeF 37 estagiários, representando diversos países: Estados Unidos, Canadá, Porto Rico, Brasil, França, Áustria, Turquia e Nepal. Além dos estagiários, estiveram sempre presentes durante minha estadia na FeF, Marcin e o responsável pela hospitalidade. Muitos dos estagiários haviam tentado contribuir com os projetos da OSE antes de participarem do programa de verão. No entanto, não conseguiram devido à dificuldade em encontrar as informações relevantes na plataforma de colaboração da organização, incluindo os históricos dos projetos e as atividades que precisam ser realizadas. 


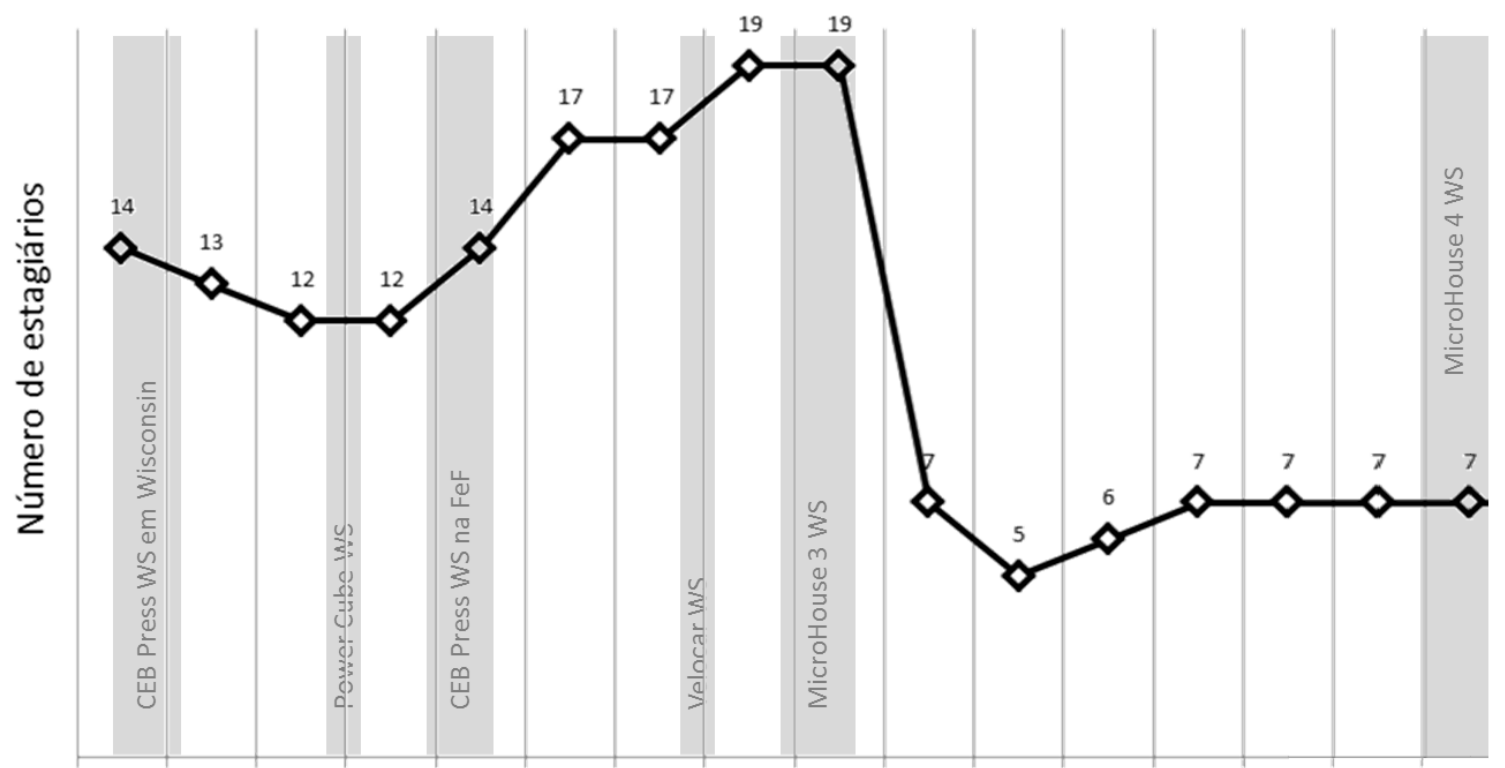

$\begin{array}{lllllllllllllllll}15-21 & 22-28 & 29-05 & 06-12 & 13-19 & 20-26 & 27-02 & 03-09 & 10-16 & 17-23 & 24-30 & 31-06 & 07-13 & 14-20 & 21-27 & 28-01\end{array}$ JUN JUN JUL JUL JUL JUL AGO AGO AGO AGO AGO SET SET SET SET OUT

Figura 23 - Variação do número de estagiários durante o período de observação participante e períodos dos workshops

A wiki da OSE, responsável por centralizar as informações distribuídas nos diversos websites da organização (Tabela 6), não possui uma organização clara, e muitas das informações disponibilizadas encontram-se incompletas e desatualizadas. Entre os colaboradores não há uma visão unificada sobre como a wiki deveria ser organizada, e não há responsáveis por revisar seu conteúdo, contribuindo para desorganização dessa plataforma. $O$ volume de contribuições e o número de colaboradores ativos também são baixos. A Tabela 8 apresenta alguns dados extraídos da wiki que refletem a desorganização das informações e a baixo volume de contribuições. 
Tabela 8 - Estatísticas da wiki (OSE, 2015a)

\begin{tabular}{|c|c|}
\hline \multicolumn{2}{|l|}{ Estatísticas das páginas } \\
\hline Total de páginas de conteúdo & 6.125 \\
\hline Total de páginas (incluindo páginas de conversa, redirecionamentos, etc.) & 23.751 \\
\hline Total de arquivos & 9.341 \\
\hline Total de categorias & 702 \\
\hline Total de páginas não categorizadas & 5.753 \\
\hline Total de arquivos não categorizados & 7.236 \\
\hline $\begin{array}{l}\text { Total de páginas órfão (uma página na qual nenhuma outra página da wiki possui um } \\
\text { link para ela) }\end{array}$ & 3.725 \\
\hline Total de páginas mortas (uma página que não possui links para outras páginas na wiki) & 5.820 \\
\hline \multicolumn{2}{|l|}{ Estatísticas de edição } \\
\hline Páginas editadas desde a criação da wiki (19 de Agosto de 2007) & 13.097 \\
\hline Média de edições por página & 5,51 \\
\hline \multicolumn{2}{|l|}{ Estatísticas de usuários } \\
\hline Usuários registrados & 3.382 \\
\hline Usuários ativos (usuários que tenham executado alguma ação nos últimos 30 dias) & 20 \\
\hline Usuários bloqueados & 319 \\
\hline Administradores & 4 \\
\hline \multicolumn{2}{|l|}{ Estatísticas de visualização } \\
\hline Total de visualizações & 22.986 .724 \\
\hline Razão visualizações/edições & 175,51 \\
\hline
\end{tabular}

Os dados apresentados na Tabela 8 nos permite tirar algumas conclusões sobre a dinâmica das contribuições que ocorrem por meio da wiki. Primeiramente, é interessante observar que aproximadamente $45 \%$ das páginas criadas na wiki, nunca foram editadas, ou seja, não foram revisadas nem atualizadas. Além disso, dos 3.382 usuários cadastrados na wiki da OSE, somente 20 são usuários ativos. No entanto, boa parte das edições (92\%) se concentra no iniciador, em alguns poucos colaboradores que possuem papeis de liderança. O gráfico apresentado na Figura 24 ilustra essa desproporcionalidade entre as contribuições.

${ }^{49}$ Tomando como referência o dia 20/06/2015. 


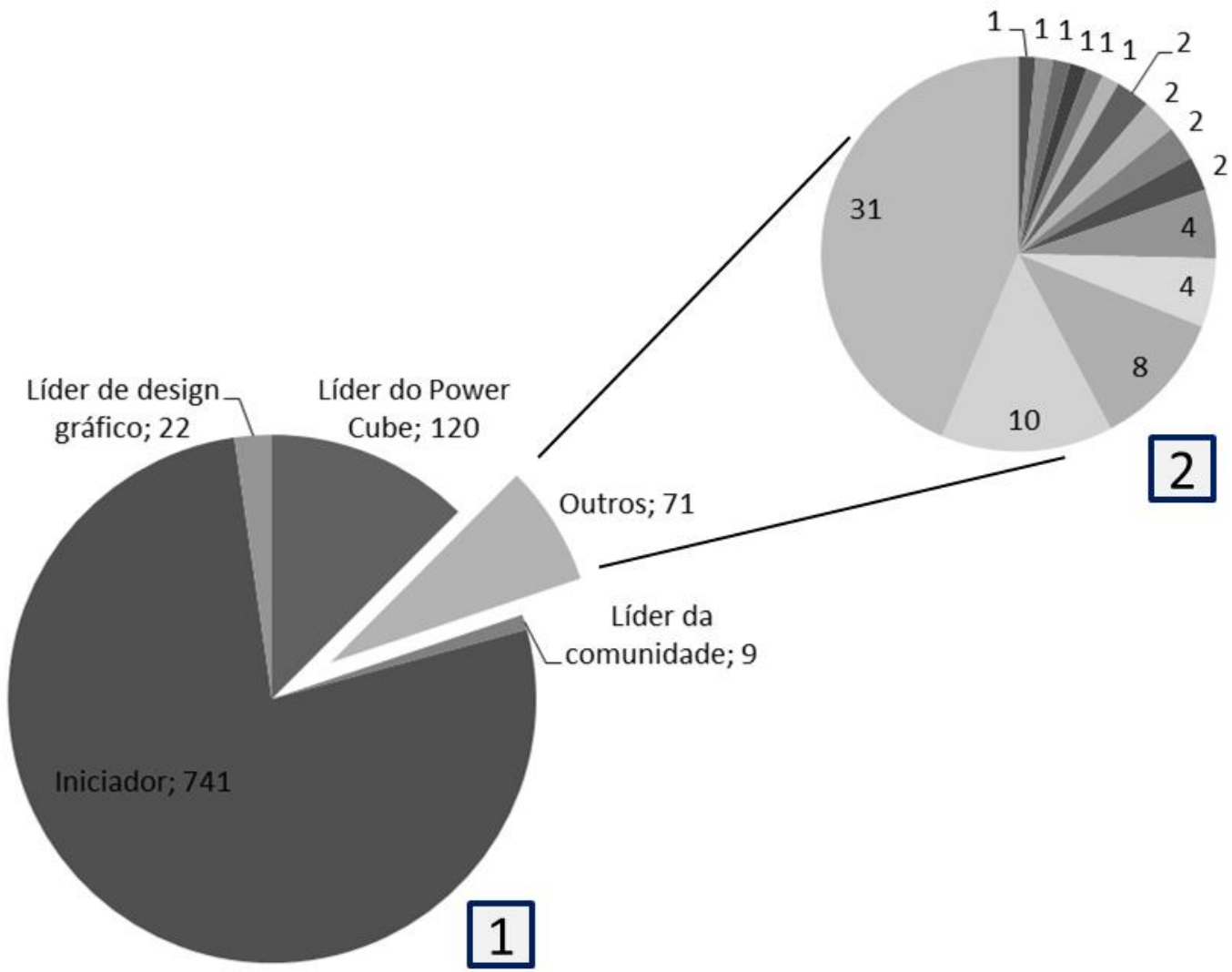

Figura 24 - Distribuição das edições dos usuários ativos na wiki (OSE, 2015a): (1) indica o número de edições dos quatro colaboradores que possuem papel de liderança, enquanto que (2) indica 0 número de contribuições dos demais colaboradores, sendo que cada fatia da pizza representa um colaborador e seu respectivo número de edições.

A dificuldade em encontrar informações relevantes na wiki, pode ter contribuído para o fato de que, fora o Marcin, nenhum dos colaboradores que tive contato durante o período de observação participante conhecia o modelo de referência da OSE. Segundo esse modelo, apresentado em detalhes na seção 3 do APÊNDICE B, o PDP da OSE possuía seis fases: (1) Pesquisa e design inicial, (2) Primeira revisão do design, (3) Refinamento do design, (4) Revisão do design, (5) Construção e documentação, e (6) Revisão do projeto. Durante o período de observação participante, os projetos com os quais tive contado se encontravam principalmente na fase de construção e documentação, de modo que foram organizados alguns workshops para incentivar a participação de mais colaboradores e acelerar a construção dos protótipos. Os workshops também eram importantes para a geração de receita para organização, já que custava aos participantes cerca de US\$300,00 por inscrição. Esses workshops foram os principais eventos do programa de verão, tanto que as demais atividades realizadas estavam relacionadas ou à preparação do próximo workshop, ou à documentação dos resultados obtidos 
no workshop anterior. Os períodos em que ocorreram os workshops para a construção dos protótipos estão indicados pela cor cinza no gráfico da Figura 23.

Devido ao fato de workshops representarem os principais eventos do programa de verão, optou-se por estruturar esta narrativa ao redor desses eventos. Assim, nas subseções a seguir são relatados os principais acontecimentos relacionados a cada workshop.

\subsubsection{CEB Press Workshop em Wisconsin}

O programa de verão havia começado duas semanas antes da minha chegada, porém, nenhum protótipo havia sido construído. A primeira prototipagem ocorreria no dia 17 de Junho, com o objetivo de construir uma CEB Press, descrita na Figura 25. Marcin havia dividido a CEB Press em módulos, e os estagiários tinham ficado responsáveis por criar instruções que ilustrassem o passo-a-passo das atividades referentes à montagem de cada módulo. O objetivo era que as instruções permitissem a qualquer pessoa com acesso aos materiais e equipamentos necessários, replicar o projeto. Com uma documentação detalhada, buscava-se diminuir a necessidade de conhecimentos técnicos ao replicar o projeto. No entanto, nesta iteração, partia-se do pressuposto que aqueles que estivessem interessados em replicar o projeto conseguiriam obter os componentes necessários para a etapa de montagem, por meio da disponibilização da lista de materiais contendo as especificações técnicas de cada componente, e do livre acesso aos arquivos CAD. 


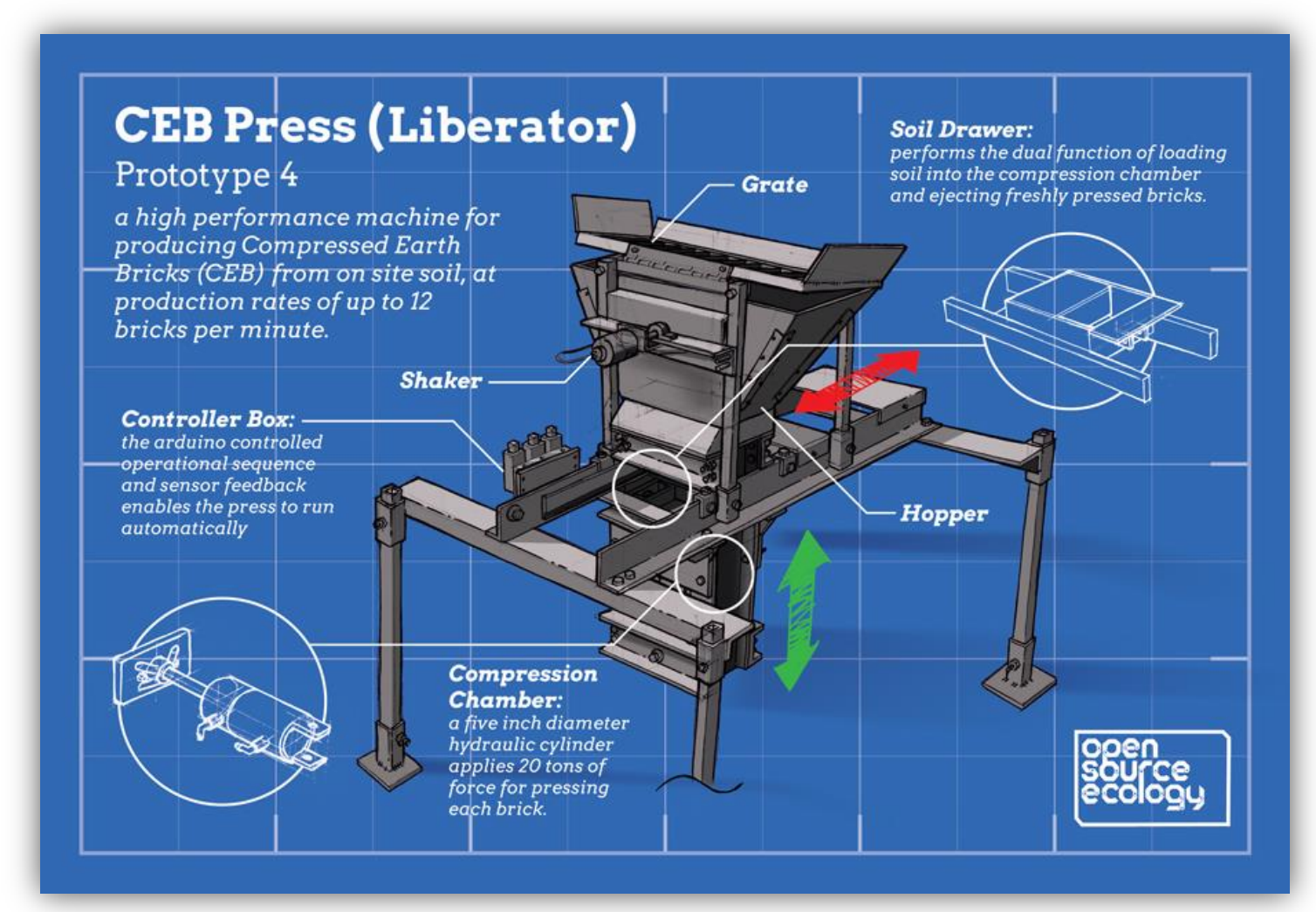

Figura 25 - Descrição da CEB Press (OSE, 2015a)

Como era o primeiro contato desses colaboradores com a CEB Press, eles haviam realizado a desmontagem e posterior montagem máquina, assim, haviam adquirido um maior aprendizado sobre o processo de montagem. Além disso, com essas atividades, eles puderam fazer o registro de alguns passos por meio de fotos e vídeos. Com esse material, mais os arquivos CAD que haviam sido produzidos por meio da ferramenta FreeCAD ${ }^{50}$, os estagiários vinham trabalhando na elaboração das instruções de montagem da CEB Press com o apoio da ferramenta Google Slides ${ }^{51}$. Além do passo-a-passo da montagem, as instruções de cada módulo deveriam conter o tempo total estimado para montagem, o nível de dificuldade, os materiais e equipamentos necessários, uma visão geral do módulo, e uma vista com as peças explodidas. A Figura 26 apresenta uma ilustração de parte das instruções elaboradas para um dos módulos da CEB Press. No ANEXO III, as instruções para construção deste módulo da CEB Press são apresentadas na integra, em um tamanho legível.

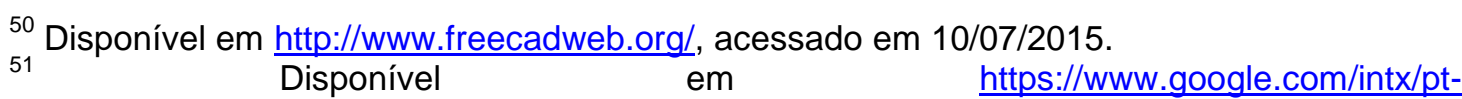
BR/work/apps/business/products/slides/?utm medium=cpc\&utm source=google\&utm campaign=lata m-br-pt-gafw-skws-all-trial-b\&utm term=\%2Bslides, acessado em 10/07/2015. 

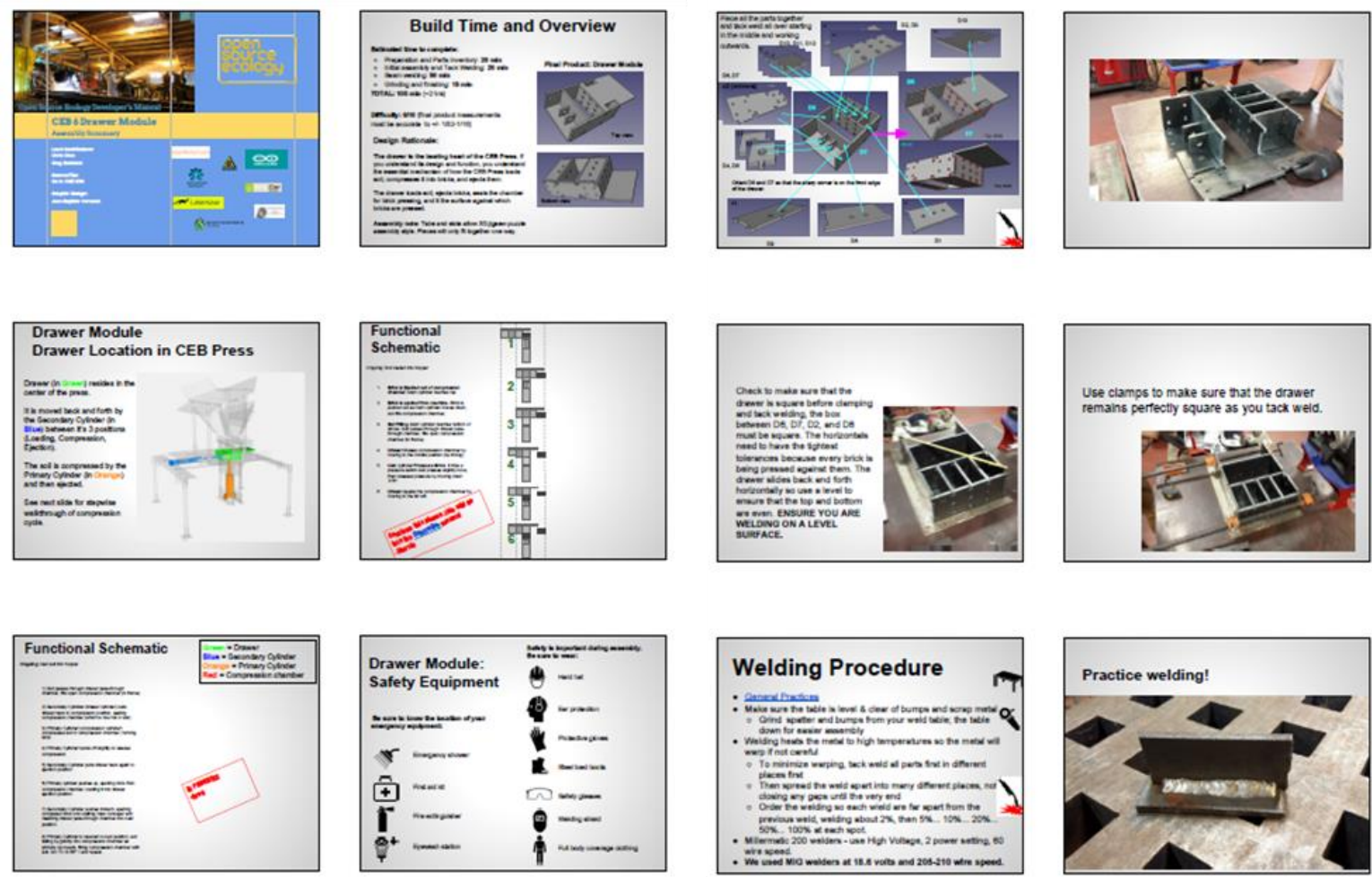

Figura 26 - llustração das instruções para a monagem de um dos módulos da CEB Press (OSE, 2015a)

Como eu havia chegado no final de semana, pude me inteirar um pouco sobre o que estava sendo feito antes de começar de fato meu estágio. Na segunda-feira, meu primeiro dia de trabalho, iniciamos o dia com uma reunião, na qual pude me apresentar oficialmente a todos os estagiários. Essas reuniões matinais serviam para o planejamento do dia de trabalho, assim como para o acompanhamento das atividades que estavam sendo feitas por cada um. Naquele dia, iríamos viajar para Wisconsin Rapids, onde realizaríamos a primeira prototipagem do programa de verão, e exporíamos a CEB Press montada em uma feira sobre energia renovável. Então, as atividades para aquele dia se concentravam em nos organizarmos para viagem. A maioria dos componentes necessários para montagem da máquina seriam levados por nós. E para garantir que não faltaria nada, tínhamos que fazer um inventário. Os componentes eram divididos em: componentes-padrão, que poderiam ser facilmente encontrados nas lojas, e peças desenvolvidas especialmente para o projeto. Como o protótipo da Torch Table ainda não estava funcionando corretamente, o serviço de corte das peças teve de ser terceirizado. Alguns componentes estavam faltando, e foi decido que eles seriam comprados, ou fabricados por nós em Wisconsin. Conforme fazíamos o inventário, íamos separando 
as peças por módulos e identificando-as de acordo com os códigos indicados nas instruções (Figura 27).

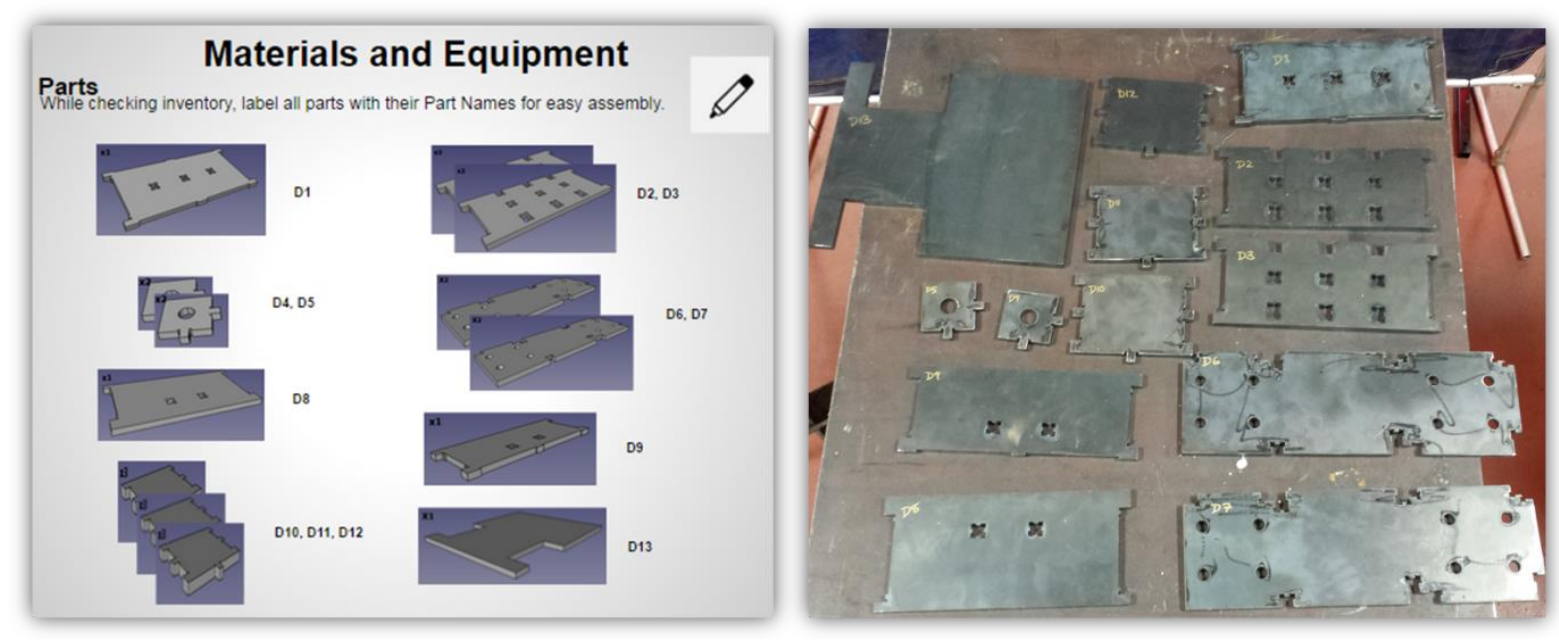

Figura 27 - Exemplo da separação das peças por módulos e identificação conforme as instruções (OSE, 2015a, 2015b)

O workshop estava sendo organizado em parceria com o Mid-State Technical College (MSTC) ${ }^{52}$, e contou com a participação de 30 pessoas, dos quais doze faziam parte da equipe da OSE, e os demais compunham um grupo diversificado de potencias usuário do produto. Macin foi o responsável por conduzir o workshop. Além dele, três instrutores do MSTC também ficaram disponíveis para auxiliar os participantes, principalmente com relação às técnicas de fabricação e montagem (soldagem, esmerilhamento, furação, etc.).

$\mathrm{Na}$ manhã do primeiro dia, nos reunimos em um auditório para uma apresentação sobre a OSE e também sobre a máquina que seria prototipada. Neste momento, os participantes foram divididos em grupos (duplas ou trios), de modo que cada grupo estava associado à montagem de um módulo específico. Um dos participantes do grupo era responsável por documentar, enquanto que os demais eram responsáveis pela construção. Quem ficasse responsável pela documentação deveria marcar o tempo de cada atividade, tirar foto do passo-a-passo, e tomar notas que pudessem auxiliar um leigo na montagem. A divisão do produto em módulos, além de facilitar o design colaborativo, facilitava também no momento da montagem, pois permitia a realização de várias atividades em paralelo.

\footnotetext{
52 Disponível em http://www.mstc.edu/news/06-23-2014-workshop-makes-compressed-earthbrick-press-scratch-one-day, acessado em 10/072015.
} 
O workshop durou três dias no total. No último dia, tínhamos conseguido montar a máquina, porém, o tempo não havia sido suficiente para conseguirmos instalar o controlador, e realizar os ajustes necessários para testarmos a CEB Press. Essas duas atividades foram realizadas nos dois dias seguintes, enquanto expúnhamos a máquina na feira. A parte dos ajustes foi a mais complicada, e a mais difícil de ser documentada. Nas instruções não havia quase nada falando sobre isso, e por isso, dependíamos muito da experiência do Marcin. Tivemos muito retrabalho nessa parte. Também desperdiçamos bastante tempo dos participantes esperando que alguns módulos ficassem prontos para poder dar continuidade na montagem da máquina. No final, ainda tivemos dificuldades para conseguirmos produzir tijolos estáveis, no entanto, a máquina estava funcionando. Essa dificuldade foi atribuída à alta humidade do solo, causada pelo clima chuvoso que estávamos enfrentando naqueles dias. Durante o workshop pude observar que surgiram algumas propostas de melhoria, tanto no design do produto, quanto na documentação das instruções de construção. A Figura 28 reúne alguns registros fotográficos desse workshop.

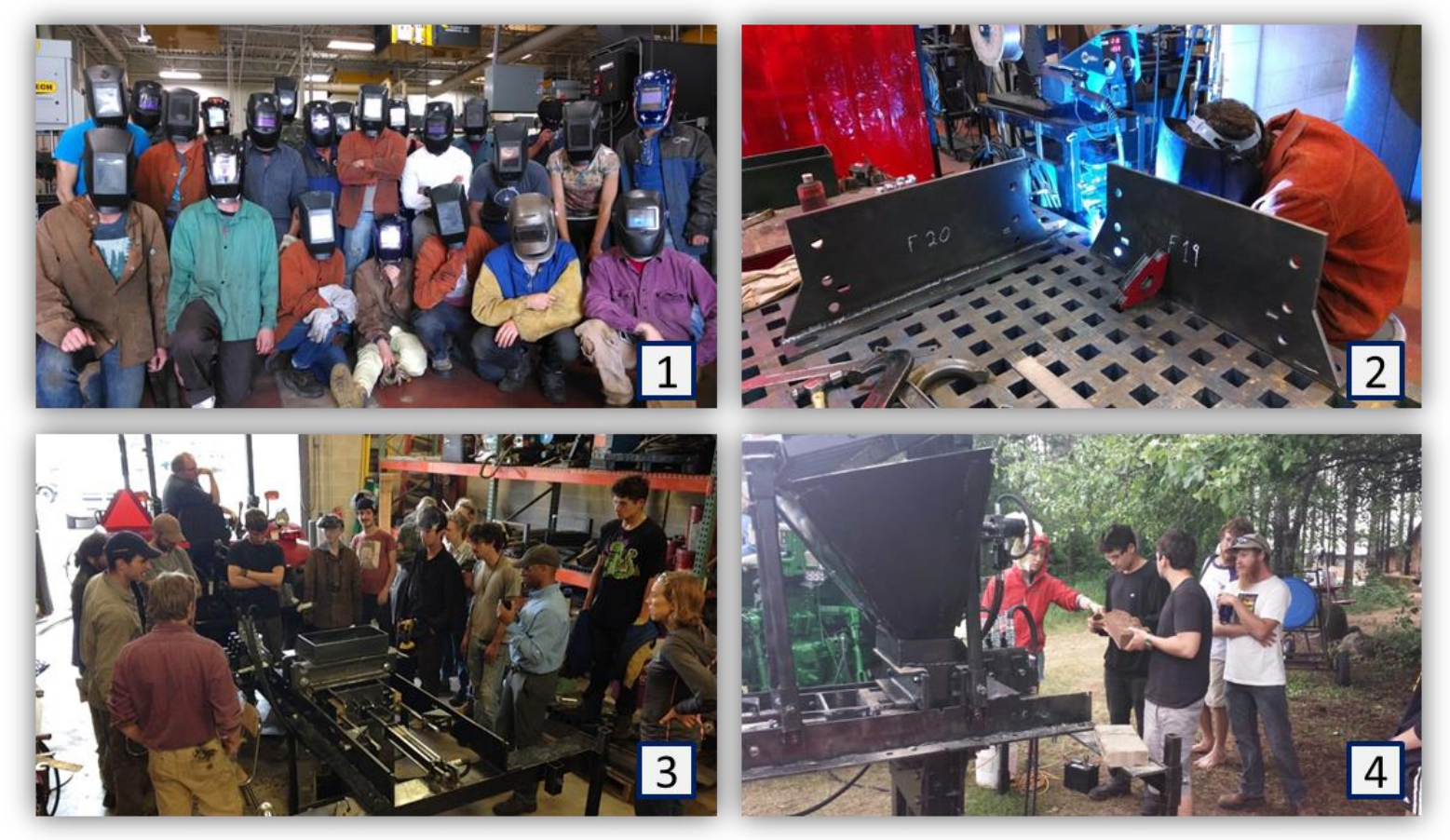

Figura 28 - Registros fotográficos do workshop da CEB Press em Wisconsin: (1) participantes reunidos; (2) montagem de um dos módulos; (3) montagem final e ajustes da máquina; (4) produção de tijolos para teste (OSE, 2015b)

De volta a FeF, trabalhamos por cerca de mais duas semana melhorando as instruções de construção da CEB Press, com base nas propostas realizadas pelos participantes. Focávamos nessa atividade no período da manhã. Durante a tarde, 
trabalhávamos melhorando a infraestrutura da FeF, pois dentro de um aproximadamente um mês receberíamos muitos colaboradores para o workshop da MicroHouse 3, e a FeF ainda não estava preparada para acomodar um grande número de pessoas. Antes do workshop da MicroHouse 3, precisaríamos construir no mínimo mais uma CEB Press e um Power Cube, pois iríamos produzir os tijolos que seriam utilizados na construção da casa.

Como todos os estagiários moravam juntos, haviam muitos momentos informais no qual conversávamos sobre o trabalho. Na noite do dia 26 de Junho, tive a oportunidade de participar de uma discussão sobre o PDP da OSE. Estávamos em quatro estagiários, um era engenheiro de computação recém-formado, e os outros dois, engenheiros mecânicos, um recém-formado, o outro no último ano da gradação. Entre nós, havia um consenso de que o processo não estava funcionando bem. Para o estudante de engenharia mecânica, o problema era que nós queríamos melhorar todo o protótipo de uma vez, e assim alteramos muitas variáveis, e não conseguimos identificar qual melhoria havia realmente funcionado. Sua opinião era de que deveríamos focar em uma variável por vez, e melhorar um ponto do protótipo de cada vez. Para o engenheiro mecânico recém-formado, o problema estava no pouco tempo que tínhamos para construir os protótipos durante os workshops, pois fazíamos as coisas às pressas e, além disso, a maioria dos envolvidos não possuía experiência alguma em desenvolvimento de produtos, fabricação e montagem. Dessa forma, não conseguimos resolver com calma os problemas que surgiam na construção dos protótipos, e assim, perdíamos a oportunidade de melhorar os produtos. O estudante de engenharia mecânica disse que deveríamos nos apoiar nas práticas utilizadas pelas indústrias, e que precisávamos melhorar nosso PDP, e coletar mais dados sobre o teste dos protótipos, por exemplo, por meio de sensores.

No dia seguinte, 29 de Junho, tivemos uma reunião durante o jantar, em que cada um deveria falar uma coisa que gostou e outra coisa que não gostou do que aconteceu na semana, incluindo questões tanto do trabalho quanto de convívio. Essa reunião era uma prática que vinha acontecendo todas as sextas-feiras na FeF. Como na minha primeira semana estávamos em Wisconsin, essa seria minha primeira reunião comunitária. Todos os estagiários estavam presentes, porém, Marcin não participou. Ele havia viajado para o Colorado para instalar a nova versão do controlador da CEB Press em um dos protótipos que havia sido vendido. O ponto mais discutido nessa reunião foi com relação ao trabalho de documentação que 
vínhamos fazendo nas instruções da CEB Press. Essa atividade estava se mostrando muito entediante, e por isso, nosso progresso era lento. Mesmo utilizando somente as manhãs dedicadas a isso, todos os estagiários estavam fartos de trabalhar nas instruções. Era uma documentação muito boa para nós usarmos, mas não considerávamos profissional o suficiente para ser divulgada. Faltava sistemática. Cada um estava trabalhando de uma forma.

Quando começamos a trabalhar na documentação da montagem final, no dia 1 de Julho, o desempenho da equipe com relação ao trabalho de documentação piorou ainda mais. Enquanto estávamos trabalhando na documentação dos módulos, sabíamos descrever o passo-a-passo da montagem, pois havíamos realizado aquelas atividades. No entanto, no momento de integrar os módulos, todos estavam com dúvida sobre o que deveria ser feito, e chegamos ao consenso de que não conseguiríamos avançar. Ao discutimos sobre as causas das dificuldades que estávamos enfrentando, um dos estagiários disse que faltava uma visão geral da máquina. Todos conheciam bem os módulos que haviam montado, porém não sabiam como proceder com montagem final. A integração dos módulos tinha se concentrado no Marcin e nenhum de nós conseguiu acompanhar todo o processo, pois alguns estavam trabalhando em algumas atividades que haviam ficado para trás, como por exemplo, o esmerilhamento de algumas peças. Além disso, não conseguimos montar toda a máquina em sequência. Parte dos ajustes havia sido realizada no último dia do workshop, e outra parte havia sido realizada na feira. $O$ fato de ter havido muito retrabalho durante a montagem final também dificultou que as pessoas memorizassem o passo-a-passo das atividades, e acabamos não conseguindo documentar a montagem final em detalhes, pois, ninguém havia ficado responsável por isso. Dessa forma, decidimos que iríamos finalizar as instruções da CEB Press somente após o próximo workshop, que ocorreria na próxima semana.

\subsubsection{Power Cube Workshop}

Antes do próximo workshop da CEB Press, foi realizado um workshop para prototipagem de um Power Cube (descrito na Figura 29). Para esse workshop não houve nenhuma preparação por parte dos estagiários. O líder de desenvolvimento do Power Cube chegou à FeF no dia anterior e trouxe consigo os componentes necessários para prototipagem. $O$ workshop teve três dias de duração e contou com 
16 participantes, dos quais 12 eram estagiários da OSE. O público alvo deste workshop era o de pessoas interessadas em desenvolver habilidades práticas de fabricação e montagem, ou como dizia o material publicitário do workshop, "people interested in transitioning from Zero to Maker". Marcin e o líder de desenvolvimento do Power Cube foram os responsáveis por conduzir o workshop.

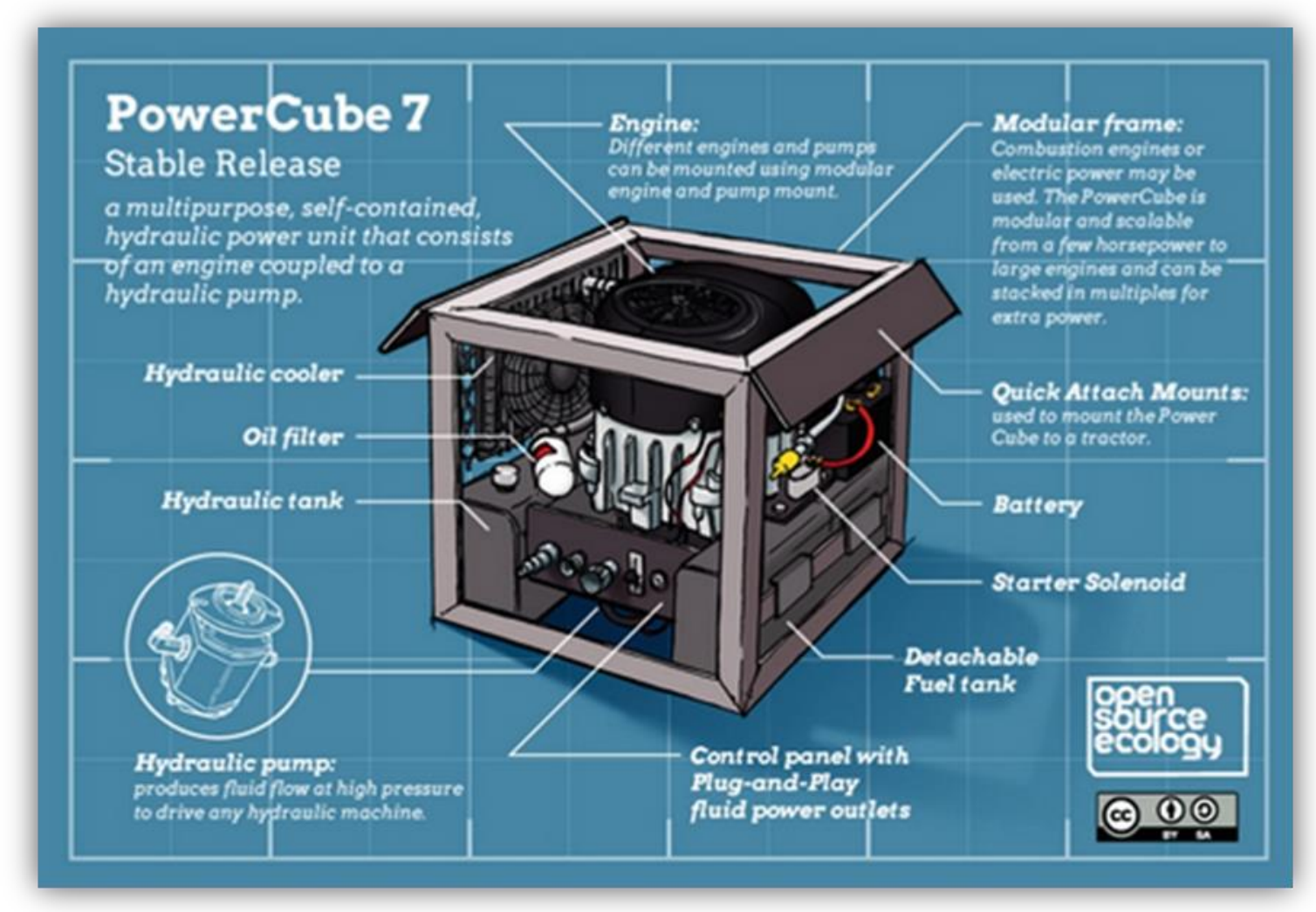

Figura 29 - Descrição do Power Cube

Na manhã do primeiro dia (4 de Julho), nos reunimos ao redor da mesa de reunião no HabLab para uma apresentação sobre a OSE e também sobre o Power Cube. Assim como no workshop anterior, os participantes foram divididos em grupos, de modo que cada grupo estava associado à montagem de um módulo específico. Um dos participantes do grupo era responsável por documentar, enquanto que os demais eram responsáveis pela construção. No entanto, neste workshop, as instruções de montagem estavam pouco detalhadas, e um dos objetivos deste workshop foi que os participantes colaborassem com a documentação (Figura 30). 


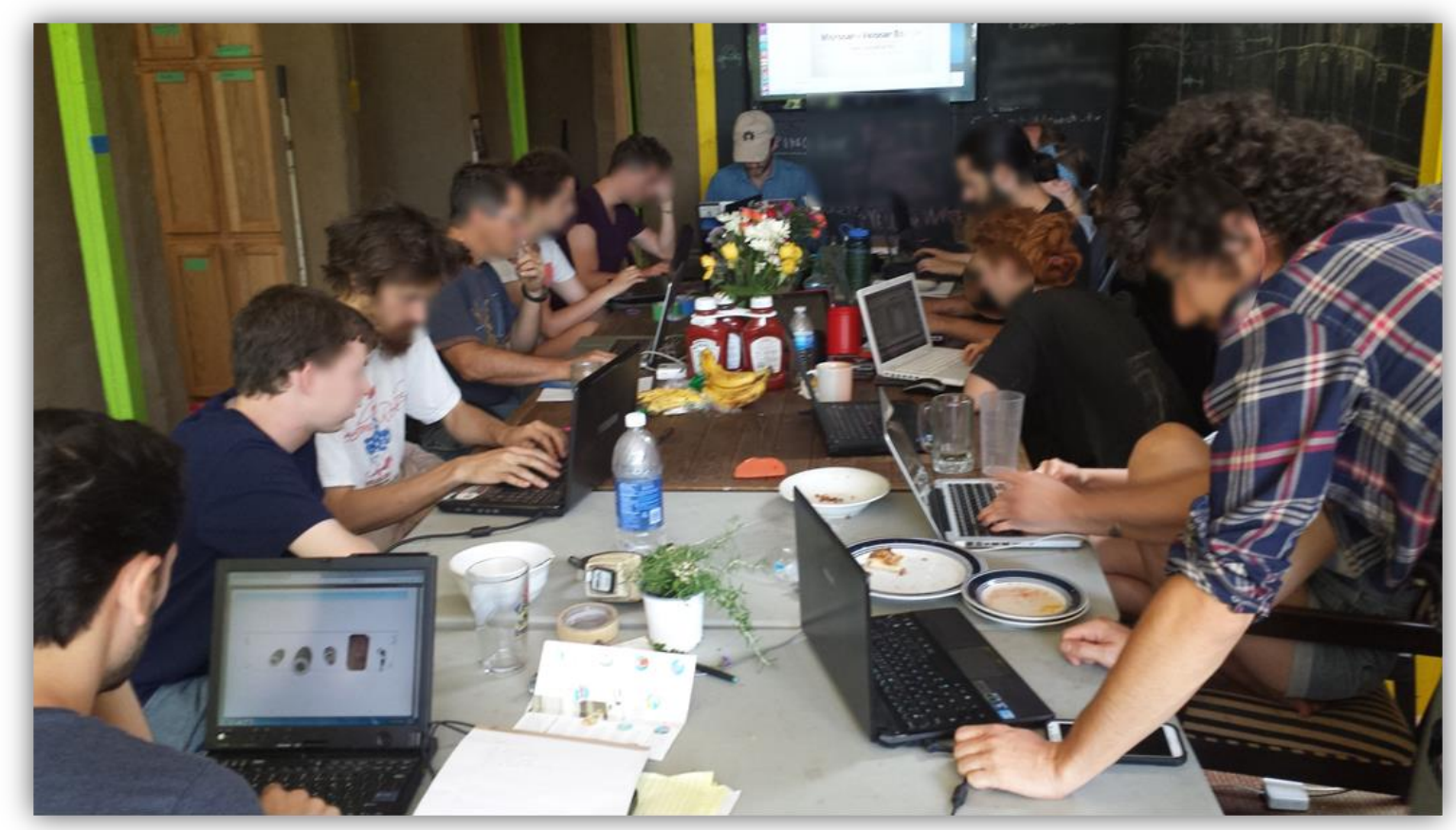

Figura 30 - Participantes trabalhando na documentação das instruções de montagem do Power Cube (OSE, 2015b)

A falta de organização e planejamento fizeram com que a montagem do Power Cube demorasse mais tempo do que o previsto, e chegamos ao final do workshop sem conseguir completar a montagem. Com as instruções incompletas, houve muitos momentos em que os participantes ficaram sem saber o que fazer. Mesmo com uma pessoa responsável por documentar a montagem, era comum que elas se distraíssem e esquecessem de documentar alguns passos. Em geral, as pessoas estão muito mais interessadas em construir do que em documentar. Além da falta de instruções, a desorganização do ambiente da oficina também contribuiu para que houvesse atraso na montagem. A Figura 31 reúne alguns registros fotográficos desse workshop. 

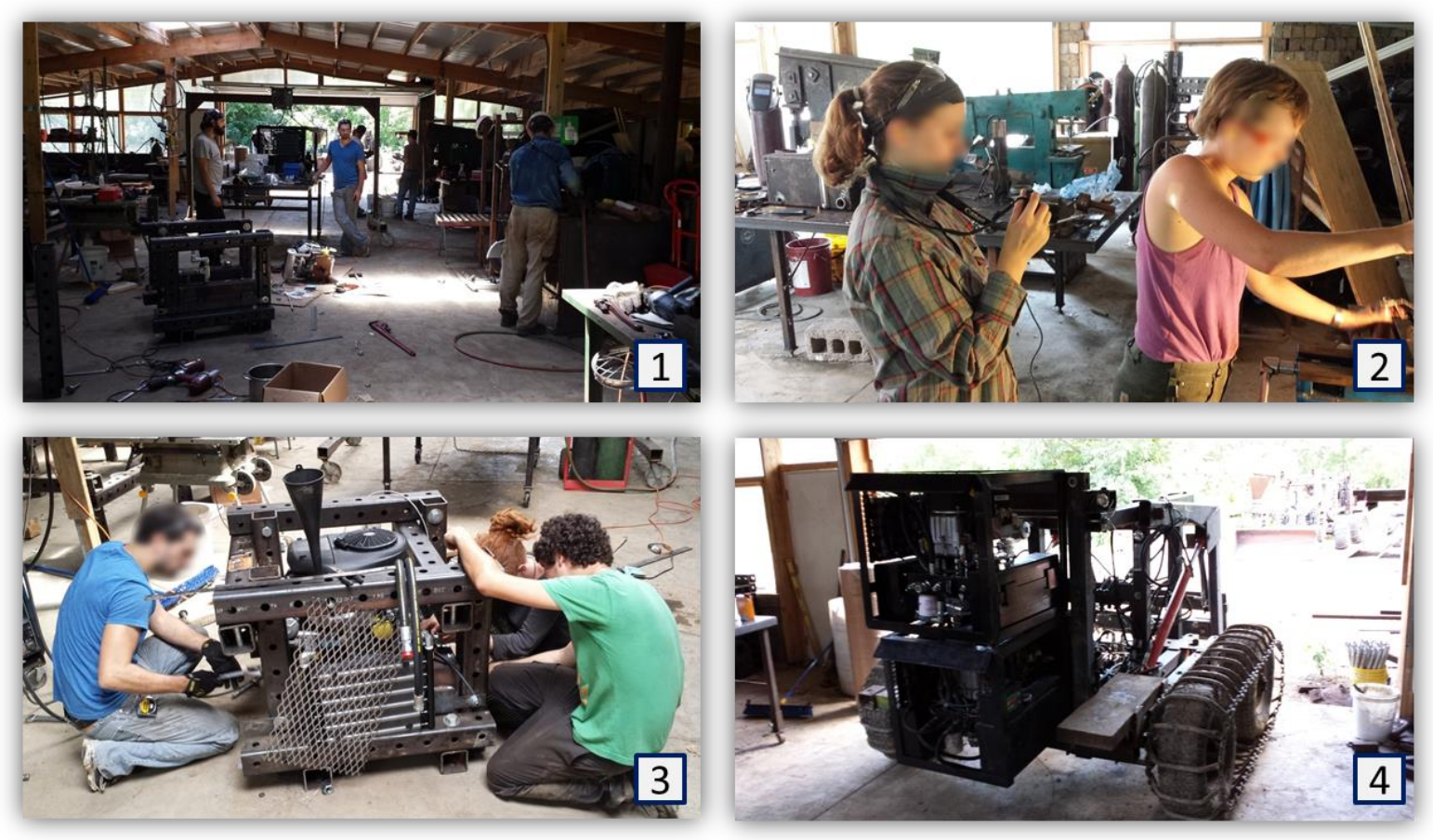

Figura 31 - Registros fotográficos do workshop do Power Cube: (1) participantes trabalhando na montagem dos módulos; (2) documentação da montagem; (3) montagem final e ajustes da máquina;

(4) teste do Power Cube no trator (adaptado de OSE, 2014)

Após a finalização da montagem do Power Cube, os estagiários seguiram trabalhando na melhoria das instruções para construção desse equipamento, em paralelo com as preparações para o segundo workshop da CEB Press. Com o material coletado durante o workshop (tempos, fotos, vídeos e anotações), foi possível adicionar muita informação às instruções, permitindo a montagem de outros dois Power Cubes durante o programa de verão. Embora não tenha conseguido participar inteiramente desses dois eventos, conversei com os estagiários que estavam responsáveis por essas montagens, e cheguei a ajudar um deles em alguns momentos. Tive a impressão de que, desta vez, o processo de montagem estava sendo muito mais eficiente. Ambas as montagens foram realizadas apenas por dois estagiários, com a ajuda de Marcin e de outros estagiários de forma pontual, além de trocarem alguns e-mails com o líder de desenvolvimento do Power Cube. Em um dos momentos que participei dessas montagens, tive a oportunidade de presenciar o primeiro teste do Power Cube, que não funcionou. A bateria estava descarregada. Trocamos a bateria, porém, ainda não funcionou. Não estávamos conseguindo dar partida no motor, e após algumas inspeções, identificamos que havia um problema na instalação dos fios. Motivado por este incidente, Marcin montou um roteiro para inspeção do Power Cube, para que fosse possível identificar 
a causa dos problemas, caso o Power Cube não esteja funcionando. A cada prototipagem, foram realizadas melhorias pontuais no design do Power Cube.

Passado este workshop, voltei minha atenção para o workshop da CEB Press, que ocorreria dentro de alguns dias na FeF.

\subsubsection{CEB Press Workshop na Factor e Farm}

A falta de organização da montagem final no workshop de Wisconsin me motivou a fazer um planejamento mais detalhado para este workshop, de modo a identificar a dependência entre as atividades e tempo estimado de cada atividade. Com a ajuda de outros dois estagiários, propus uma divisão para o projeto do workshop em cinco fases: Treinamento, incluindo noções básicas de segurança e práticas de fabricação, assim como uma visão geral da máquina; Pré-Montagem, englobando todas as atividades de fabricação que deveriam preceder a montagem dos módulos; Montagem dos Módulos; Integração dos Módulos, ou montagem final; e Teste. Baseado no workshop anterior, e com a ajuda de Marcin, montei um planejamento do projeto no MS Project, e após trabalhar em cima do caminho crítico, consegui reduzir o tempo do workshop para aproximadamente $10 \mathrm{~h}$ de duração, com uma equipe de sete colaboradores. Neste caso, não estava considerando o tempo gasto na fase de treinamento, já que todos os participantes desse workshop já haviam participado do workshop em Wisconsin, e estavam familiarizados com as práticas de oficina e com o projeto da máquina.

Trabalhei também na criação de alguns templates para as instruções de montagem das máquinas do GVCS, visando à padronização das documentações. A Figura 32, Figura 33 e Figura 34 apresentam três exemplos de parte dos templates elaborados para as instruções. Antes do workshop, conseguimos aplicar esse template em boa parte da documentação. 


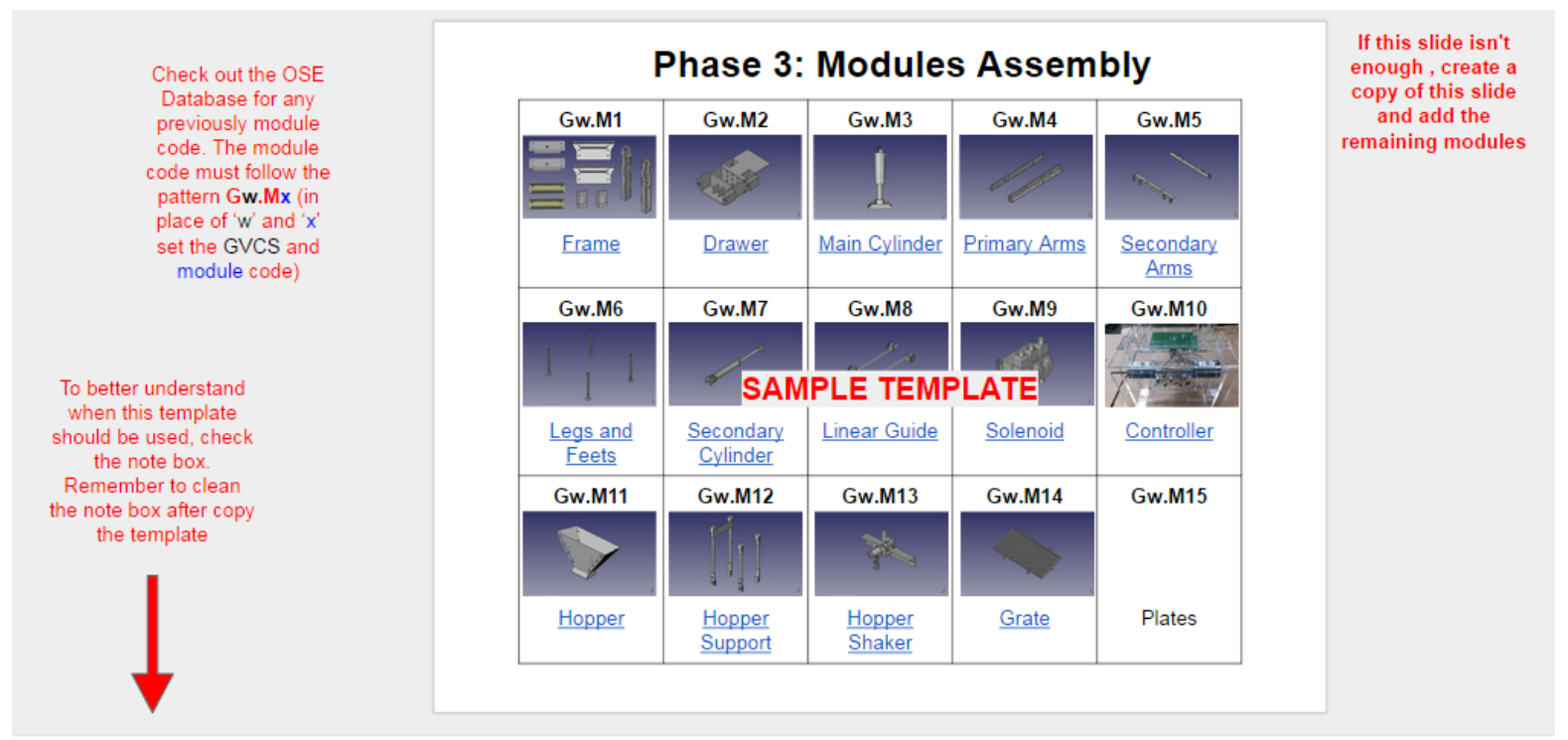

Click to add notes

Figura 32 - Template para elaboração de um índice para os módulos da máquina (OSE, 2015a)

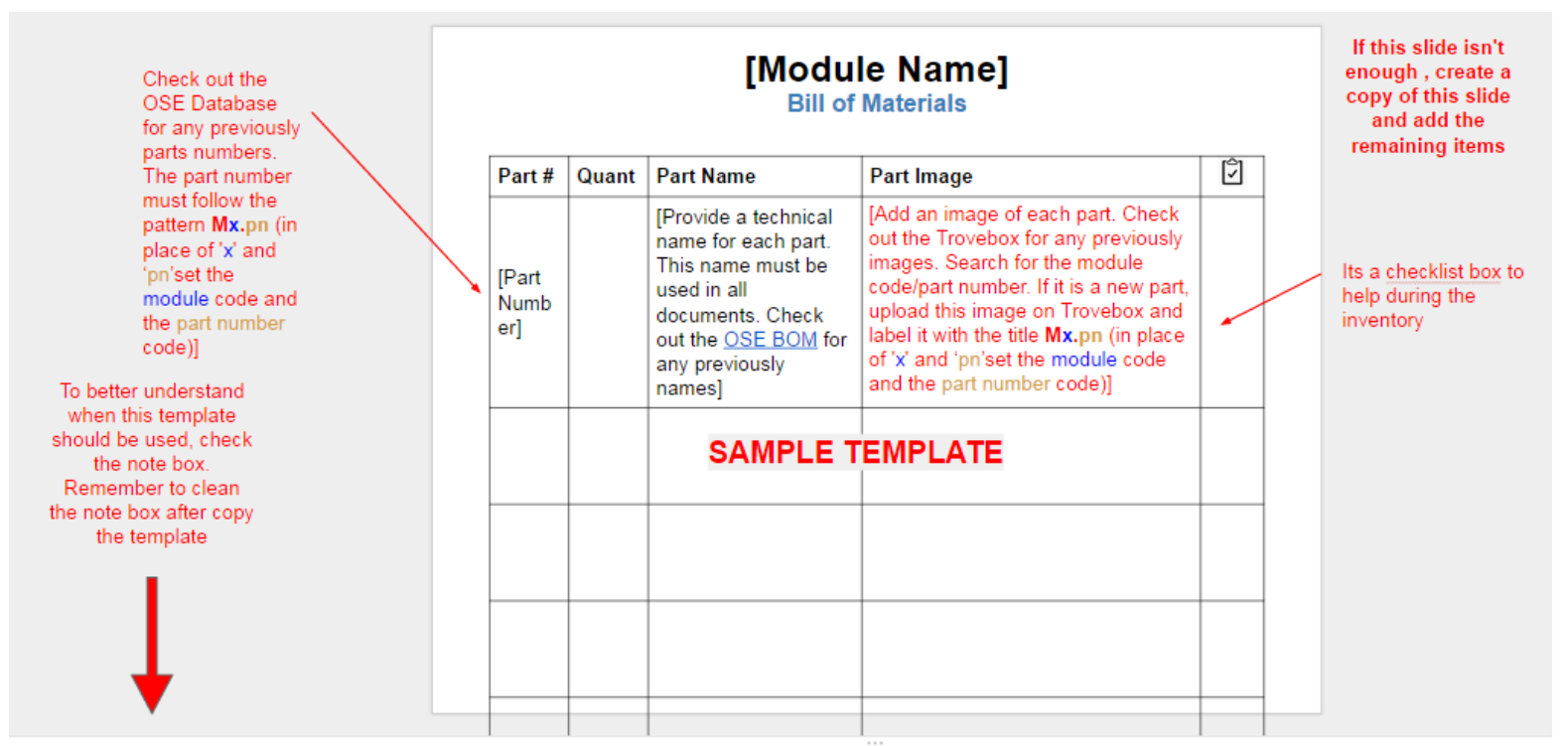

Click to add notes

Figura 33 - Template para elaboração da lista de matérias de um dos módulos da máquina (OSE, 2015a) 


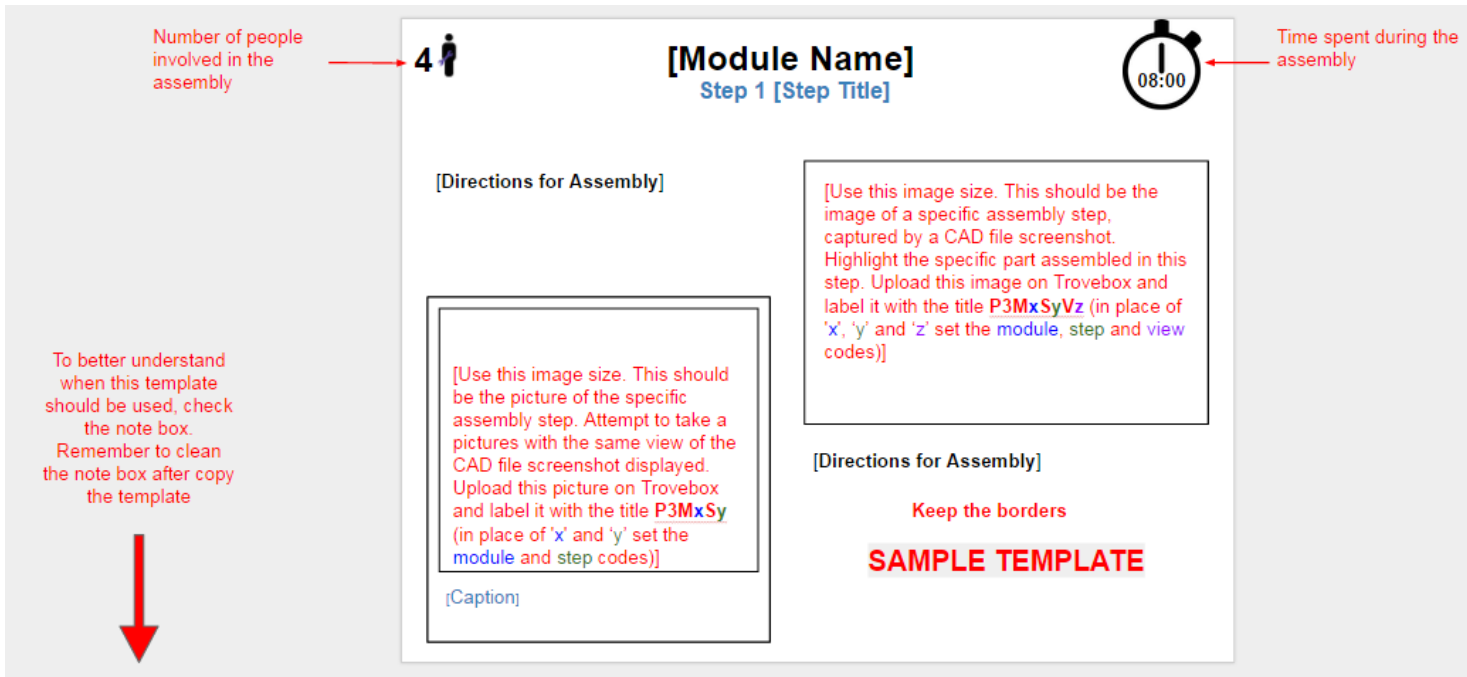

Use this template if the assembly step is simple and well defined. If the assembly step is complex and requires a well detailed explanation, use the template of the next slide and define some sub steps

Figura 34 - Template para descrição do passo-a-passo de um dos módulos da máquina (OSE, 2015a)

A desorganização da oficina durante o workshop do Power Cube nos motivou a organizar antecipadamente bancadas e as ferramentas que seriam utilizadas neste workshop. Porém, tivemos um atraso de dois dias no recebimento das peças, e com outras atividades acontecendo em paralelo, como as preparações para os workshops do MicroCar e da MicroHouse 3, no momento que iniciamos o workshop da CEB Press a oficina já estava desorganizada outra vez.

Começamos o workshop no dia 11 de Julho, no período da tarde, logo após recebermos as peças cortadas dos fornecedores. Era uma sexta-feira, e havíamos decidido tirar o final de semana de folga. Desse modo, não foi possível a realização de um workshop intensivo. Tivemos outros problemas, como a falta de algumas ferramentas durante a montagem e número reduzido de bancadas e estações de soldagem. $O$ cronograma que havia sido planejado também não foi inteiramente cumprido. Alguns colaboradores trabalharam em atividades que não haviam sido planejadas para eles e, além disso, a estimativa de tempo de algumas atividades não correspondia à realidade. Mais uma vez, não havíamos conseguido terminar a montagem dentro do prazo planejado. No entanto, havíamos sido mais eficientes que no workshop anterior, pois dessa vez tínhamos trabalhado com uma equipe menor. O planejamento do projeto, mesmo não sendo cumprido à risca, ajudou a diminuir o tempo de espera pela conclusão de alguns módulos no momento da montagem final. Neste workshop, também conseguimos prototipar algumas melhorias no design da CEB Press. No entanto, não foi realizado nenhum teste de 
forma sistemática para identificar se as melhorias prototipadas eram de fato melhorias. A Figura 35 apresenta um registro fotográfico desse workshop que ilustra como as atividades foram conduzidas nesse workshop.

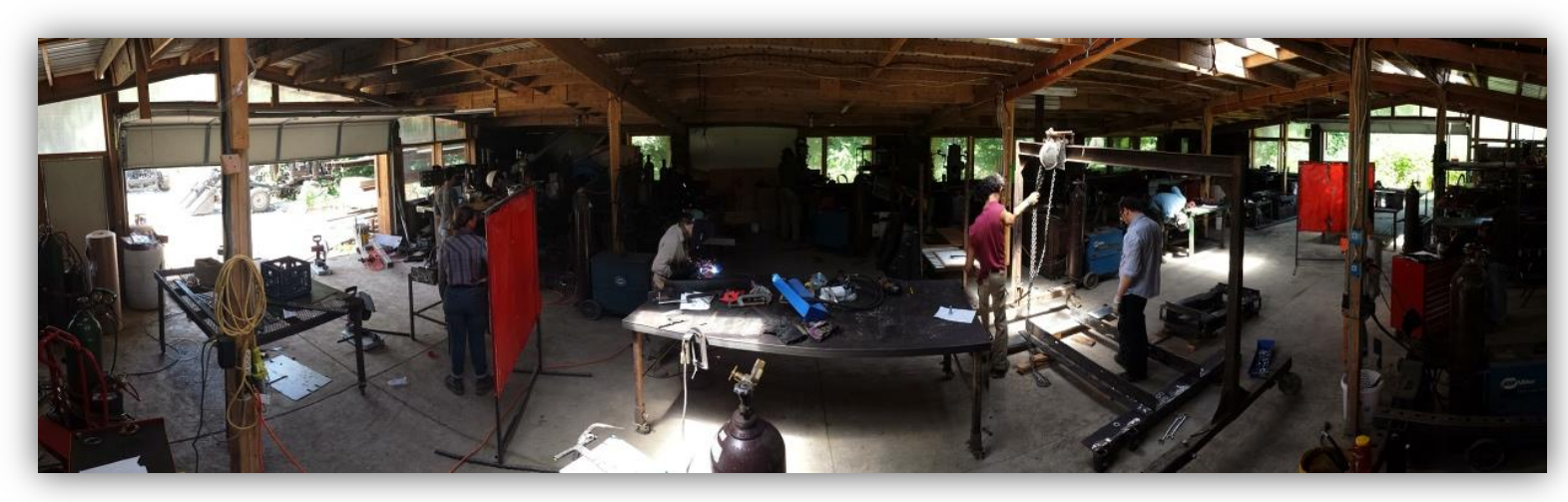

Figura 35 - Registro fotográfico do workshop da CEB Press na FeF, em que mostra os participantes trabalhando na montagem dos módulos e se preparando para montagem final da máquina (OSE, 2015b)

Após a montagem da máquina, produzimos alguns tijolos para a realização de alguns testes. Utilizamos um Google Form que estava disponível na wiki para documentar os resultados dos testes. Porém, este formulário estava confuso, e possuía somente alguns campos para serem completados com informações referentes à dimensão dos tijolos. Não havia muitas informações sobre como executar os testes. Dessa forma, não sabíamos o que tínhamos que fazer com o solo antes de comprimir os tijolos. Coletamos alguns dados a pedidos de Marcin, porém não chegamos a analisá-los.

Até o momento, somente havíamos trabalhado com a CEB Press no modo manual. $O$ código computacional para 0 modo automático estava sendo desenvolvido, e precisávamos dele o quanto antes para iniciar a produção dos tijolos que seriam usados na construção da MicroHouse 3. Porém, antes do workshop da MicroHouse 3, ainda teríamos o workshop para a prototipagem do MicroCar.

\subsubsection{MicroCar Workshop}

O MicroCar consiste em uma parceria entre a OSE e o projeto velocar.cc, liderado por um engenheiro mecânico francês. Ele já vinha trabalhando no projeto há mais de um ano, e para documentação, estava utilizando uma plataforma de 
colaboração open source chamada Rizzoma ${ }^{53}$. A maior parte do projeto havia sido realizada pelo próprio líder de desenvolvimento, com alguns colaboradores ajudando em questões pontuais, e algumas atividades sendo terceirizadas. Esse workshop seria o primeiro protótipo funcional do MicroCar, descrito na Figura 36. Esse seria um protótipo parcial, contendo apenas alguns módulos do MicroCar. Até então, o único protótipo físico que ele havia construído fora um mockup feito de neve, mas só ele teve contato.

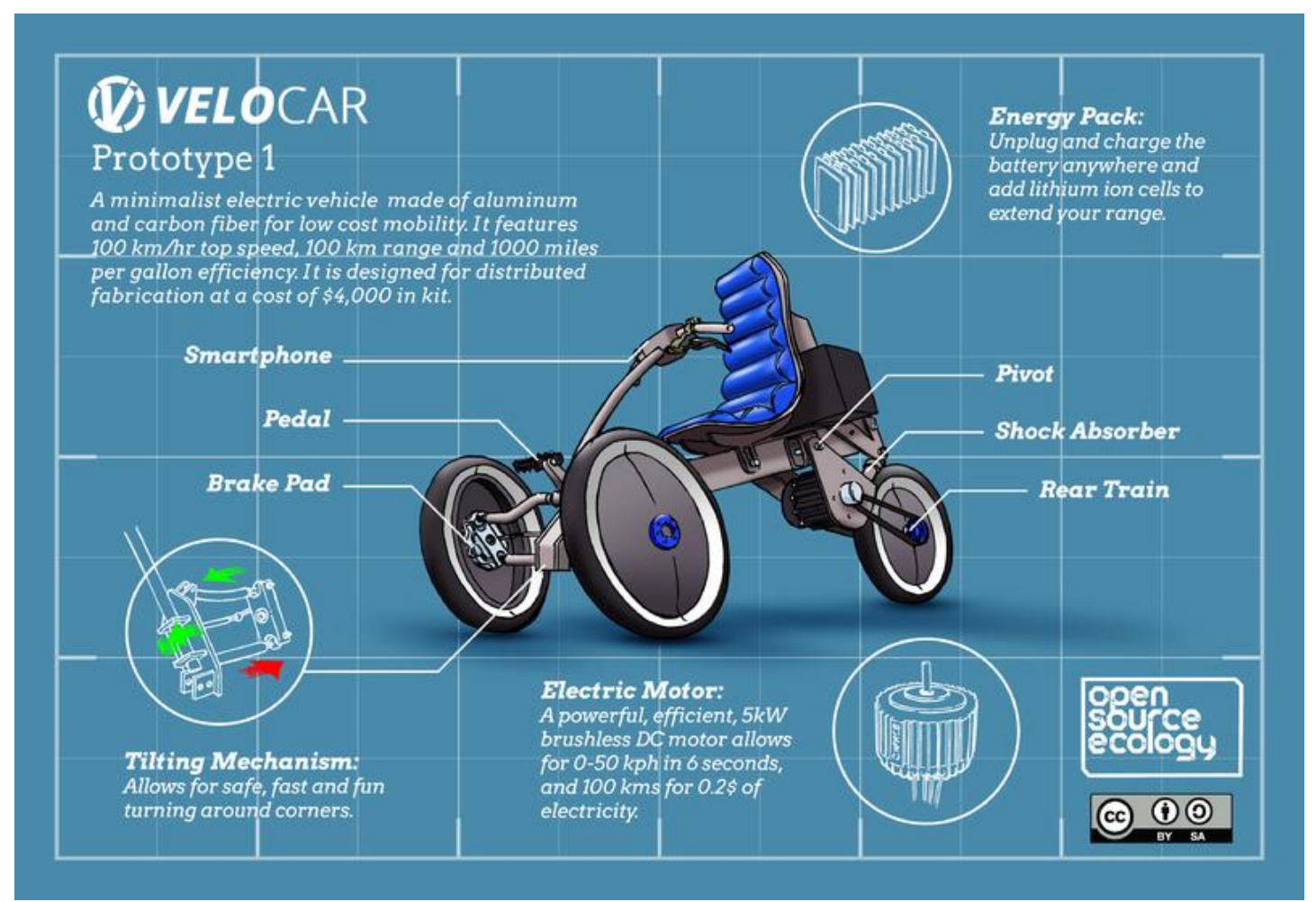

Figura 36 - Descrição do MicroCar (OSE, 2015a)

O líder de desenvolvimento do MicroCar havia chegado na FeF no dia 3 de Julho, cerca de um mês antes do workshop. O design do MicroCar estava quase completo, porém, o projeto havia sido feito com foco no mercado Europeu, e todos os componentes utilizados estavam baseadas no sistema métrico. No entanto, nos Estados Unidos o sistema de medição mais utilizado é o sistema imperial, e alguns componentes baseados no sistema métrico são de difícil acesso. Por esse motivo, o líder de desenvolvimento teve que dedicar a maior parte do tempo que precedeu 0 workshop, procurando por fornecedores e adaptando o design do MicroCar para o sistema imperial, para que tivéssemos todos os componentes necessários para a 
montagem do MicroCar no dia do workshop. Nesse período, ele também contou com a ajuda de um colaborador que havia se deslocado até a FeF para trabalhar durante uma semana exclusivamente no projeto do MicroCar.

Parte das peças seriam fabricadas na oficina da FeF e, para isso, precisávamos de uma CNC router. Marcin tinha ficado responsável por disponibilizar essa máquina para que o líder de desenvolvimento pudesse fabricar as peças. Porém, a máquina chegou apenas no dia 28 de Julho, três dias antes do workshop começar. Quando a CNC router chegou, eu e mais outros três estagiários nos juntamos ao líder de desenvolvimento para uma sprint final com o objetivo de finalizar os preparativos para o workshop. Eu fiquei responsável por fazer o inventário das peças e ferramentas necessárias para a prototipagem do MicroCar, enquanto o líder de desenvolvimento e os outros dois estagiários trabalhavam para finalizar os últimos detalhes do design, permitindo, assim, a fabricação de algumas peças.

Ao fazer o inventário das peças, identifiquei alguns componentes que estavam faltando, e também, alguns componentes que havíamos pedido em dobro. Tudo isso, por falta de uma sistemática na realização dos pedidos. Como não tínhamos ninguém responsável pelo recebimento de material, haviam peças e ferramentas que seriam usadas na prototipagem do MicroCar espalhadas pela FeF, e ninguém havia conferido se os pedidos recebidos estavam corretos, dificultando a realização do inventário. Quando assumi a responsabilidade pelo inventário, criei uma planilha com a lista de materiais do MicroCar, e agrupei os componentes em kits, de acordo com os subsistemas do carro. Desse modo, foi mais simples fazer o controle do recebimento das peças, identificar sua localização no nosso estoque, e saber quais peças ainda precisávamos comprar ou fabricar. Uma funcionalidade na plataforma de colaboração deste projeto permitia um fluxo de informação baseado no modelo de "inscrição e publicação", e me auxiliou na identificação das alterações no projeto que estavam sendo feitas pelo líder de desenvolvimento enquanto eu realizava o inventário das peças. A Figura 37 apresenta parte da lista de materiais utilizada no inventário dos componentes do MicroCar para este workshop. 


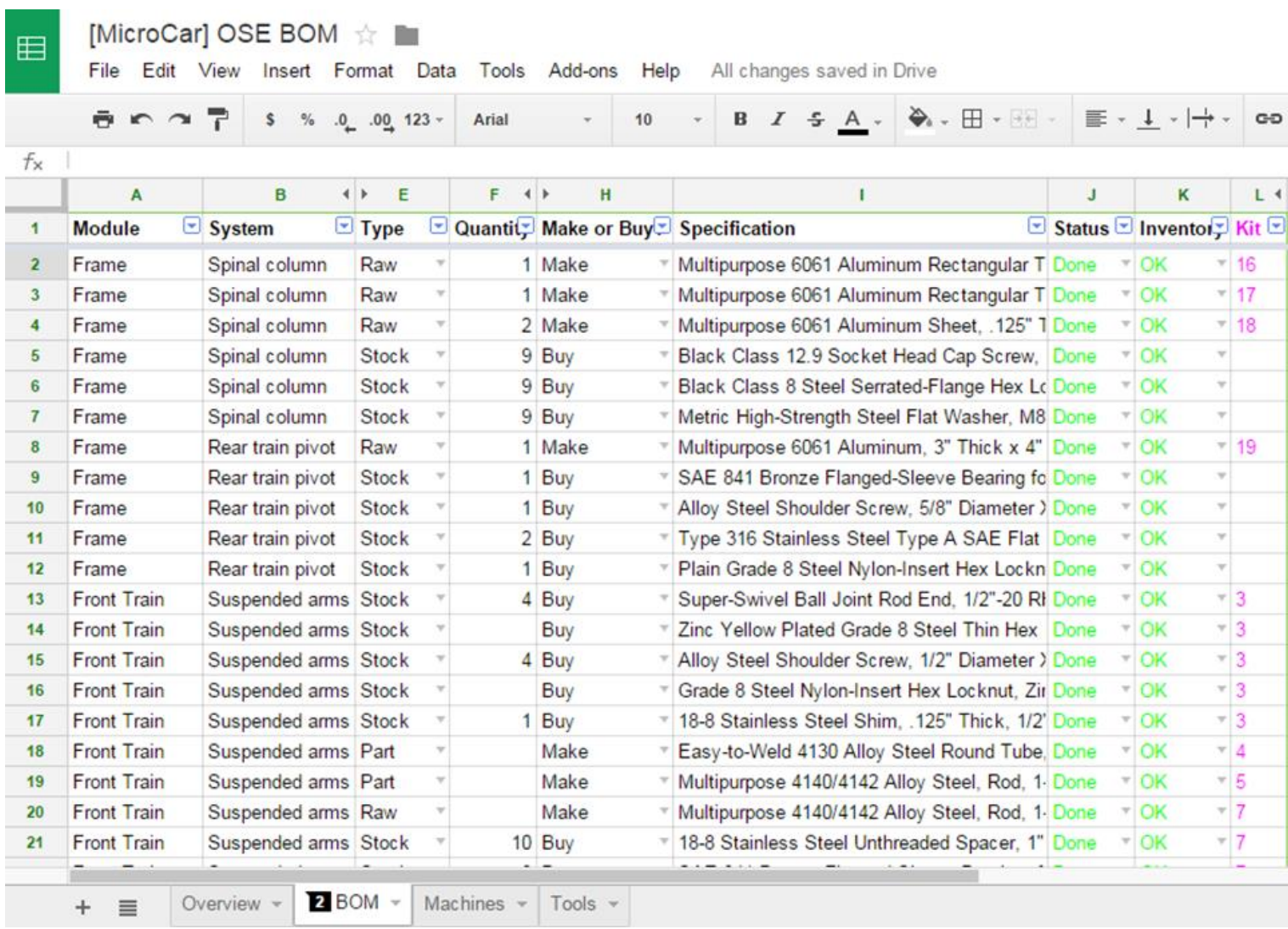

Figura 37 - Parte da lista de materiais utilizadas no inventário para o workshop do MicroCar (OSE, 2015a)

O líder de desenvolvimento do MicroCar e os outros três estagiários também tiveram bastante dificuldade na fabricação das peças. Era a primeira vez que eles estavam tendo contato com aquela CNC router, e também era a primeira vez que estavam prototipando aquelas peças. Assim, a falta de habilidade em operar a máquina, somados a falta de conhecimento sobre os parâmetros de usinagem mais adequados, fizeram com que atrasássemos ainda mais o andamento do projeto. Mesmo passando algumas noites em claro, não conseguimos deixar tudo preparado para o workshop.

O workshop teve início no dia 1 de Agosto e durou apenas três dias. Com todos os problemas que o líder de desenvolvimento havia enfrentado na preparação para esse workshop, ele não havia dedicado tempo para divulgação, e Marcin, assim como os outros estagiários, estavam ocupados com as preparações para o workshop da MicroHouse 3. Com pouca divulgação, tivemos somente quatro participantes nesse workshop, que assim como no workshop do Power Cube, estavam interessados em uma experiência "Zero to Maker". A equipe que havia participado na preparação do workshop, estava exausta e desmotivada, principalmente o líder de desenvolvimento. Sabíamos que não seria possível 
construir o protótipo completo do MicroCar, então, nos concentramos em prototipar as rodas, que eram feitas de fibra de carbono, e o sistema de baterias elétricas. Tivemos sucesso com o protótipo das rodas, porém, o protótipo das baterias não funcionou. A Figura 38 reúne alguns registros fotográficos desse workshop.

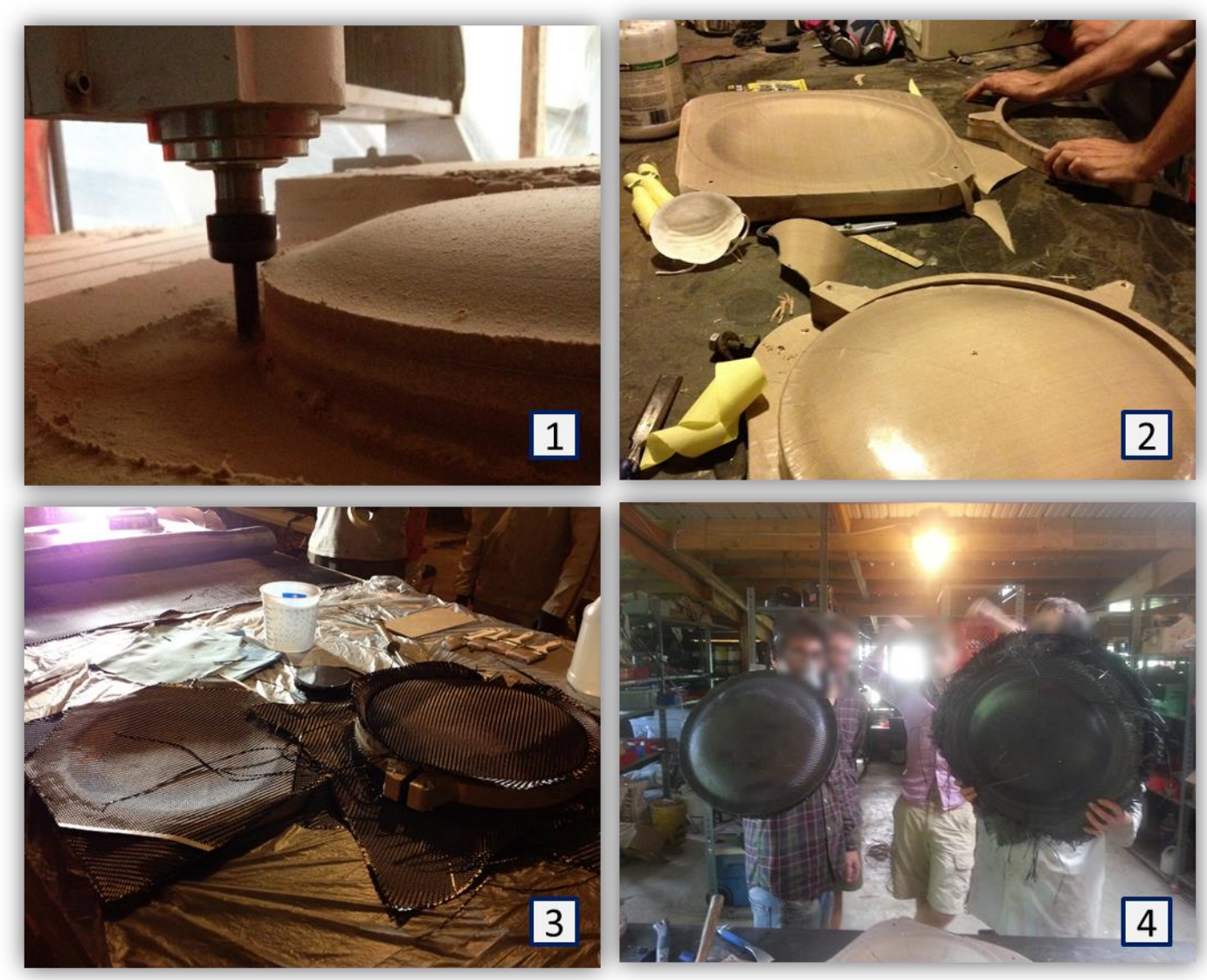

Figura 38 - Registros fotográficos do workshop do MicroCar: (1) usinagem dos moldes da roda; (2) preparação dos moldes; (3) prototipagem das rodas; e (4) apresentação do protótipo das rodas (acabada na esquerda e com rebarbas na direita) (OSE, 2015b)

Assim que terminou o workshop da MicroCar, o líder de desenvolvimento retornou para França e não trabalhamos mais nesse projeto durante o verão. Após esse workshop, toda a equipe de estagiários se dedicou exclusivamente nos preparativos do workshop da MicroHouse 3.

\subsubsection{MicroHouse 3 Workshop}

Este workshop estava sendo realizado em parceria com um arquiteto americano, que já havia colaborado com a OSE durante o workshop da MicroHouse 2. Ele tinha experiência em construção civil, e já tinha trabalhado em algumas obras em Kansas City. No entanto, esta seria a primeira vez que ele seria responsável por 
um projeto do início ao fim, contemplando o design, planejamento e execução da obra.

O líder de desenvolvimento da MicroHouse 3 havia chegado na FeF no dia 23 de Junho, e até o início do workshop, previsto para a segunda semana de Julho, ele deveria terminar o design da casa, comprar o material necessário para a construção do protótipo, elaborar as instruções para a construção, e planejar as atividades do workshop. Enquanto isso, Marcin deveria trabalhar na divulgação deste evento, nivelar o terreno, preparar a fundação da casa, instalar uma fossa séptica, e produzir em torno de 5.000 tijolos que seriam usados na construção. Como havíamos atrasado com a montagem da CEB Press, e depois com a programação do código computacional responsável pelo funcionamento da CEB Press no modo automático, somados a um período de fortes chuvas que impediam o trabalho de campo, 0 workshop da MicroHouse 3 foi adiado para iniciar no dia 8 de Agosto.

No dia 6 de Agosto, a dois dias do workshop, as instruções para a construção dos módulos da MicroHouse 3 ainda não estavam prontas. Por isso, organizamos uma reunião em que todos os estagiários iriam ajudar na elaboração dessas instruções. No entanto, após cerca de 30 minutos tentando explicar como deveríamos elaborar essa documentação, o líder de desenvolvimento desistiu de tentar fazer essa atividade em grupo. Quase ninguém tinha experiência com o software que ele estava utilizando no design da MicroHouse 3, o SketchUp ${ }^{54}$, e o pessoal não estava conseguindo acompanhar a explicação. Além disso, não sabíamos como os módulos deveriam ser montados, pois nenhum de nós havia participado do design. Diferentemente dos workshops anteriores, o líder de desenvolvimento da MicroHouse 3 não estava utilizando o Google Slides para preparar as instruções. Dessa vez, as instruções estavam sendo elaboradas diretamente no Dozuk $^{55}$, um aplicativo web que auxiliava na criação de documentações. A Figura 39 apresenta um exemplo de parte das instruções elaboradas para um dos módulos da MicroHouse 3.

No dia seguinte, véspera do workshop, ainda tínhamos bastante trabalho para fazer, no entanto líder de desenvolvimento conseguiu motivar bastante os estagiários, de modo que no final do dia, surpreendentemente havíamos conseguido nos preparar para o workshop. Como não haviam outros projetos sendo executados

\footnotetext{
${ }^{54}$ Disponível em http://www.sketchup.com/pt-BR, acessado em 06/06/2015.

${ }^{55}$ Disponível em http://www.dozuki.com/, acessado em 06/06/2015.
} 
em paralelo, e o pessoal já estava ambientado com as práticas de oficina, e com a localização dos materiais em nosso estoque, conseguimos ser mais produtivos do que na preparação dos workshops anteriores. Nesse dia, não houve muita delegação de tarefas. Cada um trabalhou no que estava com vontade, e nas tarefas que sabiam fazer, de modo que todos puderam contribuir de alguma forma.

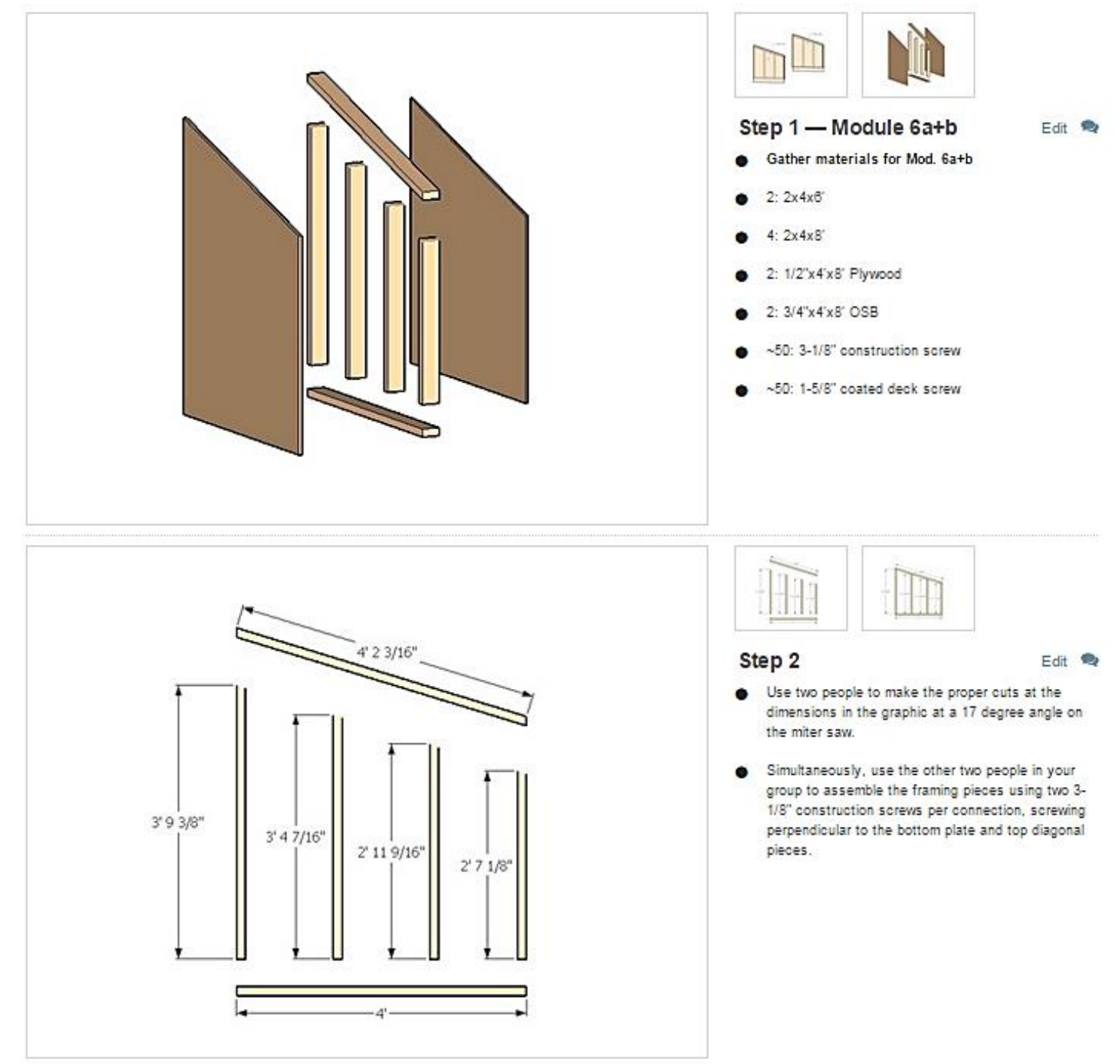

Figura 39 - Exemplo de parte das instruções elaboradas para um dos módulos da MicroHouse 3 (OSE, 2015c)

Para esse workshop estávamos esperado em torno de 60 colaboradores, considerando os 19 estagiários que estavam trabalhando na FeF naquele período, além do líder de desenvolvimento da MicroHouse 3, Martin e o responsável pela hospitalidade. Para acomodar todo esse pessoal, tivemos que trabalhar na construção de um novo banheiro, de uma área externa para nos reunirmos para as reuniões e refeições (piso, cobertura, mesas e bancos), e também na instalação de 
sinalizações, de uma cobertura na área onde a casa seria construída, e outra cobertura onde ficariam armazenados os materiais para o workshop.

No entardecer do dia 07 de Agosto, muitas pessoas já haviam chegado para o workshop, e conforme estava planejado, havíamos preparado uma recepção para eles. Marcin, como de costume, apresentou a OSE, e líder de desenvolvimento da MicroHouse 3 falou sobre como funcionaria a dinâmica do workshop, e também apresentou o projeto, com o auxílio do SketchUp e do Dozuki. Depois da apresentação, ele recebeu elogios de carpinteiros profissionais, dizendo que com a documentação desse jeito, até mesmo uma pessoa que nunca havia construído uma casa poderia fazê-la. Neste workshop, cerca de um terço dos participantes tinham experiência em construção de casas.

O workshop teve cinco dias de duração. No entanto, como não havíamos conseguido produzir todos os tijolos que precisávamos antes do workshop, nos dois primeiros dias do evento, metade dos participantes ficaram trabalhando na produção de cerca de 2500 tijolos, enquanto que a outra metade dos participantes trabalhava na construção dos módulos de madeiramento. Tanto para a pulverização do solo utilizado na produção dos tijolos, quanto para a movimentação das madeiras, estávamos utilizando os protótipos do trator do GVCS, o LifeTrac 4 e o LifeTrack 6 (quarto e sexto protótipos). Ambos os protótipos quebraram mais de uma vez durante o workshop, assim como vinha acontecendo com frequência ao longo do programa de verão. Em um dos incidentes, uma corrente de metal instalada no LifeTrac 6 quebrou, e espalhou estilhaços por todo lado. Por sorte, alguns estagiários haviam acabado de instalar uma placa de alumínio nas costas do motorista, o que preveniu um acidente mais grave. Em outro incidente, uma mangueira de um dos Power Cubes, que estava sem a capa protetora, estourou, e deu um banho de óleo em um estagiário. Por sorte o motor estava funcionando há pouco tempo, e a pressão do líquido não estava tão alta. Essas foram as duas falhas mais severas observadas nos protótipos. A ocorrência de falhas menos severas eram mais frequentes, por exemplo, o eixo da roda traseira do LifeTrac 4 quebrou mais de uma vez, e era comum ver os Power Cubes vazando óleo no solo quando estavam em funcionamento. A Figura 40 reúne alguns registros fotográficos deste workshop. 

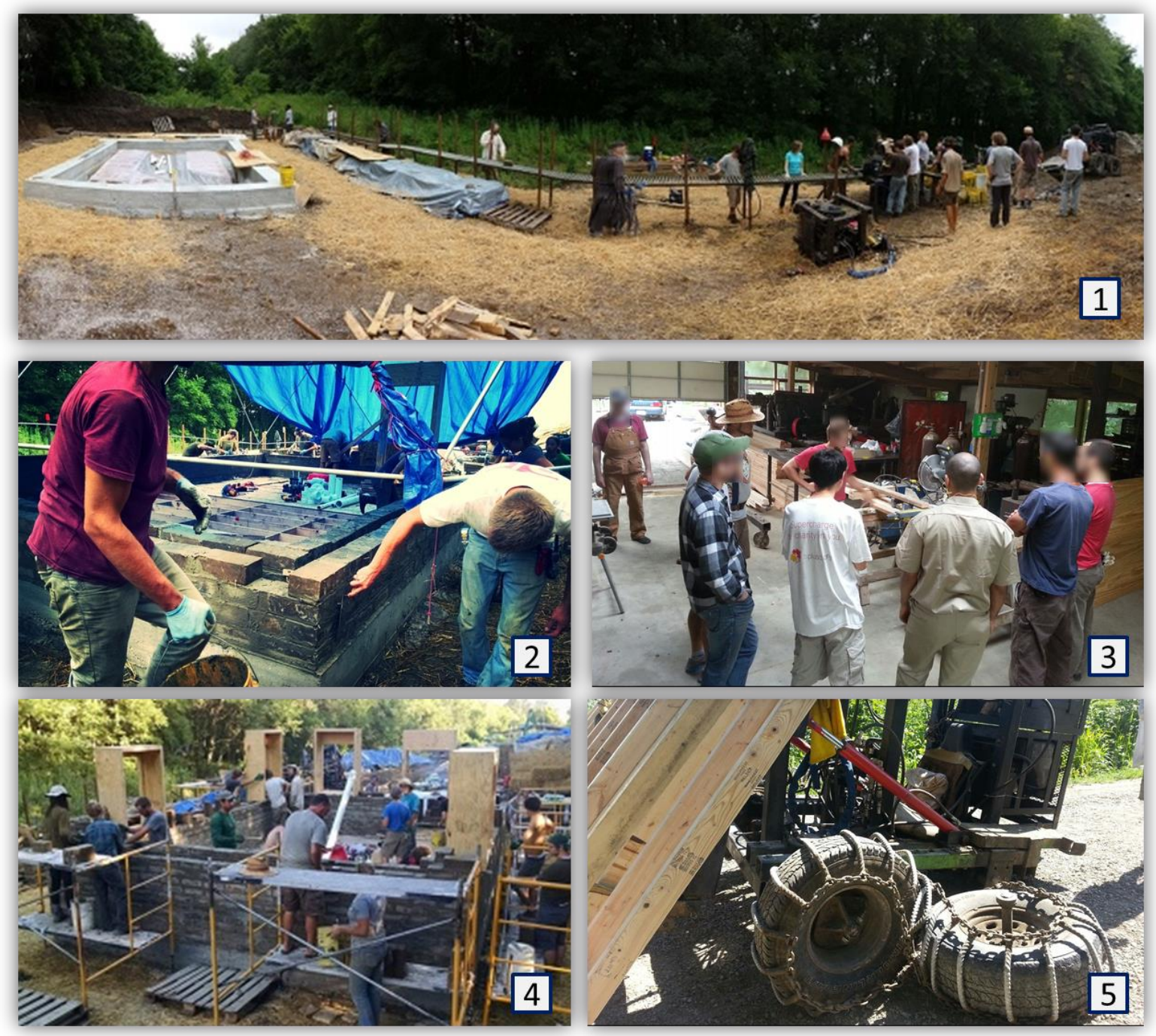

Figura 40 - Registros fotográficos do workshop da MicroHouse 3: (1) participantes trabalhando na produção dos tijolos ao lado da fundação da casa; (2) construção das paredes usando os tijolos produzidos pela CEB Press; (3) montagem dos módulos de madeira; (4) instalação dos apoios para as janelas; e (5) LifeTrac 4 quebrado (OSE, 2015b)

No final do workshop, havíamos conseguido construir cerca de $50 \%$ da casa. Porém, mesmo não tendo sido possível concluirmos a MicroHouse, os participantes se mostraram satisfeitos com o workshop, e disseram, durante a reunião de encerramento, terem gostado bastante da experiência, principalmente pela interação que tiveram entre eles, incluindo o pessoal da OSE. Nessa reunião, um dos participantes passou uma lista para que os participantes deixassem seus contatos. Após alguns dias, haviam criado um grupo de e-mails para continuarmos as discussões sobre o design da MicroHouse, e seu processo de construção. Porém, houve pouca participação no neste grupo de e-mail. Basicamente quatro pessoas estavam participando, sendo uma delas o próprio Marcin. As discussões estavam mais relacionados a questões técnicas para construção da MicroHouse, 
principalmente com foco no processo de assentamento dos tijolos nas construção das paredes, e as participações concentraram-se no compartilhamento de vídeos e textos abortando esse tópico. O líder de desenvolvimento da MicroHouse 3 não chegou a participar das discussões. Em uma conversa com Marcin, no dia 28 de Agosto, descobrimos que o líder de desenvolvimento não havia mais entrado em contado, e até hoje (20 de Junho de 2015) a documentação da MicroHouse 3 está incompleta, sem nenhum progresso desde o workshop.

No dia 14 de Agosto, dois dias após o encerramento do workshop da MicroHouse, realizamos uma reunião geral. Esta reunião foi como se fosse a última reunião do programa de verão, já que a maioria dos estagiários iria embora no dia seguinte. Por isso, foi o momento em que o pessoal se sentiu à vontade, e na obrigação, de refletir sobre toda experiência que tivemos na OSE. Foram apontados muitos problemas, dentre eles: o ambicioso cronograma, planejamentos não realistas, e projetos inacabados; a baixa qualidade dos protótipos, a falta de segurança para as pessoas que estão trabalhando e participando dos workshops, e a falta de transparência com relação aos problemas enfrentados e fracassos; e também a pouca importância dada ao impacto ambiental dos projetos e os poucos momentos em que foram realizadas atividade de design durante o programa de verão. Houve um destaque para a falta de segurança e a baixa qualidade dos protótipos. Houve também um consenso de que seria melhor focarmos em poucos projetos e consolidar o que já havia sido feito, ao invés de buscar atingir tempos recordes de prototipagem e trabalhar com vários projetos simultaneamente. A baixa qualidade dos protótipos se mostrou evidente se compararmos o tempo em que as máquinas ficaram em uso e o tempo que elas passam quebradas. Foi enfatizada a frustração que é consertar uma máquina e a ver quebrar logo em seguida, pois 0 design não foi bem pensado, e alguns problemas não foram corrigidos de um protótipo para outro. Também houve um consenso com relação aos pontos positivos dessa experiência. Todos disseram que a melhor coisa foi o contato com outras pessoas, e no potencial que um projeto open source tem de atrair pessoas interessantes. Além disso, o desenvolvimento de habilidades técnicas, e a troca de experiências também foram citados como pontos positivos.

Mesmo que a maioria dos estagiários houvesse deixado a FeF, ainda estava planejado um último workshop naquele verão: a construção da MicroHouse 4. 


\subsubsection{MicroHouse 4 Workshop}

A decisão tomada por Marcin em realizar um workshop para a construção da MicroHouse 4, sem antes terminar a construção da MicroHouse 3 não foi nenhum um pouco bem vista pelos estagiários. A vontade de todos era que fizéssemos mais workshops, porém com o objetivo de terminar a construção da MicroHouse 3, que corria o risco de ser destruída pelas fortes nevascas que comumente caem durante o inverno no Missouri. Outro ponto que incomodava os estagiários era que a MicroHouse 4 era um projeto de expansão da casa onde Marcin morava com sua esposa, e não refletia diretamente em uma melhoria na infraestrutura comunitária da FeF. Mesmo assim, Marcin manteve sua posição, causando um descontentamento geral entre os estagiários, e em parte das pessoas que haviam participado do workshop da MicroHouse 3, e ficaram sabendo dessa notícia.

Neste workshop participaram cerca de 30 pessoas. Somente dois estagiários, que haviam participado do workshop da MicroHouse 3 estavam presentes, e haviam chegado outros cinco estagiários. Jonathan, uma das pessoas que havia contribuído no workshop da MicroHouse 3, voltou a FeF para participar do workshop da MicroHouse 4, dessa vez com um papel de liderança, ao lado de Marcin. No período que antecedeu o workshop, Marcin e Jonathan conduziram juntos uma série de reuniões por vídeo conferência com o objetivo de atrair colaboradores para participar do design e do planejamento do workshop da MicroHouse 4, utilizando o Google Hangouts, o Google Slides e o SketchUp. Essas reuniões eram divulgadas por meio das redes sociais, e eram chamadas de design sprints. No entanto, poucas pessoas participavam, e a maior parte do trabalho acabou sendo feita pelos dois, com a ajuda de mais um colaborador.

Como haviam sobrado tijolos da MicroHouse 3, e a infraestrutura da FeF já havia sido melhorada, os preparativos para o workshop da MicroHouse 4 deram menos trabalho. Além disso, o design da MicroHouse 4 era mais simples, e muito parecido com o design utilizado na MicroHouse 1 e 2. Portanto, Marcin estava mais familiarizado com o que deveria ser feito.

Este workshop teve início no dia 28 de Setembro, e durou apenas três dias. Neste workshop, muitos dos participantes possuíam experiência com construção, e como estávamos em menos pessoas comparado ao workshop da MicroHouse 3, foi mais fácil nos organizarmos. Assim como no workshop da CEB Press na FeF, 
trabalhar em um menor número de pessoas se mostrou ser um modelo mais eficiente para os workshops. Um dos participantes deste workshop tinha experiência no design de móveis e se ofereceu para prototipar parte do mobiliário para a casa seguindo o modelo do open source design. A Figura 41 apresenta os registros fotográficos deste workshop que exemplificam a fabricação de móveis open source utilizando a fabricação digital.
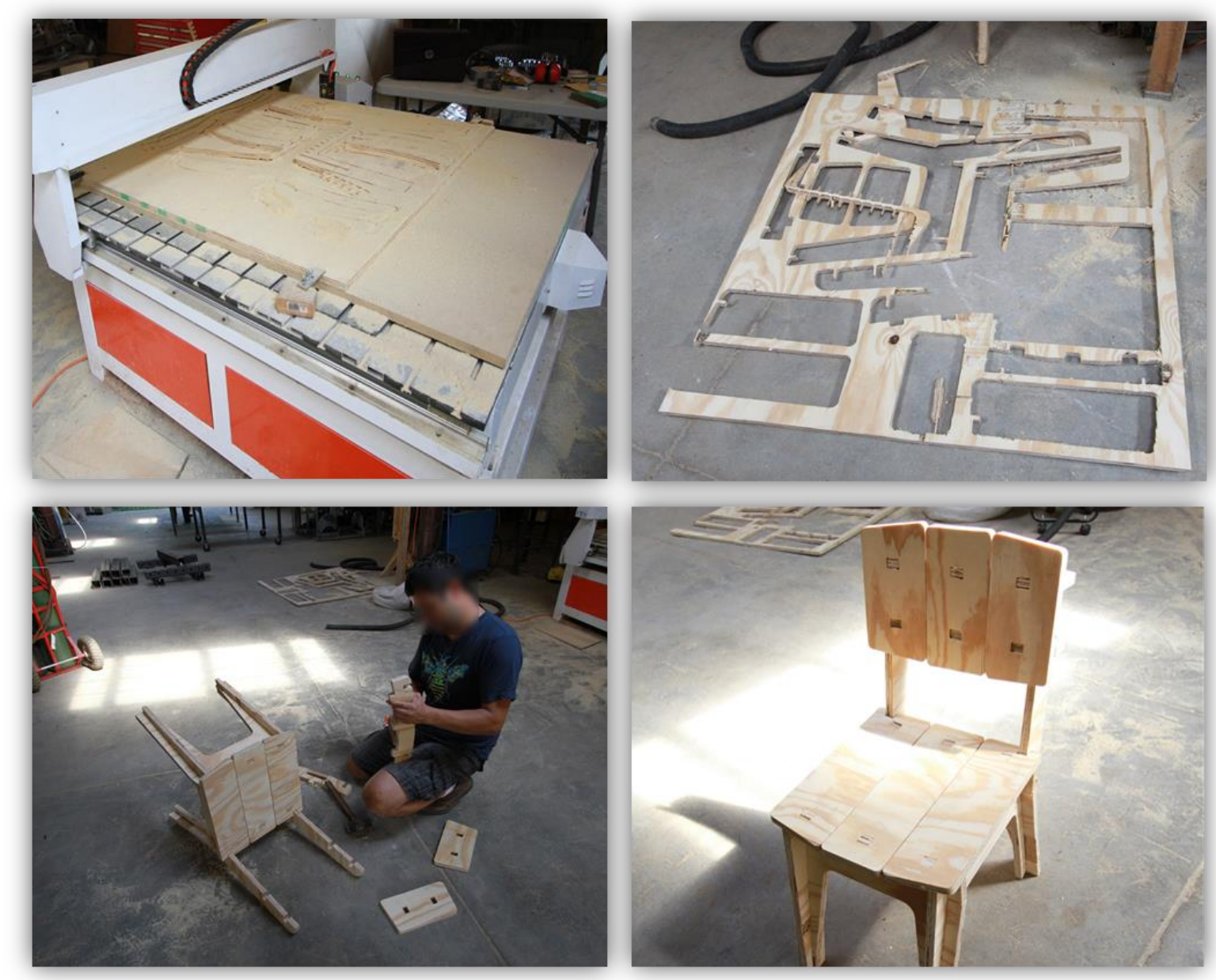

Figura 41 - Prototipagem de parte do mobiliário open source para a MicroHouse 4 utilizando fabricação digital (OSE, 2015b)

Mais uma vez não conseguimos completar a prototipagem no tempo planejado. Porém, dessa vez, houve uma maior colaboração no design. Alguns participantes com experiência na construção de casas identificaram problemas no design do telhado da MicroHouse 4, e juntamente com Marcin revisaram o projeto, de modo que as melhorias sugeridas já fossem implementadas neste protótipo. A Figura 42 ilustra a evolução na construção do protótipo da MicroHouse 4 durante 0 workshop. Após o período de observação participante, a construção da MicroHouse 
4 foi retomada. A Figura 43 apresenta o resultado obtido com a finalização do interior da casa.
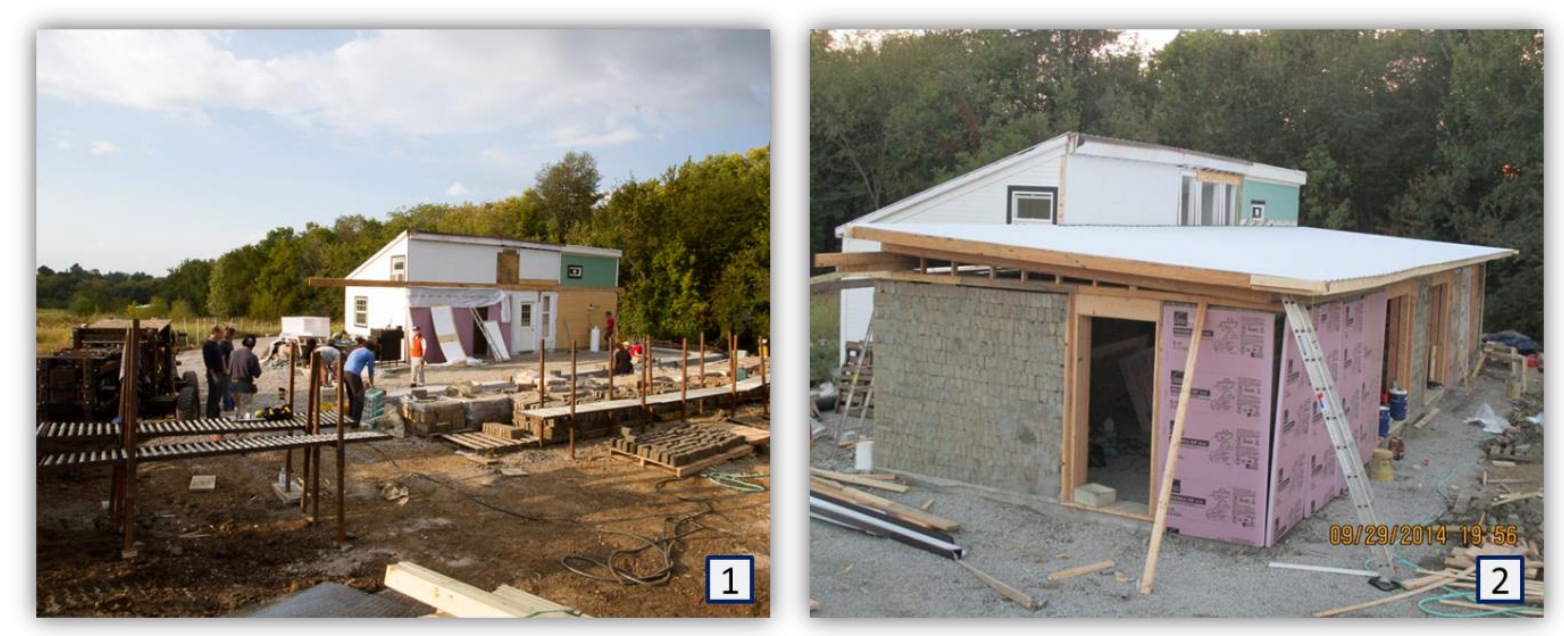

Figura 42 - Registros fotográficos do workshop da MicroHouse 4: (1) participantes trabalhando no primeiro dia de workshop; e (2) estágio do protótipo ao final do workshop (OSE, 2015b)

Com o final do workshop da MicroHouse 4, no dia 30 de Setembro, encerrouse também o primeiro programa de verão da OSE, e com ele, meu período de observação participante. No dia 1 de Outubro peguei o avião de volta para o Brasil para dar continuidade à pesquisa. O responsável pela hospitalidade havia sido contratado apenas para o programa de verão, e também deixou a FeF no mesmo dia que eu.
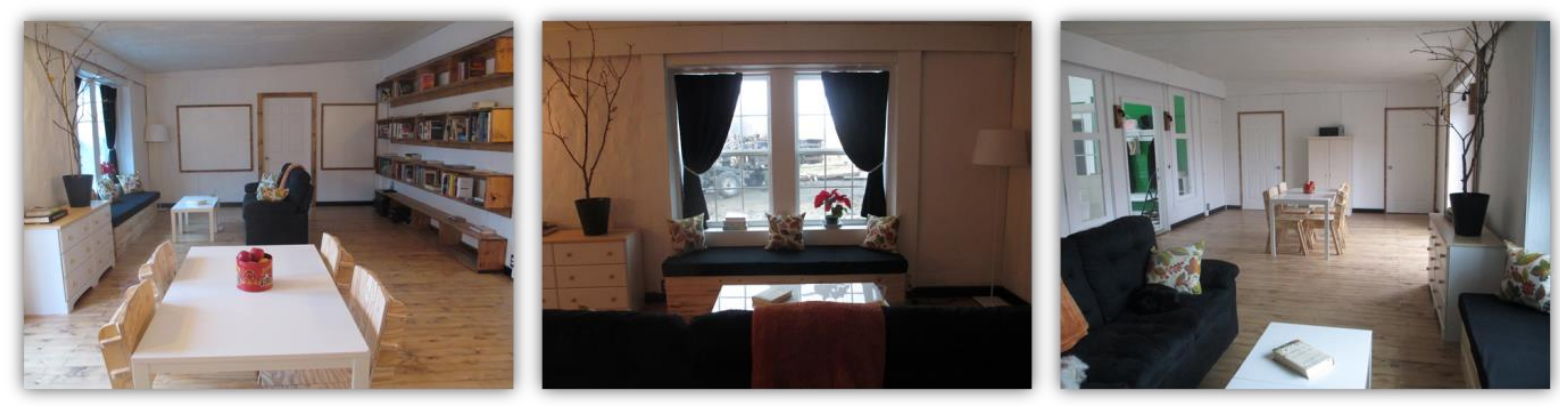

Figura 43 - Resultado obtido após a finalização do interior da MicroHouse 4 (OSE, 2015b)

\subsection{Análise dos principais incidentes observados no PDP da Open Source Ecology}

Após a redução dos dados coletados em campo, e da elaboração da narrativa do caso, foram identificados os incidentes de maior importância para essa pesquisa, 
os quais foram posteriormente codificados, e analisados por meio da Árvore de Causa e Efeito. Nesta seção, são apresentados os principais resultados obtidos após a aplicação deste método. Os detalhes sobre a utilização da Árvore de Causa e Efeito, assim como a lista de todos os incidentes identificados, e sua codificação, estão apresentados no APÊNDICE A. Nesse apêndice também é apresentada uma síntese da literatura sobre os problemas recorrentes no processo de desenvolvimento de produtos de empresas tradicionais, também identificados por meio da Árvore de Causa e Efeito. Dessa forma, é possível realizar uma comparação teórica com os problemas identificados durante o período de observação participante na OSE.

A partir da Árvore de Causa e Efeito foi possível identificar as relações entre os incidentes observados, considerados uma barreira para o open source design, ou seja, os efeitos indesejáveis no processo de desenvolvimento de produtos da organização pesquisada. Os efeitos indesejáveis considerados mais relevantes são: os efeitos que ficam na base da árvore e são a causa-raiz de todos os outros efeitos; os efeitos que ficam no topo da árvore e que são os mais visíveis para a organização, chamados efeitos principais; e os efeitos que oferecem boas oportunidades de melhoria. Os efeitos principais e as causas-raiz estão apresentados na Tabela 9, enquanto que os efeitos que apresentam boas oportunidades para melhoria estão discutidos ao longo do texto, juntamente com os principais efeitos que facilitam o open source design. A fim de facilitar a identificação dos incidentes ao longo do texto, os números correspondentes a cada um deles são apresentados entre parênteses (\# $\mathrm{X}$ ), onde $\mathrm{X}$ corresponde ao número do incidente.

Ao analisar a codificação dos incidentes apresentados na Tabela 9, observase que os efeitos principais estão relacionados ao processo de desenvolvimento de produtos, enquanto que a maioria das causas-raiz estão relacionadas aos elementos comunidade e motivadores. Os efeitos principais indicam que os resultados gerados no PDP da OSE não estão cumprindo totalmente os requisitos propostos pela organização: permitir a fabricação local, no modelo DIY, de 50 diferentes máquinas industriais de arquitetura modular, com alto desempenho e baixo custo, consideradas essenciais para a construção de uma pequena civilização sustentável, com os padrões de conforto da vida moderna.

Para permitir a fabricação local dos produtos, no modelo DIY, são necessárias instruções detalhadas, contendo o passo-a-passo das atividades ilustradas com os 
desenhos gerados no CAD, fotos, e vídeos, pois assim se reduz a necessidade de conhecimentos técnicos por parte dos interessados em replicar os protótipos (\# 47). No entanto, muitas das instruções para a construção dos protótipos da OSE ainda encontram-se incompletas (\# 78). Além disso, os protótipos desenvolvidos pela organização não possuíam um alto desempenho, falhas eram frequentes (\# 18), sendo que algumas colocavam em risco os colaboradores (\# 19).

Tabela 9 - Efeitos principais e causas-raiz do PDP da OSE. Legenda: PDP - Processo de desenvolvimento de produtos, COM - Comunidade, MOT - Motivadores; P - Prototipagem, D Design, T - Teste; ND - Detalhado; MD - Método de design; N/A - Não se aplica.

\begin{tabular}{|c|c|c|c|c|c|c|}
\hline \multicolumn{2}{|r|}{ Incidentes } & \multicolumn{4}{|c|}{ Codificação } & \multirow[b]{2}{*}{$\begin{array}{l}\text { Tipo do } \\
\text { efeito }\end{array}$} \\
\hline \# & $\begin{array}{l}\text { Ação ou comportamento } \\
\text { observado }\end{array}$ & Elemento & $\begin{array}{l}\text { Fase } \\
\text { do } \\
\text { PDP }\end{array}$ & $\begin{array}{l}\text { Nível de } \\
\text { Abstração }\end{array}$ & $\begin{array}{l}\text { Área de } \\
\text { Conhecimento }\end{array}$ & \\
\hline 6 & $\begin{array}{l}\text { Dificuldade na replicação dos } \\
\text { protótipos, sem a presença de um } \\
\text { colaborador experiente }\end{array}$ & PDP & $P$ & ND & $\mathrm{N} / \mathrm{A}$ & $\begin{array}{l}\text { Efeito } \\
\text { principal }\end{array}$ \\
\hline 19 & $\begin{array}{l}\text { Falhas severas nos protótipos } \\
\text { colocavam em risco os } \\
\text { colaboradores e o meio ambiente }\end{array}$ & PDP & $\mathrm{T}$ & ND & MD & $\begin{array}{l}\text { Efeito } \\
\text { principal }\end{array}$ \\
\hline 3 & $\begin{array}{l}\text { O iniciador não possuía experiência } \\
\text { em desenvolvimento de produtos } \\
\text { quando iniciou o projeto, e } \\
\text { desconhece algumas boas práticas } \\
\text { utilizadas no PDP }\end{array}$ & COM & $\mathrm{N} / \mathrm{A}$ & $\mathrm{N} / \mathrm{A}$ & $\mathrm{N} / \mathrm{A}$ & $\begin{array}{l}\text { Causa- } \\
\text { raiz }\end{array}$ \\
\hline 36 & $\begin{array}{l}\text { Muitos dos colaboradores não } \\
\text { possuíam experiência em } \\
\text { desenvolvimento de produtos, } \\
\text { desconhecem muitas das boas } \\
\text { práticas utilizadas no PDP }\end{array}$ & COM & $\mathrm{N} / \mathrm{A}$ & $\mathrm{N} / \mathrm{A}$ & $\mathrm{N} / \mathrm{A}$ & $\begin{array}{l}\text { Causa- } \\
\text { raiz }\end{array}$ \\
\hline 39 & $\begin{array}{l}\text { Muitos dos colaboradores não } \\
\text { tinham tanta prática em fabricação } \\
\text { e montagem }\end{array}$ & COM & $\mathrm{N} / \mathrm{A}$ & $\mathrm{N} / \mathrm{A}$ & $\mathrm{N} / \mathrm{A}$ & $\begin{array}{l}\text { Causa- } \\
\text { raiz }\end{array}$ \\
\hline 82 & $\begin{array}{l}\text { Os colaboradores estavam muito } \\
\text { mais interessados em construir do } \\
\text { que documentar, e era comum que } \\
\text { esquecessem de documentar } \\
\text { alguns passos, assim como, } \\
\text { oportunidades de melhoria } \\
\text { observadas }\end{array}$ & MOT & $\mathrm{N} / \mathrm{A}$ & $\mathrm{N} / \mathrm{A}$ & $\mathrm{N} / \mathrm{A}$ & $\begin{array}{l}\text { Causa- } \\
\text { raiz }\end{array}$ \\
\hline 2 & $\begin{array}{l}\text { A organização não possui } \\
\text { funcionários remunerados, com } \\
\text { dedicação exclusiva }\end{array}$ & COM & $\mathrm{N} / \mathrm{A}$ & $\mathrm{N} / \mathrm{A}$ & $N / A$ & $\begin{array}{l}\text { Causa- } \\
\text { raiz }\end{array}$ \\
\hline 28 & $\begin{array}{l}\text { Falta de transparência com relação } \\
\text { aos problemas enfrentados e } \\
\text { fracassos }\end{array}$ & COM & $\mathrm{N} / \mathrm{A}$ & $\mathrm{N} / \mathrm{A}$ & $N / A$ & $\begin{array}{l}\text { Causa- } \\
\text { raiz }\end{array}$ \\
\hline 10 & $\begin{array}{l}\text { Muitas vezes as atividades de } \\
\text { design dependem de um software, } \\
\text { de modo que os colaboradores } \\
\text { necessitam ter domínio do software } \\
\text { utilizado para contribuir }\end{array}$ & PDP & $\mathrm{D}$ & ND & MD & $\begin{array}{l}\text { Causa- } \\
\text { raiz }\end{array}$ \\
\hline
\end{tabular}


A realização de workshops para a construção dos protótipos apresentou um grande potencial em promover a replicação dos protótipos, visto que atraia o interesse de colaboradores em busca de aprendizado, realização de atividades práticas, diversão e desejo de contribuir com um projeto de impacto social (\# 7). Dentre os participantes dos workshops haviam usuários dos produtos (\# 4), porém a maioria dos participantes eram universitários (\# 29), dos quais boa parte estava cursando engenharia. A organização dos workshops em parceria com universidades mostrou-se vantajosa para ambas as partes, apresentando um grande potencial para a divulgação e evolução de projetos de OSD. Os workshops presenciais apresentaram, também, uma boa oportunidade para interação entre os colaboradores, incentivando a colaboração (\# 22).

Observou-se que durante os workshops surgiam propostas de melhoria tanto no design dos produtos, quanto nas instruções para construção. Geralmente, as melhorias no design do produto eram sugeridas por colaboradores mais experientes, enquanto que colaboradores inexperientes apresentaram uma tendência em contribuir com a melhoria das instruções para construção (\#14). No entanto, na maioria das vezes, os colaboradores não recebiam feedback de suas contribuições (\# 102), e somente eram implementadas nos protótipos melhorias pontuais no design dos produtos (\# 87), e o os protótipos não evoluíam tanto de uma versão para outra (\# 31).

Um bom planejamento dos workshops e a organização do ambiente de trabalho foram essenciais para que os colaboradores tivessem uma boa experiência ao replicar os protótipos. A montagem de kits, com os componentes do produto préfabricados e separados por subsistemas/módulos, mostrou-se útil ao facilitar o controle dos materiais (\# 55), e equipes pequenas demonstraram ser mais eficientes na construção dos protótipos (\# 84). Em alguns workshops da OSE, a falta de planejamento e organização dos workshops (\# 79) contribuiu para que alguns participantes tivessem uma experiência negativa, dificultando a retenção de colaboradores (\# 23).

A organização clara da plataforma de colaboração também se mostrou essencial para facilitar o open source design. No caso da OSE, muitas das informações existentes na wiki estavam incompletas e desatualizadas (\# 97) e os colaboradores tiveram dificuldades em encontrar informações relevantes sobre os projetos (\# 96), dificultando assim, a colaboração remota (\# 95). O fato de não haver 
uma visão unificada sobre como a wiki deveria ser organizada (\# 98), juntamente com a falta de um responsável para revisar o conteúdo da wiki (\# 99), se mostraram como causas para esse efeito indesejado. De acordo com Costa et al. (2013, p. 26), a falta de definição de papeis/responsabilidades é um problema recorrente no PDP nas organizações, assim como muitos dos efeitos indesejados identificados no PDP da OSE. A Tabela 10 apresenta uma correspondência entre os problemas recorrentes do PDP com os efeitos indesejados da OSE. Os problemas em destaque correspondem às causas-raiz. A lista completa dos problemas recorrentes no PDP, identificados por Costa et al. (2013, p. 26), é apresentada na seção 2 do APÊNDICE A.

Tabela 10 - Correspondência entre os problemas recorrentes do PDP com os efeitos indesejados identificados no PDP da OSE

\begin{tabular}{ll}
\hline Problemas recorrentes durante o PDP & Efeitos Indesejáveis identificados no PDP da OSE \\
\hline $\begin{array}{l}\text { Inexistência/deficiência da gestão do } \\
\text { portfolio de produtos }\end{array}$ & Falta de gestão de portfolio e gestão de projetos (\# 25) \\
\hline Inexistência/falta de visão do processo & $\begin{array}{l}\text { Os colaboradores não conhecem o modelo de } \\
\text { referência para o PDP da OSE (\# 43) }\end{array}$ \\
\hline $\begin{array}{l}\text { Inexistência/deficiência em trabalhar em } \\
\text { equipe }\end{array}$ & Pouca colaboração na fase de design (\# 91) \\
\hline $\begin{array}{l}\text { Inexistência/deficiência no uso de técnicas } \\
\text { de gestão de projetos }\end{array}$ & Falta de gestão de portfolio e gestão de projetos (\# 25) \\
\hline Inexistência/falha nos testes & $\begin{array}{l}\text { Não possuíamos uma sistemática para testar os } \\
\text { protótipos em funcionamento, e poucos dados eram } \\
\text { coletados (\# 90) }\end{array}$ \\
\hline $\begin{array}{l}\text { Falta de conhecimento sobre as boas } \\
\text { práticas do PDP }\end{array}$ & $\begin{array}{l}\text { O iniciador não possuía experiência em } \\
\text { desenvolvimento de produtos quando iniciou o projeto, } \\
\text { e desconhece algumas boas práticas utilizadas no }\end{array}$ \\
& $\begin{array}{l}\text { PDP (\# 3) } \\
\text { Muitos dos colaboradores não possuíam experiência } \\
\text { em desenvolvimento de produtos, desconhecem } \\
\text { muitas das boas práticas utilizadas no PDP (\# 36) }\end{array}$ \\
\hline Equipe desmotivada & $\begin{array}{l}\text { A elaboração das instruções para construção era } \\
\text { entediante e consumia bastante tempo, desmotivando } \\
\text { os colaboradores (\# 71) }\end{array}$ \\
\hline Problemas de relacionamento pessoal & $\begin{array}{l}\text { Muitos dos colaboradores tiveram dificuldade de se } \\
\text { relacionarem com o iniciador do projeto (\# 33) }\end{array}$ \\
\hline
\end{tabular}

Esta seção concentrou-se na análise dos principais incidentes observados no PDP da Open Source Ecology, e por fim, foram identificadas algumas semelhanças entre os problemas recorrentes do PDP com os efeitos indesejados identificados no PDP da OSE. Na próxima seção é realizada uma síntese das principais características que diferenciam o PDP no open source design das empresas tradicionais, baseada nas evidências observadas em campo (seções 4.2 e 4.3) e na revisão da literatura (Capítulo 2). 


\subsection{Características do PDP no open source design}

As atividades básicas do PDP no open source design seguem um ciclo iterativo entre as fases de pesquisa, design, prototipagem e teste. De acordo com o estudo de caso, foi identificado um predomínio de atividades relacionadas à fase de prototipagem, por exemplo, por meio da realização de workshops e de replicações independentes. As atividades da fase de teste foram muitas vezes confundidas com a utilização dos protótipos, e realizadas sem sistemática alguma, e a melhoria do design se dava por meio da tentativa e erro. Com relação às atividades de pesquisa e design, observou-se que elas eram realizadas por equipes pequenas, ou mesmo, por apenas um colaborador, devido às dificuldades em atrair colaboradores e em colaborar remotamente. Ao longo do ciclo iterativo de desenvolvimento, observou-se que era comum que ocorressem alterações nas equipes, tanto dentro de uma iteração, quanto entre uma iteração e outra, podendo acontecer de algumas das etapas deste ciclo serem realizadas de forma independente. Essa característica do OSD dificulta bastante a transferência do conhecimento entre os colaboradores, e aumenta a importância de uma boa documentação nos projetos de OSD. Durante o estudo de caso, no workshop da MicroHouse 4, das cerca de trinta pessoas que participaram da fase de prototipagem, apenas três haviam participado da fase de design, sendo que, dentre elas, apenas duas haviam participado da prototipagem da versão anterior (MicroHouse 3), e apenas uma (o iniciador do projeto) havia participado do ciclo de iterações responsáveis pelo desenvolvimento das versões anteriores (MicroHouse 1 e 2).

A colaboração mostrou-se mais frequentes e mais eficientes, entre uma iteração e outra, principalmente por meio da atualização da documentação dos projetos disponibilizadas na plataforma de colaboração da organização. $\mathrm{Na}$ preparação do workshop do MicroCar, observou-se que o fluxo de informação baseado no modelo de "inscrição e publicação" (no qual todos os participantes que estivessem trabalhando na resolução de um mesmo problema, se inscrevem para receber notificações sempre que houver uma nova publicação naquele tópico) auxiliava o diálogo entre os colaboradores e o compartilhamento de informações. Acredita-se que o fluxo de informação baseado nesse modelo tem potencial de auxiliar também na revisão do conteúdo da plataforma de colaboração, no 
fornecimento de feedback, e na busca por informações relevantes, contribuindo para tornar a colaboração remota mais eficiente.

No open source design, as informações e atividades referentes ao PDP provêm de diversas fontes, de uma maneira descentralizada e auto-organizada. Colaboradores podem entrar e sair das comunidades de OSD a qualquer momento, e com isso, aumenta-se a probabilidade de informações serem perdidas e atividades interrompidas. No estudo de caso, a saída do líder de desenvolvimento da MicroHouse 3 foi responsável pela perda de muitas informações relevantes.

A grande diversidade entre os softwares e hardwares utilizados pelos colaboradores também contribui para a diversidade de fontes de informação e atividades referentes ao PDP. Além disso, as ferramentas de design disponíveis em geral são caras, e exigem usuários habilidosos. No caso estudado, foram identificadas muitas atividades de design que dependiam de um software específico, de modo que os colaboradores necessitavam ter acesso e domínio do software utilizado para contribuir nas atividades.

Outro fator que contribui para a diversidade de fontes de informação no OSD está relacionado à cadeia de suprimentos. Normalmente na replicação de um protótipo são utilizados fornecedores locais (tanto fornecedores de materiais como de serviços, como por exemplo, serviços de manufatura), sendo que cada novo fornecedor local se torna uma nova fonte de informação. Em alguns casos, devido a problemas relacionados à disponibilidade de material, pode ser que os projetos tenham que ser adaptados para se adequar aos fornecedores locais. No estudo de caso, durante a preparação para o workshop do MicroCar, enfrentamos dificuldade de acesso a alguns componentes e o projeto teve der ser alterado.

Os projetos de OSD normalmente possuem como requisitos básicos permitir que os produtos desenvolvidos sejam: fabricados localmente, no modelo DIY; de fácil manutenção; de fácil customização; e com um custo inferior ao valor de mercado. Além desses requisitos, os colaboradores normalmente se concentram em atender aos próprios requisitos, e aos requisitos da comunidade. No estudo de caso, devido ao estágio de maturidade referente à gestão do PDP que se encontrava a organização pesquisada, alguns requisitos legais, assim como, requisitos de homologação e requisitos ambientais estavam sendo negligenciados. desconhecimento de normas e boas práticas de GDP por parte dos colaboradores, e o fato de muitos projetos ainda se encontrarem em estágios iniciais de 
desenvolvimento foram identificados como possíveis causas para essa negligência. No caso analisado, o não cumprimento desses requisitos pode ser exemplificado com falhas que ocorreram nos protótipos durante o período de observação participante, colocando em risco os colaboradores e causando danos ao meio ambiente. Os colaboradores também não possuíam uma visão de ciclo de vida do produto e seus clientes (projeto, manufatura, distribuidores, usuários, pessoal de assistência técnica, reciclagem do produto, etc.) para a gestão dos requisitos dos projetos. Os requisitos se concentravam no projeto e nos usuários, e se assumia que eles seriam os responsáveis pela fabricação e manutenção dos produtos.

No entanto, no open source design, grande parte do risco inerente ao PDP é compartilhada com a comunidade, responsável por avaliar a qualidade dos resultados gerados. Os riscos referentes à qualidade do produto, por exemplo, são compartilhados com os responsáveis pela replicação dos protótipos, permitindo que a organização seja mais ágil e libere para a comunidade versões de seus produtos, mesmo nos estágios iniciais de desenvolvimento. Já os riscos referentes à aceitação do produto no mercado também são menores, pois, nas comunidades de OSD há uma predominância de usuários, participando ativamente do PDP.

Além disso, o OSD possui flexibilidade com relação a alterações nos projetos de desenvolvimento de produtos. Como as informações referentes ao PDP são disponibilizadas abertamente na plataforma da organização, qualquer um tem a possibilidade de desenvolver soluções concorrentes em qualquer momento do projeto. Caso as soluções propostas por outros colaboradores se mostrem mais apropriadas do que a versão "oficial" do produto/protótipo apoiada pelo iniciador do projeto, nada impede que essa solução se torne a nova versão "oficial", ou que parte dela seja incorporada ao projeto. Em produtos com arquitetura modular, essa flexibilidade é ainda maior, a incorporação parcial de soluções concorrentes é facilitada. A árvore da evolução da família de produtos da comunidade RepRap (ANEXO I) exemplifica a diversidade de soluções concorrentes dentro de uma comunidade de OSD.

Nesta seção foram apresentadas principais características do processo de desenvolvimento de produtos no open source design, cumprindo com o objetivo proposto nesta pesquisa. $\mathrm{Na}$ seção a seguir são apresentadas as reflexões do pesquisador sobre os demais elementos fundamentais do open source design: plataforma de colaboração, comunidade, motivadores e modelo de negócio. 


\subsection{Reflexões sobre os demais elementos do open source design}

Como os elementos fundamentais do open source design estão fortemente conectados, ao estudar o processo de desenvolvimento de produtos, o pesquisador teve oportunidade de entrar em contato com os demais elementos do OSD ao longo da execução deste trabalho. Foi realizada uma revisão bibliográfica sobre cada um desses elementos, que também foram incluídos na identificação e análise dos incidentes observados durante a pesquisa de campo. Portanto, nesta seção, são apresentadas as reflexões do pesquisador sobre esses elementos, sem a preocupação de caracterizá-los.

Com relação à plataforma de colaboração, observou-se a enorme importância deste elemento para o bom funcionamento do PDP no open source design. Sem uma plataforma de colaboração atrativa e bem organizada, torna-se muito difícil a colaboração nos projetos de OSD. A organização pesquisada utiliza a wiki como sendo a principal plataforma de colaboração, combinada com as ferramentas do Google Apps $^{56}$ (Docs para edição de textos; Slides para edição de apresentações, Sheets para edição de planilhas; Forms para criação, envio e análise de formulários online; e Hangouts para vídeo conferências), e repositórios para vídeos (YouTube), fotos (Trovebox), e instruções para construção (Dozukı). A organização pesquisada busca adotar ferramentas computacionais gratuitas, open source, que permitam a colaboração em tempo real, e sua incorporação em páginas web ${ }^{57}$. Mesmo não sendo open source, a simplicidade e a popularidade do Google Apps contribuíram na seleção dessas ferramentas e, além disso, elas atendem a todos os outros requisitos.

A wiki, embora cumprisse todos os requisitos buscados pela organização pesquisada, não foi considerada pelo pesquisador uma boa plataforma de colaboração, pois, da forma como estava sendo utilizada, não se mostrou propícia para a estruturação de uma comunidade, desencorajando o diálogo entre os colaboradores por meio desta plataforma. No caso estudado, observou-se que o

${ }^{56}$ Disponível em https://www.google.com/intx/pt-EN/work/apps/business/products/, acessado em 30/06/2015

${ }^{57}$ Em inglês, o adjetivo utilizado para este requisito seria embeddable. 
diálogo entre os colaboradores era mais frequente nas redes socias, principalmente no Facebook.

No caso do projeto velocar.cc, principal parceiro da OSE no desenvolvimento do MicroCar, é utilizada como principal plataforma de colaboração uma página web construída baseada em uma estrutura hierárquica de dados fornecida pela ferramenta open source Rizzoma. Esta plataforma se mostrou mais adequada na estruturação de uma comunidade, e ao possibilitar um fluxo de informação baseado no modelo de "inscrição e publicação", se mostrou eficiente ao encorajar o diálogo entre os colaboradores. Outro ponto interessante sobre a plataforma de colaboração do projeto velocar.cc é o fato de o conteúdo da página web desta organização estar dividida em tópicos de interesse de acordo com tipos de usuário do PDP:

- Planejador, onde estão disponíveis o quadro kanban utilizado na gestão ágil do projeto, e o calendário do projeto;

- Empreendedor, onde estão disponíveis um vídeo que apresenta o projeto (pitch), o modelo de negócio da organização, e a evolução prevista para a liberação das versões do produto;

- Arquiteto, onde estão apresentados os sistemas e subsistemas;

- Engenheiro, onde são apresentados as especificações técnicas; e

- Técnico, onde são apresentadas as máquinas e ferramentas necessárias para a construção do produto, os processos de fabricação e montagem, e os Fab Labs parceiros do projeto, para auxiliar na construção dos produtos; e

- Usuário final, onde são apresentados os argumentos de venda, o preço alvo, e as informações de uso do produto.

Acredita-se que a organização da plataforma de colaboração com diferentes vistas para diferentes tipos de usuários é uma prática promissora, e sugere-se que essa estratégia seja complementada com as práticas de gestão de processos, principalmente com a implementação de um modelo de referência específico para o PDP com o propósito de auxiliar na estruturação/documentação da vasta quantidade de informações existentes sobre o trabalho realizado no PDP e como realizá-lo. A utilização de um modelo de referência para o PDP também pode contribuir para se definir as atividades padrão, mostrar a relação hierárquica entre as atividades, definir entregas padrão e padrões de qualidade para essas entregas, definir templates e 
ferramentas padrão para cada atividade, apresentar o processo de uma maneira intuitiva e acessível, e definir responsabilidade e habilidades padrão para os colaboradores ao participar de uma atividade (AMIGO, 2013, p. 99). Embora a OSE possuísse um modelo de referência para o PDP, nenhum dos colaboradores que 0 pesquisador entrou em contato durante o período de observação participante conhecia o modelo de referência, o que impossibilitou tirar conclusões sobre a utilização desse modelo. O APÊNDICE B apresenta em mais detalhes os tipos de modelo de processo, assim como os principais propósitos desses modelos.

Com relação às comunidades, observou-se o baixo número de colaboradores ativos na plataforma de colaboração da organização pesquisada comparado à quantidade de pessoas que já se envolveram de alguma forma com o projeto, seja por meio de da wiki, da página do Facebook da organização, e mesmo das visitas à FeF. Segundo Balka et al. (2009), este é um comportamento esperado para as comunidades que, assim como a OSE, encontram-se em estágios iniciais de desenvolvimento (dos 50 projetos da organização, 36 estão no estágio de planejamento/design virtual e 14 no estágio de prototipagem iniciada).

Observou-se também uma forte dependência entre os projetos e o seu iniciador, sendo este o colaborador mais ativo da comunidade, o responsável pela gestão da organização, e pelo provimento da infraestrutura necessária para execução dos projetos. Como a organização não possui nenhum funcionário remunerado, com dedicação exclusiva, o iniciador e líder do projeto é também, o gargalo da organização. No caso, a comunidade possui uma estrutura centralizada, e uma cultura meritocrática, com apenas dois níveis de desenvolvedor: o líder do projeto, e o resto. Dos 50 produtos no portfólio da organização, no momento, apenas um projeto possui um líder de desenvolvimento. Além dos líderes de desenvolvimento, a organização também possui outros papeis de liderança: diretor executivo, ocupado pelo iniciador do projeto, líder comunitário, líder de design gráfico, administrador web, e alguns conselheiros (mídia, desenvolvimento de negócios, projetos, e organizacional).

Ainda com relação às comunidades, observou-se no caso estudado os benefícios proporcionados por a comunidade estar se desenvolvendo ao redor de um ambiente híbrido. A reunião dos colaboradores em um espaço físico comum contribuiu bastante para o estreitamento das relações entre eles, incentivando a colaboração. A troca de experiências entre os colaboradores que estavam 
fisicamente reunidos foi destacada por muitos deles como sendo o ponto mais forte de toda a experiência durante o programa de verão. Quando o programa de verão acabou e relações de transferência de informação entre os colaboradores passaram a ser somente por meio do ambiente virtual, muitos colaboradores perderam o contato com a organização. Pelo que se tem noticias, alguns colaboradores passaram a contribuir em outros projetos de OSD, de modo que ainda continuam em contato entre si, contribuindo em outro projeto. Além de promover a interação entre os colaboradores, o espaço físico da comunidade permitiu também a colaboração durante a construção e teste dos protótipos, por meio da organização de workshops. A busca por aprendizado, realização de atividades práticas, diversão e desejo de contribuir com um projeto de impacto social foram motivadores comuns a todos os colaboradores, logo, o interesse em participar de workshops.

Além de incentivar a participação de mais colaboradores e acelerar a construção dos protótipos, do ponto de vista de negócio, os workshops também consistiam em uma importante fonte de renda para a OSE, ao lado do oferecimento de palestras e doações. No entanto, conforme apresentado no gráfico da Figura 44, a maior parte da receita provinha de uma parceria que a organização possuía com a Shuttleworth Foundation, e sem essa parceria, a OSE teria tido um balaço negativo em 2014. Os gastos com prototipagem e infraestrutura eram responsáveis pela maior parcela das despesas, porém da forma como estão apresentados, esses dados não nos permite tirar conclusões sobre quais gastos correspondem a investimentos em infraestrutura e quais gastos correspondem ao custo dos protótipos. Assim, não é possível concluir se, descontados os gastos com investimento, o negócio seria viável economicamente sem depender de doações. 


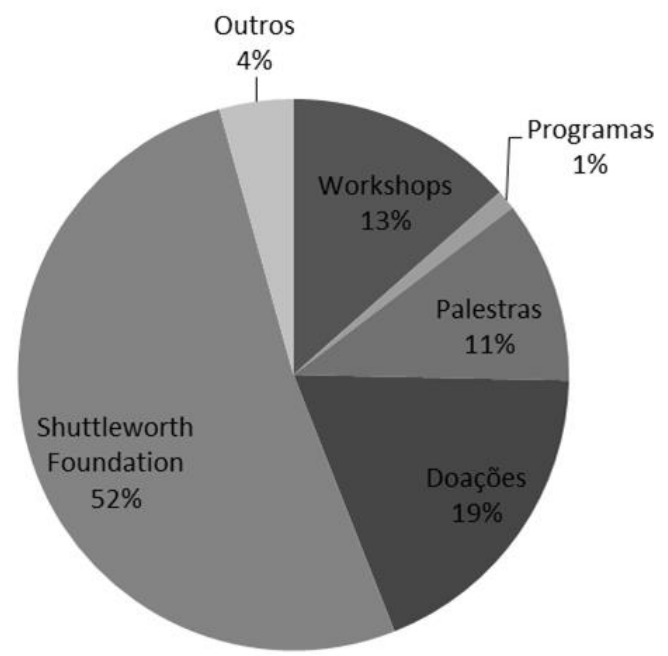

Receita 2014: US\$278k

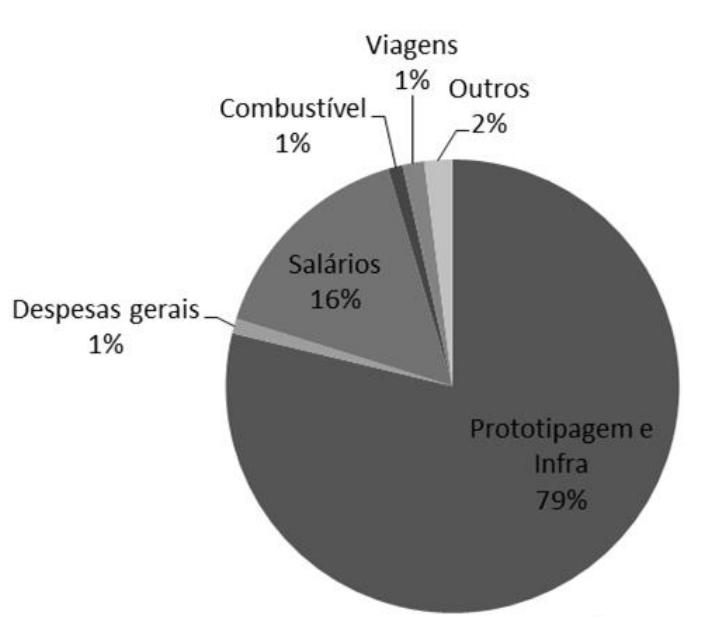

Despesas 2014: US\$256k

Figura 44 - Receitas e despesas da OSE em 2014 (OSE, 2015a)

Outra potencial fonte de renda, identificada no caso estudado, é a venda de kits com os componentes separados em módulos/sistemas, a fim de facilitar a organização de workshops e as replicações independentes dos protótipos. Além disso, o projeto RiverSimple (seção 2.2.5) mostrou um grande alinhamento entre os modelos de negócio de PSS a estratégia do open source design, representando uma e excelente oportunidade para as iniciativas de OSD.

Esta seção apresentou as reflexões do pesquisador sobre a plataforma de colaboração, a comunidade, os motivadores e o modelo de negócio, considerados por Fjeldsted et al. (2012), os elementos fundamentais do open source design juntamente com o processo de desenvolvimento de produtos. Na capítulo a seguir, são apresentadas as considerações finas deste trabalho. 


\section{Considerações finais}

O objetivo deste trabalho foi caracterizar o processo de desenvolvimento de produtos dentro do contexto do open source design. Nesta pesquisa, open source design se refere a "uma estratégia de desenvolvimento de produtos físicos por meio de uma plataforma de colaboração acessível e compartilhável, em que comunidades motivadas compartilham de forma transparente, adotam, produzem e desenvolvem continuamente soluções inovadoras sob os créditos e licenças estabelecidas em comum acordo, desde que essas licenças permitam que qualquer pessoa possa estudar, modificar, distribuir, produzir, e vender o design ou o produto baseado nesse design, formando uma cadeia de valor caracterizada pela co-criação e comunicação contínua".

A fim de alcançar este objetivo, foram utilizados dois procedimentos técnicos: a revisão bibliográfica e o estudo de caso de caráter etnográfico junto à organização Open Source Ecology. Esta organização é conhecida como uma sendo uma das pioneiras a aplicar os princípios do open source design no segmento de bens de consumo duráveis e bens de capital. No estudo de caso, foram realizadas em torno de 800 horas de observação participante apoiada pela análise de documentos. Com a combinação destas duas fontes de evidência foi possível investigar o fenômeno de interesse sob a perspectiva tanto externa, quanto interna à organização.

As evidências coletadas no estudo de caso foram analisadas com base nos estágios propostos por Karlsson (2009) para a análise de dados em estudos longitudinais, e utilizou como método analítico a Árvore de Causa e Efeito. Foram definidos quatro estágios para a análise de evidências do caso (redução dos dados e narrativa do caso, identificação de incidentes, codificação dos incidentes, e construção da teoria) que levaram à identificação das principais características do PDP no open source design, atingindo, assim, o objetivo desta pesquisa.

A escolha pelo estudo de caso de caráter etnográfico como procedimento técnico de pesquisa, combinado à revisão bibliográfica, mostrou-se eficaz ao fornecer uma caracterização robusta do objeto de estudo, e as etapas delineadas na metodologia, auxiliaram a obtenção dos resultados de maneira eficiente.

Os resultados obtidos no estudo de caso apresentam indícios que a organização pesquisada ainda não possui maturidade no processo de 
desenvolvimento de produtos, e que muitas das boas práticas de GDP utilizadas na indústria não são adotadas. Logo, ocorrem desperdícios ao longo do PDP, e ao final, são gerados produtos de baixa qualidade, com falhas frequentes, algumas das quais, colocam em risco a segurança dos usuários e causam problemas ambientais. Além disso, quando consideramos todo o ciclo de vida de um produto, as falhas frequentes vão de encontro a uma das propostas de valor do OSD, identificada na literatura: a redução de custo dos produtos. Assim, vale a pena uma reflexão sobre em quais produtos, ou tipos de produtos, a fabricação no modelo DIY é vantajosa.

Na próxima seção são apresentadas as contribuições desta pesquisa.

\subsection{Contribuições da pesquisa}

As contribuições desta pesquisa estão organizadas em cinco tópicos: contribuições para a comunidade acadêmica, contribuições para a comunidade prática, contribuições para a sociedade, contribuições para a organização pesquisada, e contribuições para o pesquisador.

Quanto às contribuições para a comunidade acadêmica, destacam-se:

- A caracterização do PDP no open source design, contribuindo para o avanço da teoria acerca deste fenômeno contemporâneo, e evolução do modelo conceitual proposto por Fjeldsted et al., (2012);

- A síntese da literatura e as reflexões do autor, com base no estudo de caso, sobre as características da plataforma de colaboração, das comunidades e seus membros, dos motivadores, e dos modelos de negócio do open source design, contribuindo para a caracterização dos demais elementos fundamentais do open source design;

- A proposição de uma definição para o termo open source design, levando em consideração às definições identificadas na literatura para outras terminologias que também se referem a este fenômeno, contribuindo para o entendimento dos limites do open source design e para a identificação das semelhanças e diferenças entre o OSD e outras estratégias e práticas de co-criação; e 
- A metodologia utilizada nesta pesquisa, contribuindo para realização de estudos qualitativos no campo do design, que tenham como objetivo a caracterização robusta de um fenômeno.

Quanto às contribuições para a comunidade prática, destacam-se:

- O relato das experiências vivenciadas junto à comunidade Open Source Ecology e a análise dos principais incidentes observados no PDP desta organização, possibilitando a outras iniciativas de OSD um caso benchmarking; e

- A síntese da literatura sobre as oportunidade e ameaças para o open source design, de modo a incentivar novas iniciativas de OSD (oportunidades) e alertar as iniciativas existentes (ameaças);

- A síntese da literatura sobre as oportunidade e ameaças para as indústrias existentes, de modo a incentivar um maior envolvimento das empresas tradicionais nas iniciativas de OSD.

Quanto às contribuições para a sociedade, destacam-se:

- A contextualização e a síntese da literatura sobre as oportunidade e ameaças para o open source design, contribuindo para um maior entendimento de um fenômeno crescente, com potencial de mudar radicalmente a maneira como nós adquirimos uma grande variedade de produto.

Quanto às contribuições para a organização pesquisada, destacam-se:

- O relato das experiências vivenciadas pelo autor deste trabalho junto à comunidade e a análise dos principais incidentes observados no PDP desta organização, contribuindo para a identificação de oportunidades de melhoria no processo de desenvolvimento de produtos dessa organização e a apresentação de um feedback detalhado, e cuidadosamente elaborado, sobre a primeira edição do programa de verão denominado "Summer of Extreme Design/Build".

Quanto às contribuições para o pesquisador, destacam-se:

- A realização de um estudo de caso de caráter etnográfico, proporcionando ao pesquisador a criação de empatia com o tema estudado, e o desenvolvimento confiança e habilidades para a prototipagem de produtos no modelo DIY; e 
- A publicação de três artigos acadêmicos em congressos nacionais e internacionais (MACUL et al., 2014; MACUL; ROZENFELD, 2015a, 2015b).

Nesta seção foram apresentadas as contribuições desta pesquisa. Na seção a seguir são apresentadas as limitações da pesquisa e a sugestão de trabalhos futuros.

\subsection{Limitações da pesquisa e sugestão de trabalhos futuros}

Como toda pesquisa, este trabalho apresenta suas limitações. A principal limitação desta pesquisa consiste no tamanho da amostra do estudo de caso. Por se tratar de um estudo de caso único, as características do PDP identificadas no caso não podem ser generalizadas para todo o movimento do OSD. Há também outras limitações, relacionadas às fontes de evidência selecionadas. A análise de documentos pode apresentar uma seletividade tendenciosa, já não foi realizada uma analise completa dos documentos da organização pesquisada. Já a observação participante limita-se por ser uma fonte de evidência obrigatoriamente seletiva, pois depende dos eventos que o pesquisador decidiu participar. Durante o período de observação participante, o pesquisador participou de muitas atividades relacionadas às fases de prototipagem e teste, no entanto, pouco foi observado das atividades relacionadas às fases de pesquisa e design. Além disso, as observações realizadas podem apresentar vieses devido a manipulações dos eventos por parte do pesquisador, e os acontecimentos podem ocorrer de forma diferenciada por estar sendo observado (YIN, 2005, p. 113).

Um dos maiores riscos na utilização da observação participante é de o pesquisador imergir totalmente na organização pesquisada de forma que isso faça com que ele perca a oportunidade de identificar situações que necessitam explicação (Scott, 1965 apud Karlsson, 2009, p. 213). Uma maneira de evitar que isso ocorra é intercalar o período de observação participante com períodos em que o pesquisador volta para o ambiente da academia. Esse tempo é útil para que 0 pesquisador possa revisar a literatura, escrever sobre suas notas de campo e discutir com seus colegas os resultados obtidos (KARLSSON, 2009, p. 213). Caso 
pesquisas futuras se baseiem na metodologia utilizada neste trabalho, aconselha-se que essa recomendação seja seguida.

De uma maneira geral, sugere-se para trabalhos futuros, a realização de mais estudos qualitativos, a fim de proporcionar um entendimento mais profundo do PDP no open source design, explorando outros casos nos quais esta estratégia é adotada. Sugere-se, também, que sejam realizadas investigações a fim de caracterizar os demais elementos do OSD, como as plataformas de colaboração, as comunidades, e os modelos de negócio adotados pelas organizações que atuam nesse contexto. Sugestões mais pontuais para trabalhos futuros incluem:

- Um estudo da aplicação de um modelo de referência para o PDP em iniciativas de open source design, com o propósito de auxiliar na estruturação/documentação da vasta quantidade de informações existentes sobre o trabalho realizado no PDP e como realizá-lo;

- Um estudo sobre como melhorar a experiência dos colaboradores ao interagir por meio das plataformas de colaboração, por exemplo, utilizando práticas de gamification ${ }^{58}$ e a tecnologia de realidade virtual $^{59}$;

- Um levantamento do tipo survey entre as comunidades de OSD a fim de identificar as características dos colaboradores destas comunidades, de acordo com dimensões apresentadas na seção 2.2.3: (1) expertise; (2) intensidade de uso; (3) novas necessidades; e (4) originalidade;

- Um estudo dos pontos positivos e negativos de adotar o open source design, como estratégia para o desenvolvimento de um PSS; e

- Um estudo sobre a adoção de um caso de open source design como projeto didático para auxiliar no ensino de design e engenharia.

\footnotetext{
${ }^{58}$ Gamification consiste no uso de elementos de game e técnicas de design de game fora do contexto de um game (HUNTER; WERBACH, 2012).

${ }^{59}$ Realidade virtual é uma tecnologia de interface avançada entre um usuário e um sistema computacional com o objetivo de recriar ao máximo a sensação de realidade para um indivíduo. Disponível em https://pt.wikipedia.org/wiki/Realidade virtual, acessado em 19/07/2015.
} 


\section{Referências}

ABEL, B. VAN; EVERS, L.; KLAASSEN, R. Preface. In: B. van Abel; R. Klaassen; L. Evers; P. Troxler (Eds.); Open Design Now: Why Design Cannot Remain Exclusive, 2011. Amsterdam: BIS Publishers. Disponível em: $<$ http://opendesignnow.org/>. .

ABEL, B. VAN; EVERS, L.; KLAASSEN, R.; TROXLER, P. Open Design Now: Why Design Cannot Remain Exclusive. BIS Publishers, 2011.

ALMIRALL, E.; LEE, M.; WAREHAM, J. Mapping Living Labs in the Landscape of Innovation Methodologies. Technology Innovation Management Review, , n. September, p. 12-18, 2012.

AMIGO, C. R. Modelos de referência para o processo de desenvolvimento de produtos: novas possibilidades de representação, 2013. Universidade de São Paulo.

AMIGO, C. R.; IRITANI, D. R.; ROZENFELD, H.; OMETTO, A. R. Product development process modeling: state of the art and classification. In: M. Abramovici; R. Stark (Eds.); Smart Product Engineering. Series: Lecture Notes in Production Engineering. p.169-179, 2013. Berlin: Springer-Verlag Berlin Heidelberg. Disponível em: <http://link.springer.com/chapter/10.1007/978-3-642-30817-8_17>. .

ATKINSON, P. Do It Yourself: Democracy and Design. Journal of Design History, v. 19, n. 1, p. 1-10, 2006. Disponível em: <http://jdh.oxfordjournals.org/cgi/doi/10.1093/jdh/epk001 >. Acesso em: 6/6/2014.

ATKINSON, P. Boundaries? What Boundaries? The Crisis of Design in a PostProfessional Era. 8th European Academy Of Design Conference. Anais... . p.30-34, 2009. Aberdeen, Scotland.

ATKINSON, P. Orchestral Manoeuvres in Design. In: B. van Abel; R. Klaassen; L. Evers; P. Troxler (Eds.); Open Design Now: Why Design Cannot Remain Exclusive, 2011. Amsterdam: BIS Publishers. Disponível em: $<$ http://opendesignnow.org/>. .

AVITAL, M. The Generative Bedrock of Open Design. In: B. van Abel; R. Klaassen; L. Evers; P. Troxler (Eds.); Open Design Now: Why Design Cannot Remain Exclusive, 2011. Amsterdam: BIS Publishers. Disponível em: $<$ http://opendesignnow.org/>. .

BALDAM, R.; VALLE, R.; ROZENFELD, H. Gerenciamento de Processos de Negócio - BPM: Uma referência para implantação prática. 1st ed. Rio de Janeiro: Elsevier, 2014. 
BALDWIN, C.; HIPPEL, E. VON. Modeling a Paradigm Shift: From Producer Innovation to User and Open Collaborative Innovation. Organization Science, v. 22, n. 6, p. $1399-1417,2011$.

BALKA, K.; RAASCH, C.; HERSTATT, C. Open source enters the world of atoms: A statistical analysis of open design. First Monday, v. 14, n. 11, 2009.

BALKA, K.; RAASCH, C.; HERSTATT, C. How Open is Open Source? Software and Beyond. Creativity and Innovation Management, v. 19, n. 3, p. 248256, 2010. Disponível em: <http://doi.wiley.com/10.1111/j.1467-8691.2010.00569.x>. Acesso em: 30/5/2014.

BALL, L. J.; ORMEROD, T. C. Applying ethnography in the analysis and support of expertise in engineering design. , v. 21, p. 403-421, 2000. Disponível em: <http://www.sciencedirect.com/science/journal/0142694X>. .

BAUWENS, M. The Emergence of Open Design and Open Manufacturing. we_magazine, 2010. Disponível em: <http://www.we-magazine.net/we-volume02/the-emergence-of-open-design-and-open-manufacturing/>. .

BERT MULDER. Design and Government. In: B. van Abel; R. Klaassen; L. Evers; P. Troxler (Eds.); Open Design Now: Why Design Cannot Remain Exclusive, 2011. Amsterdam: BIS Publishers. Disponível em: <http://opendesignnow.org/>. .

BROWNING, T. R. The Many Views of a Process: Toward a Process Architecture Framework for Product Development Processes. Systems Engineering, v. 12, n. 1, p. 69-90, 2008.

BROWNING, T. R.; FRICKE, E.; NEGELE, H. Key concepts in modeling product development processes. Systems Engineering, v. 9, n. 2, p. 104-128, 2006. Disponível em: <http://doi.wiley.com/10.1002/sys.20047>. .

BROWNING, T. R.; RAMASESH, R. V. A survey of activity network-based process models for managing product development projects. Production and Operations Management, v. 16, n. 2, p. 217-240, 2007. Disponível em: $<$ http://apps.isiknowledge.com/full_record.do?product=UA\&search_mode=GeneralSe arch\&qid $=3 \& S I D=1 F 2 e c 4512 P 3 N c G P F I D 3 \&$ page $=2 \& d o c=62 \&$ colname $=W O S>$. .

BRUIJN, E. DE. On the viability of the Open Source Development model for the design of physical objects: Lessons learned from the RepRap project, 2010. University of Tilburg.

CASH, P.; HICKS, B.; CULLEY, S.; ADLAM, T. A foundational observation method for studying design situations. Journal of Engineering Design, , n. March, p. 1-33, 2015. Disponível em: <http://www.tandfonline.com/doi/abs/10.1080/09544828.2015.1020418>. .

CLARK, K. B.; WHEELWRIGHT, S. C. Managing new product and process development: text and cases. Free Press, 1993. 
CONFORTO, E. C. Modelo e ferramenta para avaliação da agilidade no gerenciamento de projetos, 2013. Universidade de São Paulo.

COOPER, R. G. Winning at New Products: Accelerating the Process from Idea to Launch. 3rd ed. Cambridge, Mass.: Perseus, 2001.

COOPER, R. G.; EDGETT, S. J. Successful Product Innovation. Product Development Institute Inc., 2009.

COSTA, J. M. H.; ROZENFELD, H.; AMARAL, C. S. T.; MARCACINIT, R. M.; REZENDE, S. O. Systematization of Recurrent New Product Development Management Problems. Engineering Management Journal, v. 25, n. 1, p. 19-34, 2013.

CRAWFORD, C. M.; BENEDETTO, C. A. DI. New products management. 8th ed. McGraw-Hill//Irwin, 2006.

DENZIN, N. K.; LINCOLN, Y. S. Introdução: A disciplina e a prática da pesquisa qualitativa. In: N. K. Denzin; Y. S. Lincoln (Eds.); Planejamento da pesquisa qualitativa - teorias e abordagens. 4th ed., p.15-41, 2006. Porto Alegre: Artmed.

DICK RIJKEN. Design Literacy: Organizing Self-Organization. In: B. van Abel; R. Klaassen; L. Evers; P. Troxler (Eds.); Open Design Now: Why Design Cannot Remain Exclusive, 2011. Amsterdam: BIS Publishers. Disponível em: $<$ http://opendesignnow.org/>. .

ECHEVESTE, M. E.; AMARAL, C. S. T.; ROZENFELD, H. A support tool for the selection of statistical techniques for industrial product development and improvement processes. In: G. Loureiro; R. Curran (Eds.); Complex Systems Concurrent Engineering. 1st ed., v. 55, p.247-255, 2007. London: Springer.

ESTELLES-AROLAS, E.; GONZALEZ-LADRON-DE-GUEVARA, F. Towards an integrated crowdsourcing definition. Journal of Information Science, v. 38, n. 2, p. 189-200, 2012. Disponível em: <http://jis.sagepub.com/cgi/doi/10.1177/0165551512437638>. Acesso em: 27/9/2013.

FABLAB. Fab Lab Location. Disponível em: <https://www.fablabs.io/map>. Acesso em: 29/5/2015.

FATHIANATHAN, M.; PANCHAL, J. H.; NEE, A. Y. C. A platform for facilitating mass collaborative product realization. CIRP Annals - Manufacturing Technology. Anais... . v. 58, p.127-130, 2009. Disponível em: $<$ http://linkinghub.elsevier.com/retrieve/pii/S0007850609000213>. Acesso em: 28/1/2014.

FJELDSTED, A. S.; ADALSTEINSDOTTIR, G.; HOWARD, T. J.; MCALOONE, T. Open Source Development of Tangible Products. NordDesign 2012. Anais... . p.1-9, 2012. Aalborg, Denmark. 
GACEK, C.; ARIEF, B. The many meanings of Open Source. IEEE Software, p. 34-40, 2004.

GASSMANN, O. Opening Up the Innovation Process: Towards an Agenda. R\&D Management, v. 36, n. 3, p. $223-228,2006$.

GOLDRATT, E. M. It's not luck. Great Barrington: North River Press, 1994.

GOOGLE. Google Maps. Disponível em: <https://www.google.com.br/maps>. Acesso em: 14/6/2015.

HACKERSPACES.ORG. Hackerspaces Location. Disponível em: <https://wiki.hackerspaces.org/List_of_Hacker_Spaces>. Acesso em: 29/5/2015.

HIENERTH, C. The commercialization of user innovations: The development of the rodeo kayak industry. R\&D Management, v. 36, n. 3, p. 273-294, 2006. 2005.

HIPPEL, E. VON. Democratizing Innovation. Cambridge, MA: MIT Press,

HIPPEL, E. VON; JONG, J. P. J. DE; FLOWERS, S. Comparing business and household sector innovation in consumer products: Findings from a representative study in the UK. 2011.

HIPPEL, E. VON; KROGH, G. VON. Open Source Software and the "PrivateCollective "Innovation Model: Issues for Organization Science. Organization Science, v. 14, n. 2, p. 209-223, 2003.

HIPPEL, E. VON; OGAWA, S.; JONG, J. P. J. DE. The Age of the ConsumerInnovator. MIT Sloan Management Review, v. 53, n. 1, p. 27-35, 2011.

HOWARD-GRENVILLE, J. A. The Persistence of Flexible Organizational Routines: The Role of Agency and Organizational Context. Organization Science, v. 16, n. 6, p. 618-636, 2005. Disponível em: $<$ http://pubsonline.informs.org/doi/abs/10.1287/orsc.1050.0150>. Acesso em: 29/4/2014.

HOWE, J. The Rise of Crowdsourcing. Wired Magazine, , n. 14, p. 1-5, 2006.

HUMMELS, C. Teaching Attitudes, Skills, Approaches, Structure And Tools. In: B. van Abel; R. Klaassen; L. Evers; P. Troxler (Eds.); Open Design Now: Why Design Cannot Remain Exclusive, 2011. Amsterdam: BIS Publishers. Disponível em: <http://opendesignnow.org/>. .

HUNTER, D.; WERBACH, K. For the Win: How Game Thinking Can Revolutionize Your Business. Wharton Digital Press, 2012.

IACONO, J.; BROWN, A.; HOLTHAM, C. Research Methods - a Case Example of Participant Observation. The Electronic Journal of Business Research Methods, v. 7, n. 1, p. $39-46,2009$. 
ILAN, Z. B. From Economy of Commodities to Economy of Ideas: Hardware as Social Medium. Design Management Review, v. 22, n. 3, p. 44-53, 2011.

ISO-9241-210. Ergonomics of human-system interaction - Part 210: Human-centred design for interactive systems. 2010.

JESTON, J.; NELIS, J. Business Process Management - Practical Guidelines to Successful Implementations. Elsevier, 2006.

JONG, J. P. J. DE; BRUIJN, E. DE. Innovation Lessons From 3-D Printing. MIT Sloan Management Review, v. 54, n. 2, p. 43-52, 2013.

KAMBIL, A.; FRIESEN, G. .; SUNDARAM, A. Co-creation: A new source of value. Accenture Outlook, p. 38-43, 1999. Disponível em: $<$ http://www.accenture.com/SiteCollectionDocuments/PDF/cocreation2.pdf>. .

KARLSSON, C. Researching in Operations Management. New York: Routledge, 2009.

KATZ, A. Authors and Owners. In: B. van Abel; R. Klaassen; L. Evers; P. Troxler (Eds.); Open Design Now: Why Design Cannot Remain Exclusive, 2011. Amsterdam: BIS Publishers. Disponível em: <http://opendesignnow.org/>. .

KATZY, B. R. Designing Viable Business Models for Living Labs. Technology Innovation Management Review, , n. September, p. 19-24, 2012.

KLAASSEN, R.; TROXLER, P. Do It with Droog. In: B. van Abel; R. Klaassen; L. Evers; P. Troxler (Eds.); Open Design Now: Why Design Cannot Remain Exclusive, 2011. Amsterdam: BIS Publishers. Disponível em: $<$ http://opendesignnow.org/>. .

LEMINEN, S.; WESTERLUND, M.; NYSTRÖM, A.-G. Living Labs as OpenInnovation Networks. Technology Innovation Management Review, , $\mathrm{n}$. September, p. 6-11, 2012.

LERNER, J.; TIROLE, J. Some Simple Economics of Open Source. The Journal of Industrial Economics, v. 50, n. 2, p. 197-234, 2002. Disponível em: <http://doi.wiley.com/10.1111/1467-6451.00174>. .

MACUL, V. C.; AFFONSO, C. A. C.; AMARAL, D. C.; ROZENFELD, H. Caracterizando o Open Collaborative Design: o fenômeno do desenvolvimento colaborativo de produtos open-source por meio de comunidades de usuários. XXXVI ENCONTRO NACIONAL DE ENGENHARIA DE PRODUCAO. Anais... , 2014. Curitiba/PR: ENEGEP.

MACUL, V. C.; ROZENFELD, H. How an open source design community works. International Conference of Engineering Design, ICED15. Anais... , 2015a. Milano. No prelo. 
MACUL, V. C.; ROZENFELD, H. Caracterização do processo de desenvolvimento de produtos em uma comunidade de open source design. Congresso Brasileiro de Gestão de Desenvolvimento de Produto, CBGDP. Anais... , 2015b. Itajubá/MG. No prelo.

MCPHEE, C.; WESTERLUND, M.; LEMINEN, S. Editorial: Living Labs. Technology Innovation Management Review, , n. September, p. 3-5, 2012.

MUL, J. DE. Redesigning Design. In: B. van Abel; R. Klaassen; L. Evers; P. Troxler (Eds.); Open Design Now: Why Design Cannot Remain Exclusive, 2011. Amsterdam: BIS Publishers. Disponível em: <http://opendesignnow.org/>. .

NIITAMO, V.-P.; WESTERLUND, M.; LEMINEN, S. A Small-Firm Perspective on the Benefits of Living Labs. Technology Innovation Management Review, , n. September, p. 44-49, 2012.

OSE. Open Source Ecology Wiki. Disponível em: <http://opensourceecology.org/wiki/>. Acesso em: 9/6/2015a.

OSE. Open Source Ecology Albums. Disponível em: <https://opensourceecology.trovebox.com/albums/list>. Acesso em: 9/6/2015b.

OSE. Open Source Ecology Documentation. Disponível em: <http://opensourceecology.dozuki.com/>. Acesso em: 9/9/2015c.

OSTERWALDER, A.; PIGNEUR, Y. Business Model Generation. Amsterdam: Self Published, 2010. 1988.

PAHL, G.; BEITZ, W. Engineering Design. London: The Design Council,

PANCHAL, J. H.; FATHIANATHAN, M. Product realization in the age of mass collaboration. ASME 2008 Iternational Design Engineering Technical Conferences \& Computers and Information in Engineering Conference. Anais... . p.1-11, 2008. New York.

PETTIS, B. Made in My Backyard. In: B. van Abel; R. Klaassen; L. Evers; P. Troxler (Eds.); Open Design Now: Why Design Cannot Remain Exclusive, 2011. Amsterdam: BIS Publishers. Disponível em: <http://opendesignnow.org/>. .

PMI. Um Guia Do Conhecimento Em Gerenciamento de Projetos: Project Management Institute, 2008.

PRAHALAD, C. K.; KRISHNAN, M. S. The new age of innovation: driving co-created value through global networks. McGraw-Hill, 2008.

RAASCH, C.; HERSTATT, C.; BALKA, K. On the open design of tangible goods. R and D Management, v. 39, n. 4, p. 382-393, 2009. 
RENTES, A. F. TransMeth - Proposta de uma metodologia para condução de processos de transformação de empresas, 2000. Universidade de São Paulo.

ROZENFELD, H.; FORCELLINI, F. A.; AMARAL, D. C.; et al. Gestão de Desenvolvimento de Produtos. 1st ed. São Paulo: Saraiva Editora, 2006.

ROZENFELD, H.; FORCELLINI, F. A.; TOLEDO, J. C. DE; et al. Development of a reference model for integrating product development process-related knowledge. 17th International Congress of Mechanical Engineering. Anais..., 2003.

SCHAFFERS, H.; TURKAMA, P. Living Labs for Cross-Border Systemic Innovation. Technology Innovation Management Review, , n. September, p. 2530, 2012.

SCHUH, G.; ASSMUS, D.; ZANCUL, E. Product Structuring - the Core Discipline of Product Lifecycle Management. Proceedings of LCE2006. Anais... . p.393-398, 2006. 13th CIRP International Conference on Life Cycle Engineering.

SCHUH, G.; ROZENFELD, H.; ASSMUS, D.; ZANCUL, E. Process oriented framework to support PLM implementation. Computers in Industry, v. 59, n. 2-3, p. 210-218, $2008 . \quad$ Disponível em: <http://linkinghub.elsevier.com/retrieve/pii/S0166361507001042>. .

SCHUURMAN, D.; MAREZ, L. DE. Structuring User Involvement in PanelBased Living Labs. Technology Innovation Management Review, , n. September, p. 31-38, 2012.

SEND, H.; FRIESIKE, S.; ZUCH, A. N.; STEINGRÍMSSON, J. G.; SELIGER, G. Value creation in open source hardware models. In: G. Seliger (Ed.); 11th Global Conference on Sustainable Manufacturing - Innovative Solutions. Anais... . p.542548, 2013. Berlin.

SHAH, S. Sources and patterns of innovation in a consumer products field: Innovations in sporting equipment. Cambridge, MA, 2000.

SHIRKY, C. Generalizing Peer Production into the Physical World. Disponível em:

<https://groups.yahoo.com/neo/groups/decentralization/conversations/topics/6967>. Acesso em: 31/3/2015.

SINGH, S.; GOODYER, J.; POPPLEWELL, K. Integrated environmental process planning for the design and manufacture of automotive components. International Journal of Production Research, v. 45, n. 18-19, p. 4189-4205, 2007. Disponível

em: <http://www.tandfonline.com/doi/abs/10.1080/00207540701472710>. Acesso em: $31 / 5 / 2014$.

STAPPERS, P. J.; VISSER, F. S.; KISTEMAKER, S. Creation \& Co: User Participation In Design. In: B. van Abel; R. Klaassen; L. Evers; P. Troxler (Eds.); 
Open Design Now: Why Design Cannot Remain Exclusive, 2011. Amsterdam: BIS Publishers. Disponível em: <http://opendesignnow.org/>. .

SUROWIECKI, J. The Wisdom of Crowds. New York: Anchor Books, 2005.

TAN, A. R. Service-oriented product development strategies, 2010. Technical University of Denmark (DTU).

TECHSHOP. TechShop Location. Disponível em: $<$ <ttp://www.techshop.ws/locations.html>. Acesso em: 28/4/2015.

THACKARA, J. Into the Open. In: B. van Abel; R. Klaassen; L. Evers; P. Troxler (Eds.); Open Design Now: Why Design Cannot Remain Exclusive, 2011. Amsterdam: BIS Publishers. Disponível em: <http://opendesignnow.org/>. .

THOMSON, C. C.; JAKUBOWSKI, M. Toward an Open Source Civilization. Innovations, v. 7, n. 3, p. 53-70, 2012.

TROXLER, P. Libraries of the Peer Production Era. In: B. van Abel; R. Klaassen; L. Evers; P. Troxler (Eds.); Open Design Now: Why Design Cannot Remain Exclusive, 2011. Amsterdam: BIS Publishers. Disponível em: <http://opendesignnow.org/>. .

ULRICH, K. T.; EPPINGER, S. D. Product Design and Development. 4th ed. McGraw-Hill Higher Education, 2007.

VERNADAT, F. Enterprise Modeling and Integration: Principles and Applications. Springer, 1996.

WELLMAN, B.; BOASE, J.; CHEN, W. The Networked Nature of Community: Online and Offline. IT\&Socity, v. 1, n. 1, p. 151-165, 2002.

WEST, J.; O'MAHONY, S. The Role of Participation Architecture in Growing Sponsored Open Source Communities. Industry \& Innovation, v. 15, n. 2, p. 145168, 2008.

YIN, R. K. Estudo de Caso: planejamento e métodos. 3rd ed. Porto Alegre: Bookman, 2005. 


\section{APÊNDICE A - Análise dos dados}

Este apêndice apresenta alguns detalhes sobre a análise dados, a Etapa 4 desta pesquisa. Na seção 1 uma síntese da literatura sobre Árvore de Causa e Efeito, de modo a esclarecer eventuais dúvidas sobre a utilização desse método. $\mathrm{Na}$ seção 2, a fim de fornecer material para comparação, são apresentados os problemas, identificados na literatura, que ocorrem durante o processo de desenvolvimento de produtos em empresas tradicionais, ou seja, que não realizam projetos de open source design. Na seção 3, é apresentada a lista dos incidentes identificados, acompanhado de sua codificação. Por fim, na seção 4 é apresentada a Árvore de Causa e Efeito retratando a situação atual da OSE no período da observação praticante.

\section{Como utilizar a Árvore de Causa e Efeito}

A Árvore de Causa e Efeito baseia-se na relação-chave: SE-ENTÃO. SE a hipótese for verdadeira (causa), ENTÃO logicamente deve existir um fato relacionado a ela (efeito). Na construção da Árvore de Causa e Efeito, as causas são relacionadas aos efeitos por meio de setas. No caso de mais de uma causa para um mesmo efeito, são utilizados dois tipos de conectores lógicos: o conector do tipo 'OU' e conector do tipo 'E'. Utiliza-se o 'OU' quando a eliminação de apenas uma das causas não é garantia da eliminação do efeito. Utiliza-se o 'E' quando, se eliminada apenas uma das causas, o efeito também é eliminado (GOLDRATT, 1994). A Figura 45 apresenta como estes conectores são representados na construção da Árvore de Causa e Efeito. 


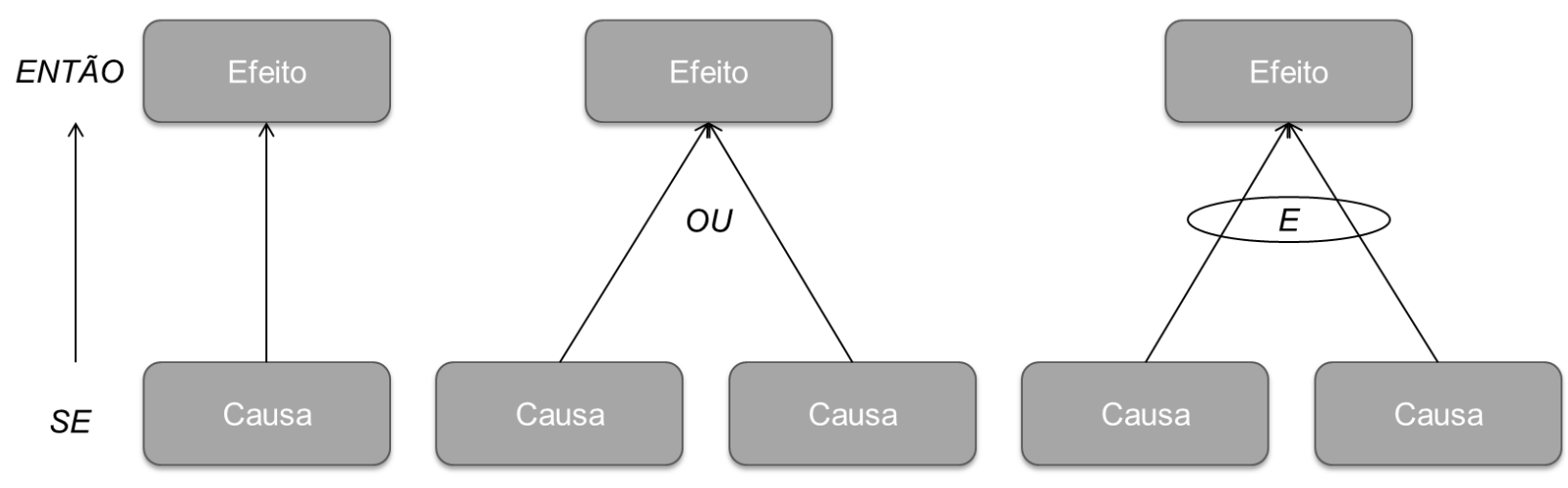

Figura 45 - Representação lógica da relação causa-e-efeito

Além da lógica por trás dos conectores, a construção da Árvore de Causa e Efeito segue algumas regras, também chamadas de Categorias de Reservas Legítimas. Com essas regras, busca-se a padronização, a melhoria da qualidade da Árvore de Causa e Efeito e o direcionamento das críticas efetuadas no momento do escrutínio da árvore, isto é, sua conferência (DETTMER, 1997, apud RENTES, 2000 , p. 128). Os principais pontos definidos pelas Categorias de Reservas Legítimas são:

- Clareza, isto é, bom entendimento da estrutura;

- Existência da entidade, isto é, afirmações propriamente estruturadas e completas;

- Existência de causalidade, isto é, conexões entre causa e efeito;

- Insuficiência de causa, isto é, as causas levantadas não são suficientes para provocar o efeito apresentado.

A fim de auxiliar a utilização da ferramenta, Rentes (2000) propõe um processo de construção para Árvore de Causa e Efeito, apresentado na Figura 46. $\mathrm{O}$ autor sugere que o processo seja conduzido por uma equipe, contendo de quatro a oito pessoas, e que parte dela tenha participado no levantamento da situação atual, ou seja, na identificação dos efeitos indesejáveis (RENTES, 2000, p. 127). No entanto, devido à intensidade do trabalho durante a pesquisa de campo e de acordo com as prioridades do líder do projeto, não foi possível realizar a análise dos dados simultaneamente com a coleta, e perdi a oportunidade de construir a Árvore de Causa e Efeito com a ajuda de outros colaboradores da OSE. Desse modo, a Árvore de Causa e Efeito foi realizada pelo pesquisador no Brasil. A Figura 47 ilustra parte do processo de construção da Árvore de Causa e Efeito. 


\section{Criação de uma lista de Efeitos Indesejáveis}

-Colete os Efeitos Indesejáveis (EI) levantados.

-Individualize estes efeitos em uma lista de EI na forma de afirmações claras. Utilize um

post-it para cada afirmação;

-Disponha os El em um quadro.

2. Inter-relação (um a um) entre os El.

-Inter-relacione os El, criando relações de causa e efeito;

- Construa pequenos fragmentos de árvore.

\section{Construção da primeira tentativa de Árvore da Realidade Atual}

- Construa ligações entre os fragmentos;

-Pense na existência de causas mais profundas, que possam fazer conexões entre os fragmentos;

- Leia a Árvore da Realidade Atual (ARA) resultante, considerando as Categorias de Reservas Legítimas;

-Adicione mais informações se necessário.

\section{Escrutínio da ARA}

-Apresente a árvore para o grupo de projeto que foi entrevistado durante o Levantamento de Situação;

- Identifique e registre as críticas e observações complementares à realidade apresentada na ARA.

\section{Reconstrução da ARA, caso necessário}

- Individualize as novas entidades ou El em afirmações, incluindo-as na ARA;

-Modifique as relações entre as entidades, caso necessário;

-Questione se a ARA resultante reflete a sua intuição sobre a área;

-Adicione novas entidades se necessário;

-Apresente a ARA novamente para o grupo de projeto.

\section{Identificação das Causas Raízes}

• Examine as "entradas da ARA", isto é, entidades que não têm seta "entrando", só saindo;

•Identifique as causas raízes que apresentam mais contribuições em termos de El.

Figura 46 - Processo para a construção da Árvore da Realidade Atual (RENTES, 2000, p. 127) 


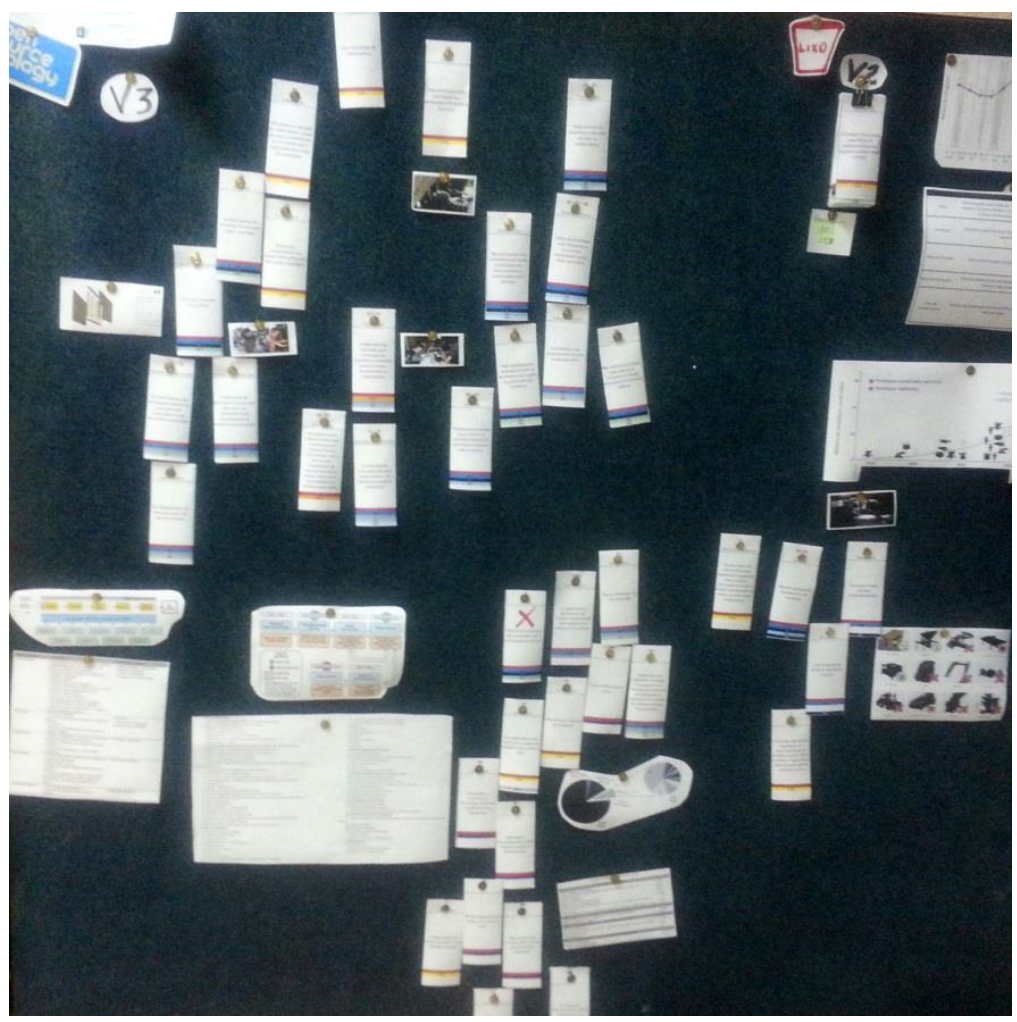

Figura 47 - Representação de parte do processo de construção da Árvore de Causa e Efeito

\section{Problemas recorrentes do PDP segundo a literatura}

A implantação do processo de desenvolvimento de produtos é um grande desafio, e muitas empresas não atingem os resultados esperados quando colocam o processo em prática. Cooper e Edgett (2009, p. 45) corroboram com essa visão e apontam que a diferença entre as organizações bem-sucedidas e as mal sucedidas está na maneira com que o processo é implantado. Há evidências de que as organizações apresentam dificuldades comuns na gestão do processo de desenvolvimento de produtos (COSTA et al., 2013, p. 25). A falta de recursos, a execução de muitos projetos simultaneamente, e a falta de comprometimento da alta direção podem ser a base de alguns desses problemas (COOPER; EDGETT, 2009, p. 63).

Costa et al. (2013) investigaram os problemas que ocorrem durante o PDP em oito estudos de caso $^{60}$, e levantaram uma lista de problemas recorrentes, de modo a facilitar o diagnóstico do processo de desenvolvimento de produtos em

60 Foram conduzidos 8 estudos de caso, nos quais foram entrevistados 124 pessoas envolvidas com o processo de desenvolvimento de produtos. 
casos específicos. Dentre os problemas levantados, foram identificadas as causasraiz, ou seja, os problemas responsáveis por originar todos os outros. A Tabela 11 apresenta a lista dos problemas relevantes que ocorrem durante o PDP. Os problemas em destaque na tabela representam aqueles identificados como causasraiz.

Tabela 11 - Lista de problemas relevantes do PDP (COSTA et al., 2013, p. 26)

\begin{tabular}{ll}
\hline Problemas recorrentes durante o PDP & Ocorrência \\
\hline Inexistência/deficiência da gestão do portfolio de produtos & 6 \\
\hline Inexistência/deficiência da gestão de requisitos dos produtos & 6 \\
\hline Inexistência/deficiência do planejamento estratégico & 5 \\
\hline Inexistência/falta de benchmarking & 5 \\
\hline Inexistência/falta de gestão dos recursos humanos & 5 \\
\hline Inexistência/falta de melhoria de processos & 5 \\
\hline Inexistência/falta de integração entre as pessoas envolvidas no PDP & 5 \\
\hline Inexistência/falta de visão do processo & 5 \\
\hline Inexistência/falta de planejamento do processo de produção & 5 \\
\hline Inexistência/falta de desenvolvimento de fornecedores & 5 \\
\hline Inexistência/falta de treinamento & 5 \\
\hline Alto custo do produto & 5 \\
\hline Inexistência/deficiência da gestão de mudanças de engenharia & 4 \\
\hline Inexistência/deficiência do planejamento estratégico de produtos & 4 \\
\hline Inexistência/deficiência em trabalhar em equipe & 4 \\
\hline Inexistência/deficiência na circulação de informações & 4 \\
\hline Inexistência/deficiência no uso de técnicas de gestão de projetos & 4 \\
\hline Inexistência/falha nos testes & 4 \\
\hline Inexistência/falta de definição de papéis/responsabilidades & 4 \\
\hline Inexistência/falta de medição dos custos & 4 \\
\hline Inexistência/falta de procedimentos & 4 \\
\hline Atraso no lançamento dos produtos & 4 \\
\hline Alta carga de trabalho & 4 \\
\hline Sistema de informação limitado & 4 \\
\hline Falta de conhecimento sobre as boas práticas do PDP & 4 \\
\hline Estrutura organizacional mal definida & 4 \\
\hline Reinventar a roda & 4 \\
\hline Equipe desmotivada & 4 \\
\hline Inexistência/deficiência na classificação dos projetos & 3 \\
\hline Inexistência/falta de um processo formal para gestão de projetos & 3 \\
\hline Falta de um repositório de conhecimentos sobre PDP & 3 \\
\hline Planejamento estratégico incompleto & 3 \\
\hline Inexistência/falta de formalização do PDP & 2 \\
\hline Dificuldade na identificação de habilidades & 2 \\
\hline Falta de conhecimento sobre as melhores práticas de gestão de projetos & 2 \\
\hline Falta de conhecimento sobre as potenciais tecnologias de informação e comunicação & 2 \\
\hline Problemas de relacionamento pessoal & 2 \\
\hline Redução de custos como uma meta principal & 2 \\
\hline Imaturidade tecnológica & 2 \\
\hline & \\
\hline
\end{tabular}


problemas recorrentes do PDP de organizações tradicionais, contribuindo assim, para a identificação de características que diferenciam 0 processo de desenvolvimento de produtos no open source design do PDP em organizações que não fazem parte desse fenômeno.

Na próxima seção são apresentados os incidentes identificados no estudo de caso, assim como os detalhes sobre sua codificação. 


\section{Os incidentes do caso e seus códigos}

Nesta seção são apresentados os incidentes identificados, acompanhados de seus códigos. Foram utilizadas seis categorias de códigos, descritas na Tabela 12. Conforme descrito na seção 3.5.3, há duas maneiras de selecionar as categorias utilizadas na classificação dos incidentes: retirar as categorias da teoria ou derivá-las dos próprios dados. Da teoria, foi retirada a categoria 'elementos'. As demais categorias foram derivadas dos próprios dados (narrativa), com base na semelhança do conteúdo dos incidentes e de acordo com o conhecimento sobre OSD adquirido pelo pesquisador durante o estudo de caso.

Tabela 12 - Categorias, opções e códigos utilizados na classificação dos incidentes

\begin{tabular}{|c|c|c|c|}
\hline Categoria & Descrição & Opção & Código \\
\hline Efeito & $\begin{array}{l}\text { Efeito causado pelo incidente. É classificado } \\
\text { como positivo quanto o incidente facilita o } \\
\text { OSD, e negativo quando ele se torna uma } \\
\text { barreira para o fenômeno (efeito indesejado) }\end{array}$ & $\begin{array}{l}\text { Positivo } \\
\text { Negativo }\end{array}$ & + \\
\hline Elemento & $\begin{array}{l}\text { Elemento fundamental do OSD ao qual o } \\
\text { incidente está associado }\end{array}$ & $\begin{array}{l}\text { Processo de } \\
\text { desenvolvimento de produtos } \\
\text { Plataforma de colaboração } \\
\text { Comunidade } \\
\text { Motivadores } \\
\text { Modelo de negócio }\end{array}$ & $\begin{array}{l}\text { PDP } \\
\text { PLA } \\
\text { COM } \\
\text { MOT } \\
\text { NEG } \\
\end{array}$ \\
\hline Fase do PDP & $\begin{array}{l}\text { Fase do PDP na qual o incidente está } \\
\text { associado }\end{array}$ & $\begin{array}{l}\text { Pesquisa } \\
\text { Design } \\
\text { Prototipagem } \\
\text { Teste }\end{array}$ & $\begin{array}{l}\text { R } \\
D \\
P \\
T\end{array}$ \\
\hline $\begin{array}{l}\text { Nível de } \\
\text { Abstração }\end{array}$ & $\begin{array}{l}\text { Nível de abstração das atividades do PDP } \\
\text { na qual o incidente está associado }\end{array}$ & $\begin{array}{l}\text { Conceitual } \\
\text { Detalhado }\end{array}$ & $\begin{array}{l}\mathrm{NC} \\
\mathrm{ND}\end{array}$ \\
\hline $\begin{array}{l}\text { Área de } \\
\text { Conhecimento }\end{array}$ & $\begin{array}{l}\text { Área de conhecimento, dentro do PDP, na } \\
\text { qual o incidente está associado }\end{array}$ & $\begin{array}{l}\text { Gestão de projetos } \\
\text { Gestão de processos } \\
\text { Métodos de design }\end{array}$ & $\begin{array}{l}\text { GP } \\
\text { BPM } \\
\text { MD }\end{array}$ \\
\hline
\end{tabular}

Um incidente pode ser classificado em mais de uma categoria, possibilitando a análise dos dados por diferentes pontos de vista. Nos casos em que não se aplica a classificação de um incidente em nenhuma segundo uma categoria, utiliza-se o código N/A. A Tabela 13 apresenta os incidentes que facilitam o OSD na organização pesquisada, já a Tabela 14 reúne os efeitos indesejados identificados.

$\mathrm{Na}$ seção 4.3 é realizada uma análise mais profunda sobre os principais incidentes do caso. Seguindo a metodologia apresentada na seção 3.5.4, os incidentes classificados com efeito negativo, ou seja, aqueles que representam uma 
barreira ao open source design, foram analisados por meio da construção da Árvore de Causa e Efeito. Na próxima seção, a Árvore obtida é apresentada na integra. 
Tabela 13 - Os incidentes que facilitam o OSD na OSE

\begin{tabular}{|c|c|c|c|c|c|c|c|}
\hline \multicolumn{4}{|c|}{ Incidentes } & \multicolumn{4}{|c|}{ Codificação } \\
\hline \# & $\begin{array}{l}\text { Atores ou } \\
\text { objetos }\end{array}$ & Ação ou comportamento observado & Fonte & Elemento & $\begin{array}{l}\text { Fase do } \\
\text { PDP }\end{array}$ & $\begin{array}{l}\text { Nível de } \\
\text { Abstração }\end{array}$ & $\begin{array}{l}\text { Área de } \\
\text { Conhecimento }\end{array}$ \\
\hline 7 & Colaboradores & $\begin{array}{l}\text { A busca por aprendizado, realização de atividades práticas, } \\
\text { diversão e desejo de contribuir com um projeto de impacto } \\
\text { social eram motivadores comuns a todos os colaboradores, logo, } \\
\text { o interesse em participar de workshops }\end{array}$ & $A D$ & MOT & $\mathrm{P}$ & ND & N/A \\
\hline 8 & Oficina & Havia uma oficina disponível & OP & COM & $\mathrm{N} / \mathrm{A}$ & $\mathrm{N} / \mathrm{A}$ & $\mathrm{N} / \mathrm{A}$ \\
\hline 9 & $\begin{array}{l}\text { Líder de } \\
\text { desenvolvimento }\end{array}$ & $\begin{array}{l}\text { Liderar um projeto de OSD é uma forma de fazer portfolio e } \\
\text { ganhar experiência }\end{array}$ & OP & MOT & N/A & N/A & N/A \\
\hline 14 & Workshop & $\begin{array}{l}\text { Colaboradores experientes, ao participarem dos workshops, } \\
\text { tendem a contribuir com a melhoria do design do produto } \\
\text { enquanto que colaboradores inexperientes tendem a contribuir } \\
\text { com a melhoria das instruções para construção }\end{array}$ & OP & PDP & $\mathrm{D}$ & ND & N/A \\
\hline 17 & Colaboradores & $\begin{array}{l}\text { Quando os colaboradores escolhem as atividades que vão } \\
\text { realizar, eles tendem a ser mais eficientes }\end{array}$ & OP & MOT & N/A & N/A & N/A \\
\hline 20 & Protótipo físico & Utilização dos protótipos desenvolvidos & $A D$ & PDP & $\mathrm{T}$ & ND & N/A \\
\hline 22 & Colaboradores & $\begin{array}{l}\text { Os colaboradores valorizavam a interação entre si, e o convívio } \\
\text { entre os eles incentiva a colaboração }\end{array}$ & OP & COM & N/A & N/A & N/A \\
\hline 29 & Colaboradores & $\begin{array}{l}\text { Muitos dos colaboradores eram universitários, e workshops } \\
\text { eram organizados em parceria com universidades }\end{array}$ & OP & COM & $\mathrm{N} / \mathrm{A}$ & $\mathrm{N} / \mathrm{A}$ & N/A \\
\hline 35 & Design sprints & $\begin{array}{l}\text { Reuniões por vídeo conferência com objetivos bem definidos e a } \\
\text { utilização de ferramentas que permitem a colaboração remota } \\
\text { em tempo real auxiliam no design e na documentação }\end{array}$ & OP & PDP & $\mathrm{D}$ & ND & N/A \\
\hline 38 & Workshop & $\begin{array}{l}\text { Algumas sugestões de melhoria do protótipo foram feitas no } \\
\text { início do workshop, e já foram implementadas no protótipo } \\
\text { construído }\end{array}$ & OP & PDP & $\mathrm{P}$ & ND & N/A \\
\hline 40 & Colaboradores & Haviam usuários dos produtos entre os colaboradores & OP & COM & $\mathrm{N} / \mathrm{A}$ & N/A & $\mathrm{N} / \mathrm{A}$ \\
\hline 46 & $\begin{array}{l}\text { Arquitetura do } \\
\text { produto }\end{array}$ & Divisão do produto em módulos & OP/AD & PDP & $\mathrm{D}$ & NC & MD \\
\hline
\end{tabular}


Tabela 13 - Os incidentes que facilitam o OSD na OSE (continuação)

\begin{tabular}{|c|c|c|c|c|c|c|c|}
\hline \multicolumn{4}{|c|}{ Incidentes } & \multicolumn{4}{|c|}{ Codificação } \\
\hline \# & $\begin{array}{l}\text { Atores ou } \\
\text { objetos }\end{array}$ & Ação ou comportamento observado & Fonte & Elemento & $\begin{array}{l}\text { Fase do } \\
\text { PDP }\end{array}$ & $\begin{array}{l}\text { Nível de } \\
\text { Abstração }\end{array}$ & $\begin{array}{l}\text { Área de } \\
\text { Conhecimento }\end{array}$ \\
\hline 47 & $\begin{array}{l}\text { Instruções para } \\
\text { construção }\end{array}$ & $\begin{array}{l}\text { Instruções detalhadas, contendo o passo-a-passo das atividades } \\
\text { ilustradas com os desenhos gerados no CAD, fotos, e vídeos, } \\
\text { reduzem a necessidade de conhecimentos técnicos }\end{array}$ & OP & PDP & $\mathrm{D}$ & ND & MD \\
\hline 49 & Protótipo físico & $\begin{array}{l}\text { Desmontar e montar o protótipo auxilia o colaborador no } \\
\text { entendimento da arquitetura do produto e de seu processo de } \\
\text { montagem }\end{array}$ & OP & PDP & $\mathrm{P}$ & ND & N/A \\
\hline 53 & $\begin{array}{l}\text { Instruções para } \\
\text { construção }\end{array}$ & $\begin{array}{l}\text { As instruções de cada módulo deveriam conter o tempo total } \\
\text { estimado para montagem, o nível de dificuldade, os materiais e } \\
\text { equipamentos necessários, uma visão geral do módulo, e uma } \\
\text { vista com as peças explodidas }\end{array}$ & OP/AD & PDP & $\mathrm{D}$ & ND & MD \\
\hline 54 & $\begin{array}{l}\text { Reunião de } \\
\text { acompanhamento }\end{array}$ & $\begin{array}{l}\text { Reuniões diárias auxiliam no planejamento e acompanhamento } \\
\text { das atividades }\end{array}$ & $\mathrm{OP}$ & PDP & $\mathrm{N} / \mathrm{A}$ & N/A & GP \\
\hline 55 & $\begin{array}{l}\text { Preparação para } \\
\text { workshop }\end{array}$ & $\begin{array}{l}\text { Montagem de kits com os componentes separados por } \\
\text { subsistemas/módulos auxiliam no controle dos materiais e } \\
\text { facilitam a organização de workshops }\end{array}$ & OP & PDP & $P$ & ND & N/A \\
\hline 57 & Instrutores & $\begin{array}{l}\text { Instrutores auxiliam os participantes na execução de atividades } \\
\text { técnicas de fabricação e montagem }\end{array}$ & OP & PDP & $P$ & ND & N/A \\
\hline 59 & Workshop & $\begin{array}{l}\text { Alocação de um responsável pela documentação durante a } \\
\text { prototipagem auxiliava na captura de informações úteis para a } \\
\text { elaboração das instruções para construção }\end{array}$ & $\mathrm{OP}$ & PDP & $\mathrm{P}$ & ND & N/A \\
\hline 60 & $\begin{array}{l}\text { Arquitetura do } \\
\text { produto }\end{array}$ & $\begin{array}{l}\text { A divisão do produto em módulos facilita o design colaborativo e } \\
\text { a prototipagem parcial }\end{array}$ & OP & PDP & $\mathrm{P}$ & ND & N/A \\
\hline 70 & $\begin{array}{l}\text { Reunião de } \\
\text { acompanhamento }\end{array}$ & $\begin{array}{l}\text { Reuniões comunitárias periódicas auxiliam a troca de feedback e } \\
\text { a interação entre os colaboradores }\end{array}$ & $\mathrm{OP}$ & COM & N/A & N/A & N/A \\
\hline 84 & Workshop & Equipes pequenas tendem a ser mais eficiente na construção & OP & PDP & $\mathrm{P}$ & ND & GP \\
\hline 85 & $\begin{array}{l}\text { Instruções para } \\
\text { manutenção }\end{array}$ & $\begin{array}{l}\text { Um roteiro para inspeção e manutenção do protótipo auxilia na } \\
\text { identificação e resolução de eventuais problemas }\end{array}$ & OP & PDP & $\mathrm{D}$ & ND & N/A \\
\hline
\end{tabular}


Tabela 13 - Os incidentes que facilitam o OSD na OSE (continuação)

\begin{tabular}{|c|c|c|c|c|c|c|c|}
\hline \multicolumn{4}{|c|}{ Incidentes } & \multicolumn{4}{|c|}{ Codificação } \\
\hline 87 & Workshop & $\begin{array}{l}\text { A cada prototipagem foram realizadas melhorias pontuais no } \\
\text { design do produto }\end{array}$ & $\mathrm{OP}$ & PDP & D & ND & $\mathrm{N} / \mathrm{A}$ \\
\hline 88 & $\begin{array}{l}\text { Preparação para } \\
\text { workshop }\end{array}$ & $\begin{array}{l}\text { Planejamento de workshops e a identificação do caminho crítico } \\
\text { na construção dos protótipos reduz o tempo de replicação dos } \\
\text { protótipos }\end{array}$ & $\mathrm{OP}$ & PDP & D & ND & GP \\
\hline 89 & $\begin{array}{l}\text { Instruções para } \\
\text { construção }\end{array}$ & $\begin{array}{l}\text { Templates auxiliam na elaboração das instruções para } \\
\text { construção }\end{array}$ & OP & PDP & $\mathrm{D}$ & ND & GP \\
\hline 105 & Workshop & Os workshops contribuíam para a geração de receita & OP/AD & NEG & N/A & N/A & $\mathrm{N} / \mathrm{A}$ \\
\hline
\end{tabular}


Tabela 14 - Os efeitos indesejados da OSE que se tornam uma barreira para o OSD

\begin{tabular}{|c|c|c|c|c|c|c|c|}
\hline \multicolumn{4}{|c|}{ Incidentes } & \multicolumn{4}{|c|}{ Codificação } \\
\hline \# & $\begin{array}{l}\text { Atores ou } \\
\text { objetos }\end{array}$ & Ação ou comportamento observado & Fonte & Elemento & $\begin{array}{l}\text { Fase do } \\
\text { PDP }\end{array}$ & $\begin{array}{l}\text { Nível de } \\
\text { Abstração }\end{array}$ & $\begin{array}{l}\text { Área de } \\
\text { Conhecimento }\end{array}$ \\
\hline 2 & Funcionários & $\begin{array}{l}\text { A organização não possui funcionários remunerados, com } \\
\text { dedicação exclusiva }\end{array}$ & OP & COM & $N / A$ & $\mathrm{~N} / \mathrm{A}$ & $\mathrm{N} / \mathrm{A}$ \\
\hline 3 & Iniciador & $\begin{array}{l}\text { O iniciador não possuía experiência em desenvolvimento de } \\
\text { produtos quando iniciou o projeto, e desconhece algumas boas } \\
\text { práticas utilizadas no PDP }\end{array}$ & $A D$ & COM & $N / A$ & $\mathrm{~N} / \mathrm{A}$ & $\mathrm{N} / \mathrm{A}$ \\
\hline 6 & Workshop & $\begin{array}{l}\text { Dificuldade na replicação dos protótipos, sem a presença de um } \\
\text { colaborador experiente }\end{array}$ & $A D$ & PDP & $\mathrm{P}$ & ND & $\mathrm{N} / \mathrm{A}$ \\
\hline 10 & Softwares & $\begin{array}{l}\text { Muitas vezes as atividades de design dependem de um software, } \\
\text { de modo que os colaboradores necessitam ter domínio do software } \\
\text { utilizado para contribuir }\end{array}$ & OP & PDP & $\mathrm{D}$ & ND & MD \\
\hline 19 & Protótipo físico & $\begin{array}{l}\text { Falhas severas nos protótipos colocavam em risco os } \\
\text { colaboradores e o meio ambiente }\end{array}$ & OP & PDP & $\mathrm{T}$ & ND & MD \\
\hline 18 & Protótipo físico & $\begin{array}{l}\text { Falhas nos protótipos eram frequentes e recorrentes, ocasionando } \\
\text { muitas vezes sua quebra }\end{array}$ & OP & PDP & $\mathrm{T}$ & ND & MD \\
\hline 23 & Colaboradores & Dificuldade na retenção de colaboradores & OP & COM & $\mathrm{N} / \mathrm{A}$ & $\mathrm{N} / \mathrm{A}$ & $\mathrm{N} / \mathrm{A}$ \\
\hline 24 & $\begin{array}{l}\text { Líder de } \\
\text { desenvolvimento }\end{array}$ & $\begin{array}{l}\text { Um dos líderes de desenvolvimento abandonou o projeto no meio } \\
\text { sem terminar de documentá-lo }\end{array}$ & OP & COM & $N / A$ & $\mathrm{~N} / \mathrm{A}$ & $\mathrm{N} / \mathrm{A}$ \\
\hline 25 & Planejamento & Falta de gestão de portfolio e gestão de projetos & OP & PDP & $\mathrm{N} / \mathrm{A}$ & $\mathrm{N} / \mathrm{A}$ & GP \\
\hline 28 & Iniciador & $\begin{array}{l}\text { Falta de transparência com relação aos problemas enfrentados e } \\
\text { fracassos }\end{array}$ & OP & COM & $\mathrm{N} / \mathrm{A}$ & $\mathrm{N} / \mathrm{A}$ & $\mathrm{N} / \mathrm{A}$ \\
\hline 31 & Protótipo físico & Os protótipos não evoluem tanto de uma versão para outra & $\mathrm{OP}$ & PDP & $\mathrm{D}$ & ND & $\mathrm{N} / \mathrm{A}$ \\
\hline 33 & Iniciador & $\begin{array}{l}\text { Muitos dos colaboradores tiveram dificuldade de se relacionarem } \\
\text { com o iniciador do projeto }\end{array}$ & OP & $\mathrm{COM}$ & $\mathrm{N} / \mathrm{A}$ & $\mathrm{N} / \mathrm{A}$ & $\mathrm{N} / \mathrm{A}$ \\
\hline 36 & Colaboradores & $\begin{array}{l}\text { Muitos dos colaboradores não possuíam experiência em } \\
\text { desenvolvimento de produtos, desconhecem muitas das boas } \\
\text { práticas utilizadas no PDP }\end{array}$ & $\mathrm{OP}$ & COM & $\mathrm{N} / \mathrm{A}$ & $\mathrm{N} / \mathrm{A}$ & $\mathrm{N} / \mathrm{A}$ \\
\hline 39 & Colaboradores & $\begin{array}{l}\text { Muitos dos colaboradores não tinham tanta prática em fabricação e } \\
\text { montagem }\end{array}$ & OP & COM & $\mathrm{N} / \mathrm{A}$ & $\mathrm{N} / \mathrm{A}$ & $\mathrm{N} / \mathrm{A}$ \\
\hline 43 & Colaboradores & $\begin{array}{l}\text { Os colaboradores não conhecem o modelo de referência para o } \\
\text { PDP da OSE }\end{array}$ & OP & COM & $N / A$ & $\mathrm{~N} / \mathrm{A}$ & BPM \\
\hline
\end{tabular}


Tabela 14 - Os efeitos indesejados da OSE que se tornam uma barreira para o OSD (continuação)

\begin{tabular}{|c|c|c|c|c|c|c|c|}
\hline \multicolumn{4}{|c|}{ Incidentes } & \multicolumn{4}{|c|}{ Codificação } \\
\hline \# & $\begin{array}{l}\text { Atores ou } \\
\text { objetos }\end{array}$ & Ação ou comportamento observado & Fonte & Elemento & $\begin{array}{l}\text { Fase do } \\
\text { PDP }\end{array}$ & $\begin{array}{l}\text { Nível de } \\
\text { Abstração }\end{array}$ & $\begin{array}{l}\text { Área de } \\
\text { Conhecimento }\end{array}$ \\
\hline 65 & Workshop & $\begin{array}{l}\text { Não realizávamos testes para saber se as mudanças no design } \\
\text { consistiam em melhorias efetivas }\end{array}$ & OP & PDP & $\mathrm{T}$ & ND & MD \\
\hline 66 & Workshop & $\begin{array}{l}\text { Tínhamos pouco tempo para construir os protótipos durante os } \\
\text { workshops e fazíamos tudo às pressas }\end{array}$ & OP & PDP & $P$ & ND & $\mathrm{N} / \mathrm{A}$ \\
\hline 68 & Workshop & $\begin{array}{l}\text { Não investigávamos sistematicamente os problemas que surgiam } \\
\text { na construção dos protótipos }\end{array}$ & OP & PDP & $P$ & ND & MD \\
\hline 71 & $\begin{array}{l}\text { Instruções para } \\
\text { construção }\end{array}$ & $\begin{array}{l}\text { A elaboração das instruções para construção era entediante e } \\
\text { consumia bastante tempo, desmotivando os colaboradores }\end{array}$ & OP & MOT & $\mathrm{D}$ & ND & $\mathrm{N} / \mathrm{A}$ \\
\hline 73 & $\begin{array}{l}\text { Instruções para } \\
\text { construção }\end{array}$ & $\begin{array}{l}\text { As instruções para construção não eram padronizadas e não } \\
\text { possuíam um aspecto profissional }\end{array}$ & OP & PDP & D & ND & MD \\
\hline 75 & Colaboradores & Os colaboradores não possuíam uma visão geral do produto & OP & PDP & $\mathrm{D}$ & ND & N/A \\
\hline 11 & $\begin{array}{l}\text { Instruções para } \\
\text { construção }\end{array}$ & $\begin{array}{l}\text { Os colaboradores não conseguiam elaborar as instruções para } \\
\text { construção sem ter participado do processo }\end{array}$ & OP & PDP & D & ND & $\mathrm{N} / \mathrm{A}$ \\
\hline 78 & $\begin{array}{l}\text { Instruções para } \\
\text { construção }\end{array}$ & Muitas instruções para construção estavam incompletas & OP/AD & PDP & $P$ & ND & $\mathrm{N} / \mathrm{A}$ \\
\hline 79 & Workshop & Falta de organização e planejamento nos workshop & OP & PDP & $\mathrm{P}$ & ND & GP \\
\hline 81 & Workshop & $\begin{array}{l}\text { Alguns colaboradores ficavam sem saber o que fazer durante a } \\
\text { prototipagem dos produtos }\end{array}$ & OP & PDP & $P$ & ND & $N / A$ \\
\hline 82 & Colaboradores & $\begin{array}{l}\text { Os colaboradores estavam muito mais interessados em construir do } \\
\text { que documentar, e era comum que esquecessem de documentar } \\
\text { alguns passos, assim como, oportunidades de melhoria observadas }\end{array}$ & OP & MOT & $\mathrm{N} / \mathrm{A}$ & $\mathrm{N} / \mathrm{A}$ & $\mathrm{N} / \mathrm{A}$ \\
\hline 90 & Protótipo físico & $\begin{array}{l}\text { Não possuíamos uma sistemática para testar os protótipos em } \\
\text { funcionamento, e poucos dados eram coletados }\end{array}$ & OP & PDP & $\mathrm{T}$ & ND & MD \\
\hline 91 & Colaboradores & Pouca colaboração na fase de design & OP & PDP & $\mathrm{D}$ & ND & $\mathrm{N} / \mathrm{A}$ \\
\hline 95 & Colaboradores & Dificuldade ao colaborar remotamente & OP & COM & $\mathrm{N} / \mathrm{A}$ & $\mathrm{N} / \mathrm{A}$ & $\mathrm{N} / \mathrm{A}$ \\
\hline 96 & Colaboradores & $\begin{array}{l}\text { Dificuldade em encontrar as informações relevantes na plataforma } \\
\text { da organização }\end{array}$ & OP & PLA & $\mathrm{N} / \mathrm{A}$ & $\mathrm{N} / \mathrm{A}$ & $\mathrm{N} / \mathrm{A}$ \\
\hline 97 & Wiki & $\begin{array}{l}\text { Informações disponibilizadas na wiki estão incompletas e } \\
\text { desatualizadas }\end{array}$ & OP/AD & PLA & $\mathrm{N} / \mathrm{A}$ & $\mathrm{N} / \mathrm{A}$ & $\mathrm{N} / \mathrm{A}$ \\
\hline
\end{tabular}


Tabela 14 - Os efeitos indesejados da OSE que se tornam uma barreira para o OSD (continuação)

\begin{tabular}{|c|c|c|c|c|c|c|c|}
\hline \multicolumn{4}{|c|}{ Incidentes } & \multicolumn{4}{|c|}{ Codificação } \\
\hline \# & $\begin{array}{l}\text { Atores ou } \\
\text { objetos }\end{array}$ & Ação ou comportamento observado & Fonte & Elemento & $\begin{array}{l}\text { Fase do } \\
\text { PDP }\end{array}$ & $\begin{array}{l}\text { Nível de } \\
\text { Abstração }\end{array}$ & $\begin{array}{l}\text { Área de } \\
\text { Conhecimento }\end{array}$ \\
\hline 98 & Wiki & $\begin{array}{l}\text { Não há uma visão unificada sobre como a wiki deveria ser } \\
\text { organizada }\end{array}$ & $A D$ & PLA & $\mathrm{N} / \mathrm{A}$ & $\mathrm{N} / \mathrm{A}$ & $\mathrm{N} / \mathrm{A}$ \\
\hline 99 & Wiki & Não há responsáveis por revisar o conteúdo da wiki & $A D$ & PLA & $N / A$ & $N / A$ & $\mathrm{~N} / \mathrm{A}$ \\
\hline 100 & Wiki & Poucos colaboradores ativos & $A D$ & PLA & $\mathrm{N} / \mathrm{A}$ & $\mathrm{N} / \mathrm{A}$ & $\mathrm{N} / \mathrm{A}$ \\
\hline 101 & Planejamento & Houveram muitos projetos simultaneamente & $\mathrm{OP}$ & PDP & $\mathrm{N} / \mathrm{A}$ & $\mathrm{N} / \mathrm{A}$ & GP \\
\hline 102 & Colaboradores & $\begin{array}{l}\text { Os colaboradores geralmente não recebem feedback de suas } \\
\text { sugestões de melhoria nos produtos }\end{array}$ & OP & PDP & D & $\mathrm{N} / \mathrm{A}$ & $N / A$ \\
\hline 103 & Colaboradores & $\begin{array}{l}\text { A maioria dos colaboradores estavam contribuindo com a } \\
\text { organização pela primeira vez }\end{array}$ & OP & COM & $N / A$ & $\mathrm{~N} / \mathrm{A}$ & $N / A$ \\
\hline
\end{tabular}


4. A Árvore de Causa e Efeito da OSE no período de observação participante

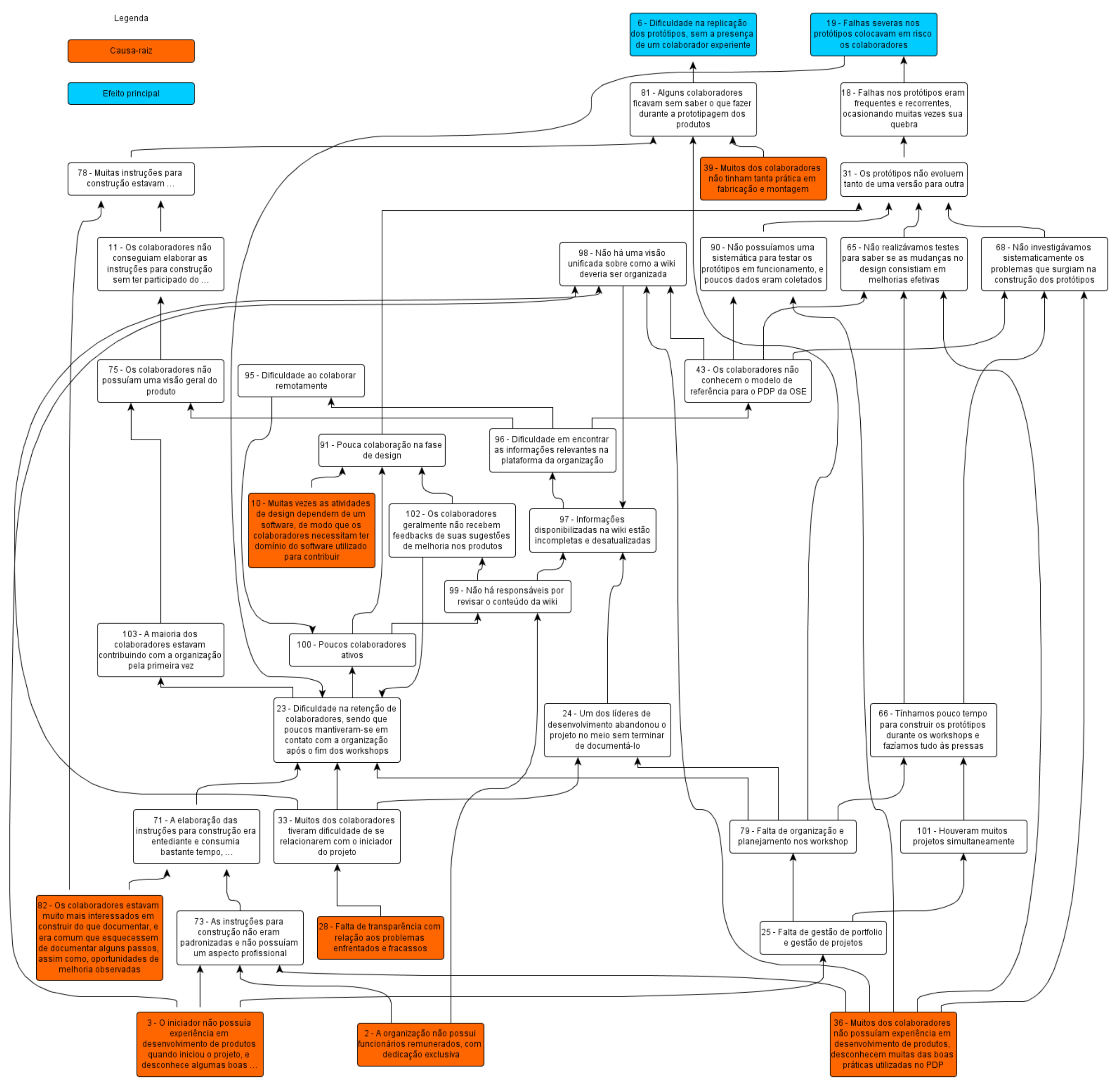

Figura 48 - Árvore de causa e efeito da OSE 


\section{APÊNDICE B - Modelagem de processos para o desenvolvimento de produto e o modelo da OSE}

Este apêndice apresenta uma síntese da literatura sobre modelagem de processos para o desenvolvimento de produto, e também descreve o modelo utilizado pela organização pela OSE. Na seção 1, os tipos de modelos de processo são apresentados, na seção 2 são apresentados os propósitos para criação de um modelo de referência, por fim, na seção 3 , é apresentado o modelo de referência utilizado pela organização pesquisada para $\circ$ processo de desenvolvimento de produtos.

\section{Tipos de modelos de processo}

Modelos são representações abstratas da realidade com o intuito de facilitar seu entendimento. Ao tentar representar a realidade, acabamos por simplificá-la, e essa redução ocasiona em erros de representação. No entanto, mesmo incorretos por natureza, modelos são úteis para auxiliar na previsão e teste de hipóteses sobre os efeitos das ações que ocorrem no mundo real, e que estão contempladas no modelo (BROWNING et al., 2006, p. 105).

Os modelos de processo retratam a maneira como um trabalho é realizado, ou como deveria ser. Quando os modelos de processo capturam o conhecimento tácito de como um trabalho é realmente realizado (as-is), configura-se um modelo descritivo. Por outro lado, quando o modelo de processo apresenta o que deveria ser feito, e até mesmo como o trabalho deveria ser feito (to-be), o modelo é caracterizado como prescritivo (BROWNING et al., 2006, p. 115).

Os modelos de processo prescritivos são mais apropriados para os casos em que o trabalho a ser realizado se repete com certa frequência. Nesses casos, os modelos prescritivos podem ser construídos de maneira dedutiva, por exemplo, por meio de processos padrões externos à organização, ou por meio de projetos anteriormente executados (BROWNING et al., 2006, p. 115). Assim, o modelo prescritivo construído pode ser utilizado como referência para a instanciação de novos projetos (BROWNING et al., 2006, p. 118). Esses modelos prescritivos são 
tratados nesse estudo como modelos de referência. Os modelos de referência para o PDP apresentam uma descrição do processo de desenvolvimento de produtos, proporcionando uma visão unificada do processo e o nivelamento do conhecimento existente entre os usuários do modelo (ROZENFELD et al., 2003, p. 1). Os modelos de referência ainda podem ser classificados entre modelos genéricos ou específicos (ECHEVESTE et al., 2007, p. 248).

Os modelos de referência genéricos são "representações de processos de negócio contendo as melhores práticas da área de aplicação" (AMIGO, 2013, p. 26). $\mathrm{Na}$ área de gestão do desenvolvimento de produtos (GDP), os modelos de referência genéricos mais conhecidos pertencem a autores consagrados, como Pahl e Beitz (1988), Clark e Wheelwright (1993), Cooper (2001), Crawford e Di Benedetto (2006), Rozenfeld et al., (2006), Ulrich e Eppinger (2007), entre outros. Existem também modelos de referência genéricos voltados para segmentos industriais. No caso da indústria automobilística, o modelo conhecido como $A P Q P^{61}$, fruto de uma parceria entre General Motors, Ford e Chrysler, se tornou referência para o setor (SINGH et al., 2007, p. 4190).

No entanto, quando uma organização decide aplicar um modelo de referência genérico e utilizá-lo como base para o planejamento de seus projetos, recomenda-se a revisão e adaptação deste modelo para o caso específico da organização (BROWNING et al., 2006, p. 118). Como resultado do processo de implantação do modelo de referência genérico, obtêm-se um modelo de referência específico, também chamado de processo-padrão (BROWNING et al., 2006, p. 118; ECHEVESTE et al., 2007, p. 248). Aconselha-se que a construção de um modelo de referência específico (to-be) ocorra gradualmente, a partir da melhoria do processo em vigor (as-is) ao invés da construção de um modelo prescritivo totalmente novo. É importante que os diferentes usuários do modelo sejam envolvidos na construção (ou melhoria) do modelo de referência específico (BROWNING et al., 2006, p. 118). Isso os torna mais familiarizados com o processo, contribuindo para o planejamento e instanciação de novos projetos. Projetos são definidos pelo PMI (2008) como "empreendimentos temporários realizados para criar um produto, serviço ou

${ }^{61}$ Advance Product Quality Planning, em português Planejamento Avançado da Qualidade do Produto. Disponível em https://www.aiag.org/Source/Orders/index.cfm?search=apqp, acessado em 10/07/2015. 
resultado único". A Figura 49 ilustra a relação entre modelos de referência genéricos e específicos.

Normalmente, os modelos específicos apresentam um maior nível de detalhamento quando comparados ao modelo de referência genérico. $O$ nível de detalhamento do processo de desenvolvimento de produtos representado pelos modelos específicos deve atender aos propósitos dos usuários dos modelos. Segundo Browning et al. (2006), o detalhamento do PDP é um dos fatores que contribui para que os usuários do modelo sejam capazes de se auto gerenciar. No entanto, detalhes demais podem tornar o processo complexo e de difícil entendimento, prejudicando, inclusive, sua visualização (JESTON; NELIS, 2006, p. 103). Na próxima seção são apresentados os propósitos dos modelos de referência para o processo de desenvolvimento de produtos.

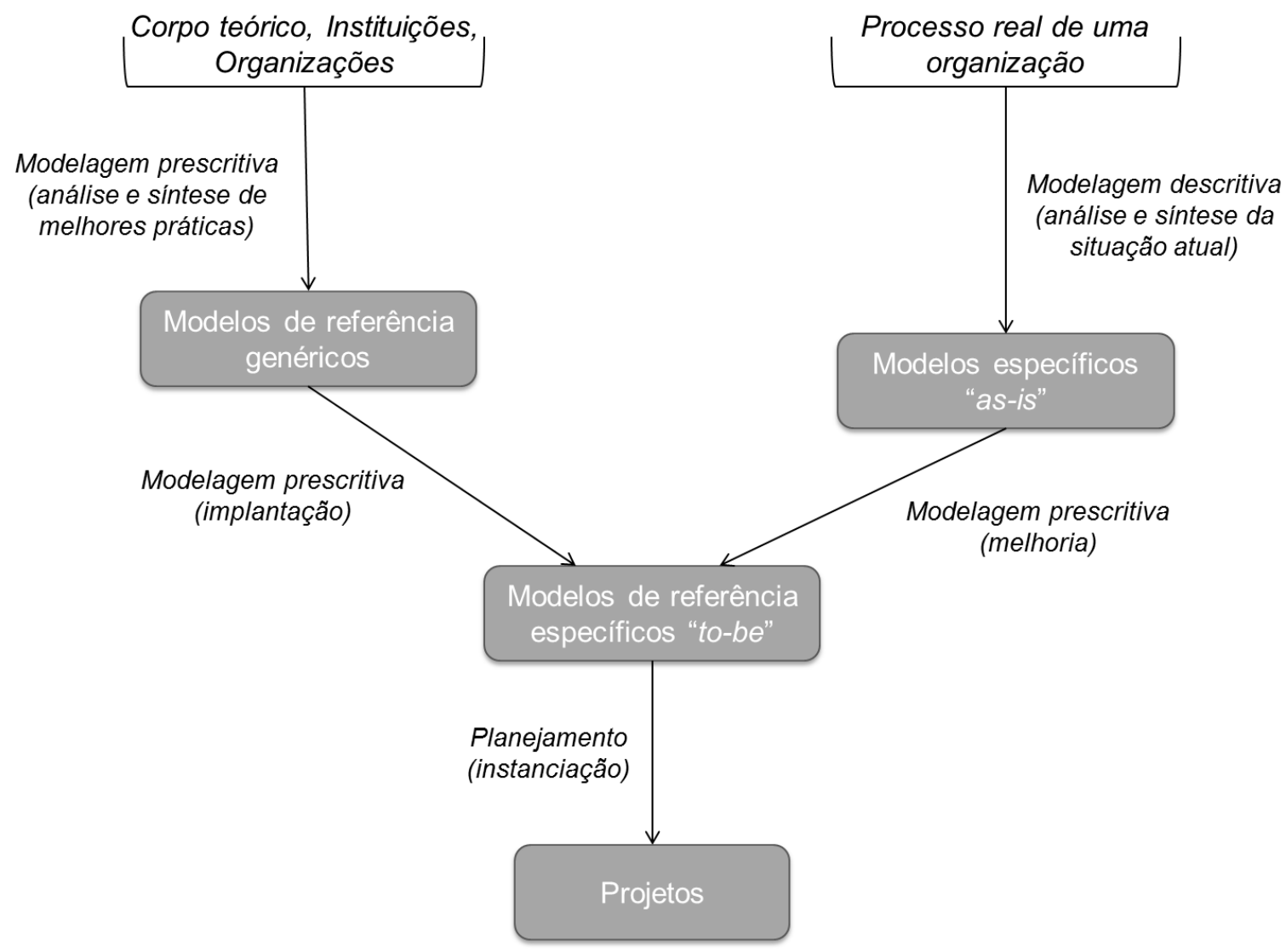

Figura 49 - Relação entre modelos de referência genéricos e específicos (adaptado de Amigo, 2013) 


\section{Propósitos dos modelos de referência do PDP}

Os modelos de referência são construídos visando atender aos propósitos relacionados às questões-chave enfrentadas pelos usuários durante a gestão do PDP (BROWNING; RAMASESH, 2007, p. 218). Identificar os propósitos dos usuários dos modelos de referência é uma tarefa importante, pois são eles que determinarão a arquitetura e a vista ideal para o modelo de referência de uma organização (VERNADAT, 1996, p. 31; BROWNING; RAMASESH, 2007, p. 221). Cada vista de um modelo de referência captura um conjunto de atributos do modelo e proporciona um guia para sua representação (BROWNING, 2008, p. 70).

Amigo (2013) realizou uma análise crítica dos propósitos para os métodos de modelagem do PDP obtidos por meio de uma revisão bibliográfica sistemática (AMIGO et al., 2013), de modo a identificar dentre eles os propósitos dos usuários de modelos de referência, ou seja, interessados em informações mais estratégicas (por ex:: fases do processo, entregas, atividades, papéis genéricos, etc.). Nessa análise foram eliminados os propósitos de nível operacional, como aqueles relacionados à gestão de projetos (por ex.: calcular tempo de folga, estimar duração; identificar e alocar recursos; agendar atividades/tarefas, etc.). A Tabela 15 apresenta a lista dos propósitos estratégicos dos modelos de referência do PDP. 
Tabela 15 - Propósitos estratégicos dos modelos de referência do PDP (AMIGO, 2013, p. 99)

\begin{tabular}{|c|c|}
\hline $\begin{array}{l}\text { Propósitos de modelos de } \\
\text { PDP }\end{array}$ & Explicação \\
\hline $\begin{array}{l}\text { Definir atividades padrão e } \\
\text { preferidas }\end{array}$ & $\begin{array}{l}\text { O modelo do processo pode listar as atividades padrão e preferidas } \\
\text { bem como descrevê-las. }\end{array}$ \\
\hline $\begin{array}{l}\text { Definir/sugerir sequência para } \\
\text { as atividades }\end{array}$ & O modelo pode ordenar as atividades padrão e preferidas. \\
\hline $\begin{array}{l}\text { Mostrar relação hierárquica } \\
\text { entre atividades }\end{array}$ & $\begin{array}{l}\text { O modelo do processo pode apresentar a hierarquia entre as } \\
\text { atividades: relações pais/filhos, decomposição estrutural. Pode } \\
\text { também indicar os níveis hierárquicos do PDP. }\end{array}$ \\
\hline $\begin{array}{l}\text { Definir entregas ou } \\
\text { milestones padrão }\end{array}$ & $\begin{array}{l}\text { O modelo pode documentar entregas e/ou milestones do processo } \\
\text { ressaltando resultados desejados e eventos importantes. Pode } \\
\text { também estabelecer momentos adequados para entrega/análise de } \\
\text { determinados pacotes de trabalho. }\end{array}$ \\
\hline $\begin{array}{l}\text { Definir padrões de qualidade } \\
\text { para as entregas padrão }\end{array}$ & $\begin{array}{l}\text { O modelo do processo pode incluir as medidas de eficácia e seus } \\
\text { níveis de aceitação para os resultados desejados de cada atividade. }\end{array}$ \\
\hline $\begin{array}{l}\text { Identificar } \\
\text { dependência/precedência de } \\
\text { atividades/funções via inputs } \\
\text { e outputs }\end{array}$ & $\begin{array}{l}\text { O modelo do processo pode relacionar entregas a atividades por } \\
\text { meio de suas entradas e saídas, resultando em um fluxo de } \\
\text { trabalho sequenciado a partir das dependências entre as atividades. } \\
\text { Dessa forma é possível mostrar paralelismo entre atividades, } \\
\text { minimizar sobreposição e analisar a rede de atividades. }\end{array}$ \\
\hline Automatizar o processo & $\begin{array}{l}\text { O modelo pode permitir o gerenciamento/modelagem do fluxo de } \\
\text { trabalho (workflow). Ou seja, pode descrever um processo de } \\
\text { maneira a ser realizado por computadores. }\end{array}$ \\
\hline $\begin{array}{l}\text { Definir ferramentas e } \\
\text { templates padrão }\end{array}$ & $\begin{array}{l}\text { O modelo pode associar a cada atividade, um conjunto de } \\
\text { ferramentas e templates padrão baseados nas melhores práticas } \\
\text { indicadas na literatura, ou benchmarking, ou projetos anteriores } \\
\text { bem sucedidos, etc. }\end{array}$ \\
\hline $\begin{array}{l}\text { Relacionar papéis a } \\
\text { atividades, entregas e demais } \\
\text { elementos do processo }\end{array}$ & $\begin{array}{l}\text { O modelo pode atribuir para cada atividade e/ou demais elementos } \\
\text { do processo um conjunto de responsabilidades e/ou papéis a serem } \\
\text { desempenhados. }\end{array}$ \\
\hline $\begin{array}{l}\text { Definir responsabilidades e } \\
\text { habilidades padrão para } \\
\text { papéis e pessoal }\end{array}$ & $\begin{array}{l}\text { O modelo pode definir responsabilidades e habilidades padrão } \\
\text { desejadas para cada papel, juntamente com o número típico de } \\
\text { pessoas, nível de esforço, e habilidades requeridas para assegurar } \\
\text { que a atividade será executada efetivamente. }\end{array}$ \\
\hline $\begin{array}{l}\text { Visualizar/entender o } \\
\text { processo de design }\end{array}$ & $\begin{array}{l}\text { O modelo pode prover uma representação concisa do processo, } \\
\text { apresentando-o de maneira intuitiva e acessível. }\end{array}$ \\
\hline $\begin{array}{l}\text { Melhorar continuamente } 0 \\
\text { processo de design }\end{array}$ & $\begin{array}{l}\text { O modelo pode indicar oportunidades de melhoria no processo a fim } \\
\text { de aumentar a sua eficiência, obter melhores resultados e/ou } \\
\text { promover sua reengenharia. }\end{array}$ \\
\hline $\begin{array}{l}\text { Identificar efeitos em cadeia } \\
\text { provocados por mudanças de } \\
\text { processo }\end{array}$ & $\begin{array}{l}\text { O modelo pode permitir a fácil visualização de efeitos em cadeia } \\
\text { gerados por solicitações de mudança no processo. } \\
\text { Quando múltiplos projetos utilizam um mesmo modelo de processo, } \\
\text { o dono do processo recebe uma série de solicitações de mudança } \\
\text { provenientes dos diferentes projetos. Ele deve ser capaz de } \\
\text { identificar facilmente os efeitos potenciais de cada mudança nas } \\
\text { demais atividades do processo. }\end{array}$ \\
\hline $\begin{array}{l}\text { Intercambiar dados do } \\
\text { processo }\end{array}$ & $\begin{array}{l}\text { O modelo pode prover intercâmbio entre diferentes sistemas } \\
\text { computacionais por meio de uma base de dados integrada ou } \\
\text { linguagem comum. }\end{array}$ \\
\hline $\begin{array}{l}\text { Organizar conhecimento } \\
\text { sobre o trabalho }\end{array}$ & $\begin{array}{l}\text { O modelo do processo pode ajudar a estruturar/documentar a vasta } \\
\text { quantidade de informação que existe em uma grande empresa } \\
\text { sobre o trabalho e como realizá-lo. }\end{array}$ \\
\hline $\begin{array}{l}\text { Avaliar a complexidade do } \\
\text { processo de design }\end{array}$ & $\begin{array}{l}\text { O modelo pode auxiliar na análise do nível de complexidade do } \\
\text { processo de desenvolvimento (por exemplo, por número de } \\
\text { atividades, dependências ou recursos necessários). }\end{array}$ \\
\hline $\begin{array}{l}\text { Decompor o processo para } \\
\text { reduzir a complexidade }\end{array}$ & $\begin{array}{l}\text { O modelo pode facilitar a compartimentação do processo em } \\
\text { pacotes de trabalho de gerenciamento mais simples. }\end{array}$ \\
\hline
\end{tabular}




\section{O modelo de processo utilizado pela OSE}

Esta seção descreve o modelo de referência para o PDP utilizado pela organização estudada, identificado por meio da análise de documentos. A versão mais atual do modelo de referência encontrada foi de novembro de 2013, em uma página da wiki denominada "template de desenvolvimento" (em inglês, Development Template). Este modelo é apresentada na Figura 50.

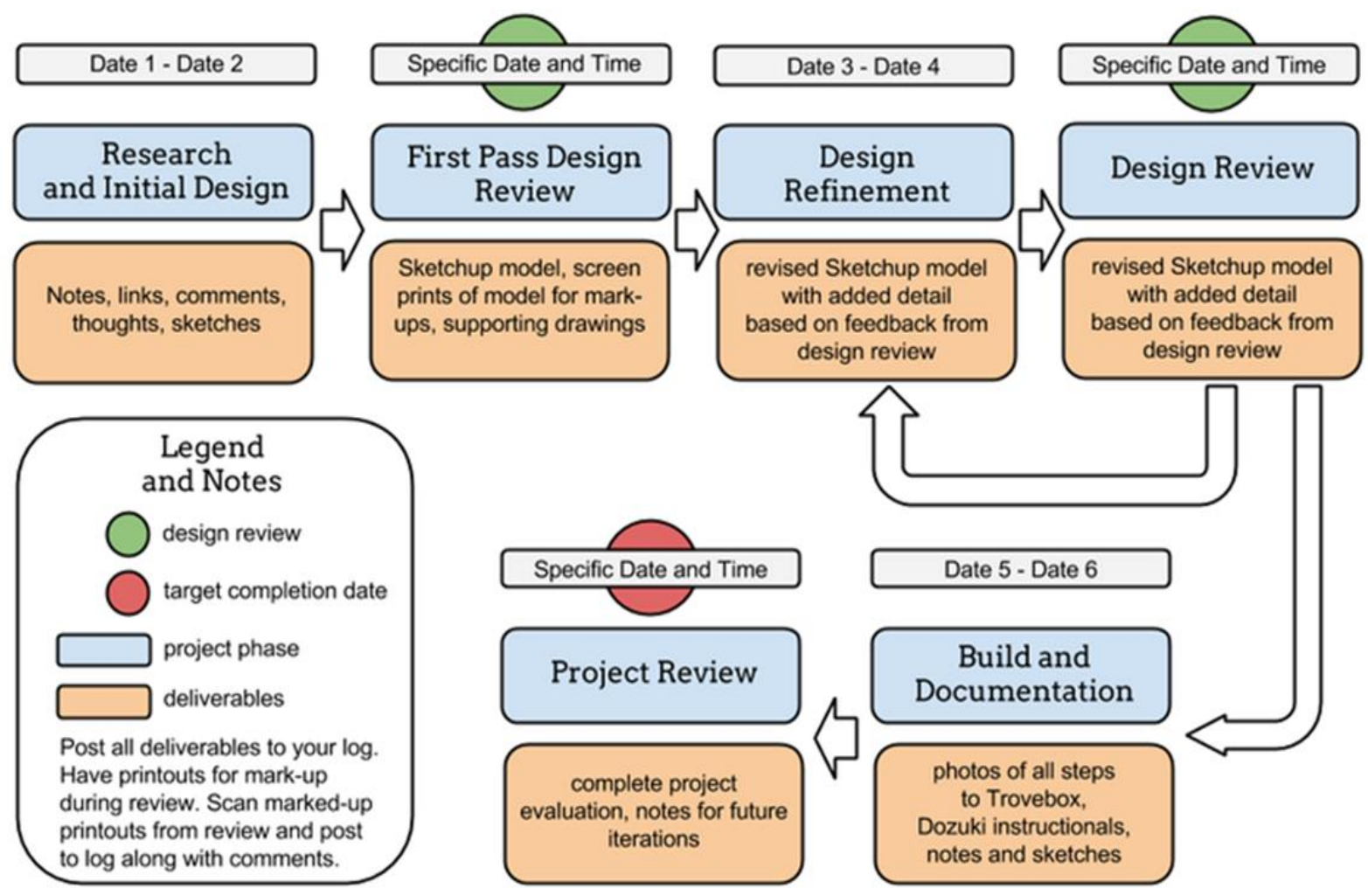

Figura 50 - Versão atual do modelo de referência para o processo de desenvolvimento de produto da OSE (OSE, 2015a)

Segundo o modelo apresentado na Figura 50, o PDP da OSE possui seis fases (representadas pela cor azul): pesquisa e design inicial, primeira revisão do design, refinamento do design, revisão do design, construção e documentação, e revisão do projeto. Embora a figura não deixe claro, trata-se de um processo iterativo

(fato explicitado por meio de uma nota no website). As entregas apresentadas no modelo (representadas pela cor salmão) correspondem apenas a um resumo das principais entregas. A fim de complementar o modelo de referência, na mesma página da wiki encontra-se também uma lista com 76 entregas do PDP, divididas em sete categorias, conforme apresentado a seguir. As categorias são representadas 
por letras maiúsculas, e as entregas estão numeradas, seguindo a mesma ordem apresentada na wiki da organização. A ideia era que para cada entrega, houvesse 0 link para um template, também disponibilizado na wiki. No entanto, para muitas entregas ainda não foram criados templates, e em alguns casos, os templates encontram-se incompletos.

\section{ENTREGAS PRINCIPAIS}

1. Canais de comunicação - nos quais ocorrem as discussões sobre o projeto;

2. Painel - uma página que identifica de forma única o projeto;

3. Requisitos - o que é exigido no projeto;

4. Módulos - divisão de máquina em módulos;

5. Projeto das interfaces - como os módulos se encaixam;

6. Desenhos do conceito - desenhos que começam a comunicar o projeto;

7. Padrões industrias - e história;

8. Árvore de escolhas técnicas - especificando as decisões tomadas durante o de desenvolvimento;

9. Diagrama das peças - especificar nomenclatura para entendimento comum;

10. Cálculos - desde rascunhos iniciais até as análises computacionais;

11. CAD 3D - desenhos técnicos em três dimensões;

12. CAD 2D - desenhos técnicos em duas dimensões;

13. Arquivos CAM (Computer Aided Manufacturing) - arquivos de fabricação digital para corte, usinagem, produção de circuitos, etc.;

14. Diagramas hidráulicos - esquemáticos dos sistemas hidráulicos;

15. Lista de materiais - lista completa das peças;

16. Lista de corte - lista das peças que precisam ser cortadas, furadas, etc.;

17. Desenhos de fabricação - desenhos técnicos que podem ser usados para auxiliar na fabricação;

18. Vista explodidas;

19. Revisões - feedback críticos;

20. Instruções de construção - passo-a-passo para produção;

21. Instruções independentes do idioma - o mesmo que o anterior, mas sem texto; 
22. Diagrama de fabricação - um esquemático que mostra quais partes podem ser fabricadas em paralelo;

23. Tempo de construção;

24. Time Lapse ${ }^{62}$ da construção;

25. Fotos da construção - no Trovebox da OSE;

26. Vídeo da construção - no YouTube da OSE;

27. Instruções de procedimento - no Dozuki da OSE;

28. Diagrama das peças ilustrado - esquemático das peças rotuladas utilizando fotos da construção;

29. Manual do usuário - instruções de operação;

30.Definição do problema - principal tópico a ser abordado no desenvolvimento;

\section{DESIGN COLABORATIVO}

35. Amplitude de movimento da máquina;

36. Revisão dos arquivos CAD 3D;

37. Diagrama de parafusos;

38. Análise CAE (Computer Aided Engineering);

39. Diagrama funcional;

40. Animação 3D de montagem;

41. Arquivos CAM;

42. Lista de materiais visual;

43. Conversão das camadas do SketchUp em um sequenciamento para construção;

44. Conversão do projeto em SketchUp para as instruções

45. Conversão do projeto em SketchUp para uma animação

\section{ELÉTRICA}

46. Diagrama lógico

47. Esquemático eletrônico

48. Eletrônicos

49. Diagrama de cabeamento

50. Software

${ }^{62}$ O time-lapse é a versão extrema de uma técnica cinematográfica de manipulação lenta e pode ser por vezes confundida com animação de paragem de movimento (stop motion). Disponível em http://pt.wikipedia.org/wiki/Time-lapse, acessado em 15/06/2015. 
51. Firmware

\section{GRÁFICOS, ANIMAÇÕES, EXPLICAÇÕES}

52. Infográfico da máquina/módulo

53. Explicação do funcionamento dos mecanismos da máquina/módulo

54. Explicações das justificativas do projeto

55. Roteiro do vídeo explicativo

56. Vídeo explicativo

57. Animação no SketchUp para vista explodida

\section{PROTOTIPAGEM RÁPIDA / PROJETO ORIENTADO A TESTE}

58. Procedimento de teste para protótipos parciais

59. Arquivo 2D para o corte a laser dos protótipos parciais

60. Corte a laser dos protótipos parciais (por exemplo, usando papel cartão)

61. Construção dos protótipos parciais

62. Fotos da construção dos protótipos parciais

63. Vídeo da construção do protótipo parcial

64. Coleta de dados do protótipo parcial

\section{PREPARAÇÕES PARA COSNTRUÇÃO}

65. Mapa da oficina e do fluxo de trabalho

66. Checklist da preparação para construção

67. Lista de ferramentas, consumíveis, infraestrutura, e fornecedores necessários

\section{CONSTRUÇÃO E REVISÃO DA CONSTRUÇÃO}

68. Checklist da construção (inclui questões relacionadas à segurança e identificação de oportunidades de melhoria)

69. Avaliação do protótipo

\section{TESTE E COLETA DE DADOS}

70. Procedimento de teste e coleta de dados

71. Dados da construção

72. Sugestões e soluções para melhoria do produto

\section{EMPREENDIMENTO}

73. Análise econômica

74. Modelo de negócio para produção colaborativa

75. Infográfico do fluxo de desenvolvimento 
Antes da criação do modelo de referência apresentado na Figura 50, a organização utilizava o termo "visão geral dos sistemas"63 para se referir ao modelo de referência específico para o processo de desenvolvimento de produtos. Esta versão do modelo de referência, publicada na wiki da OSE em Julho de 2011, está apresentada na Figura 51.

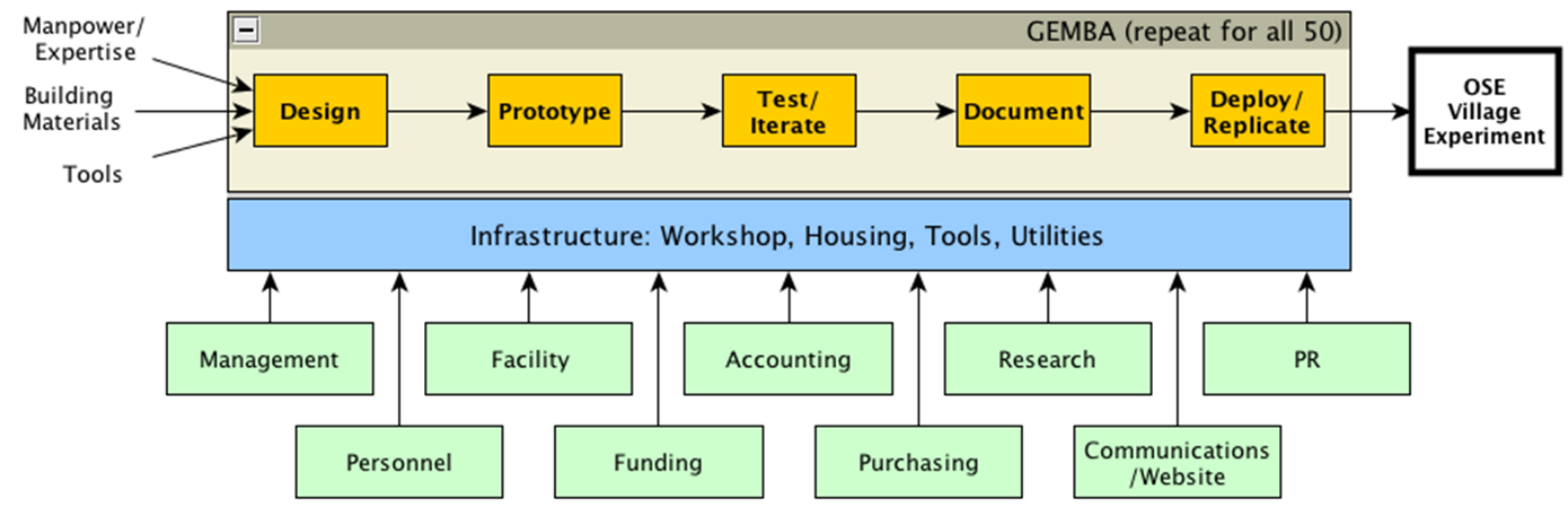

Figura 51 - Versão anterior do modelo de referência para o processo de desenvolvimento de produto da OSE (OSE, 2015a)

Segundo a própria organização, "este documento mostra como os vários sistemas da OSE se encaixam, e lista os processo utilizados na realização das tarefas diárias". Na figura, os sistemas estão representados pelas caixas de cor verde, e consistem em outros processos da organização que apoiam o PDP: gestão, pessoal, instalação, financiamento, contabilidade, compras, pesquisa, comunicação e relações públicas. Por sua vez, o processo de desenvolvimento de produtos está representado pelas caixas de cor amarela, e é composto por cinco sub-processos: desenvolver, prototipar, testar/iterar, documentar, e implantar/replicar. As entradas do processo são: força de trabalho/experiência, materiais para prototipagem, e ferramentas. A única saída do processo é o experimento de construção de uma civilização, baseada na economia livre. O modelo ainda apresenta, de uma maneira genérica, a infraestrutura necessária para que seja possível a realização do PDP: oficina, alojamento, ferramentas e utilitários.

Cada um dos sub-processos do PDP são descritos na wiki de forma narrativa, no formato de checklists. A partir dos checklists é possível identificar as principais

\footnotetext{
${ }^{63}$ Em inglês, systems overview.
} 
entregas do processo de desenvolvimento de produtos. A Tabela 16 apresenta os checklists para cada sub-processo, assim como as principais entregas identificadas.

Tabela 16 - Principais entregas do processo de desenvolvimento de produtos da OSE

\begin{tabular}{|c|c|c|}
\hline Sub-processo & Checklist & Principais entregas \\
\hline Desenvolver & $\begin{array}{l}\text { - Pesquisar as necessidades dos usuários, } \\
\text { projetos open source existentes, e as } \\
\text { melhores práticas da indústria; } \\
\text { - Especificações e requisitos definidos; } \\
\text { - Design conceitual; } \\
\text { - Estimar custos; } \\
\text { - Desenvolver para montagem; } \\
\text { - Produzir desenhos e arquivos de controle } \\
\text { numérico computadorizado (CNC); } \\
\text { - Produzir esquemáticos; } \\
\text { - Analise do modo de falha } \\
\text { - Publicação para revisão dos pares; } \\
\text { - Produzir lista de materiais (BOM); e } \\
\text { - Calcular custos, desempenho e verificar } \\
\text { se eles atingiram os alvos. }\end{array}$ & $\begin{array}{l}\text { - Especificações e requisitos } \\
\text { - Design conceitual } \\
\text { - Lista de materiais } \\
\text { - Análise do modo de falha }\end{array}$ \\
\hline Prototipar & $\begin{array}{l}\text { - Comprar material; } \\
\text { - Reunir ferramentas e preparar espaço de } \\
\text { trabalho; } \\
\text { - Construir; e } \\
\text { - Registrar o processo de construção por } \\
\text { meio de vídeos. }\end{array}$ & $\begin{array}{l}\text { - Protótipo } \\
\text { - Vídeos do processo de } \\
\text { construção do protótipo }\end{array}$ \\
\hline Testar/lterar & $\begin{array}{l}\text { - Testar a máquina em campo e avaliar sua } \\
\text { capabilidade em condições reais; } \\
\text { - Testar a interface com outras máquinas } \\
\text { do GVCS; e } \\
\text { - Ajustar se necessário, e documentar } \\
\text { mudanças. }\end{array}$ & - Protótipo aprovado \\
\hline Documentar & $\begin{array}{l}\text { - Conferir desenhos e BOM com relação às } \\
\text { mudanças realizadas; } \\
\text { - Editar fotos e vídeos; } \\
\text { - Organizar material disponível e publicar } \\
\text { na wiki; e } \\
\text { - Preparar e publicar o manual do usuário } \\
\text { (procedimentos de operação, segurança. } \\
\text { manutenção, solução de problemas e } \\
\text { reparo). }\end{array}$ & - Manual do usuário \\
\hline Implantar/Replicar & $\begin{array}{l}\text { - Otimização da fabricação; e } \\
\text { - Desenvolvimento de uma rede de } \\
\text { usuários. }\end{array}$ & - Rede de usuários \\
\hline
\end{tabular}

Ao analisar a os modelos de referência apresentados tanto na Figura 50 quanto na Figura 51, é possível perceber que a notação utilizada não segue o formalismo de nenhum dos métodos de modelagem conhecidos para o PDP. No modelo atual (Figura 50), destaca-se a presença de etapas de revisão de fases (gates), embora não tenham sido encontrados os critérios utilizados em cada uma 
dessas revisões. As duas primeiras revisões consistem em revisões técnicas (design reviews), enquanto que na última revisão, trata-se de uma revisão gerencial (project review). Estas etapas de revisões de fase não estavam presentes no modelo anterior (Figura 51), além disso, o sub-processo de desenvolvimento foi dividido em duas fases ('inicial' e 'refinamento'), os sub-processos de prototipagem e documentação foram agrupados na fase 'construção e documentação', e os sub-processos de teste/iteração e implantação/replicação mesmo não estando explicitados no modelo, possuem entregas que os contempla (categorias 'teste e coleta de dados' e 'empreendimento'). Observa-se também um grande aumento na quantidade de entregas da versão anterior do modelo referência para o modelo atual, de nove para setenta e cinco.

Na seção 0 , ao serem apresentadas as características do PDP da OSE, a discussão sobre o modelo de referência da OSE volta à tona, de modo a contrastar as fases e entregas previstas no modelo com o que foi observado durante a pesquisa de campo. 
ANEXO I - Árvore da evolução da família de produtos da comunidade RepRap entre 2006 e $2012^{64}$

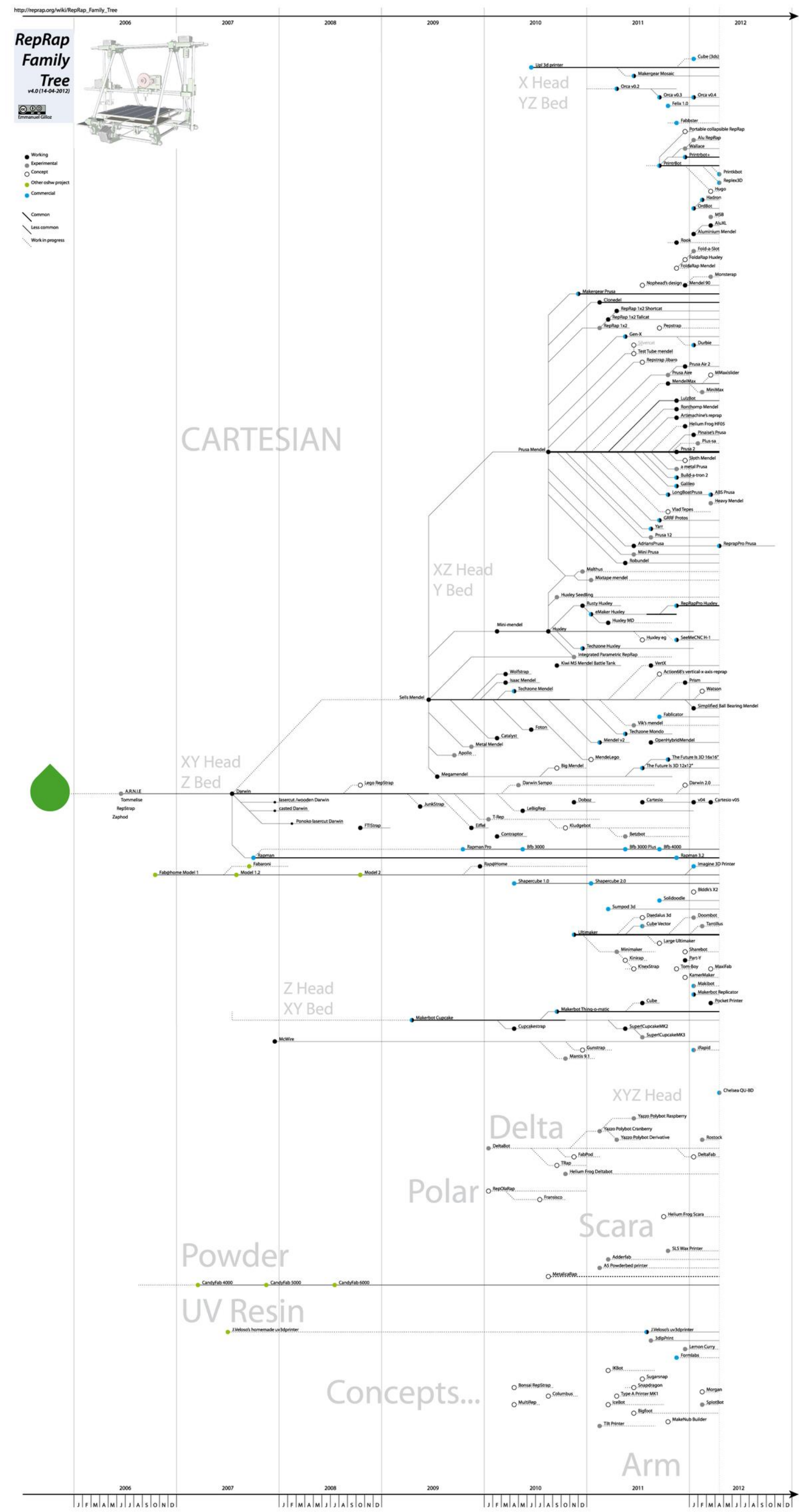

${ }^{64}$ Disponível em http://reprap.org/wiki/RepRap Family Tree, acessado em 30/06/2015. 


\section{ANEXO II - Global Village Construction Set $t^{65}$}

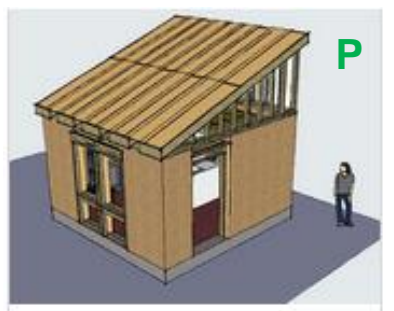

MicroHouse

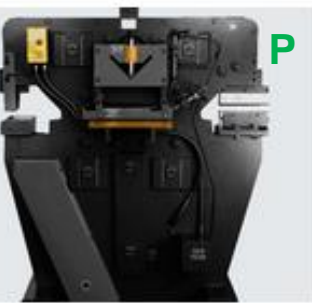

Ironworker Machine

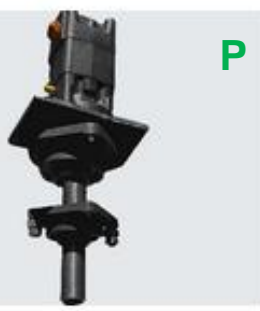

Universal Rotor

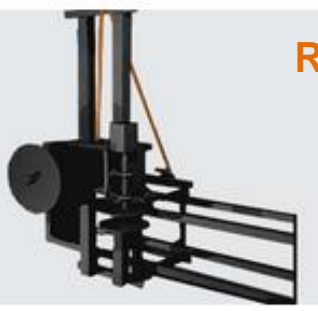

Dimensional Sawmill

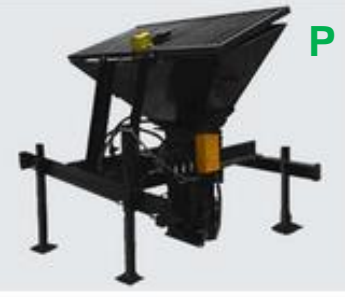

CEB Press

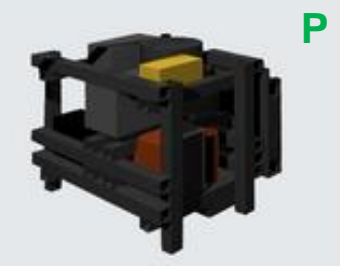

Power Cube

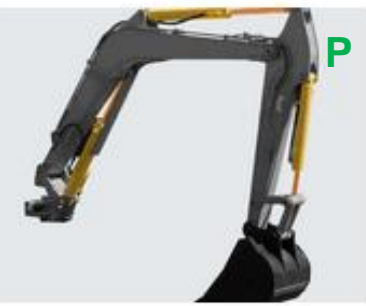

Backhoe

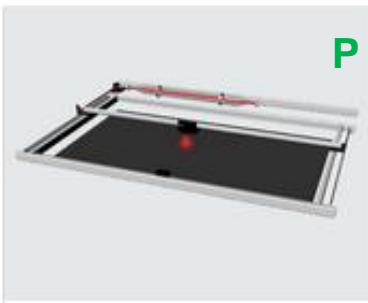

Laser Cutter

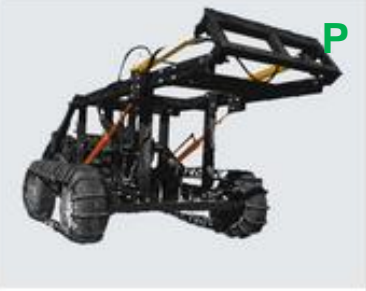

Tractor

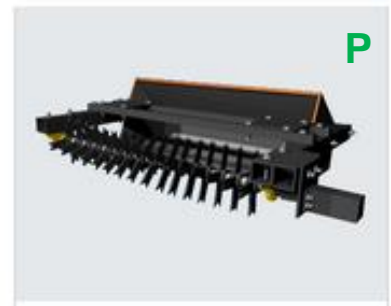

Rototiller and Soil Pulverizer

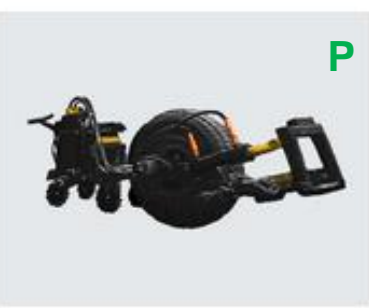

Microtractor

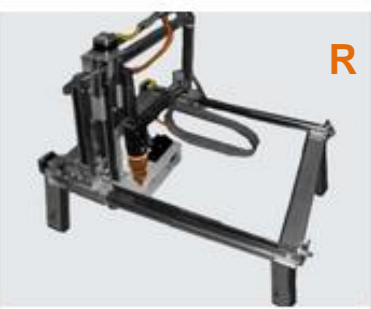

CNC Circuit Mill

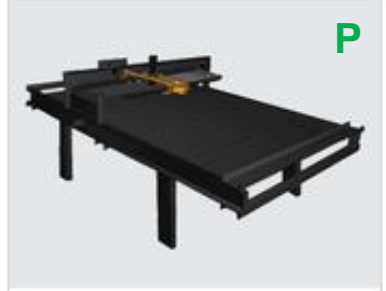

CNC Torch/Router Table

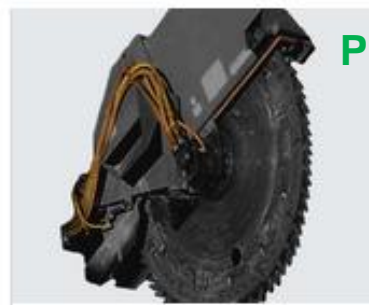

Trencher

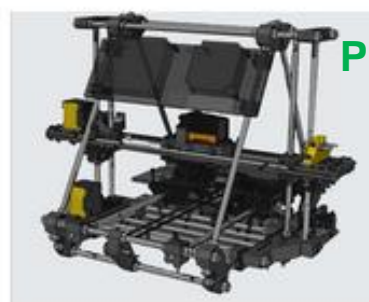

3D Printer

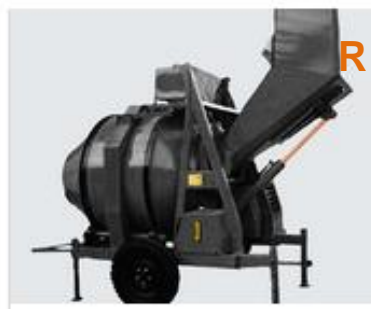

Cement Mixer

65 Disponível em http://opensourceecology.org/gvcs/gvcs-machine-index/, acessado em 30/06/2015. As letras localizadas no canto superior direito da ilustração de cada produto indica 0 estágio de desenvolvimento que 0 produto se encontra: $R$ - Planejamento/Pesquisa, D Desenvolvimento virtual, e P - Prototipagem iniciada. 


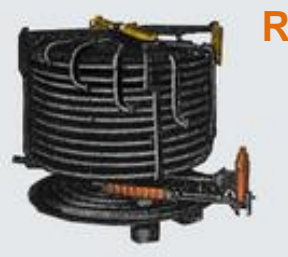

Heat Exchanger

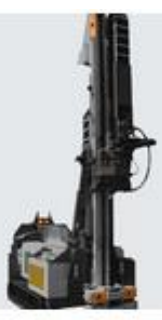

Well-Drilling Rig

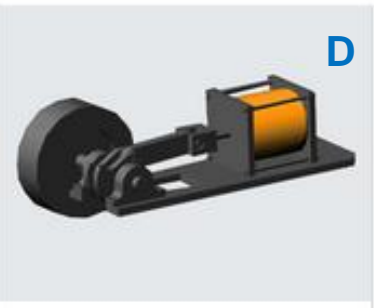

Modern Steam Engine

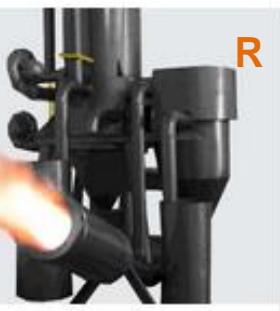

Gasifier Burner

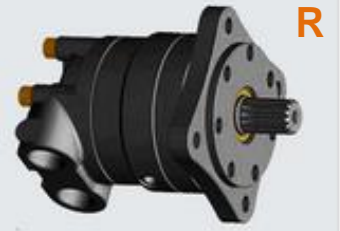

Hydraulic Motor

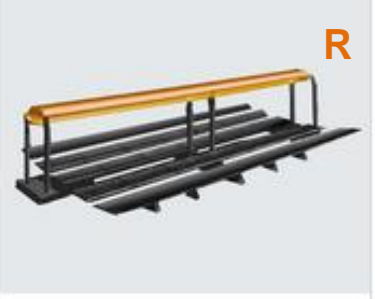

Linear Solar Concentrator

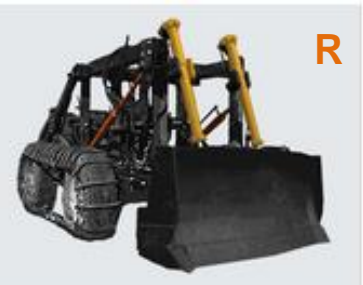

Bulldozer

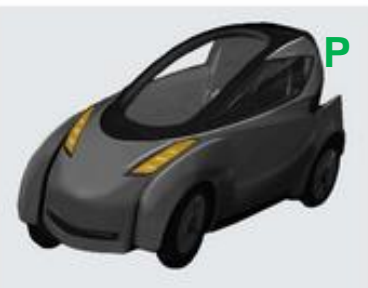

Open Source Automobile

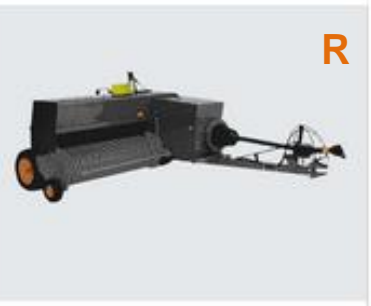

Baler

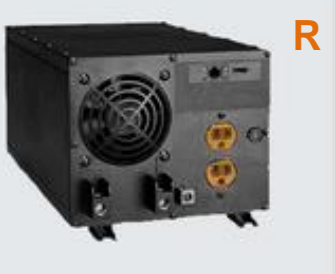

Universal Power Supply

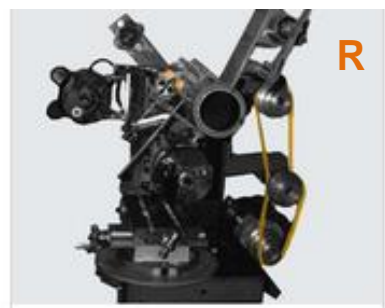

CNC Precision Multimachine

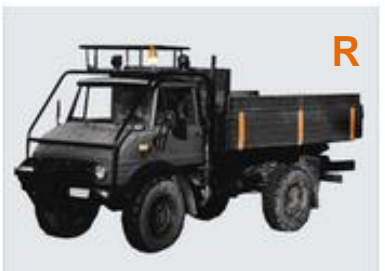

Open Source Truck

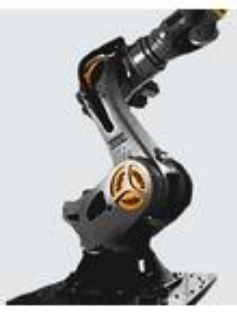

Industrial Robot

$R$
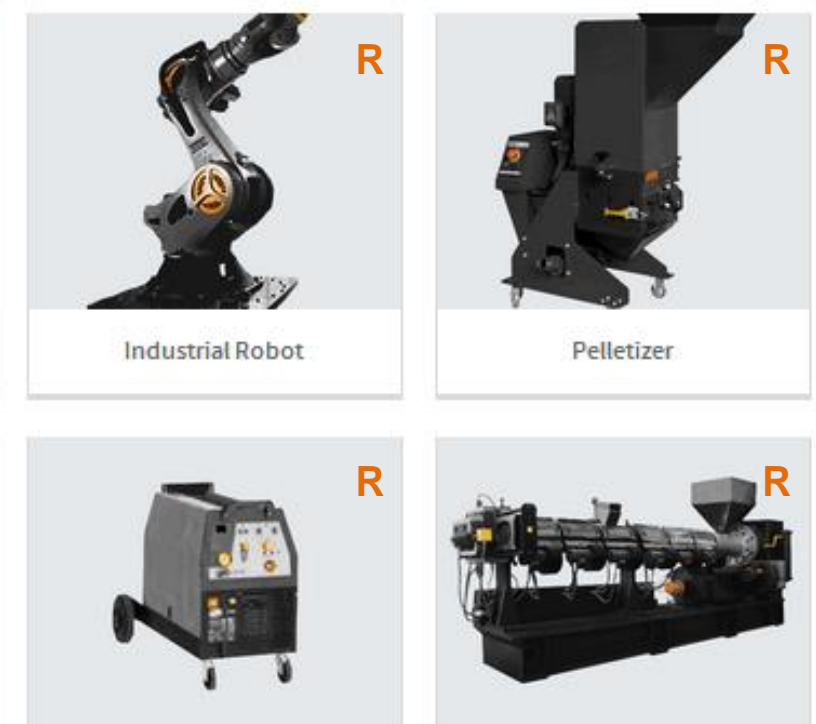

Open Source Welder

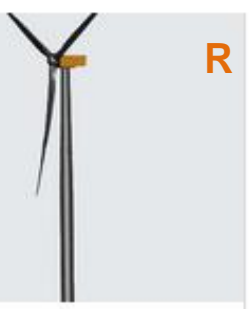

$50 \mathrm{~kW}$ Wind Turbine
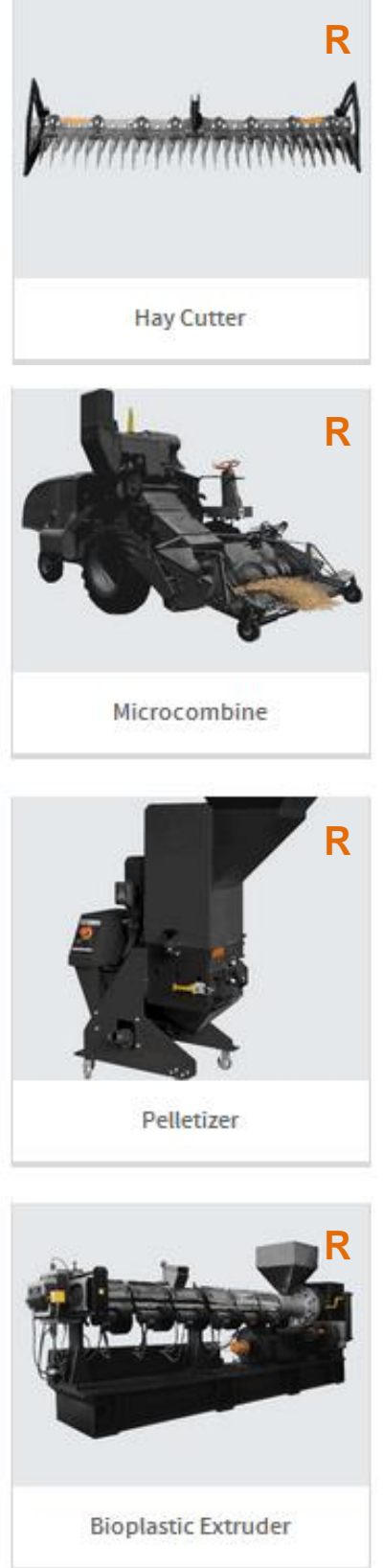

Microcombine

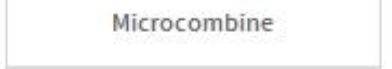

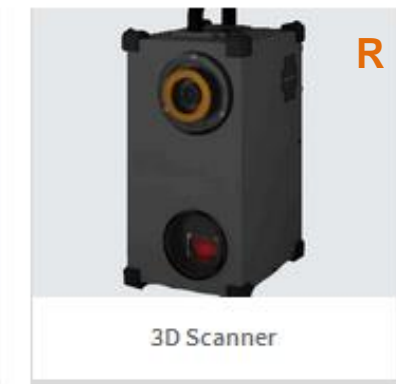

3D Scanner

R 


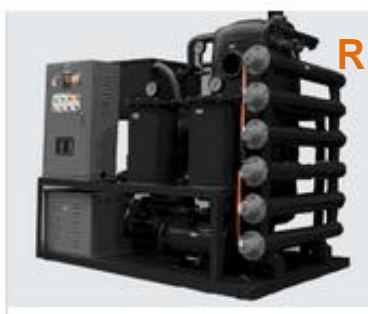

Aluminum Extractor from Clay

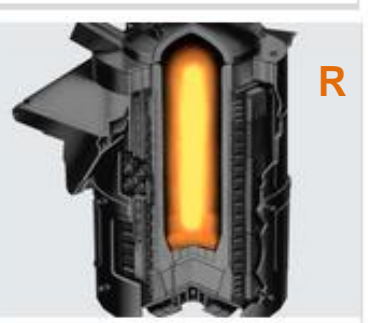

Induction Furnace

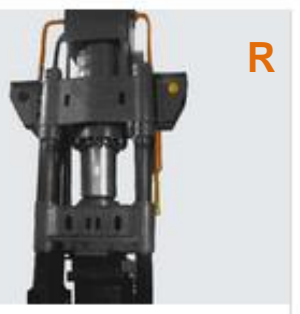

Press Forge

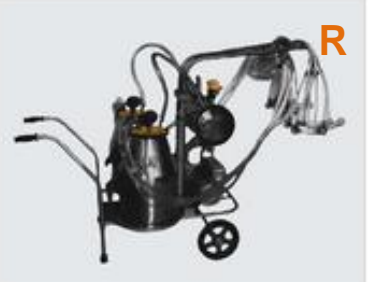

Dairy Milker

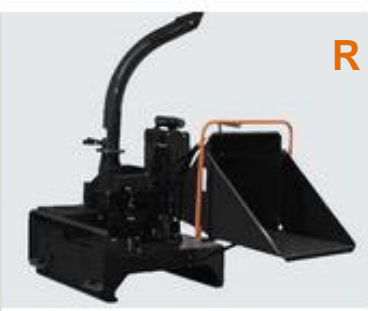

Chipper/Hammermill

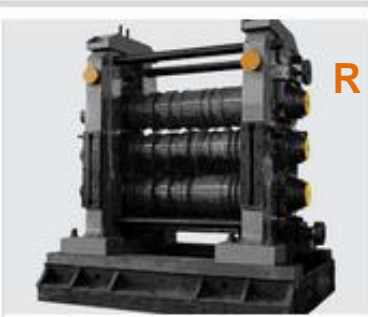

Metal Rolling

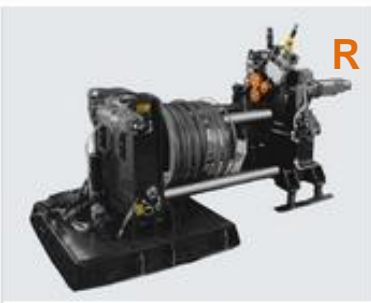

Rod and Wire Mill

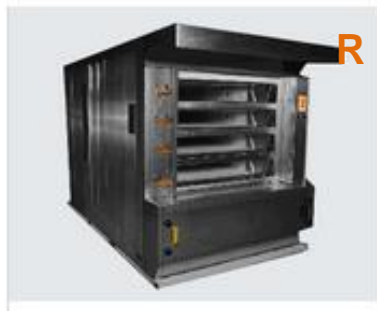

Bakery Oven

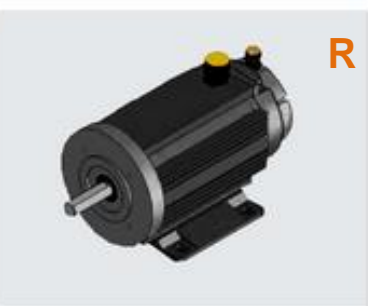

Electric Motor/Generator

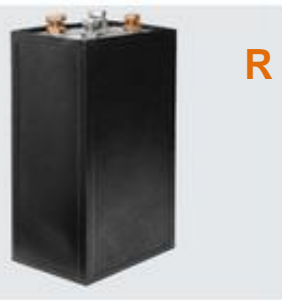

Nickel-Iron Batteries

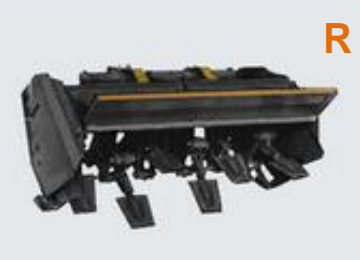

Spader

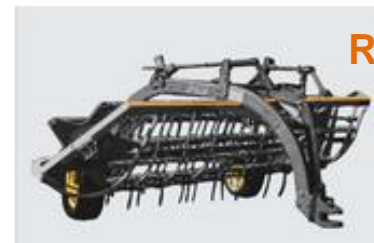

Hay Rake

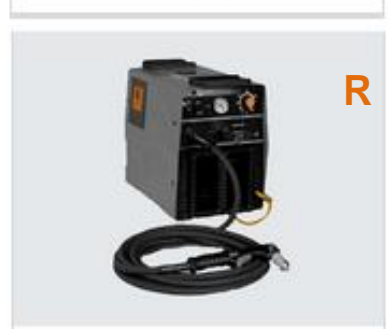

Plasma Cutter

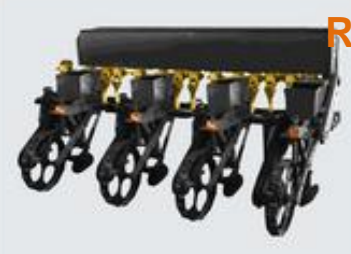

Universal Seeder 


\section{ANEXO III - Exemplo das instruções de montagem da CEB Press ${ }^{66}$}

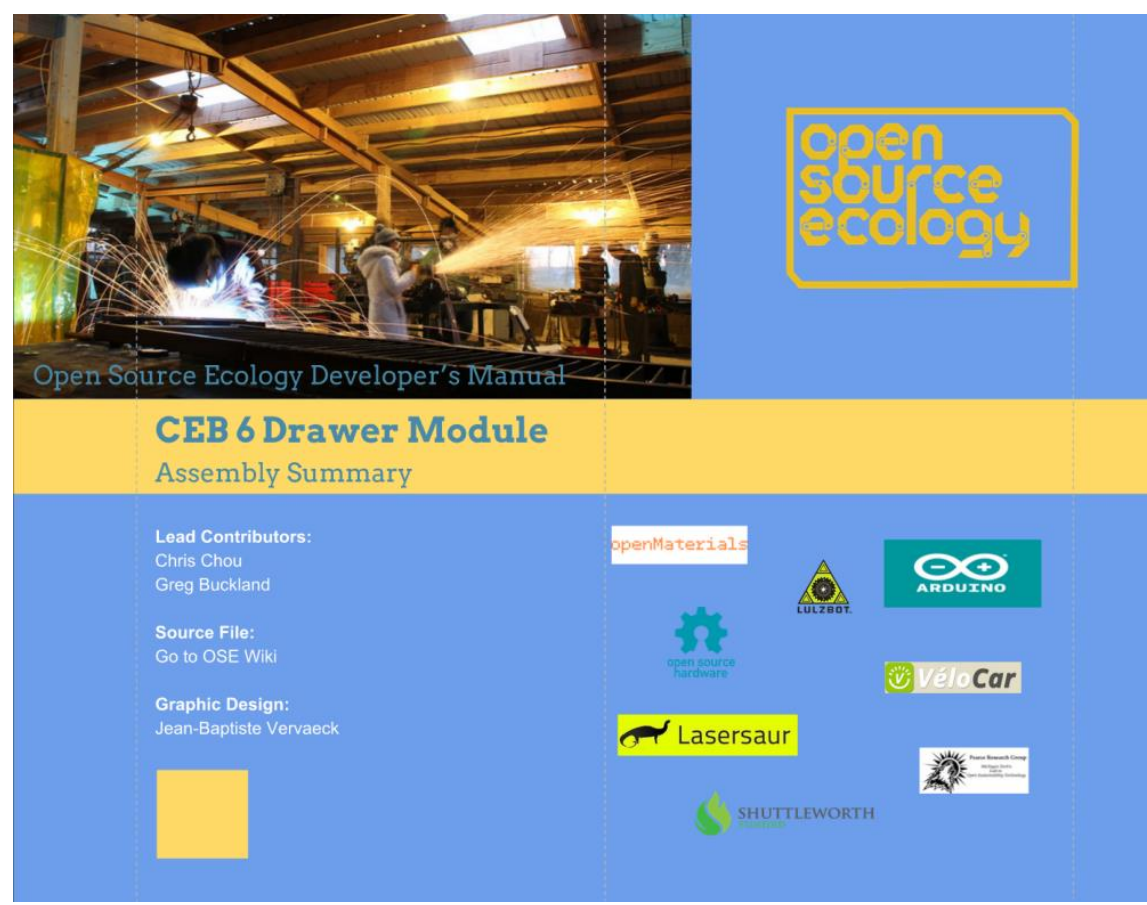

\section{Build Time and Overview}

\section{Estimated time to complete:}

- Preparation and Parts Inventory: 20 min

- Initial assembly and Tack Welding: 20 min

- Seam welding: $\mathbf{5 0}$ min

- Grinding and finishing: $\mathbf{1 5}$ min

TOTAL: $105 \mathrm{~min}$ ( 2 hrs)

Difficulty: $6 / 10$ (final product measurements must be accurate to $+/-1 / 32-1 / 16$ )

\section{Design Rationale:}

The drawer is the beating heart of the CEB Press. If you understand its design and function, you understand the essential mechanism of how the CEB Press loads soil, compresses it into bricks, and ejects them.

The drawer loads soil, ejects bricks, seals the chamber for brick pressing, and it the surface against which bricks are pressed.

Final Product: Drawer Module
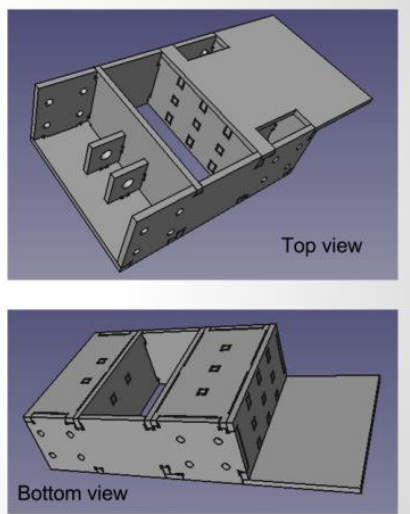

Assembly note: Tabs and slots allow 3D-jigsaw-puzzle assembly style. Pieces will only fit together one way.

66 Disponível em https://docs.google.com/presentation/d/11ZlpOzMNIIssL34HmSoQ4j0asGqrDSd10Xue7zYJZQ/edit\#slide=id.g34cf01eaa 50, acessado em 30/06/2015. 


\section{Drawer Module Drawer Location in CEB Press}

Drawer (in Green) resides in the center of the press.

It is moved back and forth by the Secondary Cylinder (in Blue) between it's 3 positions (Loading, Compression, Ejection).

The soil is compressed by the Primary Cylinder (in Orange) and then ejected.

See next slide for stepwise walkthrough of compression cycle.
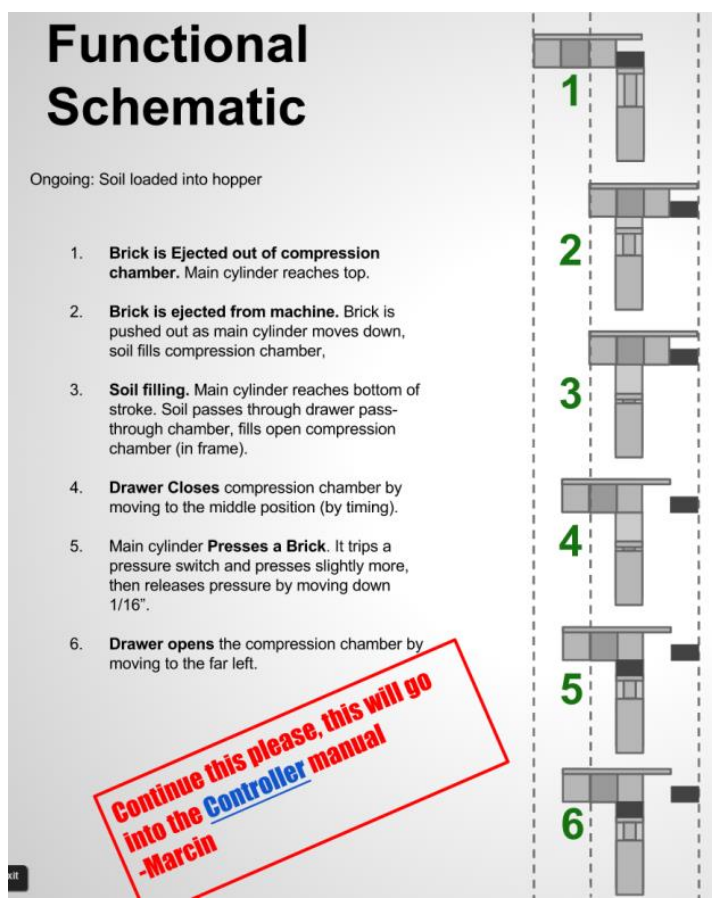
Drawer Module: Safety Equipment

Safety is important during assembly. Be sure to wear:

Be sure to know the location of your

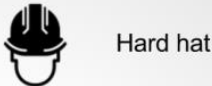
emergency equipment:
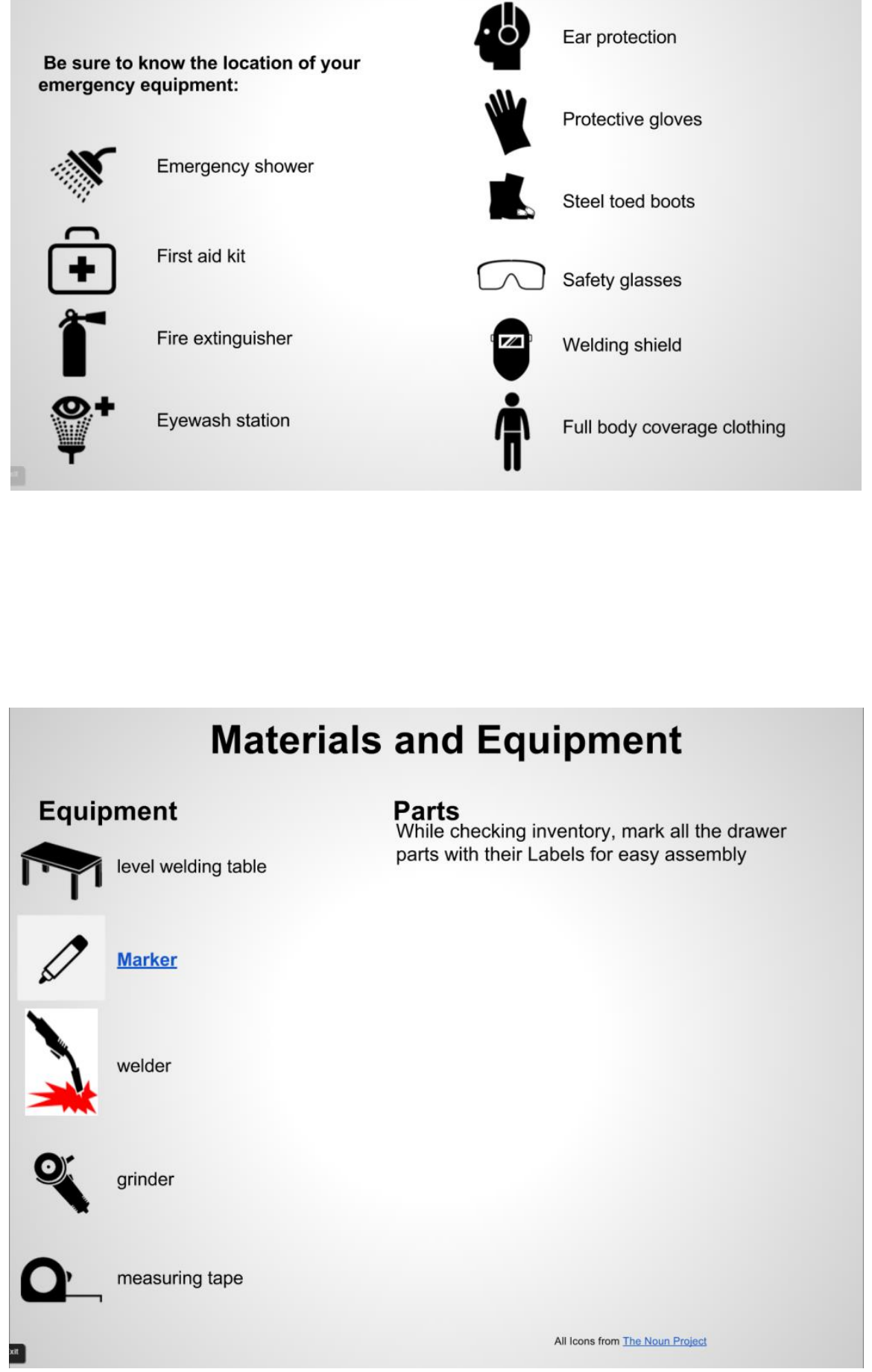

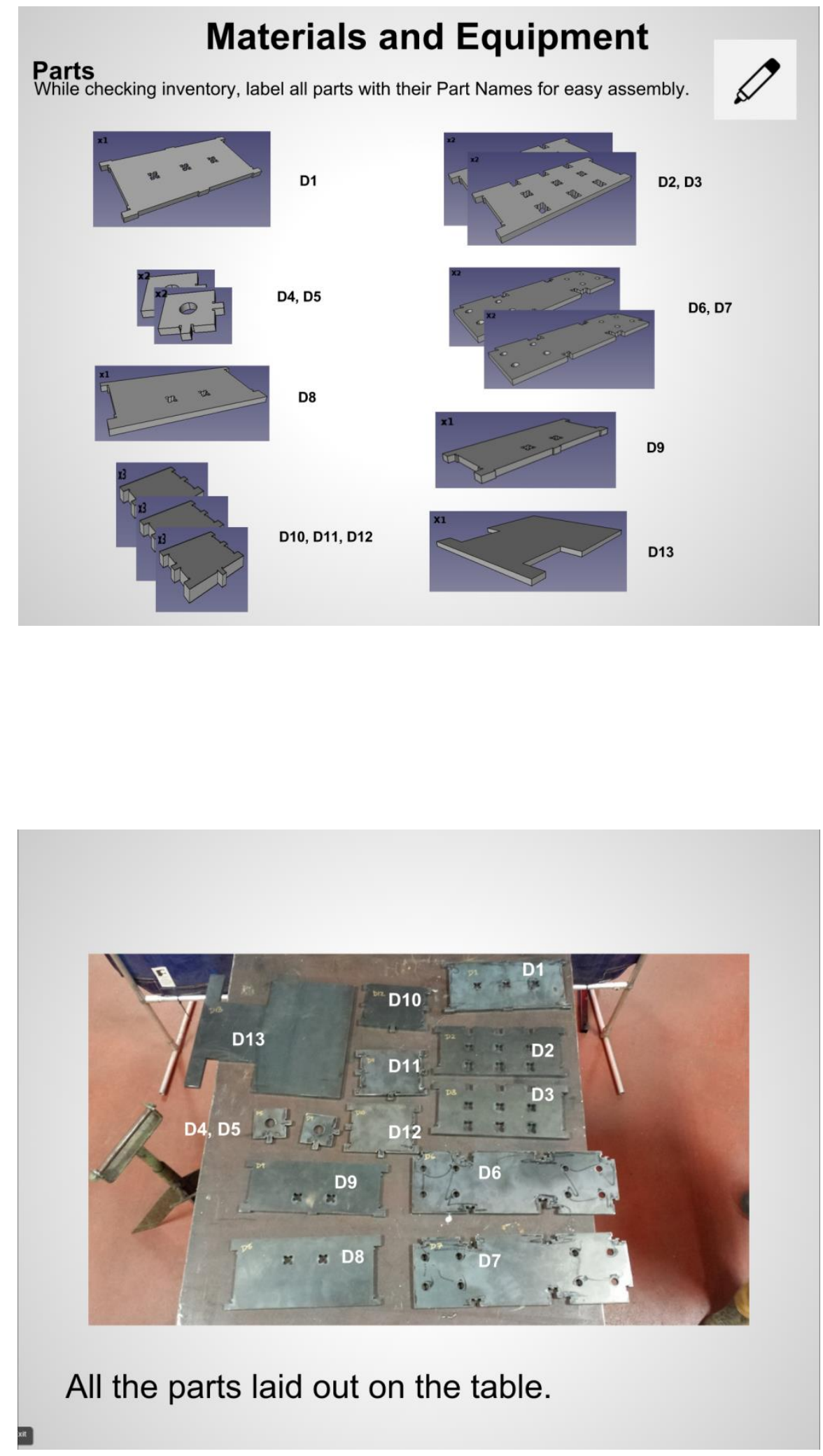
Before assembly, use a round file to deburr the holes through D4 and D5 to ensure that a 1" round shaft can easily

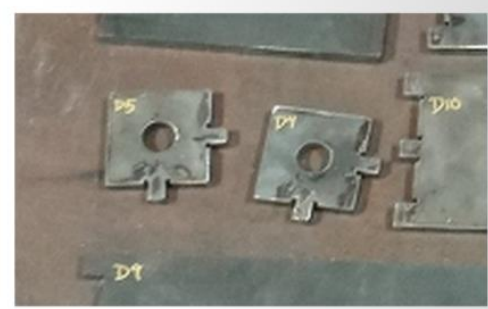
slide through.

Assemble the parts in the following order:

D1, D9, D6 =>

D8, D2, D10, D11, D12

D3, D4, D5, D7, and finally $\mathrm{D} 13$.

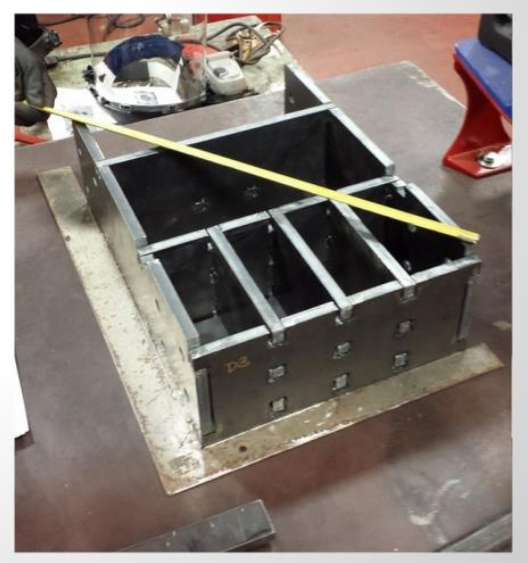




\section{Drawer Module} Assembly Overview
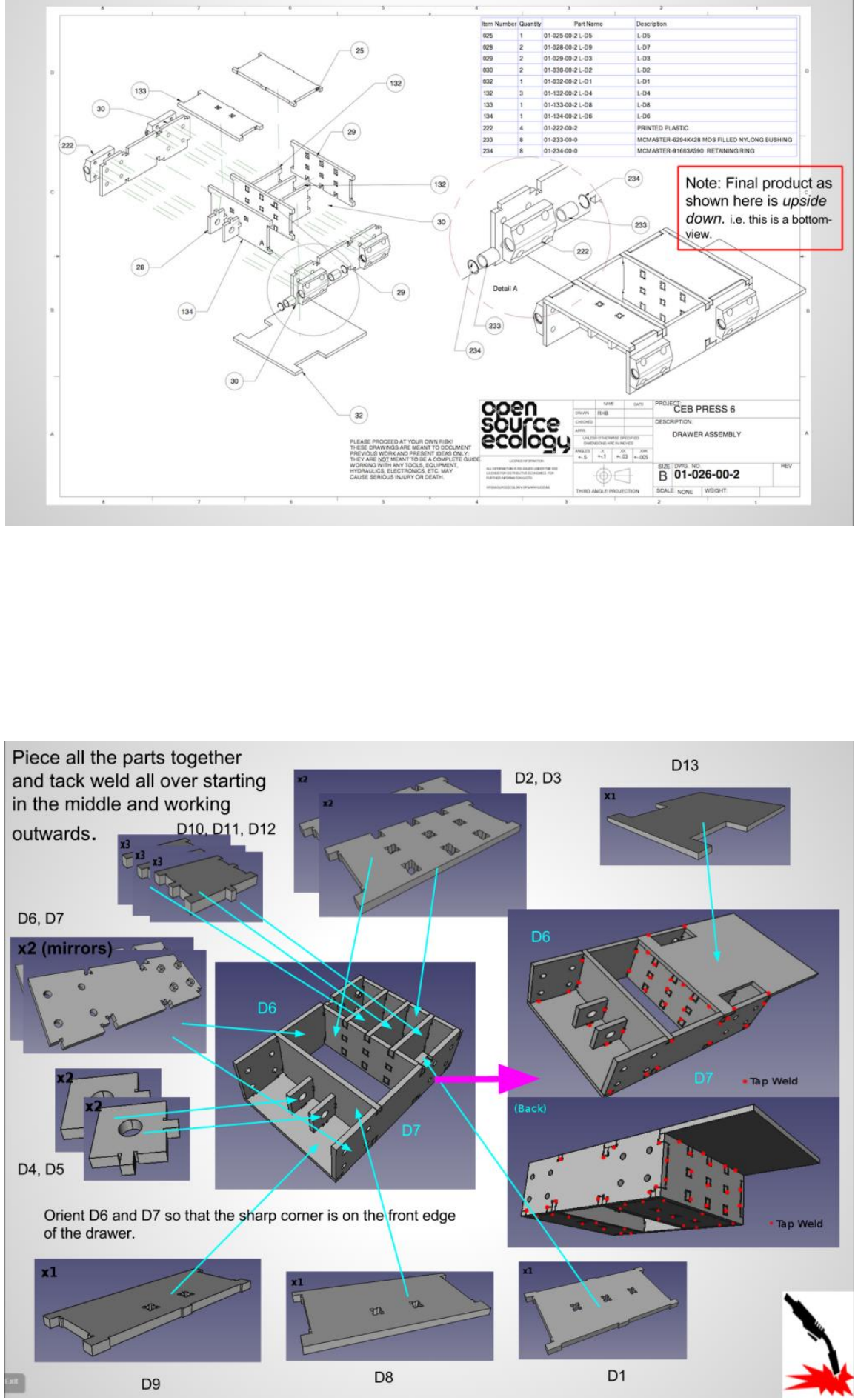


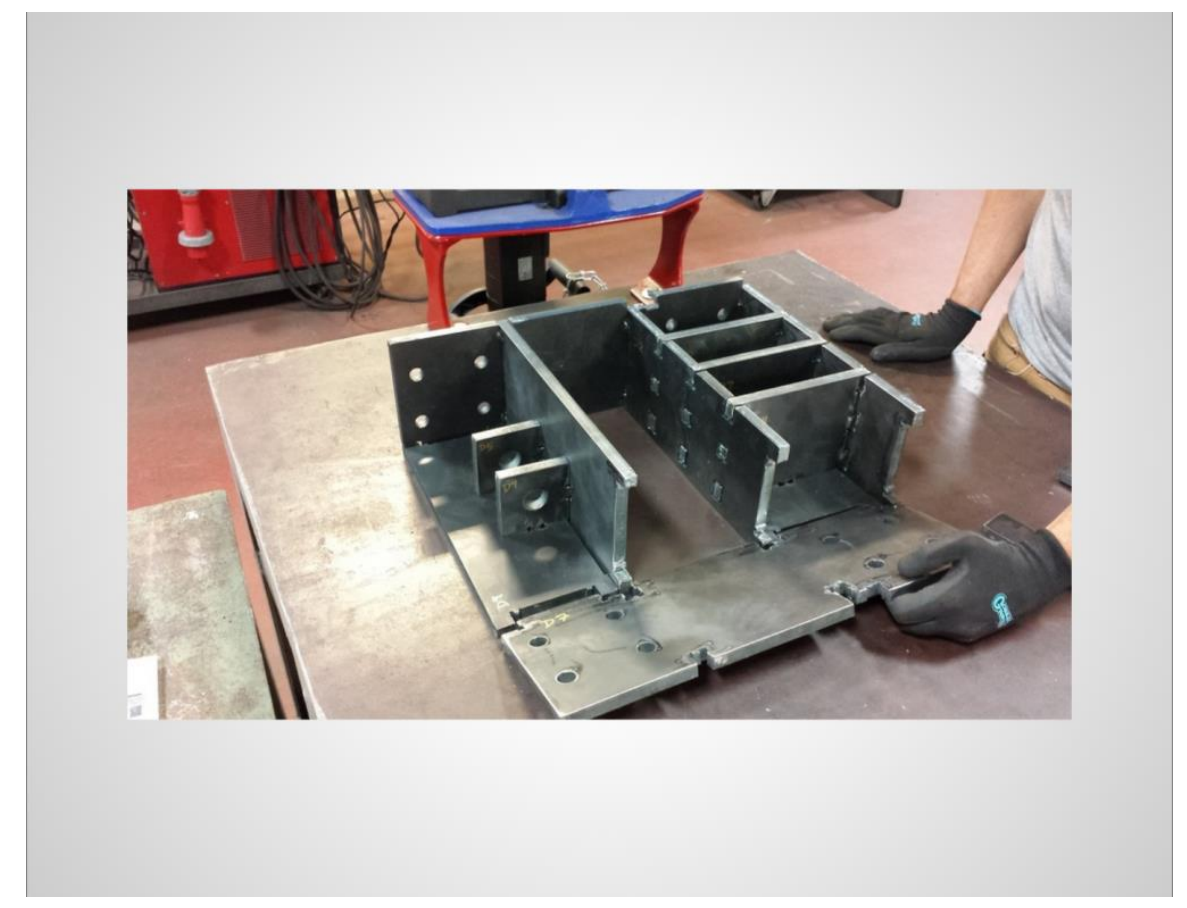

Check to make sure that the drawer is square before clamping and tack welding, the box between D6, D7, D2, and D8 must be square. The horizontals need to have the tightest tolerances because every brick is being pressed against them. The drawer slides back and forth horizontally so use a level to ensure that the top and bottom are even. ENSURE YOU ARE WELDING ON A LEVEL SURFACE.

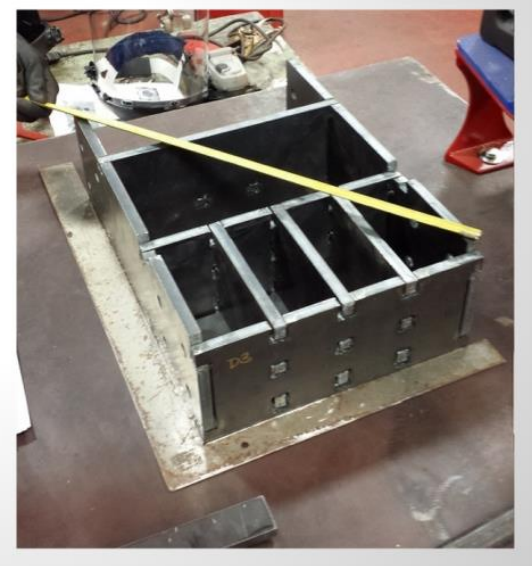


Use clamps to make sure that the drawer remains perfectly square as you tack weld.

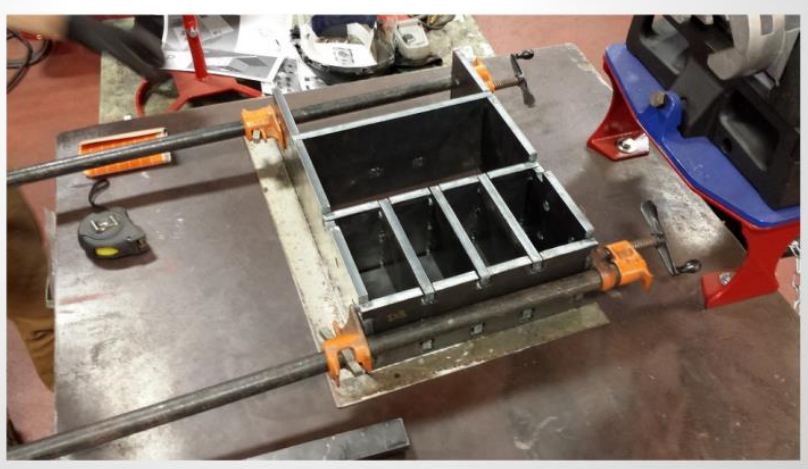

xat

\section{Welding Procedure}

- General Practices

- Make sure the table is level \& clear of bumps and scrap metal - Grind spatter and bumps from your weld table; the table down for easier assembly

- Welding heats the metal to high temperatures so the metal will warp if not careful

- To minimize warping, tack weld all parts first in different places first

- Then spread the weld apart into many different places, not closing any gaps until the very end

- Order the welding so each wield are far apart from the previous weld, welding about $2 \%$, then $5 \% \ldots 10 \% \ldots 20 \%$... $50 \% \ldots 100 \%$ at each spot.

- Millermatic 200 welders - use High Voltage, 2 power setting, 60 wire speed.

- We used MIG welders at 18.6 volts and 205-210 wire speed. 


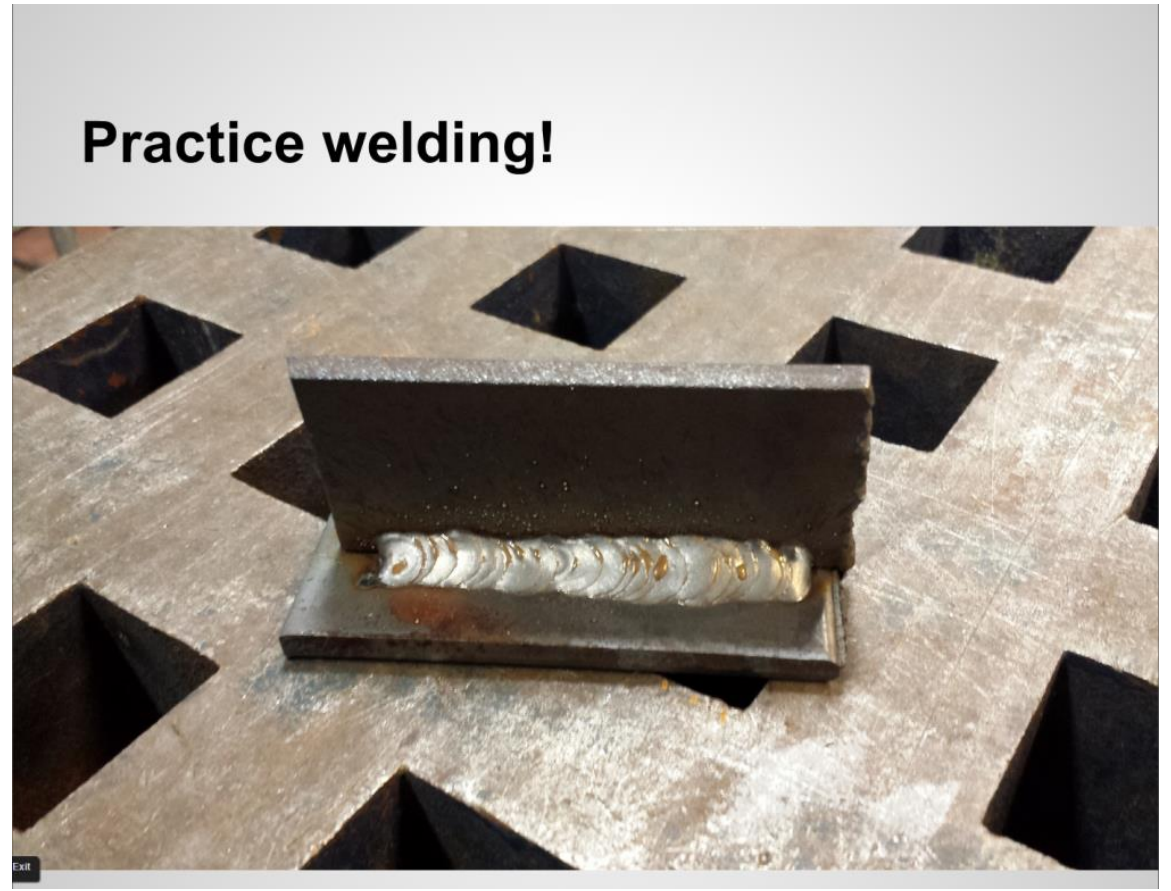

Fully tacked!

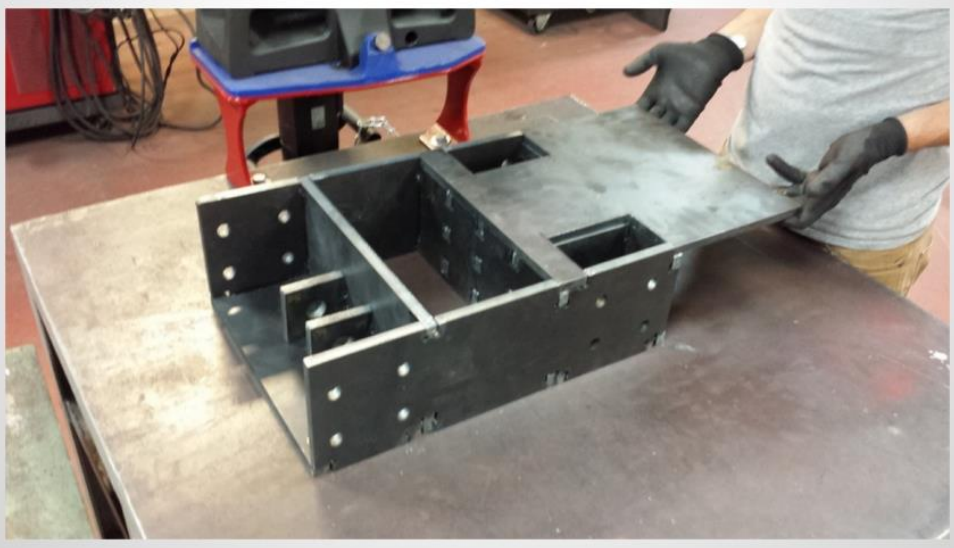


Clamp as you finish the welds.

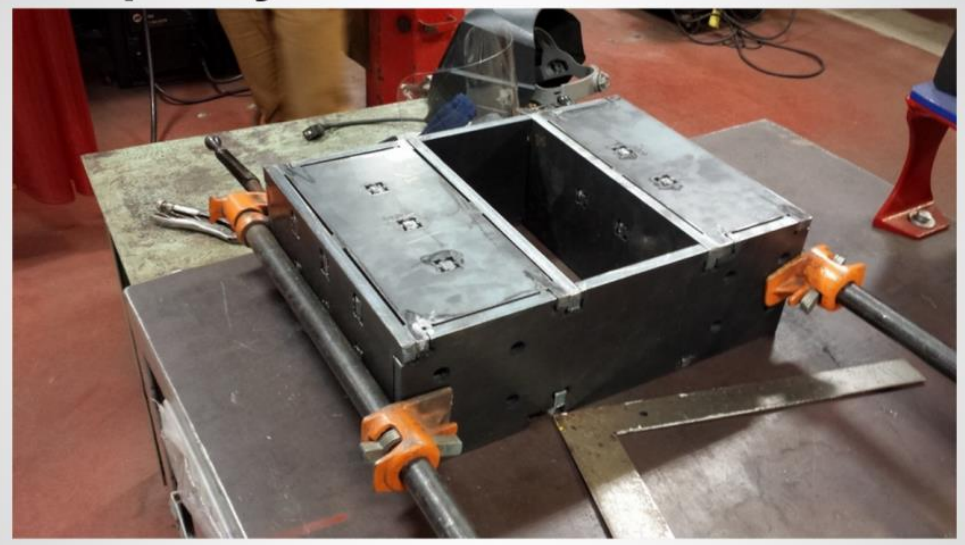

Rotate the drawer so you are welding horizontally.

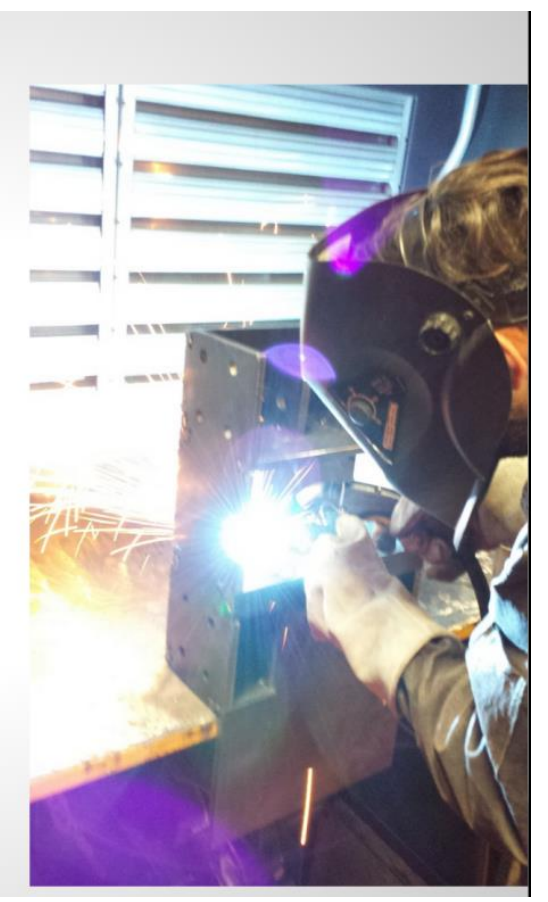


Before welding D4 and D5, slide a 1" round stock pin through them to ensure that they are perfectly parallel. Cut 1 " steel stock to $37 / 8$ " long. Check the distance between D4 and D5 with the secondary cylinder to make sure it fits. We needed to grind about $1 / 16$ " off each side of the secondary cylinder to make it fit.

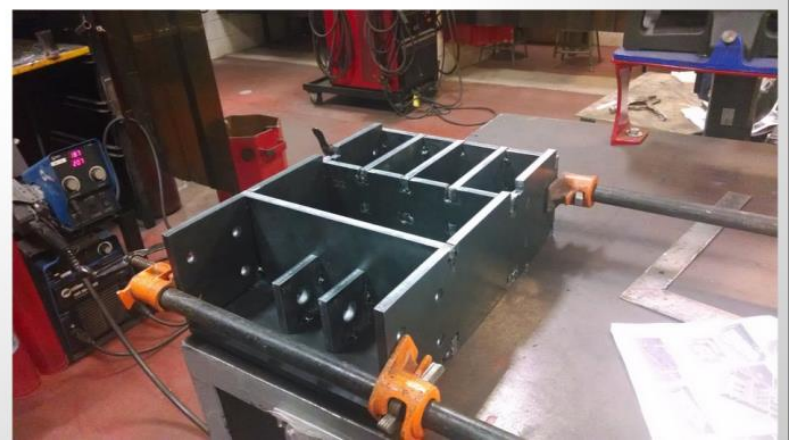

Prepare the shaft by turning it on a lathe. We cut a groove for the snap ring approximately .1" from the end of the shaft and .25" deep.

Weld a washer on the opposite side to create the pin for attaching the secondary cylinder to the main drawer.

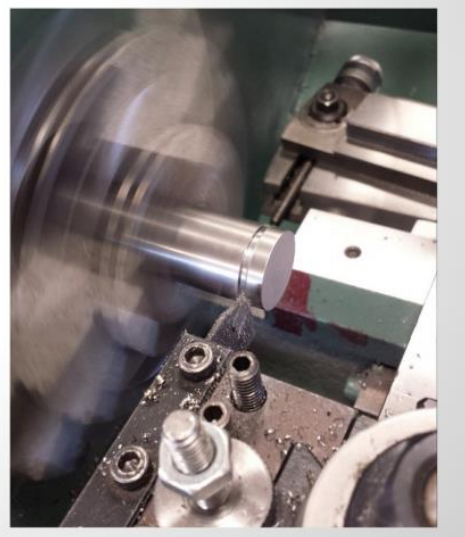


Tack weld the washer to the side of the pin without the groove.
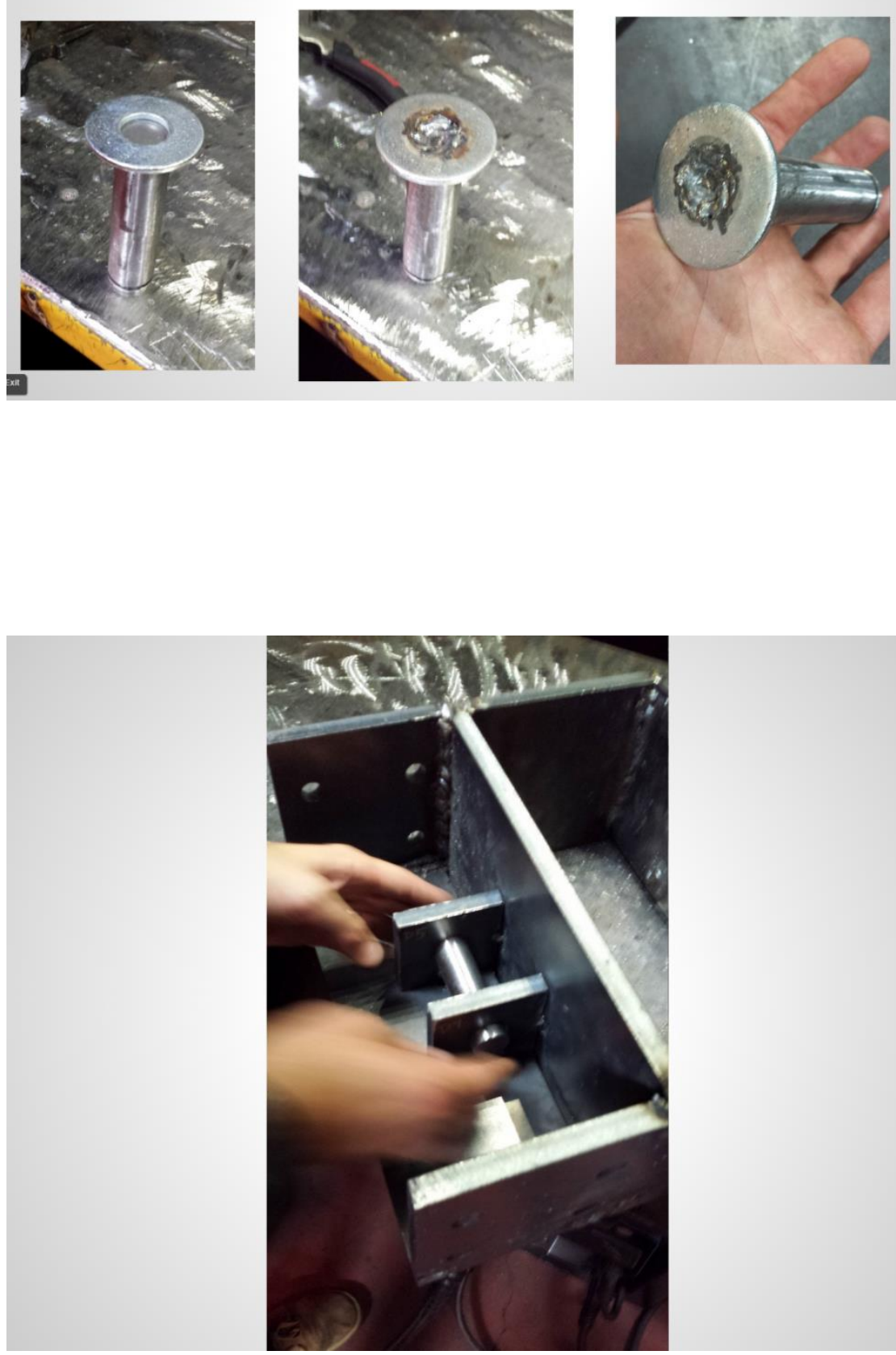
Finish welding all the seams on the outside going through proper welding percentage sequence.

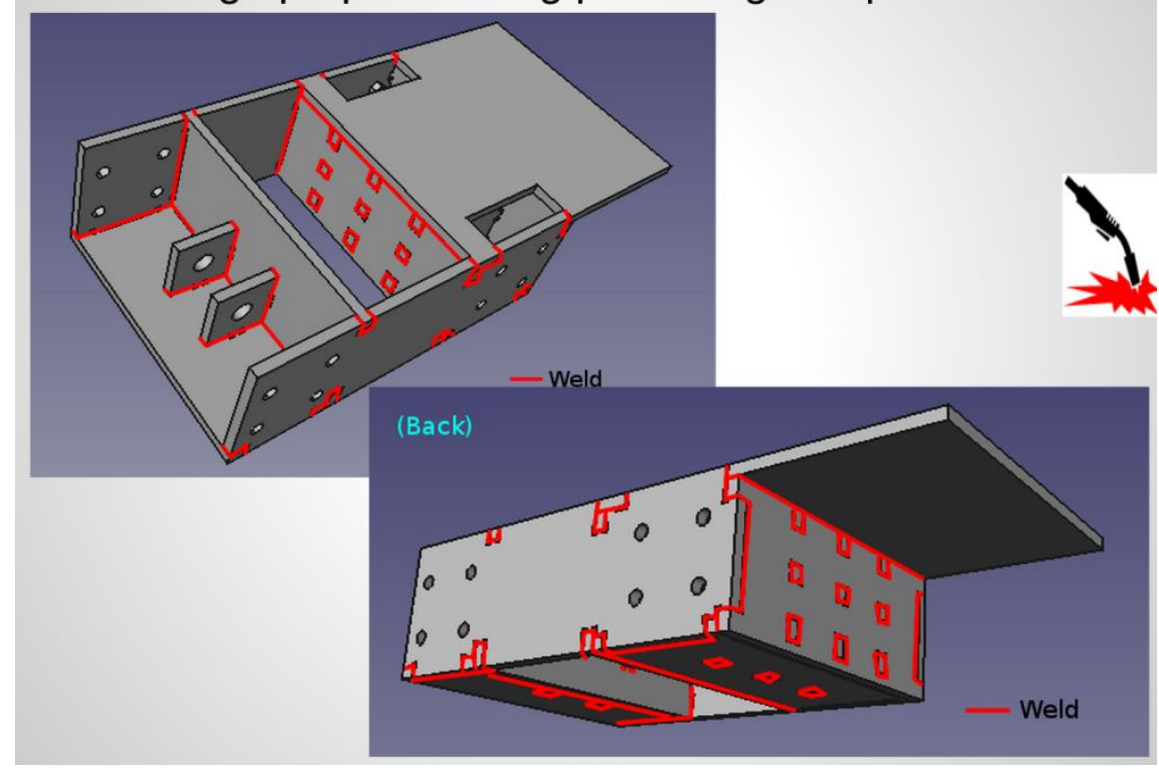

Grind down the essential parts.

Then briefly grind down the sharp corners and edges on the outside for safety for others.

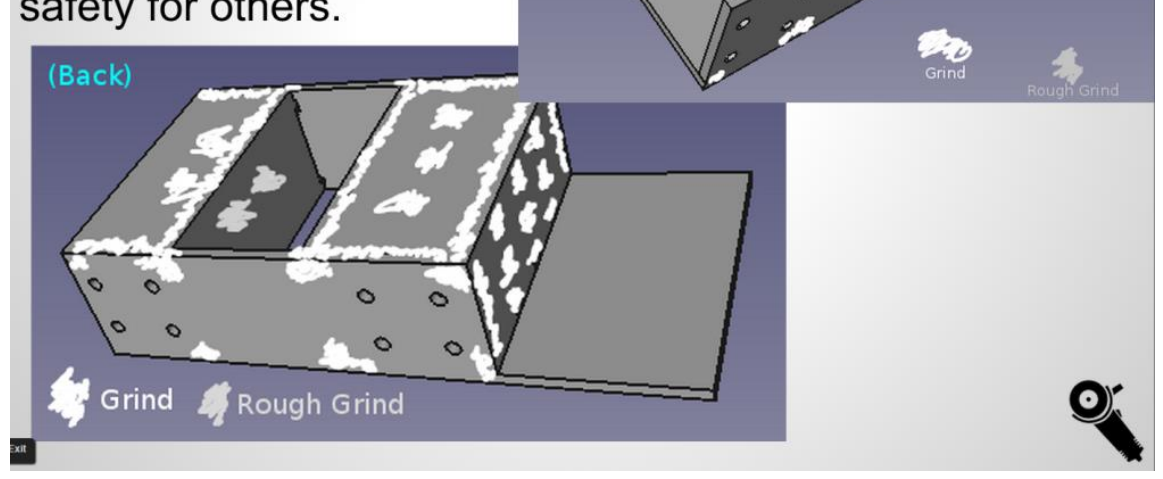


The highlighted box is what the main cylinder presses against to make each brick. This must be ground to ensure that it is totally flat. The welds inside the drawer are less important as soil simply falls through the opening.

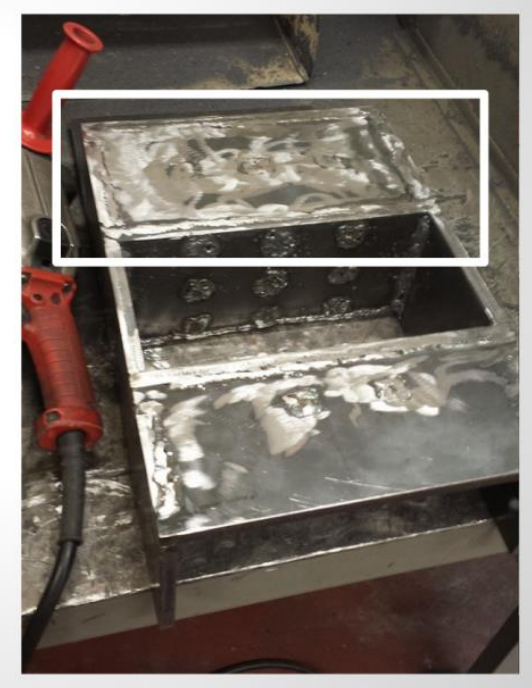

\section{Drawer Module}

Were these instructions helpful?

Please rate from 1 to 10 (10 being the highest)

Are there any parts that needed improvement?

What parts did you like that you found helpful? 